\title{
DIE ALPWIRTSCHAFT DER LANDSCHAFT DAVOS
}

\section{ULRICH SENN}

\author{
Mit 6 Figuren und 8 Abbildungen
}

\section{EINLEITUNG}

Bei einer wirtschaftsgeographischen Untersuchung von Davos rücken zwei Fragen in den Vordergrund. Aus der alten landwirtschaftlichen Walsersiedlung entwickelt sich im 19. Jahrhundert plötzlich ein Kurort, der enorm wächst, und innerhalb von 90 Jahren steht an der Stelle von einigen Häusergruppen ein Fremdenort von über 9000 Einwohnern mit städtischem Charakter. Wie wirkt sich dieser Kurort auf die umliegende bäuerliche Bevölkerung aus, wie stark beeinflußt er die Landwirtschaft? Diese Frage versucht CHR. JosT in seiner nationalökonomischen Dissertation zu beantworten, die gleichzeitig mit der vorliegenden Arbeit entstanden ist.

Die zweite Frage bezieht sich im besondern auf die Alpwirtschaft und die Entwicklung der Landschaft. Die Alpwirtschaft paßt sich ganz ihren natürlichen Grundlagen an. Sie ist keineswegs einheitlich, sondern so vielgestaltig und interessant wie die Gebirgswelt und gliedert sich in viele Gruppen und Zwischenformen auf. Nicht nur Höhenlage und Relief beeinflussen die alpine Landwirtschaft, auch historische und völkische Momente können sich entscheidend auswirken. Davos als deutschsprachige Walserkolonie, umgeben von einer romanischen Bevölkerung, entwickelte sich seit dem 13. Jahrhundert selbständig. Es ist nicht meine Aufgabe, die gegenseitige Beeinflussung der beiden Volkstypen zu untersuchen; auch würde sie die Kenntnis beider Wirtschaftsformen voraussetzen. Die genaue Beschreibung der walserischen Alpwirtschaft schafft jedoch die Grundlagen für einen späteren Vergleich mit andern alpinen Wirtschaftsformen. Schon die ausgedehnten Kartierungen im Sommer 1949 zeigten eine starke historische Bindung der alpwirtschaftlichen Verhältnisse in Davos. Die Ergebnisse sind in meiner Diplomarbeit: „Davos, eine geographische Auswertung von Nutzungs- nnd Siedlungskarte mit Protokoll, unter besonderer Berücksichtigung der Alpwirtschaft" zusammengestellt. Die Nutzungskarte im Maßstab 1:10000, die meiner Diplomarbeit beiliegt, gibt auch die geographische Grundlage zu dieser Arbeit. - Das große, unübersichtliche Material aus den einheitlichen Fragebogen, das sich durch persönliche Befragung bei 185 Bauern ansammelte, wurde zerstreut in den einzelnen Kapiteln verwertet. - Viele Fragen blieben offen und schienen sich nur genetisch erklären zu lassen. Die Erweiterung und Ausdehnung der Untersuchung in kulturgeographischer Richtung drängte sich daher auf. Aufbauend auf Nutzungskarte und Fragebogen versuchte ich durch Literatur und Quellenstudium die geschichtliche Entivicklung der Alpwirtschaft zu erfassen. Wenn diese letztere in der folgenden Arbeit dominiert, so ist das der Form des Stoffes zuzusprechen, die sich besser zur textlichen Darstellung eignet. Immer mehr zeigte es sich, wie stark das Wesen des Walsers und die rechtlichen Verhältnisse die heutige Alpwirtschaft bestimmen. Ich konnte mich auf die vielen Veröffentlichungen über die Walser stützen. Für die Rechtsfragen diente mir in erster Linie die Arbeit von E. BRanger, der im besondern auch die rechtlichen Verhältnisse in Davos klar darstellt. Die Untersuchungen von LIVER am Heinzenberg und im Hinterrheintal schufen mir wertvolles Vergleichsmaterial. Die Entdeckung der Monsteiner Spruchbriefe und einige weitere Dokumente gaben mir die Unterlagen für die Entwicklung der Landnutzung. Die Entzifferung dieses Briefes und Textherstellung verdanke ich Herrn Prof. A. Largiadėr, Staatsarchivar in Zürich. Herrn Prof. R. Weiss danke ich für die Hilfe bei der Textauslegung. Eine vollständige Abschrift des Briefes befindet sich im Anhang. Die heutige Alpwirtschaft wurzelt so stark in der walserischen Geschichte, daß auch die Entwicklung des Kurortes diese nur noch umgestalten und anpassen konnte. In der heutigen Landschaft spiegelt sich noch das Bild der ersten Kolonisation, die Siedlungen, die vielen verstreuten Höfe, Flurnamen, Waldrodungen, Grenzen und Straßenanlagen lassen den Weg von der ersten Landbesitznahme bis zur Gegenwart erkennen.

Herrn Prof. Dr. H. BđEsch danke ich für viele Hinweise und Ratschläge. Während meiner Assistentenzeit und auf vielen Exkursionen lernte ich neben dem Forscher vor allem auch den Menschen schätzen. Die vorliegende Arbeit hätte ohne das Entgegenkommen der Davoser Amtsstellen und die große Hilfe der Bauernbevölkerung nicht entstehen können. Viele Tage verbrachte ich mit ihnen bei der Arbeit oder in der gemütlichen Bauernstube. Sie gaben mir bereitwillig Auskunft und ließen mich an ihren Problemen teilnehmen, so verhalfen sie mir zum Verständnis der heutigen Alpwirtschaft. Den Davoser Bauern und allen denen, die mir bei der Sammlung des Materiels behilflich waren, möchte ich danken.

Herrn Dr. W. MörIKOFER danke ich für die Hilfe bei der Drucklegung. Die Gemeinde Davos, die Schweiz. Naturforschende Gesellschaft und die Stiftung de Giacomi halfen mit bei der Finanzierung des Druckes; ihnen sei hiermit gedankt. 


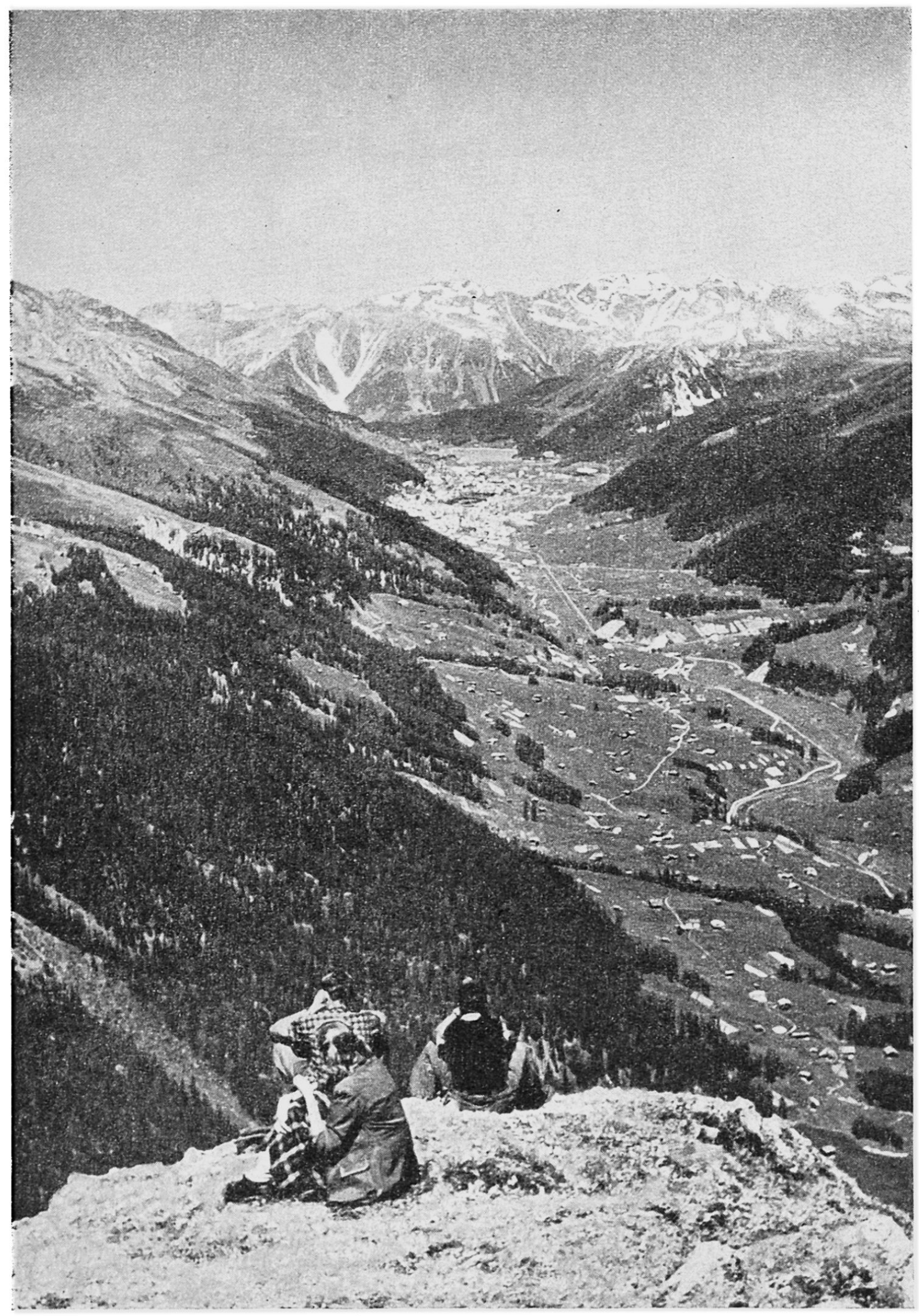

Aufnahme H. SEN

Abb. 1 Das Davoscrlal im Herbst. Auf den vorspringenden Terrassen die verstreuten Höfe, an den Sïdhängen die Äcker. Blick vom Altein. 


\section{I. 'Teil}

\section{Die Grundlagen}

\section{LAGE - AUSDEHNUNG - TOPOGRAPHISCHE VERHÄLTNISSE}

Davos als Lungenkurort oder Wintersportort im nordöstlichen Graubünden ist heute ein bekannter Begriff. Daß die Landschaft ${ }^{1}$ Davos als Gemeinde und auch als eigener Gerichtskreis eine Flächè von $253 \mathrm{qkm}$ (Kt. Zug $240 \mathrm{qkm}$ ) einnimmt und damit in eine Größenordnung unserer kleinsten Kantone reicht, wird wenig beachtet. Neun Zehntel der Bevölkerung leben in der geschlossenen Hauptsiedlung Davos-Dorf und -Platz (Bevölkerung von Davos 1. Dez. 1950:10 332) auf einer Fläche von etwa $1,75 \mathrm{qkm}$, was ungefähr $1 / 145$ der Landschaftsfläche ausmacht. Etwa 1300 Einwohner als Bauernbevölkerung nutzen die große übrig bleibende Fläche.

Davos liegt an einem früher viel henutzten Übergang, einer Nord-Süd-Linie über die Alpen: Chur - Schanfigg - Strelapaß - Flüelapaß - Unterengadin - Italien. Die Davoser waren Säumer und holten Wein aus dem Veltlin und Salz aus dem Tirol. Der größte Teil dieser Waren wurde weiter gebracht ins Prättigau und nach Chur. Heute haben der Flüelapa $\beta$ und der Scalettapa $\beta$ vor allem durch den Bau der Albulabahn ihre Bedeutung verloren. Der wichtigste Verbindungsweg, den auch die. Bahn nimmt, führt von Landquart durch das Prättigau über Davos nach Filisur. Ein kleiner Autoverkehr benützt noch den Flüelapaß als Verbindungslinie ins Unterengadin (im Sommer Postautokurs). Alle andern Pässe: Strela, Maienfelderfurka, Scaletta, Sertig besitzen nur noch lokale Bedeutung.

Die Gemeinde Davos teilt sich heute in 5 Fraktionsgemeinden auf:

Davos-Dorf (Wolfgang, Laret, die vordersten Teile des Flüela- und Dischmatales, soweit sie im Haupttalboden liegen) 2215 Einwohner.

Davos-Platz (Dischma, Brüche, Clavadel) 7378 Einwohner 2.

Frauenkirch (Sertig, Langmatte) 318 Einwohner.

Glaris (Kumma, Spina) 276 Einwohner.

Monstein 145 Einwohner ${ }^{3}$.

Davos-Dorf und -Platz sehließen also noch ein großes bäuerliches Gebiet ein. Die andern drei Fraktionen sind rein landivirtschaftlich. Die Fraktionen sind Schulund Kirchgemeinden mit eigenen Fonds und verschiedenen Steueransätzen. Frauenkirch, Davos-Platz und Davos-Dorf besitzen 2 Primarschulen, noch je ein Schulhaus im Sertig, Dischma und Laret (Gesamtschulen: Monstein, Sertig, Dischma, Laret). Der Pfarrer von Monstein predigt auch in Wiesen. Glaris und Frauenkirch besitzen einen Pfarrer, der im Sommer auch alle 14 Tage im Sertig predigt. In Davos-Dorf und Laret amtet der gleiche Pfarrer.

Eine sehr gebräuchliche Unterteilung der Landschaft Davos, die historisch bis in die Anfänge und Besiedlung durch die Walser im 13. Jahrhundert zurückreicht, ist diejenige von Ober- und Unterschnitt ${ }^{4}$. Die Grenze durchquert das Tal bei der Hauptkirche St. Johann in Davos-Platz. Sie trennt heute nicht nur eine vorwiegend bäuerliche Bevölkerung von einer größtenteils städtischen. Sie ist auch weitgehend eine sprachliche und klimatische Grenze, eine Grenze zwischen zwei Bauerntypen: einem offeneren, mit dem Kurort in Berührung gekommenen Oberschnitter und cinem bodenständigeren, verschlosseneren Unterschnitter.

1 Landschaft wird in Davos als offizielle Bezeichinung für Gemeinde gebraucht und nicht im Sinne des geographischen Begriffes. Ich brauche daher auch in meiner Arbeit den Ausdruck „Landschaft" und meine damit das Areal der politischen Gemeinde Davos.

2 Vergl. Fig. 1.

3 Zählung 1. Dez. 1950.

4 Ursprünglich Schnitz $=$ Teil, schnitzen $=$ teilen. 
Die Gemeindegrenze ist wenig gegliedert und umfaßt ein geschlossenes, fast quadratisches Gebiet. Sie verläuft größtenteils auf der Wasserscheide des Einzugsgebietes des Landwassers, und nur im Norden überschreitet sie diese und umfaßt noch ein kleines Einzugsgebiet der Landquart (Stützbach, Schwarzsee). Im Südosten bilden die Höhen die Grenze zum Engadin. Die Gemeindegrenze zieht vom Bühlenhorn über den Ducanpaß - Ducangruppe zum Sertigpaß, Kühalphorn Scalettapaß, Piz Grialetsch - Grialetschpaß, Radünerpaß — Flüelapaß und biegt dann gegen Norden über den Grat Flüela - Weißhorn - Pischahorn bis zum Seehörnli. Im Nordwesten trennen die Höhen Davos vom Schanfigg und Arosa. Die Grenze verläuft über die Wasserscheide der Weißfluh - Schiahorn zum Strelapaß, Küpfentluh, Mädrigerfluh, Thiejerfluh zur Maienfelderfurka, Amselfluh Altein. (Kleinere Ausnahmen: Zwischen Küpfenfluh und Mädrigerfluh: Die frühere Grenze lief noch über die Wasserscheide, den Wannengrat. Zwischen Mädriger- und Thiejerfluh: Die alte Grenze führte über den Schafgrind. Diese beiden Flächen gehören heute zum Einzugsgebiet der Plessur.)

Das Haupttal, NE-SW verlaufend, wird vom Landwasser durchflossen, das im Davosersee entspringt (Länge $25 \mathrm{~km}$ ). Die Wasserscheide befindet sich am Wolfgang $1663 \mathrm{~m}$ ü. M. Das Tal besitzt vorerst wenig Gefälle. Das Landwasser durchfloß die breite Sohle vor der Kanalisation im Jahre 1885 in vielen Mäandern und überschwemmte bei Hochwasser große Wiesenflächen. (Der Flurname «Kännlene »zwischen Davos-Platz und Frauenkirch erinnert uns noch an diese Zeit. Das Seitenbächlein, das dort in den Hauptfluß mündet, mußte in Holzkänneln auf einem Gerüst in das Landwasser geleitet werden, das höher als die umliegenden Wiesen zwischen künstlichen Dämmen floß. "Isla », in den Islen, dort wo heute der Schießplatz von Davos steht, bezeichnet die Inseln, die durch Teilarme des Landwassers entstanden waren.) Von Frauenkirch an nimmt das Gefälle zu. Links und rechts schneidet sich der Fluß in die alten Seeterrassen und tritt nach Monstein in die tiefe, ausgefressene Zügenschlucht ein. Die Gemeindegrenze durchquert die Schlucht am tiefsten Punkt der Landschaft $1257 \mathrm{~m}$ ü. M. bei Brombenz. Gefälle des Landwassers in den beiden Hauptabschnitten:
Davosersee bis Sertigbach
8 Promille
Einmündung Sertigbach
Landschaftsgrenze
27 Promille

Von links münden vier große parallel laufende Seitentäler ein. Bei Davos-Dorf endet das Flüelatal (Länge $9 \mathrm{~km}$ ). Der Flüelabach floß früher direkt ins Land. wasser, heute kann das Wasser durch einen unterirdischen Abzugskanal in den Davosersee geleitet werden. Das Dischmatal (Länge $11 \mathrm{~km}$ ) mündet ganz in der Nähe etwa tausend Meter weiter. Das Sertigtal (Länge $8 \mathrm{~km}$ ) tritt bei Frauenkirch ins Haupttal ein. Der Sertigbach baute hier ein großes Delta in den postglacialen Davoser-Groß-See hinein. Der Wildboden und Junkersboden, die heutigen Überreste, dringen als Sporne. weit ins Haupttal vor. Das kürzeste und auch steilste, größere Seitental ist dasjenige von Monstein (Länge 1,2 km). Die rechten Zuflüsse sind alles kurze Bergbächc mit großem Gefälle. Diese Wildbäche reissen bei starken, kurzen Niederschlägen Erde und Steine mit und treten im Unterlauf über die Ufer. Um die Jahrhundertwende wurden darum große Verbauungsarbeiten am Totalpbach, Schiabach, Guggerbach, Albertibach, Bildlibach und Bolgenbach vorgenommen. Diese Arbeiten dauern auch heute noch an. Beim Albertibach versucht man, mit Aufforstung in den obern Zonen dem Rückwärtsschreiten und Einfressen des Baches zu wehren.

Die vertikalen Höhenunterschiede sind relativ klein. Durch seine entfernte Lage zur Erosionsbasis ist Davos ein Hochtal geblieben, ähnlich dem Engadin oder dem Urserental. Die größten Höhenunterschiede vom Talboden zur Trogschulter betragen in der Zügenschlucht $1000 \mathrm{~m}$, sie vermindern sich jedoch schon in Glaris auf $500-600 \mathrm{~m}$. 
Die Dauersiedlungen befinden sich im Tale entweder auf Terrassen oder an Hängen, im obern 'Teil des Davosertales auch im Talboden. Auch die Seitentäler sind das ganze Jahr bewohnt: Sertig bis zur Bäbi $1770 \mathrm{~m}$ ü. M., Dischma bis Gulrigen $1700 \mathrm{~m}$. Die beiden Gasthöfe im Sertig auf $1860 \mathrm{~m}$ Höhe bilden eine Ausnahme. Im Flüelatal finden wir heute keinen ganzjährlich bewohnten Hof mehr.

Die 'Talhänge sind bewaldet mit Tannen und Lärchenbeständen, die Süd- und Südwesthänge oft stark gelichtet. Magerwiesen greifen weit in den geschlossenen Waldgürtel hinein. Die obere Waldgrenze schwankt im Haupttal um die 2000 Isohypse und reicht in den Seitentälern bis zu Höhen von $2100 \mathrm{~m}$. An die Waldgrenze schließen die Alpen an. Die Gebäude liegen meistens auf der Trogschulter des Haupttales und hinten in den Seitentälern auf den Talböden.. Die Weiden dehnen sich bis auf die entferntesten Gipfel aus. Das unproduktive Fels- und Gletscherareal ist, verglichen mit anderen bündnerischen Gemeinden, klein. Die höchsten Erhebungen Hoch-Ducan $3066 \mathrm{~m}$, Flüela-Schwarzhorn $3150 \mathrm{~m}$, Piz Grialetsch $3131 \mathrm{~m}$ ü. M., überschreiten gerade die Dreitausender-Grenze. Die Distanzen vom Talbetrieb zu den Alpen sind nicht groß. Einzig die hintersten Alpen in den Seitentälern liegen etwas entfernter, aber auch sie können in 2-3 Stunden zu Fuß erreicht werden. Diese günstige Lage vom Talbetrieb zum Alpbetrieb wirkt sich auch ganz besonders auf die Davoser Wirtschaftsstruktur aus.

\section{GEOLOGIE - MORPHOLOGIE}

Die Landschaft Davos liegt am Rande der oberostalpinen Decken. An ihrer Nordwestgrenze gegen Arosa hin unterschieben sich die nächst tiefer liegenden Decken, der Aroser Dolomitzug, die Tschirpendecke, die Aroser Schuppenzone und, als tiefstes Element, nicht mehr auf Davoser Boden, das Unterostalpin der Sulzfluhund Falknis-Teildecken. Das Landwassertal, von Nordost nach Südwest streichend, ist durch eine alte tektonische Mulde vorgebildet. Den südöstlichen Teil gegen das Engadin hin nimmt das Kristallin der Silvrettadecke ein (Gneiße, Glimmerschiefer und Amphibolithe). Im untern Teil des Tales reicht das Kristallin auch noch auf die rechte Seite und dringt bis an die Wasserscheide gegen Arosa hin. Darüber liegen in der Ducanmulde und südöstlich von Glaris in der Landwassermulde über dem Permo-Werfénien (Porphyre, rote Sandsteine) noch die gewaltigen Sedimentpakete der Trias, Ducan - Muchetta-Altein (Dolomite, Kalke, Rauwacken). Die nordwestliche Hälfte und der ganze nördliche Teil von Davos wird durch die reich verschuppten, tieferen, mittelostalpinen Decken gebildet (Hauptdolomit: Thiejerfluh, Mädrigerfluh, Küpfenfluh, Schiahorn, Weißfluh). In der Gegend nördlich des Woltganges, der Totalp, drangen basische und ultrabasische Eruptiva in die Serien der Aroser Schuppenzone ein. Durch Metamorphose sind sie in Grünschiefer und Serpentine umgewandelt worden.

Die sauern Gesteine des Kristallins, die Kalke und Dolomite der Sedimentdekken und die Ophiolithe der Totalp bilden die Gesteinsunterlage, die Böden der Davoser Alpen. Der größte Teil liegt im kristallinen Bereich. Dort ist die Vergandung relativ klein. Einzig die Karmulden zu Füßen der Amphibolithstöcke sind ausgefüllt mit grobem Blockmaterial, das oft in einzelnen Strömen bis weit ins Weidegebiet hinein greift (Vorderes Dischmatal, Flüela - Schwarzhorn, Leidbachhorn). Im Kristallin besitzt die, saure Böden liebende alpine $Z_{\text {wergstrauchformation (Eri- }}$ caceen, Alpenrosen), eine große Ausdehnung und schränkt die Weide noch hoch über die Waldgrenze hinauf ein (Talflanken des Dischmatales) ${ }^{5}$. Die Alpen im sedimentären Teil der Silvrettadecke oder der Aroser Dolomitdecke an der östlichen Gemeindegrenze weisen große ausgedehnte Schutthalden auf, die von den steilen Hängen der Mädrigerfluh oder Thiejerfluh herunterziehen. Eine Sonderstellung nimmt das Serpentingebiet der Totalp ein, wo nur spärlicher Graswuchs

\footnotetext{
5 Vergl. Fig. 3.
} 
vorhanden ist. Der rotbraune Boden (der Serpentin besitzt hier eine rotbraune Verwitterungskruste) tritt überall nackt hervor und bildet eine ideale Angriffsfläche für die Erosion. Viele verzweigte und sich bald stark einschneidende Rinnen durchziehen die Flanken der Totalp.

Die Anlage des Davosertales ist als tektonische Mulde im Gesamtbau der Alpen sehr alt. Das Tal entwässerte sich nach Osten zum Unterengadin und zum Inn axial gegen die Silvrettadepression im Raume Silvrettapaß - Süß - Zernez ${ }^{6}$. Doch die tiefer liegende Erosionsbasis des Rheinsystems im Raume des -heutigen Sarganserlandes lie $\beta$ die Landquart hinein greifen bis in die Landwassermulde und machte sich so das Davosertal schon früh tributär. (Das zeigen auch die besterhaltenen alten Taltröge von $2100 \mathrm{~m}$ und $2300-2550 \mathrm{~m}$ ü. M. Sie fallen von Süden gegen Norden ab. Alle Seitentäler: Sertig, Dischma und Flüela weisen nach Norden und münden heute in einem spitzen Winkel ins Haupttal ein.) Es war eine alte Landschaft mit Mittelgebirgsformen. Noch fehlten die scharfen Gräte und Kämme, die Kare. (Auf diesen breiten, flachen, präglacialen T'alböden liegen heute die Alpgebäude, ca. $2100 \mathrm{~m}$ ü. M.) In den Interglacialzeiten wurde das heutige Tal ausgeräumt und von den Gletschern geformt. In der letzten $Z_{\text {wischeneiszeit }}$ entstand die Zügenschlucht durch rückwärtsschreitende Erosion des Jenisbergerbaches. Die Wasserscheide zwischen Albula- und Landquartsystem lag bei Glaris. Moränen der Würm-Eiszeit verstopften jedoch die Zügenschlucht wieder. Die entscheidende Flußumkehr zum heutigen Lauf brachte ein postglacialer Bergsturz von der Toltalp, der den Wolfgang aufschüttete, und dessen letzte Ausläufer bis nach Klosters hinunter reichten. Er staute einen See auf, dessen höchster Spiegel auf ca. $1550 \mathrm{~m}$ Höhe lag. In diesen See bauten die Seitenbäche ihre Deltas vor. (Von Frauenkirch abwärts ziehen sich auf der Höhe von $1550 \mathrm{~m}$ horizontal, die oft bis zu einigen $100 \mathrm{~m}$ breiten Terrassenvorbauten an den 'Talhängen entlang bis nach Monstein: Wildboden, Junkersboden, Spina, Monstein, Langmatte, Kumma, Hitzeboden.) Diese Aufschüttungen aus den Seitentälern teilten den See in einzelne Teilseen auf, die zu verlanden begannen; anderseits wurde der Schutt in der Zügenschlucht ausgeräumt und ein Seebecken nach dem andern zur Entleerung gebracht. Zurück blieb ein See an der Staustelle beim Wolfgang, der immer mehr aufgefüllt wurde von den Kiesen und Sanden des Flüelabaches, bis der heutige Davosersee entstand ${ }^{7}$. So kurz auch die Lebensdauer des Davoser-Groß-Sees war, so entscheidend war doch die Zeit für das heutige morphologische Bild des Unterschnittes. Auf den breiten Terrassen liegen die besten Wiesen und die vielen verstreuten Bauernhöfe (Abb. 1).

\section{KLIMA}

„Das hiesige Clima ist außerordentlich gesund, ansteckende Krankheiten gibt es sehr selten “, so schreibt 1805 Landammann VAL.̈̈R ${ }^{8}$. „Es ist kalt und rauh, die Gebirge umringen Davos. Die feuchten Nebel der tiefern Gegenden sind hier ganz unbekannt, sodaß zuweilen angenehme Witterung herrscht, während man in zahmern Thälern von der Kälte leidet."

Das erkannten auch die Gründer des Kurortes Davos. Die früh gegründete meteorologische Station (1867) sammelte ein reiches Material, um die Vorzüge des Davoser Klimas auch wissenschaftlich beweisen zu können. Es lag daher für dic Davoser Meteorologen nahe, eine ihrer Hauptaufgaben in der Erforschung der biologischen Auswirkungen des Klimas zu sehen und die Medizin zu unterstützen. Das erkannte auch Dorno":

„Die meteorologischen Tabellen in ihrer heutigen gebräuchlichen Form sind wenig geeignet zur Beurteilung der Eignung eines Klimas für den Menschen. Welcher Arzt kann wohl auf Grund der meteorologischen Tabellen unseres Hochgebirgskurortes einen Patienten nach Davos senden?

- Sraub, R.: Grundzüge alpiner Morphologie, S. 83.

7 Cadisch, J.: Zur Talgeschichte von Davos.

${ }^{8}$ VAL.Ä, J.: Topographische Beschreibung der Landschaft Davos, S. 8, 13.

${ }^{0}$ Dorno, C.: Klimatologie des Hochgebirges, S. 139. 
Des Winters Kälte, die gewaltigen Temperaturschwankungen, die hohe relative Feuchtigkeit scheinen das doch vollständig auszuschließen.. Und doch ist der Wärmeanspruch, den das Klima in Davos stellt ein geringerer als wohl an allen Orten nördlich der Alpen und kaum größer als an der Riviera der schweizerischen und oberitalienischen Seen, und die Gleichmäßigkeit des Wärmeanspruches im Tages- und Jahreslauf ist eine größere als an allen diesen Orten. Dies ist bewiesen durch systematisch während etlicher Jahre durchgeführte Messungen der Abkühlungsgröße."

Die Abkühlungsgröße ist die gesamte Wirkung der auf einem physikalischen Körper von 36,5 Grad Celsius wirkenden abkühlenden Faktoren: es sind dies die Luftemperatur, Wind und Ausstrahlung abzüglich Einstrahlung.

Dorno und 'Thilenius konstruierten zu deren Messung das Davoser Frigorimeter. Zur Charakterisierung der Abkühlungsgröße entnehme ich einer Arbeit von Mörikofer die beiden folgenden Tabellen ${ }^{10}$.

r. Mittelwert der Abkiühlungsgröße in Milligrammkalorien pro Quadratzentimeter und Sekunde:

\begin{tabular}{|c|c|c|c|c|}
\hline & April-September & Oktober-März & Mittel & Amplitude \\
\hline $\begin{array}{l}\text { Davos-Platz } \\
\text { Locarno-Monti } \\
\text { Zürich } \\
\text { Dresden }\end{array}$ & $\begin{array}{r}10.9 \\
9.0 \\
12.0 \\
21.3\end{array}$ & $\begin{array}{r}14.7 \\
-15.1 \\
19.8 \\
36.7\end{array}$ & $\begin{array}{l}12.8 \\
12.0 \\
15.9 \\
29.0\end{array}$ & $\begin{array}{r}6.5 \\
10.2 \\
13.7 \\
23.9\end{array}$ \\
\hline
\end{tabular}

Diese niedrigen Werte für Davos sind vor allem auf den ausgezeichneten Windschutz und die häufigere und intensivere Strahlung zurückzuführen. Für eine biologische Wertung kann folgende Skala gebraucht werden.

$$
\begin{aligned}
\text { Abkiihlungsgröße } 0-5=\text { unangenehm heiß } \\
5-10=\text { angenehm } \\
10-15=\text { leicht kühI } \\
15-20=\text { kalt } \\
\text { über } 20=\text { unangenehm kalt }
\end{aligned}
$$

\begin{tabular}{|c|c|c|c|c|c|c|}
\hline & & $0-5$ & $5-10$ & $10-15$ & $15-20$ & über \\
\hline & Frühling & 3 & 22 & 35 & 25 & 15 \\
\hline & Sommer & 25 & 32 & 24 & 12 & 7 \\
\hline Davos: & Herbst & 6 & 27 & 38 & 20 & 9 \\
\hline & Winter & - & 13 & 47 & 25 & 15 \\
\hline & Jahr & 8 & 23 & 36 & 21 & 12 \\
\hline & Frühling & 16 & 30 & 30 & 15 & 9 \\
\hline & Sommer & 59 & 25 & 12 & 3 & 1 \\
\hline Basel: & Herbst & 13 & 26 & 31 & 18 & 12 \\
\hline & Winter & - & $\because$ & 24 & 35 & 41 \\
\hline & Jahr & 22 & 20 & 24 & 18 & 16 \\
\hline
\end{tabular}

2. Häufigkeit der einzelnen Stufen der Abkiihlungsgröße während des Krankentages (7.30-20 Uhr) in \%

Mit Ausnahme des Sommers fallen die größten Prozentzahlen in Davos immer in die Stufe «leicht kühl». Bei Basel ist der Sommer in $59 \%$ der Zeit « unangenehm heiß» und der Winter in $4.1 \%$ der Zeit « unangenehm kühl ». Auch die Untersuchungen der täglichen Schwankungen der Abkühlungsgröße zeigen für Davos ähnliche günstige Resultate.

Die Vielfalt der topographischen Verhältnisse bringt einen Reichtum an lokalklimatischen Variationen. Die Sonnenscheindauer wechselt je nach Gunst der Lage. Zwischen Talboden und Hängen (Beispiel Davos - Schatzalp) findet zeitweise eine Temperaturumkehr statt. Nachts ist es zu jeder Jahreszeit auf der Schatzalp im Durchschnitt wärmer als in Davos, über Tag aber nur im Winter, im Sommer ist es oben kühler.

Auf einem um 30 Grad ansteigenden Südabhang, ist die Insolation zu allen Jahreszeiten außer im Sommer beträchtlich größer, als auf einem nur 15 Grad geneigten.

10 Mörikofer, W.: Zur Klimatologie der Abkühlungsgröße. 
Exposition und Lage zeigen sich in der Anlage der Äcker, die vorwiegend an Südwesthängen zu finden sind und die Talsohle $\cdot$ meiden ${ }^{\mathbf{1 1}}$.

Entsprechend der kontinentaleren Lage kommt die Vegetationsgrenze in Graubünden höher zu liegen, als an den Außenflanken der Alpen. Die Kontinentalität wird durch den Temperaturverlauf charakterisiert. Durch die kräftige und schnelle Ein- und Ausstrahlung werden die 'Temperaturen der kalten Jahres- und Tageszeit herab gedrückt, die der warmen erhöht. Eine Ausnahme bildet das Klima der Talhänge, deren tägliche Schwankungen viel kleiner sind.

Die jährliche Niederschlagsmenge von $965 \mathrm{~mm}$ (Mittel von 1886-1940) ist eher niedrig und bildet ein Kennzeichen für die abgeschlossene Lage des Tales. Der größte Teil der Niederschläge fällt in den Sommermonaten, während in den Wintermonaten die Niederschlagsmenge beträchtlich zurückgeht. Schneefälle können in allen Jahreszeiten auftreten, in den Sommermonaten jedoch nur ausnahmsweise.

Das Haupttal ist, besonders an den Seiten, sehr windgeschützt; in den Seitentälern ist die Luftbewegung wesentlich stärker.

Kennzeichnend für das Davoser.Klima ist die geringe Bewölkung und die große Sonnenscheindauer. Der Einfluß der geringen Bewölkung des Winters läßt sich daran erkennen, daß in üieser Jahreszeit die Werte der Sonnnenscheindauer trotz der Verkleinerung des Tagbogens durch die, das Tal einschließenden Berge bedeutend größer werden, als im Tiefland.

Das Klima von Davos ist durch seine meteorologische Station und das Physikalisch-Meteorologische Observatorium Davos eingehend untersucht. Es kann allgemein als Hochgebirgsklima mit folgenden Merkmalen charakterisiert werden:

Verminderter Luftdruck, große Lufttrockenheit mit gesteigerter Verdunstung, reichliche Besonnung, intensive Strahlung, besonders im Ultraviolett, große Gleichmäßigkeit der Strahlungsvorgänge im Tages- und Jahresverlauf, niedrige und sehr gleichmäßige Abkühlungsgröße bei vorzüglichem Windschutz und niedrigen Temperaturen, Staub- und Keimfreiheit der Luft.

Speziell für die Landwirtschaft sind folgende Punkte von Bedeutung:

1. Da die verschiedenen Nutzungsflächen eines Bergbauernbetriebes sich in ganz verschiedenen Höhenlagen befinden und große Höhenunterschiede aufweisen, so sind auch die klimatologischen Verhältnisse sehr verschieden.

2. Die niedrigen Temperaturwerte, vor allem die Möglichkeit von Nachtfrösten im Frühling und Herbst, bedingen eine kurze Vegetationszeit.

3. Die Trockenheit der Luft und kleine Niederschlagsmengen in trockenen Sommern können die Alpweiden stark ausdörren lassen.

4. Die Kaltluftseen, die sich in den gef:̈̈llsarmen 'Talböden bilden, erhöhen die Nachtfrostgefahr stark und schliefen dort den Ackerbau aus.

5. Nach LoEwy ${ }^{12}$ hat das Hochgebirgsklima viele günstige Wirkungen auch auf die Tiere (guter Gesundheitszustand, gesunder Knochenbau, Vitaminreichtum der Milch usw.).

Im statistischen Anhang sind für Davos die wichtigsten Klimadaten auf Grund langjähriger Mittelwerte zusammengestellt.

\section{GESCHICHTLICHER ÜBERBLICK}

Im 13. Jahrhundert wurde das ' $\Gamma$ al von den Walsern besiedelt. 1289 stellte ihnen ihr Grundherr, der Freiher von Vaz, einen Lehensbrief aus, der sie als freie Leute anerkannte. Sie nahmen daher für die allgemeinen Verhältnisse des frühen Mittelalters eine bevorzugte rechtliche Stellung ein. 1323 starb Donat von Vaz. Seine Tochter heiratete Friedrich V. von Toggenburg. 1436, nach dem Aussterben des

11 Vergleiche Abb. 1.

12 LewwY, A.: Der Höhenaufenthalt in seiner Wirkung auf Mensch und Tier. 
Geschlechts, schloß sich Davos mit den übrigen Gerichten zum Zehngerichtenbund zusammen und übernahm bis zum Jahre 16:49 (Waser'scher Spruch) die Führung als Hauptort mit dem Bundeslandammann. Die Erben der Toggenburger, die Grafen von Montfort, bestätigten die Rechte 1437 und verkauften das Land an den Herzog Sigismund von Österreich. Von diesem kani es an den Grafen von Matsch, der Davos 1478 wieder an Sigismund abtrat. Unter der österreichischen Schirmherrschaft wurden die alten Rechte immer mehr unterdrückt, soda $\beta$ es 1621 zum Krieg, zu den Büñdnerwirren kam. Mit dem Ende des 30-jährigen Krieges erhielt Graubünden seine Freiheit, auch Davos kaufte sich ron der Herrschaft los. Seit dieser Zeit ist die Landschaft im Besitze ihrer alt hergebrachten Freiheiten, mit Ausnahme der 5 Jahre helvetischer Einheitsform von 1798-1803, bei völlig, unveränderter Verfassung und Verwaltung geblieben. Seit 1803 bekam es auch gewisse gemeinsame kantonale Landesgesetze. 1851 wurde Arosa als eigene politische Gemeinde abgetrennt, und die Landschaft Davos entstand in ihrer heutigen Form.

\section{ALPWIRTSCHAFT}

Unter Alpwirtschaft im weitesten Sinne verstehe ich die Wirtschaftsform des Bergbauern, der auf ganz bestimmten klimatischen, pedologischen und topographischen Verhältnissen seine Landwirtschaft aufbaut.

Während des langen Winters ist er genötigt, sein Vieh im Stall zu halten. In der kurzen Zeit des Sommers muß er also für das Futter, für genügend Heu zur Überwinterung sorgen.

Im Sommer stehen ihm große Nutzungsflächen zur Verfügung, die wegen der kurzen Vegetationszeit, bedingt durch die Höhenlage, nur einen geringen Nutzungswert besitzen.

Der zu einer Intensivierung benötigte Lünger (Mist) wird in den am nächsten am Hauptbetrieb liegenden Nutzungsfï̈chen aufgebraucht.

So kommen wir zu einer natürlichen Aufteilung des Nutzungsareales. Die günstigste Stelle (klimatisch, pedologisch, verkehrstechnisch usw.) nimmt das Zentrum ein. Es ist der Talbetrieb. Hier wird das Vieh überwintert. Um diesen Talbetrieb liegen die «Futterreservoire », die intensiv bewirtschafteten Wiesen und Äcker, welche die Möglichkeit zur Überwinterung geben. Je weiter und je ungünstiger die Nutzungsareale liegen, desto extensiver werden sie bewirtschaftet. Vorerst die Magerwiesen, die jedes Jahr gemäht werden, dann nur noch jedes zweite Jahr, schließlich sind es Weiden ${ }^{13}$. Die $W^{r}$ eiden dürfen nicht unterschätzt werden, sie bilden die Futterbasis für den Sommer. So kann der ganze Ertrag der Talwiesen für den Winter gespeichert werden.

Wenn auch diese sicher ursprüngliche Form heute in großer Vielfalt abgewandelt ist, wenn auch viele Alpen äufierlich ganz unabhängig von einem Talbetrieb bewirtschaftet werden und kaum mehr einen direkten Zusammenhang mit diesem zeigen, so sind gerade diese engen und einfachen Verhältnisse für Davos bezeichnend. Zwei Hauptfaktoren können dafür verantwortlich gemacht werden:

1. Die günstigen natürlichen Grundlagen, die sehr eng zusammenliegenden Nutzungsflächen, die kurze Distanz zur Alp.

2. Der bestimmte Charakter der walserischen Landwirtschaft, die ganz auf privatrechtlicher Basis aufbaut, sodali auch heute die ganze Wirtschaftsform im einzelnen Betrieb, in der einzelnen Familie verankert ist.

Alpwirtschaft ist ein Ganzes und sollte gleichgesetzt werden mit alpiner Viehwirtschaft und entspricht nicht nur dem eigentlichen Sömmerungsbetrieb. Die Alpung ist das charakteristische Merkmal dieser Wirtschaftsform und gibt ihr daher

13 Vergleiche auch Teil III. 
den Namen 14. WeIss scheidet sie zwar als die am höchsten liegende Betriebsstufe der alpinen Viehwirtschaft von der 'Tal- und Maiensäß-Stufe $a b$, weist anderseits auch auf den innern Zusammenhang dieser drei Stufen hin ${ }^{15}$. Der Begriff Alpwirtschaft wird jedoch heute auch oft im engern Sinn nur für die Wirtschaftsform der Alp während der Sömmerung gebraucht.

Im Gemeindeareal von Davos liegen 46 Alpen, dazu kommen noch 14 Sömmerungsweiden, Sonderweiden und $Z$ wischenformen, die nicht als Alp bezeichnet werden können. 6 Alpen gehören andern Gemeinden, Genossenschaften oder Privaten, die nicht in der Gemeinde Davos wohnen. Alle andern Alpen sind Privatoder Privatkorporationsalpen 16. (Mehrere private Betriebe schlossen sich zusammen.) Jeder Bauer besitzt sein Alpgebäude und verarbeitete ursprünglich seine Milch selber. Heute kommt alle Milch in die Zentralmolkerei nach Davos. Gemeinsam geschieht nur das Hüten des Viehs und einige Arbeiten, die im «Gmeiwärch » 17 verrichtet werden, z. B. Alpverbesserungen. Am Abend kommt das Vieh in den Stall zurück. Dies ist nur möglich, wenn die Alpen wie in Davos nahe liegen und ein Glied der Familie nach der Tagesarbeit im Tal (heuen) noch hinaufsteigen kann, um das Vieh zu besorgen. Daher finden wir in Davos auch nur den 2stufigen Betrieb Tal-Alpstufe, die Maiensäßzone fällt weg oder mit der Alpstufe zusammen.

Die Form der Alpwirtschaft in Davos ist in so hohem Maße durch die Tatsache der Walsersiedlung, der Walsereigenart bestimmt, daß nur eine kulturhistorische Betrachtung, die Untersuchung der Entwicklung der Alpwirtschaft, ein besseres Verständnis der heutigen Davoser Landwirtschaft geben kann.

\title{
II. Tril
}

\section{Die Entwicklung der Davoser Alpwirtschaft}

\author{
DIE WALSERSIEDLUNG IM 13. JAHRHUNDERT
}

Die vorwalserische Zeit.

Die Vermutung, daß Graubünden schon in uralter Zeit bewohnt war, bestätigt sich durch prähistorische Funde immer mehr. Auch in Davos fand man 1867 beim Straßenbau auf dem Flüelapaß eine Bronzelanze von ungarischem Typ, und im Juni $1889 \mathrm{kam}$ beim Legen einer Wasserleitung auf der Drussatscha-Alp in $1774 \mathrm{~m}$ Höhe ein Bronzebeil zum Vorschein. Weitere Funde deuten auf eine Verbindung Inntal - Flüela - Landwassertal, daß also bereits zur Bronzezeit ein Teil der Handelsbeziehungen über Bünden diesen Weg genommen hat ${ }^{1}$.

Die ersten dokumentarischen Nachrichten finden wir in den Jahrzeitbüchern der Kirche von Chur. Sie vermerken 1170 ein Gut zu Tavaus gelegen, das von Priester Heinrich verwaltet wird und Abgaben in Käse entrichtet. Eine andere Urkunde aus dem Jahre 1213 nennt das Gut in Kristis oder «Tavauns valle», welches dem Kloster Kurwalden 60 Käse und 4 Frischlinge (Schafe) abzuliefern hat.

Die Untersuchung der Flurnamen kann uns etwas weiter Aufschluß geben. Der Name Davos hat bis jetzt fünf Deutungen erfahren:

1. J. C. Muorh: von ad avenes $=z u$ den Wassern. 2. Ferdmax: von "dava ", thrazisch = Siedelung. Durch das Volk der Dazier hergebracht. Davos bedeutet demnach eigentlich Dazier oder

it Vergleiche Teil III, Alpbegritt.

ii Verglejche WEiss: Das Alpwesen Graubündens.

10 Weiss : Das Alpwesen Graubündens. S. 86.

17 „Gmeiwärch “ - Gemeinsame Arbeit, zur Erstellung von öffentlichen Arbeiten: Alpverbesserungen, zäunen, Wege verbessern usw.

1 Ferdmani, J.: Die Anfänge des Kurortes Davos. S. 8. 
Davier (wie Schweizer, Bündner usw.) ${ }^{2}$. 3. PLANi A, R. : von tovum, tovani = Tobelleute ${ }^{3}$. 4. BIERT, L. : von da Vaz (den Vazern untertan) ${ }^{4}$. 5. Von romanisch "davos “ im Sinne von ", hinten “, im Hintergrund, auf der rückıärtigen Seite gelegen. Schüle gibt eine Zusammenstellung der Flurnamen "davos “ aus dem romanischen Graubünden". Bergün: Davos Siala (Wald), Davos Cuolm (Wiesen), "God davos Chant sech, God davos sum Diess (Wald). Das Jenatzer Tobel hieß früher "val davos “" Sent: Piz und Vadret Davo Lais (Hinter den Seen). Bündner Oberland: Val Davos Glatschers (Tal hinter den Gletschern). An diese Deutung knüpft auch die Sage an, daß Jäger des Freiherrn von Vaz zufälligerweise die Gegend entdeckt und nachher vom schönen, weiten Tal „dahinten " erzählt hätten.

Auf eine vorwalserische Besiedelung deuten folgende romanische Flurnamen hin:

An der Landschaftsgrenze gelegen :

Scalettapaß: lat. scala $=$ Treppe, Leiter.

Pischahorn: von pischàr $=$ Wasserfall.

Grialetsch: lat. gregaricium $=$ Schafweide (Berg und $\mathrm{Pa}$ ).

Ducan: Berggruppe, Tal und Paß.

Fanez: $\quad 1491$ Fenez geschrieben. Bergwiese.

Parsenn: 1562 Persenn geschrieben. Bergwiesen.

Die Haupttäler :

Dischma: lat. decimanus $=$ zum Zehnten gehörig.

Sertig: früher Sartig. Rhätisch sarratauna $=$ mit Zäunen durchzogene Alptrift.

Monstein : mons - tain = Bergwiese. (Das angrenzende Dorf, Wiesen hieß früher Tein, der gegenüberliegende Berg ist der Altein.) oder: monasterium. Es soll zu einem Kloster in Alvaneu gehört haben.

Flüela : mittelhochdeutsch "vluo " = Felswand. Es ist das einzige größere Tal, dessen Name nicht in die romanische Zeit hinein reicht.

Glaris : Höfe ${ }^{6}$, lat. glarea $=$ Kiesfeld.

Pedra, Bedra, Bedera: Alp, Höfe, romanisch pedra $=$ Stein.

Spina und Spinnlena: Höfe und Hof, lat. spina = Dorn, Dorngestrüpp.

Laret: Höfe, lat. larix, larictum = Lärchenwald.

Cheisara, Kaisern: Höfe, von casaria zum Haus gehörend.

Drostobel, Drussatscha (Betonung auf dem u): Alp, rom. dros = Alpenerle.

Fatschil, Fatschül: Tobel, Höfe, lat. fauces, foceolum $=$ Töbelchen.

Saleza: Alp, rom. saletsch $=$ Weidenstauden.

Clavadel: Höfe, rom. clavau, clavo $=$ Heustall.

Foppa: Wiesen, rom. foppa = Grube, Mulde.

Palüda: Höfe, romanische Bezeichnung für Ried.

Ortolfi : Hof, Eigenname.

Albertibach : von Albertini = Eigenname.

Pravigan: Höfe, lat. pratum vicanum $=$ Dorfiviese.

Gaschurna: Hof, als Gadenstatt 1562 genannt.

Taferna: (Betonung auf dem ersten a) von Taverna? Im Spendbuch von Davos $1562^{\top}$ sind drei Familien Daffernun oder Zurdaffernun angegeben. Die eine lebt auf ihrem "Hus, Hof und Guot zur Daffernun “. Die örtliche Beschreibung stimmt mit dem heutigen Hof Taferna überein, welcher der Landschaft gehört und vom Abdecker bewohnt wird.

Rodungsnamen: Rongg, Ronggje, Ronggi wird vom lateinischen runcare oder romanischen runc, das heißt gerodetes Land abgeleitet und gibt uns einen Hinweis auf romanische Rodungsarbeit. (Rongg : zweimal als Weide im Dischma, Weide der Stafelalp, Weide der Leidbachalp. Ronggje : (Gaden und Wiese unterhalb Monstein.) Alle diese Rongg liegen im Bereich des heutigen Waldes und der frühern Allmenden.

Als deutsche Rodungsnamen finden wir Rüti (10 mal), Schwendi, Brand (2 mal), Gebrunscht (4 mal), Stocken (3 mal) und Inschlag (3 mal).

Rüti : (in verschiedenen Verbindungen, Rütiwald, Rütiland usw.) Zweimal in Monstein, Rüti bei Glaris, hintere Hälfte des Hitzebodens, oberhalb Chumma, unterhalb den Waldalpen, am Schat $\%$ berg. Das Spendbuch 1562 gibt noch ein Rüti außerhalb der Wildi im Dischmatal und eines am obern See an.

Brunscht, Gebrunscht: Monstein, vorderes Dischmatal.

Schwendi : Monstein.

2 Vergleiche Ferdman: Die Anfänge des Kurortes Davos. S. 11.

3 BM 1924, S. 163. Woher kommt der Name Davos?

4 BM 1924, S. 111.

- BM 1930, S. 102.

- Der Flurname bezeichnet ein größeres Gebiet, das mehrere Höfe einschließst.

7 Jeckin, F.: Das Davoser Spendbuch vom Jahre 1562. 
Brand: Monstein.

Stocken: Wald bei Clavadel, beim Dorfbach.

Inschlag: In den Zügen außerhalb Rüti, im Sertig oberhalb der Mühle, Dischmatal.

Das Verhältnis von romanischen zu deutschen Rodungsnamen ergäbe $5: 22$.

Affereid, ein Weidegebiet am Büelahorn, leitet SzADRowski von ava freida $=$ kaltes Wasser ab. ${ }^{8}$ Dort befindet sich auch heute noch eine Quelle. Tieja, Stafel, Traje, Jatz, Rufena, Gufer gehen zum Teil auf romanische, teils andere Wurzeln zurück und müssen als verdeutschte Lehnwörter angesehen werden. ${ }^{9}$ Die Verdeutschung von romanischen Wörtern läßt sich in alten Davoser Geschlechter auffinden: Gampsurer (camp sur $=$ das obere Feld), Ardüser (Hof bei Glaris), Prader (pra $=$ Wiese). ${ }^{10}$

Was zeigen diese romanischen Flurnamen?

1. Die Flurnamen verteilen sich über die ganze Landschaft Davos. Im Haupttale liegen : Laret, Palüda, Pravigan, Glaris, Spina, Ardüs, Ortolfi. (Alles Bezeichnungen für Höfe.) Am Beginn der Seitentäler: Bedra, Fatschil, Clavadel. In den Seitentälern: Cheisera (Dischma), Gaschurna (Sertig).

2. Die Haupttäler sind benannt.

3. Bezeichnungen für Berge befinden sich nur an der Grenze der Landschaft.

4. Auf Besiedelung oder Bewirtschaftung weisen hin: Clavadel (Heustadel), Grialetsch (Schafweide), Sertig, Rongg, Affereid.

5. Einige Flurnamen geben Verhältnisse an, die sich für eine landwirtschaftliche Nutzung negativ auswirken: Glaris (Kiesfeld), Bedra (Stein), Spina (Dorngestrüpp), Drussatscha (Alpenerlen), Salezza (Weidenstauden), Palüda (Ried).

Die Landschaft Davos wurde also schon vor der Ansiedlung der Walser durch Romanen bewirtschaftet. Die Abgaben an das Kloster Kurwalden oder « Grialetsch » weisen auf Schafweiden hin. In kleineren Rodungen und Lichtungen wurde Gras gemäht und für Schneetage in Heustadeln aufbewahrt (Clavadel). Nur Pravigan deutet auf eine größere Siedlung.

War Davos das ganze Jahr besiedelt? Die beiden Dokumente von 1170 und 1213 sprechen von einem «Guot». Es kann also auch ein Maiensäß gewesen sein; das gleiche gilt für Pravigan. - Sicher müssen wir für Davos eine Bewirtschaftung im Sommer annehmen, die alle freien Weideflächen nutzte, Lichtungen im Wald und auch kleinere Waldflecken rodete. Es bestanden Hütten als Unterkunft für Hirten und Heustadel. Die Frage der Dauersiedlung kann mit diesen Tatsachen wohl kaum abgeklärt werden. Die entscheidende Rodung und Besiedelung im Tal geschah erst durch die Walser in 13. Jahrhundert ${ }^{11}$.

\section{Die Besiedlung durch die Walser.}

Schon Mitte des 13. Jahrhunderts (SFracher 1250, CAmpell 1270) waren die ersten Walser in dieses Hochtal gelangt 12. Sie begannen Wald zu roden und schwenden und schufen sich so Platz für ihre Höfe. Ein dichter Bergwald, der bis weit in die 'Talflanken hinauf stieg, muß das Tal bedeckt haben. Das Landwasser floß in vielen Mäandern und schüttete große Kies- und Schotterflächen auf, auch die Seitenflüsse mündeten in breiten Schotterdeltas. Diese Sand- und Steinflächen trugen wohl keinen Wald und bildeten Lïcken in der ziemlich geschlossenen Waldfläche. Mit dem Lehensbrief vom 31. August 1289 tritt die Landschaft Davos oder 'Tavaus in die Geschichte ein. Sie wurde von Walter von Vaz V. «Wilhelm dem ammen und synen Gesellen und ihren rechten Erben»verliehen.

${ }^{8}$ SZadrowski, M.: DR 1940, S. 74.

9 SCHORTA, A.: DR 1936, S. 222.

10 Die Liste der romanischen Flurnamen ist nicht vollständig; es fehlen einige, deren Deutung nicht abgeklärt ist.

11 Als hauptsächlichste Quellen zu diesem Abschnitt vergleiche: BüHLER, Bd. I, S. 252, SzADROWSKI, SCHÜLE, SCHORTA, SCHOOP.

${ }_{12}$ Für die Frage der Herkunft der Walser vergleiche die Arbeiten von K. MEYER und E. BraNGER. Die ersten Davoser scheinen demnach aus den ennetbirgischen, italienischen Walserkolonien zu stammen. Später kamen vielleicht auch noch Siedler direkt aus dem Oberwallis dazu. Darauf deuten Familiennamen wie Gotthart, Galpatramer, Gamsurer (Goms) oder Lötscher (Lötschental) hin. (Vergleiche Vat.́́R, M.: Sechs Jahrhundert Davoser Geschichte im Landbuch der Landschaft Davos, S. $26 \mathrm{f}$.) 
Als erste zwölf Höfe werden genannt:

1. Der Meyerhof ob dem Dörflein.

2. Im Thal Dischmach, in den Büelan.

7. Auf Clavadeel, im Thal Sartig.

3. Im Thal Flüela, auf Pedra.

8. Auf der Siebelmatte.

4. Am Schatzberg, in Kircher Oberschnitt.

5. $Z$ u Pravigan, ob der Hauptkirche.

9. Am See im Dörflein.

6. In der Grüene, in Kircher Unterschnitt.

10. Zu Glaris, ob der St. Niclaus-Kirche.

11. In der Spina.

12. In Monstein.

Dazu müssen später noch zwei weitere Höfe gekommen sein (Laret). Sic bilden die Grundlage der alten politischen Einteilung in 14 Nachbarschaften, die bis in die Mitte des 19. Jahrhunderts bestand, und auf die auch die heutigen Fraktionen zurückgehen ${ }^{13}$.

Óberschnitt: Die Nachbarschaften:

Unterschnitt: Die Nachbarschaften :
1. Kirchen-Oberschnitt $(5,4)^{14}$
2. Seewer-Sonnenhalb (9)
3. Seewer-lizehalb
4. Dischmah (2)
5. Flüela (3)
6. Meyerhof (1)
7. Ober- und Unterlaret

1. Kirchen-Unterschnitt (6)

2. Brüch und Siebelmatten (8)

3. Sartig und Clavadel (7)

4. Langmatte und Chumma

5. Glaris (10)

6. Spina (11)

7. Monstein (12) ${ }^{15}$

Die Ansiedlung geschah geplant. In gleichmäßigen Abständen wurde das Land aufgeteilt und den einzelnen Gesellen zugewiesen. In jeder Nachbarschaft liegt ein Hof, nur in Kirchen-Oberschnitt sind zwei Höfe, derjenige zu Pravigan muß dem Ammann Wilhelm gehört haben ${ }^{16}$. Leer gehen aus: Seewer lizehalb, das Gebiet zwischen Flüelabach und Dischmabach aut der Schattenseite im flachen Talboden gelegen, also sicher ein ungünstiger Siedlungsort, den Überschwemmungen des Flüelabaches ausgesetzt; Kumma und Langmatte, zwei aufgeschüttete Schotterdeltas der beiden reißenden Bergbäche; Laret, am nördlichen Ende der Landschaft auf der andern Seite der Wasserscheide, des Wolfgangs, das erst später noch einbezogen wurde.

Die deutschen Flurnamen geben uns Finweise auf die besondere Siedlungsweise der Walser. - Der Name Davos ist ein ausgesprochener Gebietsname und landschaftlicher Sammelbegriff, im Gegensatz zu räumlich eng gefaßten Lokalnamen mit fester Beziehung auf eine einzelne Ortschaft. Die heutige Häuserkonzentration wird daher mit Platz und Dorf bezeichnet (am Platz, im Dörfli). Diese Bezeichnung der wichtigsten Häusergruppen finden wir auch in andern Walsersiedlungen (Klosters, St. Antönien, Langwies, Safien, Vals): Der Platz ist das Zentrum der Streusiedlung. Hier befinden sich die Kirche, das Rathaus, das Gasthaus, hier findet die Landsgemeinde statt und wird Gericht gehalten. Die Bezeichnung Dörfli trägt die nächst wichtigere Häusergruppe. In dem großen und weit auseinander liegenden Gebiet der Landschaft Davos entstanden auch noch im Flüelatal und zu hinterst im Sertigtal ein Dörfli. Das «Davoser»-Dörfli änderte seinen Namen 1894 in Dorf um. Die Inhaber der einzelnen Höie bezeichnete man als Meier. Sie waren erbzinspflichtig. Meyerhof heißt die Häusergruppe am See. Über die ganze Landschaft verstreut sind die Flurnamen Hof und Höfje ${ }^{17}$. Viele Höfe wurden nach ihren Besitzern benannt: Ortolf, Ardüs, Gulrigenhus (Guler), Kindschhus (Kind) ${ }^{18}$,

18 Der kleine Rat oder das Gericht bestand ursprünglich aus 14 Mann, aus jeder Nachbarschaft einer. Der große Rat aus 3 Mann von jeder Nachbarschaft und dem Landammann, also 43. Heute wird nach politischen Parteien gewählt. Der große Landrat besteht aus 19 Mitgliedern und teilt sich auf in den kleinen Rat (4) den großen Rat (14) und den Landammann.

${ }_{14}$ Die Zahlen in der Klammer entsprechen der Nummer des Hofes, der in dieser Nachbarschaft liegt.

15 Vergleiche Landbuch der Landschaft Davos. S. XV.

${ }^{16}$ Der Wilhelmshof, so wurde eine Scheune in Pravigan genannt, wurde vor einigen Jahren abgerissen.

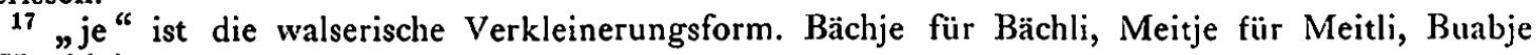
für Knäblein usw.

18 nicht von Kindschi, - sondern „em Kind sysch Hus“. 


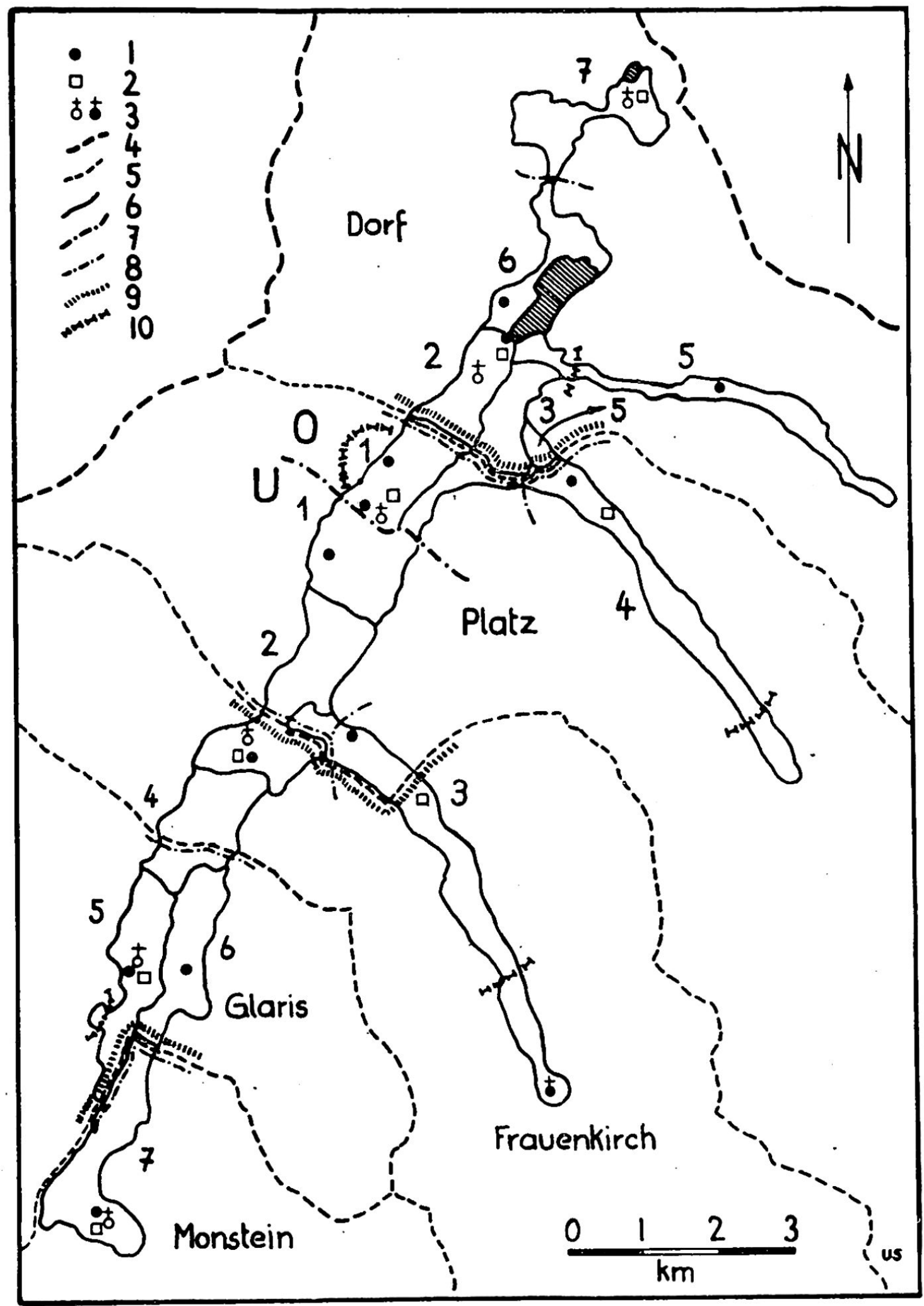

Fig. 1 Grenzen: 1 Erste 12 Siedler 1289, 2 Heutige Schulh:iuser, 3 Kirchen, Sertig nur im Sommer Predigt, 4 Gemeindegrenze, 5 Fraktionsgrenze, 6 Grenze der 14 Nachbarschaften, 7 Grenze zwischen Ober- $(\mathrm{O})$ und Unterschnitt (U), 8 Heutige Grenze der Schulgemeinden, 9 Heutige Grenze der Kirchgemeinden, 10 Obere Grenze der ganzjährlich bewohnten Siedlungen. Die Grenzen der Nachbarschaften umfassen das Dauersiedlungsgebiet im 16. Jahrhundert (größte Ausdehnung). Die alte Grenze der Kirchgemeinden verlïuft bei Glaris und Frauenkirch an der Stelle der heutigen Fraktionsgrenze.

Beelihus (Beeli). Auch eine Reihe von Alpen tragen patronymische Flurnamen: Gulrigenberg, Jenatschalp, Gadmenalp (Gadmer?), Carlimatte, Lukschalp (Luck), Alp am Rhin (Rhiner?), Büschalp, Riederalp, Rieberalp. Sie weisen auf eine sehr 
frühe Aufteilung der Alpfläche hin ${ }^{19}$. Wiesen, Weiden, Berge: Baslerschkopf (Basler), Sentischhora (Senti), Rhinerschhora (Rhiner), Wyssige Boda (Wy $\beta$ ), Rüedischtälli (Rüedi), Mattjeställi (Mattjis) ${ }^{20}$, Mäscheboda (Mäsch = walserisch Martin) usw. Der Wald trägt viele lokale Bezeichnungen, da er in Davos im Gegensatz zu andern Gemeinden im 17. Jahıhundert aufgeteilt wurde und sich nun größtenteils in Privatbesitz befindet.

Bergbenennungen sind fast durchwegs die letzten Ankömmlinge im Namenbuch einer Gegend. Die Bezeichnung des Berges vollzieht sich gewöhnlich durch Übertragung eines an seinem $\mathrm{Fuße}$ bereits festgesetzten Namens. Unabhängige Namenträger sind Schwarz-Weiß-, Grün-, Wuost-, Gefroren- und Schiahorn. Alle die vielen anderen Namen gründen sich auf Namenübertragung: Seehorn, Salezhorn, Bühlenhorn, Kühalphorn usw.

Die vielen deutschen Flurnamen bezeugen die entscheidende Rodungsarbeit und Kolonisation durch die Walser. 1289 betragen die Abgaben der Walser 473 Käse, 56 Schafe und 168 Ellen Tuch. (1213 das Davoser Gut an das Kloster Kurwalden 60 Käse, 4 Schafe 21.) Seither wurde also durch die Walser bedeutend mehr Kulturland gewonnen. Als neue Abgabe erscheinen 168 Ellen Tuch. Das deutet auf eine Dauersiedlung hin, wo fleißige Frauen und Töchter an den langen Winterabenden spannen und webten. 1335 werden bereits die 3 Kirchen St. Johann am Platz, die Kirche Unserer lieben Frau zu Frauenkirch und St. Niclaus zu Glaris erwähnt, während St. Thuoder im Dörfli jüngern Ursprungs ist und der Hauptkirche am Platz als Kapelle diente.

AUSBAU UND ENTWICKLUNG

DER WALSERISCHEN WIRTSCHAFTSFORM

\section{Die rechtliche Stellung des Walsers.}

Der Freiheitsbrief von 1289 gestand den Kolonisten für. jene Zeit besondere Rechte zu. In der Feudalzeit nahm der Stand der Freien eine kleine Gruppe ein, und $\mathrm{zu}$ dieser gehörten auch die Walser. Es ist verständlich, daß man ihnen bessere Bedingungen zusprechen mußte, als die Grundherrschaft sie den Bauern auf alt besiedeltem Gebiet zustand, wer ließe sich sonst freiwillig herbei zu der schweren Arbeit der Rodung. Die Davoser bekamen das Land als freies Erblehen, sofern sie den $Z$ ins verrichteten. Der Zins wurde nicht mehr gesteigert, sodaß er sich im Laufe der Zeit auf immer mehr Höfe verteilte. Im 14. Jahrhundert wandelte man den Naturalzins in eine Geldabgabe um (24 Pfund Pfennig). Der Zins wurde vom Ammann abgeliefert, im andern Fall konnte dieser gepfändet werden. Einzig beim Lehenszins kam der Charakter der gemeinsamen Leistung zum Ausdruck, während im übrigen jeder Genosse über seinen Anteil frei verfügte. Seit 1438 hatte es der Davoser auch in der Hand, seinen Zins abzulösen, sein Gut auszukaufen. An öffentlichen Rechten wurden ihm zugestanden:

1. Das Recht den Ammann zu wählen. Dieser durfte auch für die Gemeinde mit seinem eigenen Familiensiegel zeichnen.

2. Das Recht, eigene Satzungen aufzustellen.

3. Die niedere Gerichtsbarkeit, d. h. die ganze Zivilgerichtsbarkeit, Frevel und sogar die Zuständikeit für Streitigkeiten über freies Grundeigentum. Letzteres gehört eigentlich zur hohen $\mathrm{Ge}$ richtsbarkeit, sodaß ausschließlich die Blutgerichtsbarkeit noch dem Herrn zukommt.

4. Waffenpflicht, mit der besondern Bedingung, daß diese ganz auf Kosten des Herrn gehe, im Gegensatz zu den Leibeigenen. ${ }^{22}$

${ }^{19}$ Die Büsch- und Jenatschalp gehören auch heute noch einem einzelnen Besitzer.

20 Tälli kommt nicht von Tal, sondern ist vergleichbar mit dem schweizerdeutschen Wort "Tolla " und deckt sich mit dem morphologischen Begriff Karmulde.

21 Schafe : 1289 das 14 fache von 1213.

22 Vergleiche Branger: Rechtsgeschichte der freien Walser. 
Die Nutzungsrechtsverhältnisse (Marktgenossenschaft).

Die Walser bekamen «daz guot ze Tavaus» zu freier Erbleihe, in erster Linie das gerodete Sondergut im Tal, dann aber auch das gemeine Markland (Wald, Weide), jedoch gesamthaft ohne Ausscheidung der Mark. Eine besondere Abgabe für diese bestand nicht. Es ist daher anzunehmen, daß die Mark als gemeinsames Gut bestehen blieb, auf der jeder Walser freies Nutzungsrecht besaß. Die Markgemeinde umfaßte den ganzen Siedlungsraum der Landschaft Davos, wir können daher auch die Bezeichnung Talmark verwenden. Es ist eine unter Vogtei stehende Mark, welche jedoch weder eine Vogtstcuer entrichtete, noch dem Grundherrn eine Beteiligung an der Nutzung der Allmend einräumte 23. Überblicken wir das weite Gebiet dieser Talmark, so ist es wohl unmöglich, daß die Monsteiner mit ihrem Vieh die Weiden im Dischma atzten, oder die Lareter ihr Vieh ins Unterschnitt trieben. Es bildeten sich bald bestimmte Hotgruppen, die die Ausübung der allgemeinen Rechtsgrundsätze übernahmen. Diese Gruppen entstanden um die 14 ersten Höfe. Den 14 Nachbarschaften fiel weitgehend die Organisation und Verwaltung zu. Die gemeine Talmark war aufgeteilt in Teilmarken ${ }^{24}$. Wir können damit für Davos eine ähnliche Entwicklung annehmen, wie sie Liver für den Heinzenberg beschreibt, mit dem einzigen Unterschied, da $\beta$ aus seinen Nachbarschaften später selbständige Gemeinden entstanden ${ }^{25}$. In Davos blieben die Nachbarschaften immer ein Teil der Landschaft. Ich möchte sie daher Hofgenossenschaften nennen ${ }^{26}$. Dieser Ausdruck gibt zudem den Siedlungscharakter wieder. Die Nachbarschaften oder Hofgenossenschaften übernahmen die innere Organisation, bei Streitigkeiten war es jedoch immer der Landammann, der mit seinen Geschworenen Recht sprach.

Gab es in Davos eine gemeine Mark, Grundeigentum, das der Gemeinschaft gehörte? 27. Branger nennt zwei Dokumente, die von einer Allmein sprechen ${ }^{28}$. Vier Spruchbriefe aus der Nachbarschaft Monstein weisen mit aller Deutlichkeit den gemeinen Grundbesitz nach. Der älteste Brief stammt aus dem Jahr 149129.

Bernhard und Töntz Mustainer, Besitzer von Weiderechten in den Inneralpen, beklagen sich: Die Besitzer der Venetzalpen meinen, sie dürfen den ganzen Silberberg beanspruchen und dort ihr Vieh auftreiben ${ }^{30}$. Weiter atzen sie auch die Weide zwischen den Monsteiner Wiesen und der Spinerweide ${ }^{31}$, was bis jetzt auch immer von den Besitzern der Inneralp geschehen sei. Darauf antworteten « Hansly ageten Sunn und Stoffel Michel aus der Venetzalp», sie wüßten nichts anderes, als daß der Silberberg und das Gebiet der hohen Rüfinen (der strittige Teil zwischen Monstein und Spina) allen Monsteinern gemein ist. Dazu erhebt er noch Anspruch auf ein besonderes Stück Land in dieser Gegend, das ihm privat gehöre. Die $\mathrm{Zu}$ teilung sei schon sehr lange her, aber er getraue sich noch die Marchsteine aufzufinden.

Der Entscheid lautet in der Textherstellung mit Interpunktion ${ }^{32}$ :

23 BRANGer, Rechtsgeschichte, S. 113.

24 Eine Talmark bestand wohl immer nur in einem theoretisch, rechtlichen Sinn.

${ }^{25}$ Liver : Vom Feudalismus zur Demokratie, S. $40 \mathrm{f}$.

26 MiasKowsk1: Die schweizerische Allmend, S. 6.

27 LIVER verneint es für Davos in seiner Arbeit zur Wirtschaftsgeschichte der freien Walser (S. 214) und spricht die markgenossenschaftliche Organisation den Romanen zu.

${ }^{28}$ BRANGER : Rechtsgeschichte, S. 113. Weiter nehmen auch Fr. von WY'ss. Hoppei.ER und MoosBERGER eine Mark in Davos an.

${ }^{29}$ Monsteiner Archiv, Brief 3.

30 Der Silberberg ist der Wald am linken Abhang der Zügenschlucht bis zur Landschaftsgrenze, der auch als Weide diente. Dort befinden sich auch die Silber- und Bleigruben, die vom 16. Jahrhundert bis ins 19. Jahrhundert mit Unterbrüchen und wechselndem Erfolg ausgebeutet wurden. ${ }^{31}$ Spina ist eine eigene Nachbarschaft.

32 Die Entzifferung dieses Briefes und Textherstellung verdanke ich Herrn Prof. A. Largiadìr, Staatsarchivar in Zürich. Eine vollständige Abschrift des Briefes befindet sich im Anhang. 
"So wart erkent mit ainhelliger vrtail als vmb die weid jm silberberg so ver die uss der jndren alpen mit jrem rinder fech obna herab gen möchten vnd hintz her gebrucht hetten von heimna oder der alpen, sölt jenen zu gehören, vnd die übrig weid söllt billich gemein sin, fürbas die weid inder den wisen hintz an die hohen rufinen solt ouch beiden tailen gemein $\sin z u$ etzen ${ }^{33}$."

Bis auf einen 'Teil, das oberste Stück des Silberbergwaldes, ist also alles strittige Gebiet Gemeingut oder Allmend. Aus dem Jahr 1555 stammt ein weiterer Brief 34 .

Die Monstainer klagen, daß etliche Nachbarn ihre Weiden in den Alpen verkauft haben. Dafür trieben sie nun all ihr Vieh auf den Silberberg, der gemeine Weide sei, « und durch solliches etlichen Nachpurn in Gütern und aekern schaden beschere $\gg 35$.

Darauf antworteten die Beklagten: „der silberberg sey allwegen eine gemeine weid gsin all denen die in Munstain hushablich und sesshaft sind." Denn es müsse jeder der in Monstein seßhaft sei „erwarten lieb und leid und schuldig sin in stäg und wäg ${ }^{36}$ und in aller gstalt wie andere gemeine Nachpurn." Das Urteil erkennt:

1. Die alten Briefe sollen weiterhin gelten.

2. zum andern die nachpuren so in mustain sitzend und in künftigen zyten sitzend werdend mit einander etzen, niessen und bruchen und soll der silberberg aller gemein sin. Doch allwegen den güttern, akern und in den alpen dene ingezelten weiden ohn allen schaden."

Das Spendbuch von Davos 1562 spricht an vielen Stellen von Allmenden:

„Stost ufivert an die allmein, abwert an Uli im Boden..., stost ufwert an die allmein, inwert und "abwert an Haus und Lorentz Gamsurers güeter..." usw. "3i Bei der Grenzbeschreibung des Gutes auf Bolligen (Bolgen): "stost uf an die gemein weid, so noch nit getheilt ist“. (Dieser Spendbrief ist durch Landammann Jakob Hug 1474 gesiegelt ${ }^{38}$.)

Wir besitzen in Daros also eine wirkliche Allmend ${ }^{39}$. Alle Allmenden in Monstein befinden sich im Wald. Es ist die Waldweide, die gemeinsam genutzt wird. Bei den Allmenden des Spendbuches wird nichts über die Ausdehnung nach oben ausgesagt. Jedoch alle gemeinen Weiden und Sonderweiden ${ }^{40}$ als Nachfolger der Allmend erstrecken sich nur auf das Waldgebiet.

Was für Grundeigentumsverhältnisse bestehen auf der Alpweide, der großen Nutzungsfläche, die schon von den Romanen bewirtschaftet wurde, die auch die Walser ohne Rodungsarbeit übernehmen konnten? Wird sie als Teil der Mark gerechnet oder dem privaten Sondereigen zugefügt und damit sofort aufgeteilt?

Mit Sicherheit stellen wir fest, daß die Alpweide 1491 im Privatbesitz erscheint. «Bernhart und Töntz Mustainer mit irem mit recht erloupten fürsprechen, brachten für recht also, wie die uss der alpen venetz vermaineten recht ze haben »... Bernhart und Töntz Mustainer sind die Abgeordneten der Inneralp (jndren alp = innere Alp, die heute Inneralp heißt) Hensly ageten sunn und Stoffel Michel diejenigen der Venetzalp. Sie sind nicht die alleinigen Besitzer, sondern nur Gewährs-

3: So wurde mit einhelligem Urteil wie folgt über die Angelegenheit der Weide im Silberberg gerichtlich erkannt: So weit die aus der Inneralp mit ihrem Rindvieh von oben herab gehen mochten und es bis anhin gepflogen hatten vom Haus oder von der Alp, sollte es ihnen zustehen (dem Sinn nach: dürften sie es weiter tun). Die übrige Weide solle billigerweise Gemeingut sein, außerdem soll auch die Weide unter den Wiesen bis an die Hohen Rüfenen beiden Teilen (Parteien) gemeinsam zur Weidenutzung dienen. (Auch für diese fachgerechte Übersetzung möchte ich Herrn Prof. Largiadér danken.)

34 Monstainer Archiv, Brief 4 vom 27. Mai 1555.

${ }^{30}$ Dadurch, daß diese Bauern ihre ganze Viehhabe und nicht nur die Heimkühe auf der Allmend weiden lassen, ist diese überstellt. (Die Weide ist mit mehr Tieren besetzt, bestellt, als diese Futter liefern kann.) Aus diesem Grund läuft das Vieh über die Grenzen in die Güter und Äcker der Nachbarn.

${ }^{36}$ I Stäg u Wäg gan = zum Gemeinwerk gehen, BühlER, Bd. II, S. 50.

37 JeCKI.IN : Spendbuch, S. 47 und 55.

38 JeckliN : Spendbuch, S. 66. Es ist der gleiche Brief, von dem auch Branger in seiner Rechtsgeschichte der freien Walser auf S. 113 spricht. Vergleiche auch das nächste Kapitel, Aufteilung der Allmend.

${ }^{30}$ Miaskowski: Schweizerische Allmenden, S. 3 : Es sind Liegenschaften, die sich im Eigentum von Gemeinden oder öfentlichen Korporationen befinden und von diesen gemeinschaftlich genutzt werden.

to Vergleiche nächstes Kapitel. 
leute für die Gerichtsverhandlung: «do wart erkennt mit ainhelliger vrtail, sitmal sy sich zu baidentailen jro werlüt erbotten hetten ». . .

Monstein muß 1544 mindestens 9 Bauern besessen haben, wenigstens spricht der Spendbrief des Conrad Lampert von neun Anstößern an sein Gut. ${ }^{41}$ Ein Spruchbrief von $1567^{42}$ liennt sechs Bauern in Monstein, die alle auch wieder im Spendbuch 1562 zu finden sind. Nach dessen Angaben besitzen sicher 13 Bauern Höfe in Monstein. (Erhart Michel, Hans Müller, Valentin Rüesch, Christian Balusser, Claus Michel, Lorentz Michel, Margaretta Monstainery, Hans Marcks, Knabenhanns, Utz Helden, Ursula Keissery, Barbla Baulussers, Meißers Tochter und Drina Müllery. Dazu kommen wahrscheinlich noch Melckert Plangy, Bart Müller, Joder Michel und Jöri Joder, bei denen nicht ganz sicher zu entscheiden ist ob ihr Hof in Monstein steht, oder ob sie nur Wiesland besitzen. ${ }^{43}$

In der heutigen Fraktion Monstein liegen drei Alpen: Die Inneralp, Oberalp (= Venetzalp) und Hauptalp. Letztere wird in einem Spruchbrief aus dem Jahr 1641 genannt. $\mathrm{Zu}$ diesem Zeitpunkt, aber wahrscheinlich auch schon 150 Jahre früher bestehen schon alle drei Alpen. Daß diese Alpen nicht nur zur Nutznießung von der Nachbarschaft an eine Gruppe von Bauern übergeben wurden, beweisen die folgenden beiden Stellen:

1. Im Entscheid aus dem Jahr 1491 wird ausdrücklich ein Teil den Inneralpen zur alleinigen Nutzung zugesprochen, nämlich derjenige, den sie «von obna herab vnd hintz her gebrucht hetten von heimna oder der alpen ». Es ist dies das oberste Waldstück, das an die offene Alpweide anschließt und vor allem als Wetterflucht dient ${ }^{44}$. Die S̄treitigkeiten im Silberberg rührten daher, daß die Inneralpbauern als Monstainer Anteil an der Allmend besaßen und auch auf dem obersten Teil weideten, die Venetzer jedoch ihr Vieh ebenfalls auf dieses oberste Stück trieben, das nur den Besitzern der Inneralp gehörte ${ }^{45}$.

2. Im Entscheid aus dem Jahr 1555 heißt es: «Doch allewegen den gütern, akern und in den alpen denen ingezelleten Weiden ohn allen Schaden 》. Die Weiden sind eingezählt, das heißt jeder Bauer besitzt das Recht, nur eine ganz bestimmte Anzahl Vieh zu sömmern. Das gleiche Wort « inzella » wird auch heute noch gebraucht. Wir besitzen demnach schon im 16. Jahrhundert die gleiche, rechtliche Form wie heute.

Ein Gerichtsprozeß der Inneralp von 1924 warf ebenfalls die Frage der Nutznießung auf. Es war ein Streit, den die Inneralpgenossenschaft gegen die Fraktionsgemeinde Monstein führte. Um die Klage ungültig zu machen, anerkannte die Fraktion keine privatrechtliche Genossenschaft, sondern nur die Klage der einzelnen Personen, welche diese angebliche Genossenschaft bildeten, Kläger war aber die Genossenschaft. Damit wurde gesagt, daß die Alp- und Waldweideberechtigung, welche die Vieheigentümer, denen die Inneralp zur Nutzung überlassen worden war, keine Privatberechtigung wäre, sondern ein Ausfluß des öffentlichen Rechts, der sie als Glieder der Gemeindefraktion Monstein teilhaftig wurden ». Der Entscheid des Gerichts anerkannte die Alpgenossenschaft Inneralp als juristische Person und nahm die Klage an. Das Gericht wich damit der Grundfrage aus, gab aber der Auffassung Inneralp gleich Privatgenossenschaft recht ${ }^{46}$.

Ist die Alpweide mit der Übernahme als Erblehen aufgeteilt worden, wurde sie in einem spätern Zeitpunkt von der Mark abgetrennt und dann. aufgeteilt? Für Davos kann das nicht entschieden werden. Für den Heinzenberg nennt Liver Alpen, die als besonderes Erblehen zugesprochen wurden ${ }^{4}$. Auch WEISS sieht die Ur-

$\$ 1$ Spendbuch, S. 66.

42 Monstainer Archiv, Brief 5.

43 Vergleiche Kapitel Bevölkerung.

\#4 Besondere Servitute, Wetterschutz und Schneefluchtrechte in den Wäldern. Vergleiche Werss, Alpwesen in Graubünden, S. $182 \mathrm{f}$.

45 Diese Verhältnisse entsprechen noch den heutigen, mit dem Unterschied, daß der Allmendteil des Silberberges heute nicht mehr genutzt wird, da er zu steil ist.

${ }_{46}$ Monsteiner Archiv.

47 LIVER: Zur Wirtschaftsgeschichte des Heinzenberges, S. 35. Vergleiche auch IssLeR : Geschichte der Walserkolonie Rheinwald, S. $96 \mathrm{f}$. 
sprünge der Genossenschaftsalpen (und meint damit die Privatkorporationen) in den Erblehensverträgen, durch welche den einzelnen, walserischen Höfen, die ihnen nötigen Alpen von den Grundherren ausgeschieden wurden ${ }^{48}$. Er vermerkt jedoch richtig dazu, daß das von Fall zu Fall historisch belegt sein müßte, denn gerade für Davos ließe sich auch eine Aufteilung in späterer Zeit annehmen. Denken wir daran, wie im 16. und 17. Jahrhundert die Allmend und der Wald aufgeteilt wurden, so ist eine ähnliche Entwicklung für die Alpweiden sehr nahe liegend: Eine Weidefläche dehnte sich über den Wäldern bis zu den Gebirgskämmen aus, viel zu groß für die $1+$ Bauern. Die Erkenntnis der Bedeutung dieser Fläche war jedoch tief verwurzelt, schon dadurch, daß die Alpweide bestand und nicht erst geschaffen werden mußte. Mit der Zunahme der Bevölkerung wurde sie darum bald aufgeteilt und wie das Wiesland im $T$ al von einzelnen Gruppen in Besitz genommen. Warum beanspruchten sie nicht die ganzen Nachbarschaften gesamthaft. Es spielte sich noch einmal der gleiche Vorgang ab, wie bei der Teilung der Talmark in die Hofgenossenschaften. Einzelne Bauern und Bauerngruppen aus den Nachbarschaften belegten die Weidefläche, die durch Gräte und Tobel in kleinere Abschnitte aufgeteilt war. An diese natürliche Weidegliederung paßten sich entstehende Grenzen an. Mit der Zeit wurde die freie Weide als privates Eigen aufgefaßt, oder als Eigen einer Gruppe ${ }^{49}$. Sofern es mehrere Rauern waren, so teilten sie sich wahrscheinlich gleichmäßig in den Besitz, jeder Bauer bekam das Recht, gleich viele Külse zu sömmern (gleich viele Stöße) ${ }^{50}$. Die Aufteilung der Alpiveiden müßte sich also im 14. und Anfang des 15. Jahrhunderts abgespielt haben, denn 1491 befanden sich die Alpen schon in Privatbesitz.

\section{Die Aufteilung der Allmenden.}

Im Brief von 1491 gibt es eine Stelle, die auf die Tendenz hinweist, daß eine Gewohnheit zum bleibenden Recht werden kann. Die Angeklagten antworten: «also sy nem $\mathrm{jr}$ fürnemen frömd $\gg .$. (fürnemen $=$ das im Begriffe zu einer Gewohnheit werdende, seiende Verhalten, Vorhaben) ${ }^{51}$. 1567 52 treten Klas Joder, Kasper zur Uaffernun, Bart Margadant, Hans Monstainer, Hans Michel und Hans Paulusar, alle seßhaft in Monstein, im Namen der andern Nachbarn und allen, die im Sommer und Winter hier seßhaft sind auf gegen Meister Hans agten, Dicht Meißer, Christen Davaz, Jöri Aeble (wohnt auf dem Bort in der Langmatte) ${ }^{53}$, Hans Joder (wohnt bei der Kirche St. Niclaus, Glaris), die in Monstein Wiesen und Alpen gekauft haben. (Alpen und Weiden werden also wie Wiesen im Tale verkauft, sofern die andern Alpgenossen damit einverstanden sind.) Der Streit dreht sich wieder um den Silberberg, auf den diese Auswärtigen ihre Schafe getrieben haben. Das Urteil anerkennt die alten Briefe, und dazu kommt nun noch ein neuer Anhang: Die Weid im Silberberg soll gleichmäßig auf alle Feuerstätten in Monstein aufgeteilt werden.

"So in ein Haus mehr denn ein Haushab wäre, als viel Haushaben dann in ein Haus sind und alle nur eine Feuerplatten hätten, so sollen sie auch nit mehr als dann für ein Feuerstatt gerechnet werden. So und sie aber ein jetlich Haushab und besonder Fürplatten machend und darauf führend, so mögen sie dann auch Gerechtigkeit haben ein jeglicher Haushab, als viel als ein ander Haus, das nur ein Fürstatt hat. - So denn aber einer mehr als eine Hausstätte und doch öd und leer stünde, otwelches Haus öd stünde, dass soll kein Gerechtigkeit haben in der Weid, als dass es öd stot. - So in Monstain ein Nachbar oder Haushaben wären, die kein Weid da hätten, die mögen dann als viel deren wären ein jeglicher ein Kuh oder für ein Kuh Geiss ${ }^{54} \mathrm{da}$ sümmèrn darin nimand nüt reden soll.

$\$ 8$ WEISS: BM 1941 S. 7.

t9 Übergang von einem Gewohnheitsrecht zu einem festen Recht.

so Ähnlich der Aufteilung der Allmend, siehe daselbst.

i1 Vermerk von Prof. LaRgiadèr.

${ }^{52}$ Monsteiner Archiv, Brief 5 mit einer Kopie aus dem 18. Jahrh.

5s Nach dem Spendbuch 1562 festgestellt.

ot Für ein Kuhrecht Ziegen, also 8-12 je nachdem die Anzahl in Monstein festgelegt war. 
Damit wird die Silberbergweide gleichmäßig an alle Grundbesitzer aufgeteilt. Sofern zwei Familien in einem Haus auf dem gleichen Herd kochen, so bekommen sie nur ein Recht, besitzen sie jedoch zwei Feuerstätten mit getrenntem Haushalt, so gelten sie als zwei Familien mit zwei Rechten. Hat ein Bauer 2 Häuser, davon das eine nicht bewohnt wird, so wird ihm nur ein Recht zugestanden, solange das Haus leer steht. Auch diejenigen, die in Monstein nur ein Haus, aber kein Alprecht besitzen, dürfen eine Kuh oder entsprechend viel Ziegen dort sömmern. Auf diese oder ähnliche Art und Weise wurden im 16. Jahrhundert die meisten Allmenden aufgeteilt. Das Spendbuch 1562 unterscheidet drei Begriffe: Allmein, gemeine Weid und Sonderweid.

1. Sonderweide wird immer in Verbindung mit einer Person gebraucht: Christen Birchers sunderweid, an sin sunderweid, stöst uf und abwert an drei Sunderweiden (S. 25). Es ist cin Stück Weideland, das dem Besitzer «besonders», einzeln gehört, privates Weideland 55 .

2. Wenn von «gmeiner Weid» die Sprache ist, so wird immer beigefügt wieviel Kuhrechte der Bauer dort besitzt: Stoßt abwert an die straß, ufwert an die allmein, inwert an das Hus, uswert an den zug und ab vier Kuhweiden in Dischmaner Gemeinweid (S. 27), oder sampt einer Kuhweid in Meyerhofer gemeiner Weid (S. 57). Die gemeine Weid ist aufgeteiltes Weideland, auf dem jeder Bauer eine bestimmte Anzahl Vieh sömmern darf.

3. Allmein, Allmend ist das ungeteilte Weideland, das allen zur freien Nutzung offen steht $\mathbf{5}$.

Alle drei Begriffe wurden im Laufe der Zeit vermischt und nicht mehr scharf getrennt. Gemeine Weid und Allmein standen vor der Aufteilung gleichberechtigt nebeneinander, später wurde der Ausdruck gemeine Weid besonders für die aufgeteilte Allmend benutzt (die gemeine Weid, so noch nicht aufgeteilt ist ... Anmerkung ${ }^{28}$ ). Auch die Bezeichnung Sonderweid 57 konnte ihre ursprüngliche Bedeutung verlieren. Im Jahr 1655 entstand ein Streit innerhalb der Stafleratzung als Inhaber der Sonderweiden von Foppen und Rongg ${ }^{58}$. In beiden Weiden besaßen mehrere Bauern ganz bestimmte, festgelegte Rechte. Richtigerweise hätte sie gemeine Weid genannt werden müssen, auf die Stafleralpgenossenschaft als juristische Person bezogen waren es zwei Sonderweiden ${ }^{59}$.

\section{Der Wald, die Entstehung von Privatwäldern.}

Im Landbuch von 1595 finden wir folgende Verordnung: Es sollet in einer jetlichen Nachbarschaft im Landt zwen Waldvögte verordnet werden die sollen schauen, wo in den Walden Schaden beschehe, das einer Nachbarschaft zum Schaden sein möchte... Es sollet ain jede Nachbarschaft im Landt über iere Wälder ein guot nützlich Ordnung machen und dieselbige verschreiben ... ${ }^{60}$.

Damit wurde die Ordnung des Waldes den Nachbarschaften übertragen. Ein Waldbrief aus dem Jahre 1486 stellt die Grundsätze auf, die für die damalige Zeit allgemein angenommen werden dürfen: Keiner soll dem andern ob dem Synigen (oberhalb seinem Heimwesen) Holz nehmen. Wenn einer solches rüstet, so darf es der nehmen, der seine Güter darunter hat. Es darf kein Holz weiter verkauft werden, es soll den Nachbarn gegeben werden. Es soll nicht geschlagen werden, ohne daß es die Nachbarn brauchen ${ }^{61}$.

${ }_{55}$ Im 19. Jh. bedeutet Sonderweid im übertragenen Sinn auch Voralp oder Maiensäß. BưHL.ER Bd. I, S. 130.

${ }_{66}$ Allmeina = Auf Davos jede Atzung, auf der nicht gemäht wird, also gleichbedeutend mit Weide. BÜHLER Bd. II, S. 14.

57 Sonderweid: Weide als Privateigentum im Gegensatz zur Gemeinweide. Landbuch der Landschaft Davos S. 134.

${ }^{58}$ Davoser Archiv, Brief 84.

59 Siehe auch III. Teil, Atzungsgenossenschaft Stafelalp.

${ }^{60}$ Landbuch der Landschaft Davos 1595 „Wält oder Walden“. Das Gesetz scheint schon lange bestanden zu haben als es im Landbuch 1595 aufgenommen wurde.

${ }^{61}$ LelY A : Der Wald in der Geschichte der Landschaft Davos. S. 55. 
In einem Spruchbrief aus dem Jahr $1586{ }^{62}$ klagten die Nachbarn der Siebelund Langmatte gegen Lorenz Bulen auf dem Junkersboden. Sie behaupteten, ein Recht zu haben zum Bezug von Holz aus dem Wald oberhalb des Junkerbodens. Der Beklagte antwortete:

„dass die clag, die syne lieben Nachpuren zu ihm tuon, ihn gächligen befrömde. Er vermeine luter und clar, sie haben allda in synem Wald kein Gwalt zu hauwen, weder wenig noch viel, sondern sy müessen nehmen was er ihnen an die Hand geben thüöji.

Das Gericht entschied zu Gunsten der Nachbarn. „Was unter den hohen Börtern ist, ist als Bannwald anerkannt, wo ohne Wissen und Willen Lorenz Bulen niemand zu nehmen Gewalt hat. Was ob den hohen Börtern ist, da mögen die obgedachten Nachbarn Holz nehmen nach ihrer Notdurft."

Beide Briefe beweisen, daß der Wald noch Gemeingut ist. Für den eigenen Holzbedarf darf jedermann soviel schlagen, als er braucht. $\operatorname{Er}$ muß dieses im nächstliegenden Wald holen, damit keine Streitigkeiten entstehen. Der Wald darf nicht inehr genutzt werden als nötig, an vielen Steilen ist er schon gebannt wegen Steinschlag und Lawinengefahr. Im 17. Jahrhundert findet die Aufteilung des Waldes statt. Vergleichen wir die Verordnung «über zweijährig Holz im Wald》 im Landbuch 1595 und 1695 !

1595 heißt es : „Wer der ist allenthalben im Land, der in den Walden Holz schlüge oder niederfellte und das selbige in 2 Jahren Frist nit ufnimmt, so mag demnach und zwei Jahre verschienen sind ein jetlicher so der Erst dazue ist, sömliches Holz hinweg füeren und darmit thuon wie mit sym fry eigen Guot".

1695 ist ein Teil eingeschaltet ${ }^{63}$ : "Jetlicher, der sonsten Gemeinder oder Ansprecher in selbigem Walde ist, so der Erst dazue ist"...

Nicht mehr jeder Genosse hat am vorhandenen Wald gleiche Rechte, wie das hundert Jahre früher der Fall war. Es muß einer Gemeinder (Anteilhaber) oder Ansprecher in diesem Wald sein. Inzwischen fand also eine Unterteilung und Ausscheidung der Rechte statt. Schon der Spruchbrief von 1556 gab Lorenz Bulen mit der Ausscheidung des Bannwaldes ein gewisses privates Aufsichtsrecht. Der Aebiwald auf der linken Seite am Eingang ins Sertigtal war schon 1560 gebannt. Der Waldbann ist eine sehr alte Einrichtung für Gebirgsgegenden, eine Schutzmaß. nahme gegen Steinschlag, Erdrutsch und Lawinen. Das Recht, einen Wald zu bannen, liegt gewöhnlich in öffentlicher Hand, also der Landschaft Davos. Diese gibt jedoch mit einer Bestimmung im Landbuch 1695 den Hofbesitzern die Möglichkeit, den Bann selber zu veranlassen.

„Welcher vermeint, ihme von nöthen zu sein, einen Wald ob seinem Hus, Hof, Guot oder Sonderweid zu bannen, von wegen Rüff, Brüchen oder Laubenen, der mag allwegen für ein Gericht kehren... und was alsdann zu Bannwald erkennt, soll allwegen von Stund an Brief und Siegel gelegt werden, nach des Bannes Sag und darneben ein jeder sich wisse vor Schaden zu hüeten ${ }^{64 . " ~}$

Die Gerichtskosten mußte der Besitzer des Bannwaldes tragen. Damit konnte jeder nach seinem Belieben Wald bannen lassen. Eine Ausnahme wurde nur dort gemacht, wo eine sichtbare Gefahr für den öffentlichen Verkehr vorhanden war. Dort bannte die Landschaft und übernahm auch die Kosten (Zügenwald 1605).

1651 traten die hochmögenden Herren Landeshauptmann Meinrad Buol, Landammann Andreas Sprecher, Hauptmann Paul Sprecher, Lieut Michel Schlegel, Junker Paul Jenatsch und andere im Namen der zivei Nachbarschaften am See, sonne- und litzihalb vor den kleinen und großen Rat. In ihren Nachbarschaften sei „viel schöner und gemeiner Walden, deren sie wegen vieler Gemeinschaft nicht nach ihrem Sinn und Willen geniessen können. So haben sie sich derowegen gemeinsam vereinbart, sämtliche gemeine Walden zu teilen, teils auf die Feuerstätten, teils aber auch auf die in der Nachbarschaft liegenden Güter".

Der Wald wurde geteilt, ganze Waldpartien bestehenden Häusergruppen zugewiesen, einzelne Bestände auch einzelnen Höfen. Eine Art Genossenschaftswald

62 daselbst S. 17.

631595 wird das Landbuch durchgesehen und verbessert, dies ist die älteste bekannte Form. Nachführungen stammen aus den Jahren 1646, 1695 und 1831.

64 LÆIYY: Der Wald. S. 13. 
blieb als Wehriwald 65 bestehen. (Der Wehriwald an Eingang des Flüelatales befindet sich heute im. Besitz der Fraktionsgemeinde Davos-Dorf, die als Rechtsnachfolgerin der beiden Nachbarschaften erscheint.) io.

Das Landbuch 1695 gab nur noch die gesetzliche Verankerung, die Teilung des Waldes begann schon früher, wie das aus der Waldteilung am See ersichtlich ist. Die reichsten und vornehmsten Familien, die.führenden Persönlichkeiten gingen voran, sie wünschten diese Entwicklung. Damit war der Anstoß gegeben. Es begann ein Wettlauf um die Wälder, und niemand dachte an das Interesse der Allgemeinheit. «Es war zur völligen Mode geworden, einander die Wälder ohne die mindeste Notdurft zu bannen, $\mathrm{da} \beta$ in Glaris und in der Spina alle gebannt waren, aber doch öffentlich Holz daraus geschlagen wurde, woher sollten sie denn das Holz für den Eigenverbrauch hernehmen!»6i. Neben dem Privatwald entstand aus dem gemeinen $W$ ald auch noch Löserwald ${ }^{68}$. Ein solcher ist der Würzenwald, den die Siebelmatte und Langmatte im Prozeß 1586 gegen Lorenz Bulen zugesprochen erhielten. Ihre Schutzwälder gegen Stafel- und Chummaalp sind wenig mächtig, sodaß sie noch Holzrechte auf der andern Seite suchen mußten. Die Löserwälder wurden nicht vermarcht, das geschlagene Holz entsprechend den Anteilscheinen (Losen) verteilt. An Stelle der gemeinen Walden war derjenige der Gemeinderschaften oder Löser getreten, der noch auf das alte Zugehörigkeitsverhältnis zum Grundbesitz Rücksicht nahm und die Waldrechte nach dem Bedarf der Häuser, Güter oder Weiden einschätzte, der noch Brennholz-, Bauholz-, Zaunund Streuerechte unterschied. In diesen Löserwäldern erhielten sich gewisse Servitute wie Streue- und Zaunrechte bis ins 19. Jahrhundert.

Die meisten Alpen besitzen heute ein mehr oder weniger großes Stück Wald. Dieser Alpwald wurde nicht aufgeteilt und von den Alpgenossen im «Gmeiwärch 》 grenutzt. In andern Alpen besitzt jeder Alpgenosse ein Anteilrecht, das im Gegensatz zum Los des Löserwaldes nicht verkauft werden kann und mit dem Verlust des Alprechtes auch verloren geht. Die Alpwälder werfen heute nur noch wenig ab. In Jahrhunderten wurden sie durch Lawinen, Steinschlag und Viehfraß gelokkert und zurückgedrängt und dienen kaum mehr ihrer Aufgabe als Schutzwald. Im 13. und 14. Jahrhundert, zusammen mit der Aufteilung der Alpweide, muß der Alpenwald in die Hände der Alpgenossenschaften gekommen sein und blieb seither unangetastet gemeiner Alpbesitz.

\section{WIRTSCHAFTLICHES AUS DEM 16.-18. JAHRHUNDER'T}

\section{Die Alpen (Gesetzgebung).}

Die Organisation der Alpen ist in den einzelnen Weidbriefen verankert. Die alten Landbücher zeigen nur wenige Verordnungen, welche die Weide betreffen. Eine solche stammt aus dem Jahr 1747. Jede Atzung ist mit der nächst angrenzenden schuldig, einzuzellen um zu verhüten, daß keine derselben überstellt wird ${ }^{69}$.

„Kälber, welche in oder außer der Landschaft aufgekauft werden, sollen nicht mehr als zwei auf eine Kuhweide aufgestellt werden, wo hingegen selber gezogene Kälber vier oder je nach den bestehenden Bestimmungen der Weidbücher aufgestellt werden sollen".

${ }^{65}$ Der Wald, aus dem das Holz zur Wuhr und Brückenunterhaltung genommen wird. BÖHLER Bd. II, S. 49.

66 Auch der größte Teil des Monsteinerwaldes gehört heute der Fraktion. Sie ist die einzige Nachbarschaft, in der der Wald nicht aufgeteilt wurde. 1643 wies die Landschaft die Eigentumsansprüche der Nachbarschaft am Silberbergwald ab, dieser gehöre der Landschaft. 1652 wurde er Monstein zugesprochen.

${ }^{67}$ L/ELY: Der Wald. S. 15.

68 Es ist ein Genossenschaftswald, in dem jeder Genosse sein Teilrecht (Los) zu gut hat.

69 inzella = einzählen, zu Protokoll angeben, wieviele Weiderechte man besitzt, welcher Art Vieh und wieviele man dieses Jahr auftreiben will. Wann das Einzählen stattfand, pflegte der Küster nach beendigtem Gottesdienst auszurufen. BÜHLER Bd. I, S. 68 . 
Die Übernutzung der Weiden mußte von der Landschaft aus gesteuert werden. Sie gab auch immer wieder Anlaß zu Streitigkeiten. Da die Weiden nicht durch Mauern oder Zäune abgetrennt waren, besaß das Vieh und besonders das Galtvieh und die Schafe, die während der Nacht draußen blieben, die Möglichkeit, in die fremde Weide zu wechseln. Damit nicht zu viele Kälber zur Sömmerung gepachtet wurden, bestanden verschiedene Rechte für jene und für die selbst aufgezogenen. Das Landbuch bestimmte auch die Termine, die heute jedoch enger gesetzt sind:

8. Aug. 1697 „Namblich solle in das künfftig niemand in der ganzen Landschaft befugt sein, von Mitte Aprellen hin bis auf St. Gallentag einicherley Schmal- oder Rindviech ungehüet auszelachen / seigen gleich in Grund und Berg und das by Buoss von jedem Hopt Rindvich zwei Batzen / und von jedem Hopt Schmalvich ein Batzen".

Die Alporganisation und Ordnung war schon sehr früh festgesetzt und wurde seit dem 16. Jahrhundert in ihren Grundzügen kaum mehr geändert. Das beweist uns ein Weidbrief der Leidbachalp aus dem Jahre 155770.

16 Bauern ${ }^{71}$ verständigen sich, wie man die Weiden bestellen, reuten und wegen ${ }^{i 2}$ wolle.

1. Vor Mitte Mai durften weder Schafe, Ziegen noch anderes Vieh ausgelassen werden. Zuerst mußte man das Vieh einzählen, damit die Alp nicht überstellt werde. Dabei rechnete man ${ }^{73}$ :

$\begin{array}{lrll}\text { Kuh oder Zeitkuh } & 1 \mathrm{KR} & \text { (gleich) }^{7 t} & \\ \text { Rinder } & 1 / 2 \mathrm{KR} & (2 / 3) \\ \text { Kälber } & 1 / 4 \mathrm{KR} & (1 / 3) \\ \text { Schafe } & 1 / 6 \mathrm{KR} & \text { (keine mehr) } 2 \text { Lämmer =1 Schaf } \\ \text { Ziegen } & 1 / 8 \mathrm{KR} & \text { (keine mehr) } & 2 \text { Zicklein }=1 \text { Ziege } \\ 1 \text { Saumroß } & 2 \mathrm{KR} & \text { (keine mehr) } & \\ 1 \text { Feldroß } & 3 \mathrm{KR} & \text { (keine mehr) }\end{array}$

2. Niemand durfte vor dem heiligen Petritag (29. April) in den Alpwiesen grasen oder heuen. Wer vier Weiderechte hatte, mußte alljährlich einen ganzen Tag in der Alp arbeiten. Eine halbe Weide mehr oder weniger wurde nicht gerechnet. Wer weniger als vier Weiden besaß, war der Alpgenossenschaft auch ein Tagwerk schuldig.

3. Niemand sollte ohne Erlaubnis der Alpgenossen mehr Galtvieh auf die Weide treiben, als er Weiderechte besa $\$$, es sei denn, er habe Weiderechte seiner Nachbarn übernommen, die diese nicht benutzten ${ }^{7 \overline{5}}$.

4. Wenn ein Alpgenosse Weiderechte verkaufen oder verpachten wollte, so durfte er diese keinem Fremden anbieten. Erst wenn keiner der Alpgenossen diese übernehmen wollte, so konnte er darüber frei verfügen.

5. Die Alp besaß 58 Kuhweiden (gesetzlich) $57+1$ Hirtenweide, die Bauern schätzen jedoch nur noch 38). In einem besondern Schreiben war niedergelegt, wie sich diese auf die einzelnen Alpberechtigten verteilten.

6. Den Trejen ${ }^{76}$ durfte niemand verwüsten, Benutzte er ihn beim Holzen, Schindel- oder Brennholz, so hatte er die Pflicht diesen wieder aufzuräumen.

7. Der Berg ${ }^{77}$ sollte am St. Johannstag (24. Juni) eingezaunt werden. Der Zeitpunkt zum reuten und wegen wurde von den Nachbarn bestimmt, ebenso der Einzählungstag. Wer zum „Gmeiwärch"“ nicht erschien oder keinen Knecht schickte, für den wurde ein Arbeiter angestellt, vom Säumigen

${ }^{70}$ Der Weid- und Murmendenbrief ist im BM 1924, Nr. 12 vollständig abgedruckt.

${ }^{71}$ Hans und Casper und Martji Zertafernen, item Jöri Schuochter und Michel und Martij Schuochter, item Casper Bruner, item Christen Schuochter, item Casper und Simen Wyss, item Stoffel Bætschy, item Hans Mark, item Flury Ruosch, item Gallus Aengis, item Wilhälm Branger, item Hans Ardüser. Das sind 16 Namen, jedoch nur 11 Alprechte, indem Jöri, Michel und Martij Schuochter zusammen gehören (Brüder?) und nur ein Alprecht besitzen. Fälschlicherweise wurden hier immer 16 Alprechte angenommen. (Heute, 4 Alprechte.)

${ }^{2}$ von Weg, gangbar machen.

${ }^{73}$ Die Zahlen oder Bemerkungen in der Klammer geben den heutigen Zustand an.

It Kuhrecht, Kuhweide, Weide oder Stoß $(K R)=$ das Recht, eine Kuh zu sömmern, oder soviel Weidefläche, daß eine Kuh für einen Sommer Nahrung findet (100 Tage). Der Alprodel, Weidbrief oder das Weidbuch setzt fest wieviele Tiere gesömmert werden dürfen. Die Alpgenossen besitzen Teilrechte (Einzelrodel). für eine ganz bestimmte Kuhzahl, welche sie auf die Alp treiben dürfen. Da die verschiedenen Tiere verschieden viel Futter brauchen, sind ihre Rechte entsprechend abgestuft und wechseln oft von Alp zu Alp.

${ }^{75}$ die sin nachpurren nit loeschen wellent.

${ }^{76}$ Treja = Weg, der durch das Vieh in die Weide getreten wurde, besonders breit in der Nähe der Alp, wo alle Kühe zusammentreffen und die gleiche. Spur benutzen (Abb. 3).

77 Mit Berg wird hier Heuberg gemeint. Für Davos: Mäder und Alpwiesen. 
jedoch der doppelte Lohn verlangt. Das gleiche galt auch für denjenigen, der den Trejen verwüstete und nicht wieder aufräumte.

Anschließend folgt der Murmendenbrief, der in der gleichen Art festgelegt, was für die Murmeltiere galt, die gemeinsam ausgesetzt worden waren. Der Anteil wurde auf die 16 Genannten verteilt. Niemand durfte sein Recht verkaufen. Verkaufte jemand sein Weiderecht, so verlor er sein Murmendenrecht. Dieses konnte nur auf die Erben übertragen werden. Es durfte nur auf gemeinsamen Beschluß hin gegraben werden. Der Fang wurde gleichmäßig verteilt. Der Schaden, der durch das Graben in der Weide verursacht wurde, mußte im Frühjahr wieder gut gemacht werden.

Das Murmeltier besaß für die Gebirgseinwohner eine große Bedeutung. Es wurde im Winter ausgegraben, weil es dann am fettesten ist. Das Fleisch und das Fett waren sehr geschätzt, letzteres wurde auch als Heilmittel benutzt (Hüftweh, Gliederkrankheiten, Bauchschmerzen usw.). Die Bestimmungen im Landbuch teilten die Murmeltiere dem Grundeigentum zu, und erst im 19. Jahrhundert erlaubte ein neues Gesetz das freie Jagen und verbot das Graben und Fallenstellen.

"Welcher Murmelthier in seinem aigen Grund und Boden oder Bärg hat/erkaufft oder selbst darin gelegt/oder die sonst darin kommend werend/solle ihm dieselbigen niemand weder schiessen/ platjen ${ }^{78} /$ noch graben noch in kein ander Weg umbringen/oder hinemen... ${ }^{79}$.

Der Heuruf.

„Alle Jahre Mitte August geschieht der Obrichkeitliche Heuruf, der gegenwärtig $40 \mathrm{Fl}$ (Gulden) für ein Kuhheu ${ }^{80}$ ist, und der Handel mit Heu ist frei, außer daß der Einwohner bei gleichem Preis den Vorzug vor dem Fremden hat ${ }^{81}$."

Wann großer Heumangel im Landt were/und einer Heu zu verkaufen hat der soll es nit vom Landt verkauffen/so er es im Landt find zu geben. Doch welcher Heu vom Landt verkaufft/mögen ingesessene Landslüt das selbige in Preti des Ruoffs züchen... Es soll ein Ehrsam Rath/in begebender Heumangels Noth/auch wol Gewalt haben/uszeteilen/wo Leuth wern/die mehr als sie zur Notdurft bedörffen/Heuw hetten/ja den nächsten Verwanten oder Nachparn/so dessen mangelbar sind und die Bezahlung zu geben je nach der Gelegenheit der Sache...82

Die walserische Gesetzgebung zeigt neben dem starken, freiheitlichen und persönlichen Willen des Einzelnen doch immer wieder einen starken sozialen Zusammenhang. Die Fürsorge für den Armen, den Schwächern kommt in vielen Gesetzen zum Ausdruck. Parallel mit dem Individualismus läuft ein ausgesprochener Gerechtigkeitssinn und ein starkes Ehrgefühl. Ein gut ausgebautes Spendwesen sorgt für die Armen, sodaß VALÄR schreiben kann:

„Der Wohlstand ist allgemein blühend, weil die Einwohner haushälterisch und genügsam sind. Ein Bauer, der hier 4-500 Fl. besitzt, lebt bequemer und vergnügter als mancher in zahmern Gegenden, der die Hälfte mehr dem Kapital nach Gütern besässe ${ }^{83}$.“

\section{Der Handel.}

Immer waren die Davoser stark auf den Handel angewiesen. Das hochgelegene Tal mit seiner einseitigen Viehwirtschaft konnte sich mit seinen Erzeugnissen nie selber ernähren. Die Hauptnahrung des Davosers bestand aus Milchprodukten und Gemüse, vor allem Rüben, bis zur Einführung der Kartoffel im 19. Jahrhundert, Fleisch wurde wenig gegessen. Das Haupteinfuhrprodukt war Getreide, besonders Roggen aus dem Tirol, Unterengadin, Veltlin und Cläven, in neuerer Zeit auch aus Schwaben und von Zürich. Dazu kamen feine Mehle, wie etwa das St. Galler Mehl und viel Hafer für die Pferde. Die eigene Gerste wurde vor allem als Kochmehl verbraucht und höchstens mit Roggenmehl vermischt gebacken. Das Salz kam aus Hall. Diese Produkte brachte man meistens über den Flüela, im Gegensatz zum Wein, der aus dem Veltlin den Weg über den Scalettapaß nahm. Der Weinhandel beschäftigte einen großen Teil der Einwohner, mehr als die Hälfte des Weins kam jedoch weiter nach Chur, ins Prättigau und in die Schweiz. Den Branntwein bezo-

78 Schlagfallen. Kommt von Platte, Steinplatten aufstellen.

79 Landbuch der Landschaft Davos, S. 34.

${ }^{80} 1$ Kuhheu $=1008$ Schuh $=8$ Burden, 1 Burde $=24$ Wüsch, 1 Wüsch $=25$ kleine Krinnen, 1 Davoser Krinne $=0,521 \mathrm{~kg}$. $1 \mathrm{Kuhheu}=2498,88 \mathrm{~kg}$. also rund $25 \mathrm{q}$.

81 VALÄR: Topographische Beschreibung der Landschaft, S. 41.

82 Landbuch, S. 49.

83 VALÄR: Beschreibung der Landschaft, S. 48. 
gen die Davoser aus Cläven. Der Hanf mußte größtenteils eingeführt werden, nur sehr wenig wurde auch im Unterschnitt gepflanzt. Im Gegensatz zu der vielfältigen Liste der Einfuhrprodukte beschränkte sich die Ausfuhr auf Vieh und deren Nebenprodukte. Der Viehhandel blieb Haupternährungszweig bis zur Entwicklung des Kurortes und zur Gründung der Molkereigenossenschaft in Davos 1905. Der Aufzucht schenkte man große Aufmerksamkeit. Die besten Kälber verkauften die Davoser nach Italien, sodaß im 18 . Jahrhundert weitsichtige Männer wie C. U. SALIS von Marschlins auf eine bedeutende Zuchtverschlechterung hinwiesen, da nur die schlechten Stiere für die Zucht zurück blieben ${ }^{84}$. Die italienischen Käufer erschienen selber im Land, sie waren wohlgeachtet:

„Wann frömbd Viechkaufleuth, Walchen ${ }^{85}$ oder andere in das Land komend und Viech kaufen wollend/denen soll niemand rathen/noch vom Land nit wysen/dass sy anderswo Viech kauffend... "80

Wahrscheinlich zu Beginn des 18. Jahrhunderts trat eine Änderung ein. Die Einheimischen trieben nun ihr Vieh im Herbst selber nach Italien ${ }^{87}$. Oft überraschte sie der Winter auf den Pässen, Lawinen rissen die Tiere mit, abgemagert und müde erreichten sie ihren Bestimmungsort. Dort fanden sie womöglich nicht einmal einen Käufer und mußten zu einem Schleuderpreis verschachert werden. 1721 vereinbarten darum die eidgenössischen Stände und die drei Bünde, es soll kein Vieh mehr im Herbst nach Italien getrieben werden. Erst im März und April war dies wieder gestattet. Diese Regelung zeigte etwas Erfolg, wurde aber auch mißarchtet. So trieb Hauptmann Buol von Parpan, einer der größten bündnerischen Viehbesitzer seiner Zeit, 1737 eine starke $\mathrm{Hab}$ im Winter über den Scaletta und verlor viele Tiere durch Lawinen. - Die Zahl des jährlich verkauften Viehs und dessen Ertrag war außerordentlich schwer zu schätzen, da der Handel sich über das ganze Jahr verteilte, die Höfe in Davos zerstreut lagen und das Geschäft meistens geheim gehalten wurde ${ }^{88}$. Die Schafe fanden Absatz bei den Metzgern in Chur und der Ostschweiz. Die Butter verkaufte man nach Italien, Tirol, der Schweiz und Vorarlberg. (Die Innereggen Alpen Sertig lieferten allein einen Sommerertrag von 6000 Krinnen Schmalz, $3126 \mathrm{~kg}$.) Auch Häute, Geißfelle, Wildbret, Fische und Eier fanden Absatz. Käse, Zieger und Milch wurden im Hause aufgebraucht.

Da der Davoser so stark auf den Handel angewiesen war, so verdiente mancher mit Säumern sein Brot. Vor allem im Oberschnitt war immer ein Teil der Männer unterwegs. Der Flüela- und Scalettapaß blieben bis auf wenige Schneeund Lawinentage im Winter das ganze Jahr offen. Eine strenge Ruttnerordnung sorgte für den normalen Ablauf des Verkehrs und die Instandhaltung des Saumoder Karrenweges. Flüela- oder Scalettapaß? - Im 19. Jahrhundert brach der Streit um den Vorrang aus. Über den Flüela wurde die Straße gebaut, durch das Dischmatal und unter dem Scalettapaß durch wäre um die 20. Jahrhundertwende beinah die Bahn ${ }^{89}$ ins Engadin gelegt worden ${ }^{\mathbf{9 0}}$.

\section{DIE BEVÖLKERUNG}

\section{Die Bevölkerungsbewegung seit dem 14. Jahrhundert.}

Die statistische Untersuchung der Bevölkerung in verschiedenen Jahrhunderten spiegelt wirtschaftliche Höhepunkte wie Zeiten der Not, Seuchen und Naturkata-

84 C. U. voN SALIs, NS 1808, S. $194 \mathrm{f}$.

${ }^{85}$ So hießen in Davos die Einwohner des anstoßenden, romanisch redenden Belforter Gerichtes. Im übertragenen Sinn auch alle anderssprachigen Fremden.

86 Landbuch, S. 52.

87 SPRECHER: Geschichte der Republick der 3 Bünde. Bd. II, S. 50.

88 VALÄR: Beschreibung der Landschaft. S. 43.

89 Vergleiche DZ Jg. 1889, 1890. FERDMANN: DR 1939/40.

yo Zum Kapitel Handel vergleiche: VAL.̈R, NS 1806 ; ScHiss, BM 1935, S. 18 f. L.4iY: Der Saum und Paßverkehr in alt Davos. Ferdmanis: Die Anfänge des Kurortes Davos. 
strophen wieder. Über eine längere Zeit kann nur die Gesamteinwohnerzahl der Landschaft verglichen werden. Vom 19. Jahrhundert an bestehen offizielle Zählungen, für frühere Zeiten müssen Schätzungen verwendet werden. Mit dem Beginn des Kurortes (1860) geben die Gesamteinwohnerzahlen insofern ein falsches Bild, als der bäucrliche Teil nur noch einen kleinen Prozentsatz ausmacht. So sind von da an nur noch die landwirtschaftlichen Fraktionen, also Monstein, Glaris und Frauenkirch vergleichbar.

Die interessanteste Frage ist wohl diejenige nach der größten Bevölkerungsdichte. Gab es eine Zeit, in der die landwirtschaftliche Fläche mehr Menschen ernährte als heute? Wo lagen dann die höchsten und äußersten Dauersiedlungen ${ }^{91}$, die obere Grenze der intensiven Bodenbewirtschaftung?

Mitte 15. Jahrhundert bekommen wir durch Zinsbücher Einblick in die Entwicklung der Bevölkerung seit 1289. 1450 werden 70 Höfe genannt. Es steht jedoch fest, daß es Heimwesen gab, die keinen Zins zahlten oder diesen schon abgelöst hatten, sodaß 70 Höfe cin Minimum wären. Innerhalb 150 Jahren hat sich somit die Bevölkerung versechsfacht. Eine enorme Rodungs- und Räumungsarbeit fällt in diese Zwischenzeit.

Aus dem Jahre 1562 stammt ein Spendbuch, das uns die Schätzung der Einwohnerzahl ermöglicht. In der folgenden Form sind alle Spendpflichtigen aufgeführt:

Christian Bircher soll finfzechen schillig und fünf taler ab synem Hus und Hof, genannt die Kriegmatta in Dischma, stost ufwert an die allmein abwert an das Alpwasser, uswert an Birchers gassen, inwert an Peter Voppen guot ${ }^{92}$.

$\mathrm{Da}$ auch die Anstößer nach jeder Seite hin angegeben sind, ist es möglich, einen Plan zu konstruieren, der mindestens die gegenseitige Lage der Höfe wiedergibt. Aus diesem Netz fallen nur diejenigen Höfe, welche keine Spend zahlen und keine spendpflichtigen Anstößer besitzen. Für Monstein und die Langmatte führte ich diesen Versuch durch und stieß dabei auf folgende Schwierigkeiten: Oft fehlen die Bezeichnungen des Standortes, oder die Flurnamen sind heute unbekannt. Es ist nicht immer klar feststellbar, ob es sich nur um ein isoliertes Stück Land handelt oder ob es wirklich der Standort der Hauptsiedlung ist. Nicht feststellbare Verwandtschaftsbeziehungen können leicht ein falsches Bild geben. In beiden Fällen ist das Resultat jedoch überraschend gut, indem die einzelnen Höfe 4-6 mal in ihrer Lage durch die Anstößer kontrolliert werden. Für die ganze Landschaft zähle ich 481 verschiedene Besitzer von Land. Sind z. B. acht verschiedene Michel (Claus, Jöri, Joder, Erhart, Hans, Lorentz und Peter) angegeben, so ist es gut möglich, $\mathrm{da}$ es mehrere Bauern mit dem gleichen Vornamen gibt, wobei der eine in Monstein, der andere in Sertig wohnen könnte. Mit der Zahl 8 ist also nur das sichere Minimum erfaßt. Von diesen 481 Besitzern fallen etwa 70 weg, die früher oder später lebten, aber in dieser zusammengestellten Spendeliste auch enthalten sind. Rechne ich mit 450 Landbesitzern und einer durchschnittlichen Familienzahl von 8 Personen, so bekomme ich 3600 Einwohner. (Monstein ca. 200 Einwohner.) CAMpell schätzt für das 16. Jahrhundert 800 stimmfähige Davoser (d. h. alle männlichen Personen über 14 Jahre), eine Zahl, die in der Größenordnung mit der meinigen übereinstimmt ${ }^{93}$.

Aus dem Jahre 1623 besteht eine Schätzung von Gillardon 9:. Er besitzt als Grundlage eine Zählliste, die als Kontrolle bei der Aufnahme der Erbhuldigung ${ }^{55}$

${ }^{91}$ Unter einer Dauersiedlung verstehe ich eine das ganze Jahr bewohnte Siedlung im Gegensatz zu einer temporären, die nur im Winter oder Sommer bewohnt ist. Dort sind Haupt- und Nebensiedlungen zu unterscheiden.

${ }_{92}$ Spendbucl, S. 21.

93 Vergleiche SCHIEss : BM 1935, S. $18 \mathrm{f}$.

94 Gillardon: BM 1930, S. $163 \mathrm{f}$.

9j Der ganze Zehngerichtenbund stand damals unter der Herrschaft von Oesterreich. In einer Zeit des Krieges und der gegenseitigen Spannung darf man annehmen, daß die Liste nicht vollständig ist, daß mancher versuchte, seinen Namen zu unterschlagen. 
diente und alle männlichen Personen über 16 Jahre mit Namen anführt. Für Davos waren es zwei Rodel, von denen der eine verloren ging. Die erhaltene Liste trägt 190 Namen. (Soweit an Hand der Familiennamen festzustellen ist, scheint es diejenige des Oberschnittes zu sein.) Für die fehlende Liste kann er also mit Recht die gleiche Anzahl annehmen. Er rechnet mit 400 männlichen Personen über 16 Jahre, multipliziert sie mit 5 und kommt damit auf eine Einwohnerzahl von 2000.

Läßt sich diese große Entvölkerung innerhalb 60 Jahren erklären? ȘPREcher sagt dazu ${ }^{96}$ :

„Soviel scheint fest zu stehen, nach Campell und Kirchenbüchern, daß die Volkszahl zur Zeit jenes Chronisten (ca. 1510-1583) und bis in das dritte Jahrzehnt des 17. Jahrhunderts hinein eine beträchtlich größere war. $\mathrm{Da}$ von Beginn der Unruhen an Pest, Krieg und Hungersnot das Land rasch um ein drittel entvölkerte, und daß sie erst seit der Friedenszeit (Ende der Bündnerwirren 1639) stetig zu steigen begann. Diese $Z$ unahme dauerte fort bis nach der Vertreibung der Bündner aus Venedig und dessen Staaten (1766). Sie flüchteten sich in alle andern europäischen Länder, und von da an begann eine permanente Auswanderung. Die Geburtenzahl genügte nicht mehr, da durch Seuchen (1771-1773), Krieg und fremde Dienste große Lücken entstanden."

Pestepidemien wüteten in Davos 1585 (in der Nachbarschaft Frauenkirch und Sertig starben allein über 200 Menschen) und 1629 (140 Tote). 1622 brannten beim Durchzug der.Truppen von Baldiron $70 \mathrm{Häuser} \mathrm{ab,} \mathrm{davon} 13$ im Dörfli und 8 im Platz.

Bis ins 19. Jahrhundert sind für Davos keine Angaben mehr aufzufinden, doch gilt auch hier die Schilderung von Spreciner. Die sehr ausführliche und genaue Beschreibung der Landschaft Davos von Landammann VALÄR 1805 enthält eine Statistik der Geburten und Sterbefälle von 1789-1803 ${ }^{97}$.

\begin{tabular}{|c|c|c|c|c|c|c|c|c|c|c|}
\hline \multirow[t]{2}{*}{98} & \multicolumn{2}{|c|}{$\begin{array}{c}\text { H. } \\
555 \mathrm{E} .\end{array}$} & \multicolumn{2}{|c|}{ D. } & \multicolumn{2}{|c|}{$\mathrm{F}$} & \multicolumn{2}{|c|}{$\begin{array}{l}\text { G. } \\
304 \mathrm{E}\end{array}$} & \multicolumn{2}{|c|}{$\begin{array}{c}\mathrm{M} . \\
78 \mathrm{E}\end{array}$} \\
\hline & $*$ & $\dagger$ & & $t$ & & $t$ & $*$ & $\dagger$ & & 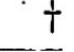 \\
\hline 1789 & 17 & 22 & 16 & 9 & 6 & 6 & 3 & 14 & 2 & 5 \\
\hline 1790 & 23 & 1 & 16 & 11 & 9 & 5 & 6 & 8 & 4 & 2 \\
\hline 1791 & 14 & 一 & 16 & 4 & 10 & 6 & 9 & 6 & - & 1 \\
\hline 1792 & 19 & 1 & 14 & 12 & 13 & 10 & 6 & 6 & - & 2 \\
\hline 1793 & 18 & 10 & 13 & 17 & 6 & 7 & 2 & 8 & 3 & 5 \\
\hline 1794 & 24 & 5 & 17 & 11 & 11 & 8 & 7 & 9 & 3 & 0 \\
\hline 1795 & 12 & 6 & 10 & 9 & 8 & 5 & 4 & 9 & 4 & 3 \\
\hline 1796 & 20 & 5 & 14 & 24 & 8 & 8 & 4 & 13 & 1 & 3 \\
\hline 1797 & 12 & 2 & 6 & 10. & 10 & 11 & 10 & 10 & - & 1 \\
\hline 1798 & 16 & - & 18 & 7 & 8 & 7 & 10 & 7 & 5 & - \\
\hline 1799 & 19 & 11 & 17 & 8 & 7 & 2 & 12 & 10 & 2 & 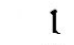 \\
\hline 1800 & 12 & 13 & 12 & 8 & 11 & 6 & 10 & 10 & 3 & 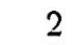 \\
\hline 1801 & 20 & 10 & 10 & 11 & 7 & 9 & 5 & 14 & 3 & 3 \\
\hline 1802 & 21 & 13 & 18 & 6 & 7 & 11 & 8 & 8 & 2 & 2 \\
\hline 1803 & 21 & 7 & 17 & 6 & 5 & 6 & 6 & 11 & 1 & 2 \\
\hline & 268 & 106 & 214 & 153 & 126 & 106 & 102 & 143 & 33 & 38 \\
\hline
\end{tabular}

Der Geburtenüberschuß für die verschiedenen Fraktionen beträgt:

$\begin{array}{ll}\text { Hauptkirche (Platz) } & +153 \% \\ \text { Dörfli } & +39 \% \\ \text { Frauenkirch } & +18 \% \\ \text { Glaris } & -29 \% \\ \text { Monstein } & -13 \%\end{array}$

Das ungünstige Verhältnis von Glaris und Monstein erklärt sich vor allem durch die hohe Sterbeziffer. Für Hauptkirche und Monstein macht das Verhältnis von Geburten zur Bevölkerungszahl ungefähr 1:2 aus, die Zahl der Gestorbenen zur Einwohnerzahl bei Platz 1:5, bei Monstein aber auch 1:2. Im Verhältnis zur Einwohnerzahl sterben also am Platz viel weniger Menschen als

${ }^{96}$ SPRECher: Geschichte der 3 Bünde im 18. Jh. Bd. II, S. 2.

97 Valär: Topographische Beschreibung der Landschaft. S. 47.

${ }^{98} \mathrm{H}=$ Hauptkirche, $\mathrm{D}=$ Dörfli, $\mathrm{F}=$ Frauenkirch, $\mathrm{G}=$ Glaris, $\mathrm{M}=$ Monstein, $\mathrm{E}=$ Einwohner $1805, *=$ geboren, $\dagger=$ gestorben. 
in Monstein. Bestehen im Unterschnitt schlechtere hygienische Verhältnisse, Armut, ist es ein Zeichen von Überalterung? (SPRECHER gibt für 179237 Personen an, die über 90 Jahre alt waren.) Die Frage bleibt wohl offen. Im 19. Jahrhundert weist der Unterschnitt die größte Auswanderung auf. Die Familien waren kinderreicher als im Oberschnitt.

Bevölkerung:

\begin{tabular}{|c|c|c|c|c|c|c|c|c|}
\hline & & Total & P. & D. & $\mathrm{F}$ & G. & M. & $Z$. \\
\hline 99 & 1780 & 2150 & & & & & & \\
\hline 100 & 1803 & 1559 & 558 & 395 & 281 & 255 & 70 & \\
\hline 101 & 1805 & 1707 & 593 & 458 & 272 & 304 & 78 & \\
\hline 102 & 1830 & 1646 & 496 & 419 & 274 & 314 & 144 & \\
\hline 103 & 1837 & 1803 & 597 & 460 & 243 & 294 & 159 & . \\
\hline & 1850 & 1680 & & & & & & \\
\hline & 1860 & 1705 & & & & & & 1.5 \\
\hline & 1870 & 1983 & & & & & & 17.4 \\
\hline & 1880 & 2868 & 2109 & 681 & 397 & 258 & 116 & 43.1 \\
\hline & 1888 & 3889 & & & & & & 35.8 \\
\hline & 1900 & 8089 & 5119 & 1687 & 347 & 257 & 124 & 111.9 \\
\hline & 1910 & 9905 & & & & & & 22.4 \\
\hline & 1920 & 8962 & 6497 & 1765 & 288 & 276 & 136 & -9.4 \\
\hline & 1930 & 11166 & 7676 & 2655 & 348 & 336 & 151 & 24.5 \\
\hline & 1941 & 9215 & 6454 & 2035 & 303 & 281 & 142 & -17.4 \\
\hline & 1949 & 9832 & 6960 & 2145 & 305 & 276 & 146 & 6.7 \\
\hline & 1950 & 10332 & 7378 & 221.5 & 318 & 276 & 145 & 5.1 \\
\hline
\end{tabular}

1805 Oberschnitt : 770 Unterschnitt : 937

$1830 \quad 683$

Zunahme: $\quad 1803-1850=7,7 \% \quad 1850-1900=381,4 \% \quad 1900-1950=27,6 \%$ $\mathrm{P}=$ Platz, $\mathrm{D}=$ Dorf, $\mathrm{F}=$ Frauenkirch, $\mathrm{G}=$ Glaris, $\mathrm{M} \cdots$ Monstein, $\mathrm{Z}=$ Zunahme der Gesamtbevölkerung in Prozenten.

Eine stetige Zunahme der Gesamtbevölkerung kennzeichnet das 19. und 20. Jahrhundert. Die Landfraktionen Frauenkirch und Glaris verändern ihre Zahl kaum. Bei Frauenkirch ist vorerst die Wirkung des Kurortes spürbar, auf eine erste Zunahme folgt um die Jahrhundertwende eine vorübergehende Abwanderung. Monstein macht zwischen 1805 und 1830 einen bedeutenden Sprung (Rückgang der Auswanderung?), stagniert dann ebenfalls. Die Bevölkerungszahl des Unterschnittes übertraf früher immer diejenige des Oberschnittes. Die starke Entwicklung des Kurortes kehrte dieses Verhältnis um.

In Jahre 1808 fand eine Zählung für die Verteilung von französischen Hilfstruppen statt. Von 1827 Einwohnern sind 555 waffenfähig (Männer zwischen 16 und 60 Jahren); 205 im Platz, 129 im Dorf, 78 in Frauenkirch, 80 in Glaris, 38 in Monstein. Die Zahl der Abwesenden betrug 111. Von diesen befanden sich: In französischen Militärdiensten 47, als Konditor oder Kaffeesieder im Ausland 30 (Italien S, davon 7 in Brescia, Rußland 7 , Polen 4, Österreich 4, Deutschland 3, Holland 2, je einer in Dänemark und Amerika), 6 hielten sich im Kanton auf (3 im Unterengadin, je einer in Chur, Malans und Splügen). Von 28 kannte man den Aufenthaltsort nicht. Diese 111 Abwesenden kehren wieder zurück und sind nicht mit Auswandern zu verwechseln. Von ihnen erzählt VaL.̈̈R: «Ihre erlernte Profession nützt ihnen hier gar nichts, sie werden dadurch bloß zur Landarbeit untüchtig, lasterhaft oder verlassen das Vaterland auf immer».

99. SPRECHFR: Geschichte der 3 Bünde im 18. Jh. Bd. II, S. $\bar{t}$.

100 Magister Rösch im Auftrage von C. U. SALIS von Marschlins.

101 VALÄR: Beschreibung der Landschaft. Zusammengestellt nach den Angaben für die einzelnen Nachbarschaften.

${ }_{102}$ Landbuch. Zusammengestellt aus den Angaben für die Nachbarschaften.

103 Ratsprotokoll vom 26. Dez. Die auswärtigen Davoser wurden hier mitgezählt, darum sind alle Zahlen etwas höher. 
Es ist die Zeit von Campell, das 16. Jahrhundert, die Zeit, in der das Davoser Spendbuch * zusammengestellt wurde. Die folgenden Angaben sind daraus entnommen.

Das Flüelatal ist heute nicht mehr dauernd besiedelt. 1450 zinste Jos Nobel ab dem Schindelboden (1820 $\mathrm{m}$ ü. M.), und auch Sererhard ${ }^{104}$ nennt dieses Gut. 1562 wohnt dort Pertsch Meysser. In Pedra sind verschiedene Höfe aufgezählt. Bei der Bedeutung des Flüelatales als Übergang darf wohl als die oberste ganzjährlich bewohnte Siedlung Tschuggen $(1941 \mathrm{~m})$ angenommen werden ${ }^{105}$. Eine Ausnahme macht das Gasthaus auf dem Flüelapaß $(2388 \mathrm{~m})$. Im Dischmatal ist das Kindschhaus der oberste Hof $(1734 \mathrm{~m})$. Die Grenze läge demnach nicht viel höher als heute, Gulrigenhaus $1703 \mathrm{~m}^{106}$. Im Sertigtal standen im Dörfli 2 Höfe (das Hus, Hof und Guot gelegen im dorffie in Sertig von Wilhalm Boumgarter und dasjenige von Christen Knopf). Für eine ehemalige Dauersiedlung sprechen auch:

1. Die Flurnamen Dörfli, Aegerta ${ }^{10 \pi}$, Sand?, Ratshus? ${ }^{108}$.

2. Im Gegensatz zu andern Alpen, wo jeder Bauer ein Gebäude, die Alphütte besitzt, die Stall und Wohnraum enthält, sind im Sertigdörfli Stall und Haus in zwei Gebäuden getrennt, wie im Tal.

3. Die heutigen alpwirtschaftlichen Verhältnisse lassen sich aus einer Dauersiedlung erklären.

Das Sertigdörfli (1860 $\mathrm{m}$ ü. M.) war also eine Dauersiedlung wie die Alp Flix von Sur in Oberhalbstein 109. Das Kirchlein wurde erst 1699 gebaut. Pfarrer Leonhard, 1689-1696 Pfarrer in Frauenkirch, erzählt, wie er acht Jahre bald auf freiem Feld oder in einem Haus gepredigt habe 110. Heute liegt das oberste, ganz jährlich bewohnte Heimwesen in der Bäbi $(1600 \mathrm{~m})$. Eine Ausnahme machen die beiden Gasthöfe mit angeschlossenem landwirtschaftlichen Betrieb im Dörfli und Sand ${ }^{311}$.

Auf der rechten Talseite des Landwassers standen noch im 19. Jahrhundert in der Rüti $(1619 \mathrm{~m})$ bei Glaris und auf der Obermatte $(1772 \mathrm{~m})$ unterhalb der Chumma-Alp Heimwesen (Fig. 1).

Aufschluß über die Siedlungsdichte können die rekonstruierten Pläne von Monstein und der Langmatte geben 112. Für die Langmatte zähle ich 19 Höfe, heute stehen 18 Heimwesen ( 7 landwirtschaftliche Betriebe, 4 Kleinbetriebe, Landwirtschaft im Nebenberuf, 7 Bauernhäuser, die als Wohn-, Ferienhäuser dienen). In Monstein sind es 156219 Höfe; 11 oberhalb und 13 unterhalb der Straße. (Heute: 10 Bauernbetriebe, 12 Bauernhäuser oberhalb und 13 unterhalb der Straße.) Für beide Orte bekomme ich ein gleiches Resultat, als ob die heute stehenden Wohnstätten schon damals bestanden hätten, mit dem einzigen Unterschied, daß es alles selbständige, landwirtschaftliche Betriebe waren. Deshalb standen wohl auch mehr Gebäude, Ställe und Scheunen, die inzwischen teilweise abgebrochen wurden. Für

* (Liste derjenigen Bauern, die Armensteuer [Spende] zu bezahlen haben.)

104 Sererhard : Einfalte Delination. 1742.

${ }^{105}$ Mit dem Hof von H. Meißers Erben in den Flüelen by der Cappel S. 42, könnte Tschuggen gemeint sein.

${ }_{106}$ Das Spendbuch nennt noch ein Gut in Gadmen (Dischma), das jedoch nicht mit der Gadmenalp gleich zu setzen ist. Es befindet sich auf der Schattenseite gegenüber Gulrigen, „in den Gädmen."

${ }^{107}$ Eine Wiese, die der Sonne zugekehrt ist. Im Prättigau = ein Acker, der in Wiese umgeändert ist. lat. arare = pflügen. BüHLER, Bd. I, S. 269.

108 Alphütte im Sand. Wahrscheinlich Beratungshaus der Alpgenossen.

109 Weiss : Bündner Alpwesen, S. 89.

$1_{10}$ ConRad : DR 1942, S. 196.

${ }^{111}$ Das Kurhaus im Sand wird diesen Sommer verkauft, sodaß also nur noch ein Betrieb bleibt.

112 Die Abbildung dieser Pläne lohnt sich nicht, da sie zu hypothetisch nur die gegenseitige Lage der Häuser wiedergeben, und nur einzelne Höfe in ihrer richtigen, örtlichen Lage fest gelegt sind. 
die Landschaft Davos zeigt sich eine ähnliche Siedlungsdichte wie heute. Einzig Spina und Dischma mögen etwas dichter besiedelt gewesen sein als heute, da im 19. Jahrhundert dort besonders viele Häuser abgerissen wurden. - Wie ist diese Feststellung mit der mehr als doppelt so großen Bevölkerungszahl zu vereinbaren? Wo lagen die 450 Höfe im Jahre 1562 ?

1. Viele Höfe stehen jetzt noch und sind keine landwirtschaftlichen Betriebe mehr.

2. An vielen heute als siedlungsfremd und ungünstig betrachteten Stellen befanden sich damals Höfe. An den. «Furen» oberhalb und im Gebiete der heutigen Landstraße von der Brücke zum Höfli bis zum Suzibach (Frauenkirch) liegen heute zwei Heimwesen, damals waren es 7 .

3. Oberhalb der heutigen Dauersiedlungsgrenze (Flüela, Sertig, Rüti).

4. Die Kinderzahl der Familien war viel größer.

Die Änderung der Bevölkerungsstruktur seit dem Beginn des Kurortes 1860.

Der Kurort Davos besitzt heute eine so komplexe Bevölkerungsstruktur, wie sie für Fremdenzentren charakteristisch ist. Die umgehende Landschaft hat sich jedoch nicht viel verändert. In den ersten $40 \mathrm{Jah}$ ren ist ein Abwandern aus den näher gelegenen Gebieten nach dem Kurort spürbar. In den letzten 20 Jahren ist die Tendenz umgekehrt. Die ländliche Bevölkerung profitiert von Davos, einmal durch die guten Absatzmöglichkeiten ihrer Produkte und anderseits durch den Aufbau ciner eigenen Fremdenindustrie im Sommer. Zimmer und Wohnungen für Sommergäste werden in vielen Bauernhäusern eingerichtet. Die starke Wanderung und Abnahme der Ortsbevölkerung zeigt sich auch in Davos:

\begin{tabular}{lcccc} 
In \% der Einwohnerzah! & 1850 & 1870 & 1941 & 1950 \\
\hline Ortsbürger & 88 & 65 & 16 & \\
Kantonsbürger & 11 & 21 & 21 & \\
Schweizerbürger & 0.9 & 6 & 38 & \\
Ausländer & 0.1 & 8 & 25 & 32
\end{tabular}

Charakteristisch für Davos ist die enorme Zunahme der Ausländer, die hier in den Sanatorien lagen, gesund wurden und sich dann für immer hier niederließen.

War 1850 Davos rein protestantisch, so sind heute alle Konfessionen vertreten (1860: 2 Katholiken, 1861:24, 1870:68, 1941:3002).

So fand in Davos-Platz und Dorf eine Umwälzung von einer rein landwirtschaftlichen Bevölkerung zu einer gewerblich-städtischen statt, mit den besondern Merkmalen eines Kurortes und Wintersportzentrums. Diese Entwicklung muß sich auch, wenn nur langsam und in kleinem Maße, auf die umliegende Bauernbevölkerung in Frauenkirch, Glaris und Monstein auswirken ${ }^{113 .}$

DIE ALPINE LANDWIRTSCHAFT IM 19. JAHRHUNDERT

Die Kircherbannatzung ( Fï̈ßlar-Alpapura»).

Im Jahre 1804 wurde das Weidbuch dieser Atzung erneuert ${ }^{114}$. Den Anlaß dazu bildeten Streitigkeiten mit der Nachbaralp Strela, der vorgeworfen wurde, sie überstelle die Weide ${ }^{115}$. Ein Schiedsgericht ordnete an:

1. Strela solle gleich wie Kircherberg die Einzelrodel angeben ${ }^{116 .}$

2. Die Kircherbergatzung solle ihre Kuhrechte festlegen.

3. In beiden Atzungen sollten Schafe und Ziegen gleich gezählt werden ${ }^{11 \bar{\tau}}$.

118 Diese Zusammenhänge wurden von CHR. JOST in seiner Dissertation dargestellt.

11 Das Weidbuch von 1804 befindet sich im Heimatmuseum Davos.

115 Vergleiche Anmerkung 35.

116 Vergleiche Anmerkung 73.

117 Auf einer Kuhweide finden 8-12 Schafe oder Ziegen Nahrung. Diese Zahl wechselt je nach Alp 6, 8, 10, 12 oder gar kein Anrecht. 


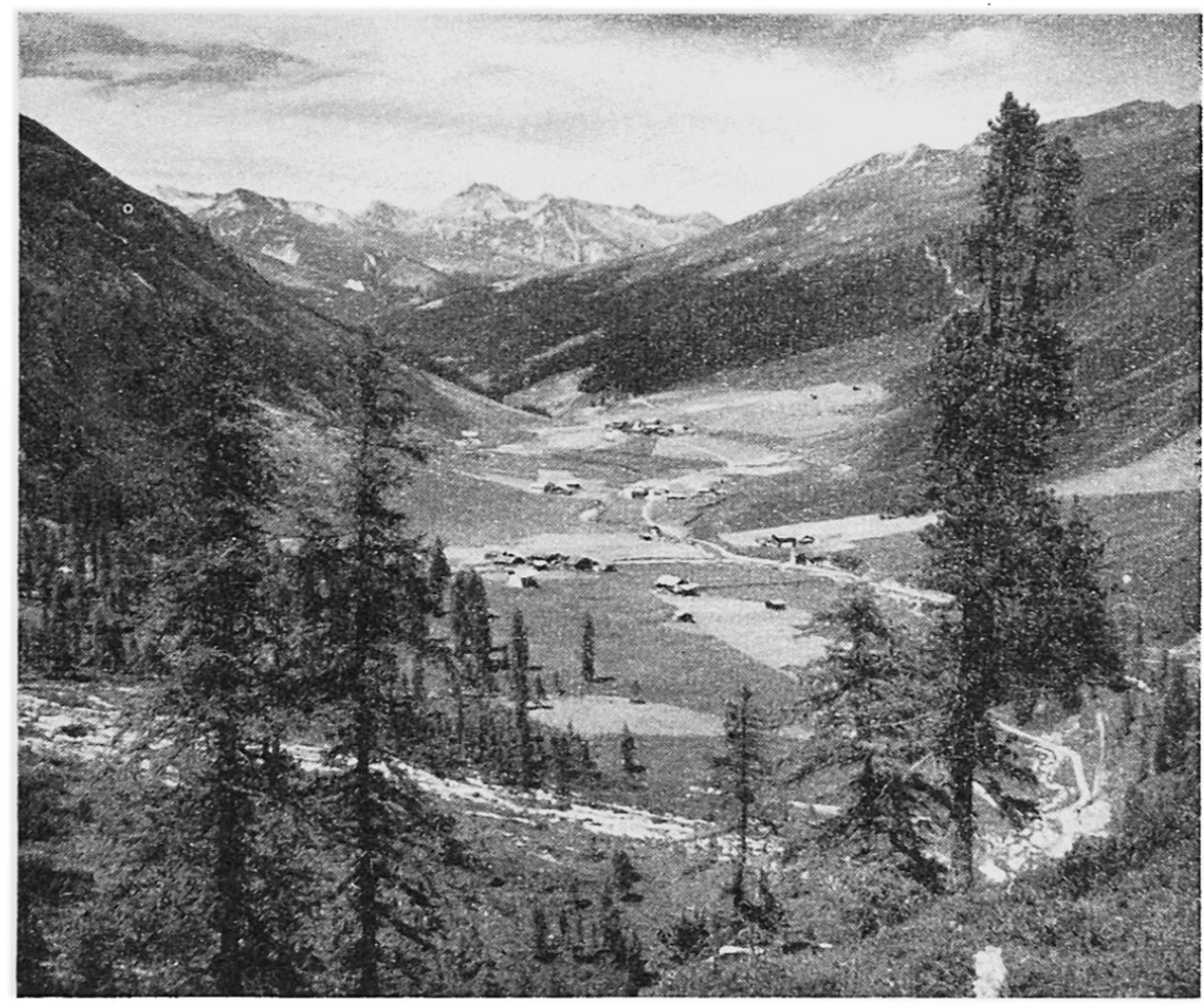

Ahh. 2 Sertig $1860 \mathrm{~m}$ ü. M. Aufgenommen mitten in der Heuernte 12. Aug. Vorderste Häusergruppe Dörfli, in der Mitte Sand, hinten links vom Sertigbach Großalp, rechts Kleinalp. Aufnahme H. SENN

Die Kircherbannatzung lag in Davos-Platz. Sie besaß die Weide im Wald über der Hauptkirche und das anschließende Weidegebiet über der Waldgrenze der heutigen Loch- und Podestatenalp oder Schatzalp. Die Waldweide, die frühere Allmend, hatte sie übernommen und aufgeteilt. Diese gehörte nun zur Alpgenossenschaft und wurde von den Alpgenossen als Frühlings- und Herbstweide, dann aber auch als Heimviehweide ${ }^{118}$ genutzt. Die ganze Atzung besa $\beta 100$ Kuhrechte, 2 Kuhrechte waren reserviert für den Saltner 119.

Das Weidbuch zählt alle Atzungsgenossen ${ }^{120}$ mit ihren Kuhrechten auf, zu Beginn diejenigen von 1789. Im Gesamten besaßen damals 46 Personen Rechte, das würde durchschnittlich zwei Kuhweiden auf jeden ausmachen.

(Flury Michel $14 \mathrm{KR} 6 \mathrm{kr}$., Jost $14 \mathrm{KR} 1 \mathrm{kr}$., M. Valär $13 \mathrm{KR}$, Podestat H. Sprecher 10 KR 2 kr., Capitain de Jenatsch 5 KR 3 F, Dr. J. Beeli 6 KR, L. Konrad 4 KR 2 F 6 kr., Statthalter J. Nadig $2 \mathrm{KR} 1 \mathrm{~F}$, Enderli Sprecher $2 \mathrm{KR} 1 \mathrm{~F}$, Leonhart Jost $2 \mathrm{KR} 2 \mathrm{~F}^{121}$ ). Es folgen 9 Personen, die zwischen 1 und 2 Kuhweiden, 21 Personen, die über $1 \mathrm{Fu} ß$, aber weniger als eine Kuhweide und 6 Personen. Total waren $97 \mathrm{KR} 6 \mathrm{kr}$. auffindbar. Es fehlten demnach $42 \mathrm{kr}$.

1842 werden 47 Genossen genannt mit zusammen $97 \mathrm{KR} 20 \mathrm{kr}$. Weitere $14 \mathrm{kr}$. hatten einen Besitzer gefunden, unter anderem wurde dem Pfrundenhaus ein Fuß zugeteilt, das es sicher schon lange besaß, das bei der 1. Aufzählung aber vergessen

118 Auf die Heimkuhweide werden die Kühe (1-2 pro Bauer) getrieben, welche zur Deckung des täglichen Milchbedarfes nicht auf die Alp kommen.

110 Saltner oder Alpvogt. Er dingt die Hirten und sorgt für Ordnung. Abwechslungsweise erfüllt jeder Alpgenosse für ein oder zwei Jahre dieses Amt. Als Entschädigung erhält er zwei Weiderechte. Sehr oft bekamen auch die Hirten eines.

120 In Davos spricht man von Atzungs- und Weidegenossenschaften im Sinne von Alpgenossenschaften.

${ }^{121}$ Ein Kuhrecht $\mathrm{KR}=4 \mathrm{Fu} \mathrm{F}, 1 \mathrm{Fu}=12$ Kreuzer kr. Es ist möglich, daß die Einheit Kreuzer vom Geldwert Kreuzer abzuleiten ist. 1805 betrug der Wert einer Kuhweide 6 Batzen - bis 2 Gulden, das sind 24-120 Kreuzer. Der Bauer zahlte pro Kuhweide 48 Kreuzer Weidezins, $1 / 48$ Kuhweide besitzt den Wert von einem-Kreuzer. 
worden war. 1871 sind es 45 Besitzer mit 97 KR 36 kr. Einer der neuen Besitzer ist Dr. Alexander Sprecher, der Gründer des Kurortes, der ein Fuß zugewiesen erhielt.

Im 19. Jahrhundert finden wir eine große Zersplitterung und Aufteilung der Alprechte. Von den 46 Weideberechtigten benutzten sicher nur die Hälfte ihre Rechte. Auf der eigentlichen Alpweide sömmerten die sieben Bauern mit zwei und mehr Kuhweiden, vielleicht noch die drei mit zwei Kuhweiden. Die andern trieben eine Kuh oder ein paar Geißen in die Waldweide und nutzten diese als Heimweide. Die eigentlichen Alpbesitzer brauchten die Waldweide nur im Frühling und Herbst und als Schneefluchtweide. Die Heimkuhweiden waren oft stark überstellt, da sie im Waldgebiet lagen, dazu auch weniger ertragreich. Es bestand daher die Tendenz, möglichst viel Vieh auf der Alp zu sömmern. Da die Alpen sehr nahe liegen, konnte man ja auch die Milch immer noch am Abend dort holen. Der Wert einer Heimweide war für die Davoser Verhältnisse klein, und die Alpbesitzer benutzten eine solche kaum. Sie wurde hingegen von den «Füaßlarn » 122 benutzt. Das sind diejenigen Besitzer von Weiderechten mit weniger als einer Kuhweide (Fuß). Sie stehen im Gegensatz zu den «Alpapura ». Der Füaßlar besitzt nur Weiderechte, jedoch keine Alpwiese, keine Alphütte. Es gibt solche, die nicht einmal Talwiese zur Überwinterung des Viehs hatten. Sie konnten sich für ihr Recht im Sommer eine Kuh oder Ziegen pachten und diese auftreiben.

Wie läßt sich dieser Zustand erklären? Betrachten wir das Nutzungsrecht auf der Alp und dasjenige im Wald getrennt:

1. Die Waldweide: Es ist die ursprüngliche Allmend, später in Rechte aufgeteilt, die gemeine Weid. Auf ihr hatten zuerst alle Nachbarn uneingeschränktes, später festgelegtes Weiderecht. Alle Nachbarn ohne großen Wiesenbesitz, aber auch diejenigen mit Alprechten an anderer Stelle im Dischmaoder Flüelatal, bekamen $1-2$ Kuhrechte zugeteilt. Im Laufe der Zeit wurden auch Witwen und weitern neuen Ansäßigen Rechte zugesprochen, meistens nur noch Füße, also für $1-2$ Ziegen.

2. Die Alpweide: Sie gehörte schon lange bestimmten Alpbesitzern, den Alpapura. Diese besaßen ebenfalls das Recht, ihr Vieh in die Allmend zu treiben, dann bekamen sie auch Rechte in der gemeinen Weid. Sie nutzten diese jedoch nur als Vor- und Nachweide, als Wetterschutz und als Heimweide. Der Alpapur gab sein Recht der Heimweide meistens bald auf oder benutzte es gar nie.

Da der Alpapur die Waldweide als Wetterschutz und als Frühlings- und Herbstweide brauchte, so waren seine Ansprüche gegenüber den Füaßlarn sehr stark. Er war der wohlhabende Bauer im Gegensatz zum Armen, zur Witwe und all denen, die nur ein kleines Weiderecht besaßen ${ }^{123}$. Sie gaben den Ton an. Die frühere gemeine Weide ging in Alpbesitz über. Die vielen aufgesplitterten Rechte blieben jedoch, wurden aber immer weniger gebraucht, Ende des 19. Jahrhunderts auch von den Alpapura aufgekauft. Zuletzt bestanden nur noch wenige Bauern mit großen Weiderechten.

Zwischen 1871 und 1900 wurde die Gesamtstoßzahl der Kircherbergatzung um $1 / 8$ herabgesetzt. Statt 48 Kreuzer für ein Kuhrecht, rechnete man neu 54 Kreuzer. (Auf ähnliche Art setzt auch die Bärentalalp in diesem Jahrhundert ihre Weidezahl herab, indem sie tür ein Kuhrecht $5 / 4$ statt $4 / 4$ rechnen.) 1905 verteilten sich die Rechte noch auf 10 Personen.

(Sanatorium Schatzalp 39 KR 20 kr., Kurhaus Davos $10 \mathrm{KR} 11 \mathrm{kr}$., Paul und Christian Beely 16 KR 47 kr., P. Kaiser 5 KR, U. Rüesch $3 \mathrm{KR} 17 \mathrm{kr}$., W. Ardüsers Erben $421 / 2 \mathrm{kr}$., Dr. L.

122 Ich benutzte die phonetische Schreibweise im alten Walserdialekt wie bei BüHLER, Bd, I, S. 35 .

123 Man beachte die Namen der Alpapura von 1789 , es sind die alten, eingesessenen, zum Teil adlig gewordenen Geschlechter. 


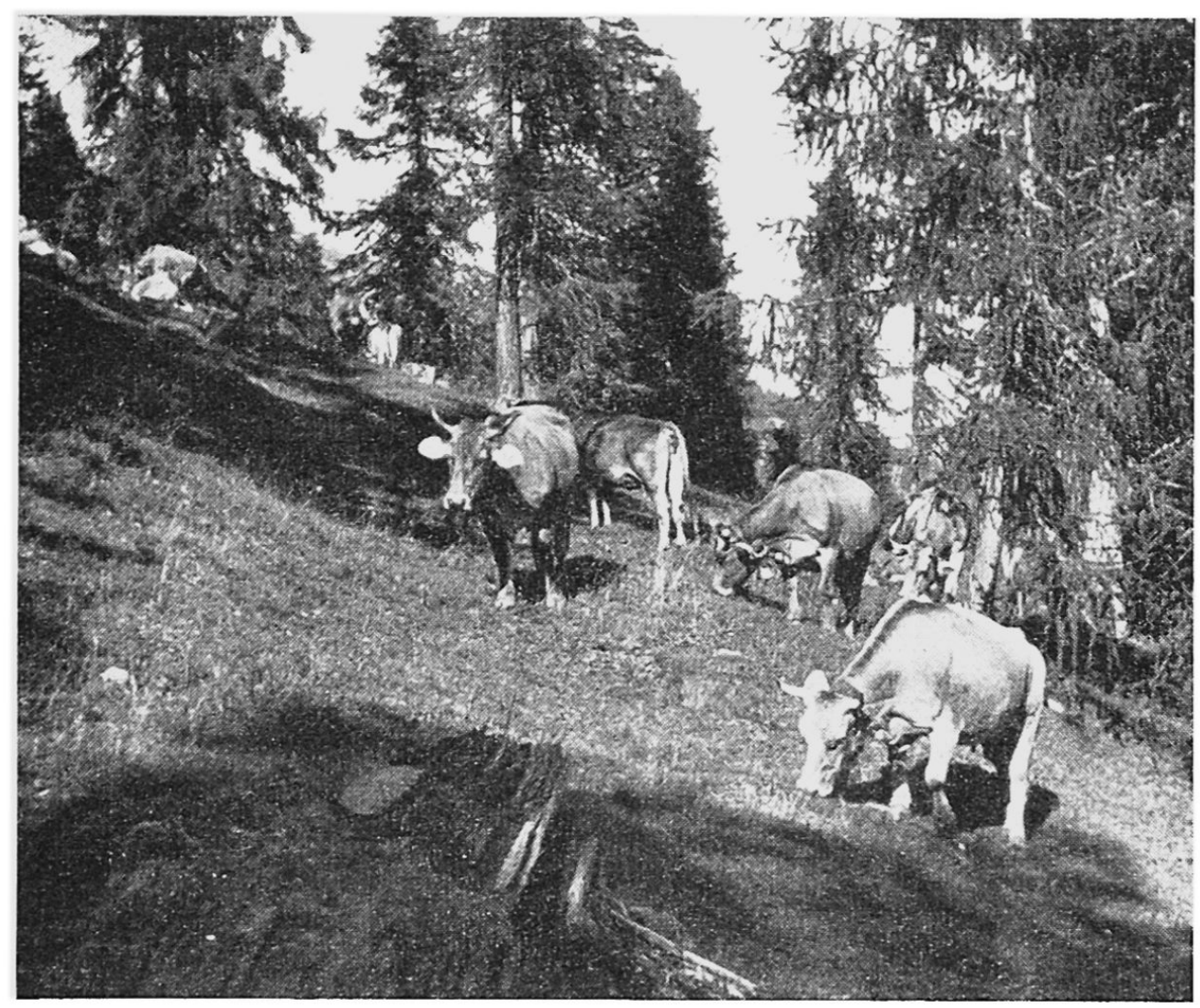

Abb. 3 Waldweide in lichten Lärchenbeständen. Aufnahme H. SENN

Spenglers Erben $38^{1 / 2}$ kr., Turban \& Co. $46^{1 / 2}$ kr., E. Michels Erben 11 kr., P. Beeli-Büsch $25^{1 / 2}$ kr., Saltnerweiden $1 \mathrm{KR} 29 \mathrm{kr} .{ }^{124}$ )

Die meisten Füaßlarrechte waren von Hotelbesitzern und Sanatorien aufgekauft worden, andere lagen rechtlich noch in den Händen von Erben, die sie aber nicht mehr benutzten. Die Waldweiderechte wurden 1900 abgelöst und von den Waldbesitzern ausgekauft.

Nach der Weideablösung im Waldgebiet sollten 1905 eigentlich keine Füaßlarrechte mehr bestehen. Ihr Weiterdauern zeigt, daß die rechtliche Stellung der Füaßlar aus der historischen Entwicklung vergessen war. Die Weiderechte der Füaßlar dehnten sich gemäß der einen großen ungeteilten Kilcherbergatzung auf die ganze Weidefläche aus, von der untersten Grenze im Tal bis hinauf in die Gipfelregion und höchsten Weiden. Da viele Füaßlarrechte gar nicht benutzt wurden, und die Heimkühe in der Nähe bleiben mußten, konnten die Alpweiden höchstens noch von den $Z$ iegen geatzt werden. Diese verbannte man jedoch vom guten Weidegebiet und jagte sie zurück in die tiefer liegenden Tobel (Albertibach), wo sic mit ihrem Zahn dem Wald stark zusetzten. Das war auch ein Hauptgrund, die Füaßlarrechte mit ihren vielen Ziegen aufzukaufen und abzulösen. Praktisch war also die Weide getrennt und die Alpweiden ausschließlich von den Alpapura genutzt ${ }^{125}$.

Diese rechtliche Unklarheit zeigt auch ein Kauf im Jahre 1899 auf dem Flüelaberg 126. Diese Alp wurde von den Alpapura mit Kühen und Galtvieh bestoßen. Die Füaßlar besaßen jedoch auch Rechte zur Sömmerung von Galtvieh. Die Füaßlarrechte kauften 1899 die Alpbesitzer für Fr. 220.- pro Stoß auf. Die Füaßlar brauchten ihren Galtviehanteil an Weide vor dem Kauf sogar als Vorsömmerung

124 Aufteilung nach der Weideablösung im Jahre 1900. Siehe Kapitel Wald-Weide.

${ }^{12 \overline{0}}$ Die heutigen Besitzer der Reste der Kircherbannatzung sind die Schatzalp, die ihre Alp, die Podestatenalp, an 2 Bauern verpachtet, und die Lochalp = Privatbesitz.

120 DZ 1899, 2. Febr. 
der Dorf-Weide. Woher kam diese Verwirrung? Die Dorfweide ist eine frühere Allmend und wurde von den Füaßlarn bestoßen. Die Besitzer der Flüelabergalp besaßen dort also auch Weiderechte. Auf irgend eine unabgeklärte Weise waren die Füaßlar zu den Galtviehweiden im Flüelaberg gekommen und benützten nun diese im Frühling gemeinsam mit den Alpapura mit dem ganzen Viehstand ${ }^{12 \pi}$. Nachher zogen die Alpapura ganz auf die Alp, die Füaßlar ließen nur noch ihr Galtvieh dort und kehrten zurück auf die Heimweide, die Dorfweide, welche die Alpapura mit ihren Heimkühen auch atzen durften.

In andern Teilen der Landschaft, vor allem im Unterschnitt gingen die gemeinen Weiden schon früh in den Besitz der Alpapura über. Es bestanden hier nicht so viele Füaßlar, oder die wenigen Rechte wurden bald aufgekauft, sodaß heute zu den meisten Alpen der unten anstoßende Wald mit der Weidemöglichkeit gehört, der als Wetterschutz und Vor- und Nachweide dient. Valär erwähnt in seinem Bericht die Füaßlar nicht, was später von BüHLER besonders vermerkt wird. Dieser wundert sich, daß diese sonst so genaue Beschreibung der Landschaft diese Tatsache nicht enthält ${ }^{128}$. VALÄR schreibt jedoch an einer andern Stelle: Die tiefer liegende Weide braucht man an einigen Orten für Heimkühe und Geißen, die man aber nach Hause treiben läßt ${ }^{129}$. Das bestätigt meine Ausführungen. Die Füaßlar mit ihren Heimkühen und Ziegen finden wir nur noch an wenigen Stellen, die Alpapura lassen in der Regel keine Heimkuh zurück.

Die Stafelalp besitzt noch heute zwei getrennte Weiden, die Alpweide mit den Alpweiderechten und die Sonderweide mit den Sonderweiderechten. - Die Dorfatzung läßt in Aufbau und Organisation noch klar die alte, unaufgeteilte Allmend durchblicken. Auf verschiedenen Entwicklungsstufen (Allmend, gemeine Weid) standen die einzelnen Atzungen still und erhielten sich dann in jener Form bis auf die heutige Zeit.

\section{Die. Aufgabe und Zusammenlegung von Kleinbetrieben zu größern Heimwesen (Wiistungen).}

Die Aufsplitterung der Alprechte hatte ihre Ursache in der starken Zerstükkelung und Aufteilung der Heimwesen in den vorangehenden Jahrhunderten. Diese Entwicklung begann schon im 16. Jahrhundert, der Zeit der größten Einwohnerdichte. Infolge von Krieg und Krankheit, durch Auswanderung wurden Heimwesen verlassen und kamen in neue Hände. In verwickelten Erbgängen übertrugen sich die Güter durch Generationen. Im 19. Jahrhundert nimmt die Bevölkerungszahl eher wieder zu. Doch aus dem 18. Jahrhundert stehen noch viele Häuser leer da und verfallen. Das zugehörige Land haben die anstoßenden Bauern schon lange übernommen. Die Lebensansprüche wurden größer. Es genügte nicht mehr, 2 Kühe, ein paar Ziegen und Schafe zu besitzen. Die Kleinbetriebe, für heutige Verhältnisse $Z$ wergbetriebe, wichen größern Heimwesen. Häuser und Ställe wurden frei, sie verfielen und wurden abgebrochen. Für 1562 schätzte ich mindestens 450 Betriebe. 1805 gibt VALÄR 419 Haushaltungen an, 1850 die Statistik 361,

$\begin{array}{rccc} & \text { Betriebe } & \text { Viehbesitzer Hauptberuf: Viehbesitzer Nebenberuf : } \\ 1850 & 311 & & \\ 1893 & 212 & 160 & \\ 1906 & 197 & 157 & 35 \\ 1911 & 195 & 199 & 56 \\ 1926 & 213 & 184 & 5 \\ 1929 & 201 & 14 & 14 \\ 1949 & 198 & & \end{array}$

${ }^{127} \mathrm{Da}$ kein verschiedenes abgegrenztes Weideareal, sondern nur verschiedene Weiderechte auf der gleichen Fläche bestehen, wurde so etwas möglich. Die Füaßlar hätten nur Anrechte auf die Galtviehweiden. Die Alpapura durften im Frühling natürlich ihre ganze Habe dort auslassen.

128 BUHLER: Bd. I, S. 35.

129 VALÄR: Topographische Beschreibung der Landschaft. S, 25. 
davon 311 Bauernbetriebe. Von diesem Jahr an kann nicht mehr die Zahl der Haushaltungen verglichen werden, da diese mit dem Anwachsen des Kurortes steigt. Die Zahl der Bauernbetriebe gibt uns jedoch weiterhin ein vergleichbares Bild.

Was diese statistischen Zahlen ausdrücken, das zeigt sich in der Landschaft als Wüstungen. In Davos sind sic nur selten deutlich an den offenen Fundamenten, den Mauerresten zu erkennen, wie etwa in Tessinertälern. Hier wurden die Häuser abgebrochen, die Steine weiter benutzt, die Keller zugedeckt und das Land eingeebnet. Nur die Bauern, die jeden Flecken ihres Bodens kennen, ahnen noch die alten Fundamente, wenn sie im Sommer mit ihrer Sense in jeder Wölbung und Vertiefung des Bodens ihr Gras mähen. Im Heimatmuseum fand ich aus dem Jahre 1939 für das Dischmatal und für Glaris zwei vollständige Verzeichnisse der Wüstungen. Ich möchte sie hier wiedergeben. Sie belegen nicht nur die obigen Zahlen. Es sollen auch die vielen Flurnamen festgehalten werden, die heute langsam verloren gehen, wenn auch nur ein Ortskenner deren Lage genau bestimmen kann.

Dischma: Früher selbständige Heimwesen : (jetzt abgetragen) Wildi, Bünda, Halda, Gufer (auch Mühle), Gsangji, Büölje, ln den Stücken, Büdmje, Gäuggeli, Innert dem Hof, Chriegmatte (Schmiede), Mühlibode (Mühle), Guldrigenhus. (Heute sind es 11 Heimwesen, und sechs Bauernhäuser dienen einem andern Zweck.)

Glaris : (Zusammengestellt von N. CONRAD-IssL.ER) Verzeichnis der seit Menschengedenken in der Fraktion Glaris abgerissenen Häuser, Mühlen und Speiclıer.

Speicher: linke Talseite: Am Alpeli 2, auf Wyßigen Boden 3, Mur-Spina 2, Bitschen 1, Nadisch 2, Jomesch 1, Singers Egga 1, Unter den Zäunen 2, Höfje 1.

Rechte Talseite: Chumma 2, Hitzeboden und Rüti 4, Gadmenstättli 1, Laubenschluocht 1, Bord 1, Ortolfi 1, Schuolers Rüti I, Zäune und Außer Ardüs 3. Total 29 Speicher.

Mühlen: linke Talseite: Leidbach 4, Spina 1.

Rechte Talseite: Chummabach 3, Bärentalbach 2. Total 10 Mühlen.

Wohnhäuser: (seit ca. 1860) linke Talseite: Alpelti (Monsteiner Gebiet) 2, Fluck 1, Happis Egga 1, Wyßigen Boden 3, Oberhalb an den Eggen 2, In den Brüchen 1, In den Chänzen 1, Singers Egga 2, Spinböden 1, Nadisch 1, Mistjeloch 1, Zünen 1, Stutz 1.

Rechte Talseite : Oberchumma 2, Schnewelins Rüti 1, Hitzeboden 1, Gadmenstättli 1, Laubenschluocht 1, Bord 1, Ägerta 1, Stücken 1, Schuolers Rüti 1, Schluocht 1. Total 28 Wohnhäuser,

Ein Vergleich der Karte von 1853 mit der Heutigen zeigt für Spina eine Abnahme der Gebäudezahl um die Hälfte ... für den Oberschnitt ergeben die Ausführungen von STIFfLER ${ }^{130}$ ein ähnliches Bild.

\section{Wald und Weide (Die Ablösung von Servituten).}

Die Weide im Waldgebiet, die ursprüngliche Allmend, bildet einen wichtigen Bestandteil der gesamten Sömmerungs-Weidefläche. Mit der Entwicklung der modernen Waldpflege, Forstordnung und Gesetzgebung entstanden zwei entgegengesetzte Lager. Auf der einen Seite steht der Förster, der die Verantwortung für einen gesunden Wald mit genügendem Nachwuchs besitzt, auf der andern der Bauer, dem man verbieten will, einen 'Teil seiner Weide, die er scit Jahrhunderten genutzt hat, zu brauchen. In Davos setzt ein Kampf gegen die Waldordnung ein, der ein halbes Jahrhundert dauert. Die Obrigkeit der Gemeinde Davos hatte einen schweren Stand. Sie sah den großen Wert einer Waldordnung, konnte aber nichts unternehmen, da die Wälder alle im Privatbesitz lagen, Waldeigentum und Weiderechte ineinander liefen. Dabei war der Davoserwald überaltert, der Nachwuchs fehlte, und der Holzhandel nahm schreckliche Ausmaße an. 1853, 1856 und 1857 lehnten die Bürger gut ausgearbeitete Forstordnungen ab, bis die Kantonsregierung am 1. November 1857 eine provisorische Ordnung einsetzte und das Kreisamt mit deren Handhabung verpflichtete. Über verschiedene genau bezeichnete Waldungen wurde der Weidbann verhängt. 1858 verbot man in allen Waldungen vom 1 . Oktober bis 1. Juni den Weidgang. Die Davoser fanden diesen Entscheid untragbar. Drei Jahre wogte nun ein erbitterter Streit. Es wurde versucht, durch eine Kommission eine den Verhältnissen angepaßte Ordnung $z u$ schaffen. Das kantonale

130 SiIfFl.ER: Davos vor 60 Jahren und mehr. DZ 1927, Nr. 62-67. 
Forstinspektorat hielt an seinen Forderungen fest. Am 14. April $1861 \mathrm{nahm}$ die Landsgemeinde endlich eine Forstordnung an, die Spannung und Gereiztheit blieb jedoch bestehen. Ein Prozeß mit dem Holzhändler Obrecht wurde von Gericht zu Gericht geschleppt bis zur eidgenössischen Appellationsinstanz, welche die Beschwerde aus formellen Gründen zurückıvies, ohne auf das Materielle einzugehen. Darauf erklärten die Davoser Bauern 1869 in einer stürmischen Versammlung die Verordnung von 1861 als aufgehoben, die Forstkommission aufgelöst und den Förster als entlassen. Das Ringen begann von neuem mit Drohungen auf beiden Seiten, bis am 10. Dezember 1873 das 2. Waldgesetz angenommen und auch der Preisgang aufgehoben wurde. Die Beibehaltung des Preisganges war der Hauptgrund für die Ablehnung des Gesetzes gewesen. Schon 1861 wurde der Schmalviehartikel nicht in der kantonalen Form, sondern abgeändert, in die Davoser Waldordnung aufgenommen. «Das Schmalvieh darf vom 15. Dezember bis zum 1. Mai eines jeden Jahres nicht in den Wald gelassen werden. Findet die Kommission infolge Witterungsverhältnissen für ratsam, dieses Verbot im Herbst schon vom 1. Dezember an in Kraft zu setzen, so ist sie ermächtigt (Kanton: 1. Oktober-1. Juni).

Der Preisgang in Davos bestand nur für das Schmalvieh oder Nösser (Schafe und Ziegen). Von Anfang Mai bis zum Gallustag unterstanden die Nösser der Hirtschaft, die für 6 Monate, 1. Mai-1. November, gedingt war. Die Schafe und Ziegen weideten in dem ihnen zugewiesenen Gebiet, zuerst in den ungünstigern Lagen der tiefern Zonen (Töbel, steile Wälder), im Sommer auf den höchsten steilsten und abgelegensten Alpweiden. Vom 1. November-1. Mai herrschte Preisgang, d. h. jeder Bauer durfte seine Tiere frei laufen lassen, ohne daß sie von fremdem Eigentum verscheucht werden durften. Sie trieben sich auf den Wiesen herum, streiften in den nahen Wäldern und bissen $a b$, was noch zu finden war, vor allem auch die jungen Sprosse der Bäume. Wenn dann der Schneefall einsetzte, kamen sie in den Stall. Auf diese Weise versuchte man die Zeit der Stallfütterung möglichst abzukürzen, um das Heu für die Kühe zu sparen. Der Preisgang ermöglichte so die Überwinterung eines großen Schmalviehbestandes. In Davos hatte es zwar schon lange einsichtige Männer gegeben. 1777, lange vor einer staatlichen Ordnung, kannte man in Davos ein Geißengesetz. Kein Bauer durfte mehr Ziegen halten, als er Großvieh überwinterte, und wenn einer schon mehr als sechs Kühe besaß, so durfte er doch nur 6 Ziegen haben. Wie weit dieses Gesetz gehandhabt wurde, ist nicht ersichtlich.

„Aus den Geißen ziehen wir wenig Nutzen, sie verderben Wiesen und Wälder, Äcker und Heumäder. Die Winterung kostet oft mehr als der Sommernutzen, und doch will man die Abschaffung nicht für gut ansehen. Nur arme Leute, die fast keine eigenen Güter haben, genießen einen Nutzen von diesen Tieren, indem sie sich auf den Gütern ihrer übrigen Mitbürger und zu deren großen Schädigung ernähren.“ So schreibt $1806 \mathrm{~V}_{\mathrm{ALÄR}}{ }^{131}$.

Mit dem Verbot des Preisganges geht die Schmalviehhaltung bedeutend zurück (1870: 1591 Schafe, 1808 Ziegen. 1896: 109 Schafe, 413 Ziegen). Bis in die heutige Zeit gab man als dürftigen Ersatz, im Herbst die Ziegen ins tiefer liegende Belfort (Schmitten, Alvaneu, Filisur). Die Behandlung ist dort jedoch meist so schlecht, daß die Tiere im Frühling abgemagert und verstruppt zurückkehren. Nur ganz wenige Ziegen werden heute noch über Winter weggegeben.

Auch nach der Annahme der Forstordnung war die Durchführung bei den besondern Davoser Verhältnissen schwierig. Sogar der Bundesrat drohte, er werde energische Maßnahmen ergreifen, um eine bessere Waldwirtschaft in der Landschaft Davos durchzuführen, nachdem den Vorschriften des Bundesgesetzes vom 24. März 1876 nicht nachgekommen wurde 132. Die Forderungen: 1. Rückkauf der Wälder durch dic Gemeinde. 2. Vermessung und Erstellung von Wirtschaftsplänen. 3. Anstellung von wissenschaftlich gebildeten Forstbeamten. 4. Anlage

131 NS 1806, S. $35,36$.

182 DZ 1887, Nr. 49. 
von Pflanzungen. 5. Bau von Waldwegen. 6. Aufhebung des Weidganges im Wald, schienen undurchführbar. Und auch heute, 80 Jahre später, arbeiten die Forstorgane noch an deren Verwirklichung. 1890 erhebt Davos beim kleinen Rat des Kantons Einspruch gegen die Erstellung von Wirtschaftsplänen, diese seien finanziell für die Gemeinde untragbar (Davos besaß über 1000 größere und kleinere Parzellen). Die Ablösung von Servituten schritt nur langsam fort. 1899 waren 32 Madrechte geregelt, 41 bestanden jedoch noch, und von 6 Streuerechten waren noch 4 nicht abgelöst. Der Weideablösung wurde hingegen von den Atzungsgenossenschaften keine Folge geleistet.

„Die Waldweide ermöglicht es speziell in Davos, daß die Alpen und Weiden rechtzeitig bezogen werden können, daß während der rauhen Witterung das Vieh eine Zufluchtsstätte findet, und $\mathrm{da} \beta$ im Herbst ebenso die Weide längere Zeit ausgenützt werden kann. Ohne Waldweide wäre manche Alp wertlos, und die Heimkuhweiden würden ganz wegfallen." 133

Auf erneute Drohung des Kantons reichten $12 S$ Bauern eine Petition ein. Der kleine Rat setzte noch einmal die folgenden Forderungen fest, welche von da an die Richtlinien bildeten für die weitere Entwicklung in Davos.

1. Die Kleinviehatzung ist auszuschließen.

2. Die Weideberechtigung ist zeitlich zu normieren und selbstverständlich abzukürzen. Ebenso muß angegeben werden, welche Anzahl Vieh weideberechtigt ist.

3. Dem Waldeigentümer muß das Recht eingeräumt werden, da Aufforstungen vorzunehmen und vor Weidegang zu schützen, wo das kantonale Forstamt solche als notivendig anordnet, und zwar so lange, bis die Kultur dem Zahn des Viehs entronnen ist. Dabei sind selbstverständlich Entschädigungen für temporären Weideentzug nicht ausgeschlossen. Es können aber mancherorts ganz gut, die für den Weidgang fast wertlosen Flächen aufgeforstet, dagegen die für denselben wertvollen Stellen der Weide reserviert bleiben, sodaß von einem Ausfall an Weide nicht gesprochen werden kann. ${ }^{134}$

Dieser sehr entgegenkommende Entscheid palite sich endlich dem Wesen der walserischen Wirtschaft an. Langsam in großer Kleinarbeit der Forstorgane wurde mit 'Zureden und Überzeugen der Bauern immer wieder ein bißchen zur Besserung der Davoser Waldwirtschaft beigetragen. Wildbachschäden oder LawinenKatastrophen, wie sie der Winter 1951 brachte, zeigen eindrücklich, wie wichtig ein gesunder und starker Wald im Gebirge ist. Vielleicht lassen solche Unglücke die Bauern wieder etwas nachdenken und helfen der Weideablösung einen Schritt. vorwärts.

Eine der ersten Weideablösungen war diejenige der Kirchenbannatzung. Im Einflußgebiet des Kurortes gelegen, war hier das Interesse der Weidebesitzer viel kleiner als in einem rein bäuerlichen Gebiet wie etwa dem Unterschnitt. Durch einen Schiedsspruch einer Kommission wurde die Weide 1900 abgelöst. Das verwickelte Verfahren soll hier als Beispiel wiedergegeben werden. Es zeigt was für Überlegungen eine solche Servitutsablösung erfordert.

Das Weidbuch von 1805 gibt für die gesamte Kircherberg-Atzung 100 Kuhweiden an. Nach der Erniedrigung sind es noch 89 effektive Kuhweiden. Die Bestossung geschieht teils durch eigenes, teils durch fremdes Vieh. Das Fremdvieh zahlt Fr. 20.- pro Stoß. ${ }^{135}$

\begin{tabular}{|c|c|c|c|c|}
\hline Unkosten : & b. Salz, Heu & $\begin{array}{l}1 \text { Hirt Lochalp } \\
\text { Schatzalp } \\
1 \text { Heimküher } \\
1 \text { Galtviehhirt } \\
\text { Salz } \\
\text { Heu bei Schneewetter } \\
\text { Total Unkosten }\end{array}$ & 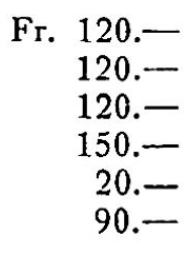 & $\begin{array}{l}\text { Fr. } 510 .- \\
\text { Fr. } 110 .- \\
\text { Fr. } 610 .-\end{array}$ \\
\hline
\end{tabular}

Brutto-Ertrag : 89 mal Fr. 20.- = Fr. 1780.-

Netto-Ertrag Fr. 1160.-.

Damit ist der Jahresertrag einer nominellen Weide (100 KR) Fr. 1160.-, der Nutzungskapitalwert zu $4 \%=$ Fr. 290.- - Der ordentliche Verkehrswert betrug bis dahin Fr. 250.- bis 350.-

${ }^{138}$ DZ 1899, Nr. 27.

${ }^{134}$ DZ 1899, 3. Okt.

135 Das vollständige Verfahren ist in der Davoser Zeitung abgedruckt. DZ 1900, 23. Oktober. 
In letzter Zeit zahlte jedoch die Kurhausgesellschaft Fr. 500.-, um möglichst viele aufkaufen zu können.

Die Weidezeit beträgt durchschnittlich 113 Tage rom 4. Juni bis 26. September. Das sind $113 \times 90=10170$ Weidetage für die gesamte Atzung.

$\begin{array}{lll}\text { Verteilung der Weide: } & \text { Lochalp } & 12 \mathrm{KR} \\ & \text { Schatzalp } & 20 \mathrm{KR} \\ & \text { Heimkühe } & 10 \mathrm{KR} \\ & \text { Galtvieh } & 48 \mathrm{KR}\end{array}$

Anteil der Waldweidezeit :

Galtvieh $\quad 48 \mathrm{KR}$

90 Kubrechte.

Heimkühe halbe Weidezeit im Wald

Frühlingsweide im Wald für das übrige Vieh (ohne Lochalp)

Galtvieh allein bei Schneewetter

Die Schatzbergkühe sind an Ruhetagen und bei Schneewetter im Wald und ebenfalls nach Ottafa ${ }^{136}$

Lochalp. Sie benutzen in der Regel die Waldweide nicht. Frühlingsweide und Schneeflucht $12+5 \mathrm{Tg}$.

Total Waldweide-Tage

$$
\begin{aligned}
& 10 \times 55 \mathrm{Tg} .=550 \mathrm{Tg} . \\
& 68 \times 12 \mathrm{Tg} .=816 \mathrm{Tg} . \\
& 48 \times 5 \mathrm{Tg} .=240 \mathrm{Tg} . \\
& 20 \times 14 \mathrm{Tg} .=280 \mathrm{Tg} . \\
& 12 \times 17 \mathrm{Tg} .=204 \mathrm{Tg} .
\end{aligned}
$$

Aus diesen Angaben folgt die Berechnung der Ablösungssumme. Fine ganze Weidezeit = 113 Weidetage entsprechen 2090 Waldweidetagen. $2090: 113=18^{1}$ i2 effektive Weiden. Diese entsprechen $20 \%$ nomineller Weide, also rund 20 Weiden.

Durch den Bau der Schatzalpstraße fielen früher schon $4 \mathrm{KR}$ weg, die direkt entschädigt wurden, desgleichen $2 \mathrm{KR}$ am linken Abhang des Albertitobels zur Aufforstung. Es bleiben also

\begin{tabular}{|c|c|}
\hline $\begin{array}{l}\text { Ablösungssumme } \\
\text { Kosten des Ablösungsverfahrens }\end{array}$ & Fr. $5800 .-\overline{208.45}$ \\
\hline Kosten für die Bannwaldbesitzer & $\overline{08.45}$ \\
\hline
\end{tabular}
14 Weiden, die entschädigt werden müssen. Nach frühern Berechnungen beträgt der Ertragswert einer Weide Fr. 290. - , da der Verkehrswert jedoch viel höher liegt, so wird eine Mittelsumme von Fr. 400.- angenommen. Die Atzungsgenossenschaft Kilcherberg erhält also von den Besitzern des Waldes $14 \times$ Fr. 400.- = Fr. 5600.- Dazu kommen noch Fr. 200.- für die Entwertung der Alpweide, Entzug des Schneefluchtortes.

Da Weide- und Waldbesitzer meistens die gleichen Bauern sind, so ist es verständlich, daß nach einem ähnlichen Verfahren bis jetzt so wenig Weiden abgelöst wurden. So verzichtet man lieber in den steilsten und ungünstig gelegenen Wäldern auf die Nutzung ${ }^{137}$.

\section{Einzelsennerei.}

Bis in die Mitte des 19. Jahrhunderts verarbeitete jeder Bauer seine Milch selber. Die frische Milch stellte man in den Kellern in Gebsen auf. Innerhalb von 2-3 Tagen entwickelte sich die Rahmschicht. Der größte Teil kam ins Stoßbutterfaß, die restliche Magermilch gab Magerkäse oder diente zur Aufzucht von Jungvieh und zur Mästung von Kälbern und Schweinen. In der Küche hing über dem offenen Feuer das Käskessi. Häufig wurden die Abfälle geziegert. Den Zieger legte man im Kuhstall in eine leere Futterkrippe, um ihn gründlich reifen zu lassen. Er wurde mit Baumrinde zugedeckt und so gepreßt. Nach Monaten kam der Zieger dann in Säcken eingewickelt in den Handel. In den Alpen besaß jeder Bauer seine Alphütte mit dem großen Küchenanteil, in dem das Käskessi hing und die Milchgebsen standen. Seltener bewahrten sie die Gebsen in einem eigenen, getrennten Seitenräumchen auf. Die Sennereiarbeit verrichtete die Frau, die im walserischen Betrieb einen großen Teil der Arbeit leistete.

186 Ottafa $=5$ Uhr abends. Ottafaweide $\ldots$ die Weide, auf der sich das Vieh nach den Melken um 17.00 Uhr befindet. Das Wort kommt von acht, gleichbedeutend mit achter Stunde, also 2 Uhr. Früher wurde sehr früh am Morgen gemolken. Da die Melkzeiten nicht mehr als 12 Stunden auseinander liegen sollten, molk man also am Nachmittag um die gleiche Zeit wieder. Im Laufe der Zeit verschob sich die Stunde auf 5 Uhr. Das Wort Ottafa ist in Davos und im Schanfigg, aber auch im Oberwallis bekannt, hingegen fehlt es im romanischen Gebiet. Es liegt nahe, anzunehmen, der Ausdruck sei von den Walsern im 13. Jh. aus ihrer.alten Heimat, dem Oberwallis, mitgebracht worden. Vergl. auch WEiss: Bündner Alpwesen, S. 343.

${ }_{187}$ Die Nutzungs- und Siedlungskarte meiner Diplomarbeit enthïlt die 1949 noch genutzten Waldiveiden. 
Warum finden wir in Davos das System der Einzelsennerei, das neben den wenigen Vorteilen so viele Nachteile besitzt? Wohl am besten gibt uns VALÄR Auskunft, der als Davoser in diese Probleme hineingewachsen ist ${ }^{138}$. Er zählt Vor- und Nachteile auf:

1. Die vielen Ställe auf den Alpen und die besondern, oft sehr kleinen Sennereien eines jeden Teilhabers erfordern mehr Holz.

2. Das einzelne Sennen erfordert mehr Leute, hingegen gestattet es weniger Betrug, und jeder Teilhaber bekommt nicht mehr oder weniger, als ihm nach der Anzahl und der Güte seiner Kühe gebührt.

3. In Absicht des Galtens seiner Kühe ist er unabhängig. Das ist vorteilhaft bei Schlacht- und Marktvieh. ${ }^{189}$

4. In der Benutzung der Milchprodukte für die Familie ist er unabhängig. Alprechnungen fallen weg. 140

5. Die Unkosten des Messens oder Wägens und die Schmausereien, die sicher in gemeinschaftlichen Sennthümern einzelne sich auf Unkosten aller erlauben, fallen weg.

6. Die eigenen Alphütten gewähren den Sennenden viel mehr Bequemlichkeiten, und da viele Alphäuser beisammen sind, so fehlt es nicht an den Vergnügen des geselligen Lebens.

7. Das Übernachten der Kühe in den Ställen hat den großen Nutzen, daß es den Alpwiesen sehr viel Dünger verschaff. Auch wird das Vieh vor Ungewitter und andern nächtlichen Gefahren besser geschützt. Es kann noch am Abend mit Heu gefüttert werden. Hingegen ist es weniger abgehärtet und gewöhnlich nicht so rein an Haar und Farbe, und deswegen im Herbst nicht so verkäuflich.

8. Das Vieh in den Alpställen ist etwas magerer, weil sich das unter freiem Himmel übernachtende in den kühlen Abend- und Morgenstunden besser füttert, als wenn es die Weide nur in der Tageshitze genießen kann. Es muß darum früh ausgelassen. und abends spät eingetan werden.

$\mathrm{Da}$ die Alpen meist nahe sind, so kann das Sennereigeschäft von dem weiblichen Teil der Familie besorgt werden, und die Hausmütter mit den Kleinen ziehen auf die Alp (die anderswo keine Sommerarbeiten versäumen). Wer es aber nicht vorteilhaft findet, eine eigene Sennerei zu halten, kann sein Vieh um einen billigen Preis, allenfalls an Milchprodukten, vermieten.

Die einzige gemeinschaftliche Sennerei in der ganzen Landschaft wird auf dem stillen Berg betrieben. Man findet aber nicht, daß die Anteilhaber mehr Nutzen beziehen als die Übrigen. ${ }^{111}$

Vom Standpunkt einer rationalisierten Alpwirtschaft aus wird die Einzelsennerei bekämpft. Mit ihren altmodischen, privaten Einrichtungen verhindert sie die Herstellung von absatzfähigen Milchprodukten. Die hygienischen Verhältnisse sind schlecht. Die Arbeitskräfte werden verschwendet. Für die Einzelsennerei in Davos bestehen zwei Hauptgründe, die sich gegenseitig unterstützen.

1. Die Erklärung aus der Eigenart des walserischen Charakters, der Walserkultur.

2. Die Erklärung aus den besondern topographischen Verhältnissen.

Der Walser besitzt einen ausgesprochenen Individualismus, einen Hang zur Selbständigkeit. Das zeigt sich schon bei der Kolonisation, er besiedelt die abgelegensten und höchsten Gebiete von Graubünden. Seinen Hof baut er gesondert inmitten durch seine Hand gerodetem und urbarisiertem Lande. Die Alpweide wird schon früh vom Einzelnen beansprucht, die Allmend, den Wald teilt er auf. Durch alle Jahrhunderte wird die Gemeinde Daros von Gruppen einzelner freier Bauern getragen, von Nachbarschaften. Wie schwierig war es, eine vom Bund und Kanton diktierte Forstordnung durchzusetzen, eine Alpordnung einzuführen! Man stützte sich auf die alten, im Landbuch festgelegten Gesetze und übernahm sie teilweise in neuer, angepaßter Form in die heutige Gemeindeordnung. Ist es nicht verständlich, da 3 die Rechtsverhältnisse einer Privatkorporation seinem Wesen, seinem. Denken entsprechen, daß auch das Einzelsennereisystem seinem Individualismus Raum bietet? Der große Kinderreichtum des Walsers, die gute Gesundheit, die ihn ein

$138 V_{A L A ̈ R}$ : NS 1806, S. 26 f.

${ }^{130}$ Er kann die Laktationsperiode so richten, daß sie \%. B. in den Spätherbst fällt, wenn er die Kuh verkaufen will, und besitzt somit bis zu dieser Zeit noch die Milch.

${ }_{140}$ Gerade der große Verschleiß an Rahm und Milch für den persönlichen Bedarf wird der Einzelsennerei von den andern vorgeworfen.

${ }_{111}$ Auf dem Stillberg standen wie in andern Davoser Alpen mehrere Alphütten, ein Zeichen für Einzelsennerei. Die gemeinschaftliche Sennerei bestand zu VALÄRS Zeit und ging vielleicht später noch einmal ein, auf jeden Fall ist sonst nirgends von ihr die Rede. 
hohes Alter erreichen ließen, schafften eine Reserve an Arbeitskräften. Die kleinen Heimwesen für heutige Verhältnisse ließen einen Arbeiterüberschuß entstehen. Zwei, drei erwachsene Söhne blieben auf dem Hof, die Alten gingen als Hirten auf die Alp, die ledige Tochter führte die Sennerei. Die Einzelsennerei wird nun noch unterstützt durch die topographischen Verhältnisse in Davos, die kurze Distanz vom Talgut zur Alp.

Das Einzelsennereisystem ist nur in seiner Zeit und seinen besondern Verhältnissen verständlich. Es wird auch Mitte des 19. Jahrhunderts von der Genossenschaftssennerei abgelöst noch vor der Entwicklung des Kurortes. Die Entstehung des Kurortes Davos unterstützte natürlich ganz besonders den Genossenschaftsgedanken und führte auch 1905 zur Gründung einer zentralen Molkereigenossenschaft, die die Milch nach modernsten und rationellsten Verfahren verwertet. Einzig die. Form der Privatkorporation konnte sich bis auf den heutigen Tag erhalten; dafür sind vielleicht gerade die günstigen topographischen Verhältnisse verantwortlich ${ }^{1+2}$.

\section{Die Entstehung des Kurortes.}

Die ersten Anfänge des Kurortes gehen auf den Landschaftsarzt Luzius Rüedi zurück, der 1841 eine primitive Anstalt für skrofulöse Kinder errichtete. Der eigentliche Begründer und unermüdliche Förderer war jedoch Dr. Alexander Spengler, der im Herbst 1853 als Landschaítsarzt gewählt wurde. Sein erster Erfolg war die Heilung eines schwindsüchtigen, dänischen Pfarrers, Seelsorgers in Glaris und Frauenkirch. Mit dem Bau der Prättigauerstraße 1850-1852 bis Klosters und dem Teilstück nach Davos 1860 nahm der Verkehr nach Davos zu. Mit diesem Jahr begann auch die Entwicklung des Kurortes Davos. 1861 wurde neben der alten, einzigen Gaststätte, dem Rathaus, der Gasthof Strela, auch Hotel oder Kurhaus Strela genannt, gebaut. Die Freundschaft Dr. Spenglers mit dem berühmten Balneologen Dr. Mever-Ahrens förderte den Ruf des Davoserklimas und dessen Heilerfolge bei Tuberkulose. 1865 erschienen die ersten Wintergäste zum Erstaunen der Einheimischen, die glaubten, der strengc Winter sei der Gesundheit nicht zuträglich. Wie ungeheuer schnell sich der Kurort in der folgenden Zeit entwickelte, zeigen die Bevölkerungszahlen ${ }^{143}$. 1868 entstand die erste Kuranstalt Spengler-Holsbœr, welche 1872 abbrannte, doch schon ein Jahr später wieder neu aufgebaut und vergrößert dem Betrieb übergeben wurde. Seit 1875 überwogen die Wintergäste, im August waren es 260, im Dezember 350 Kurgäste (vorwiegend Dcutsche, Schweizer und Engländer). Zwei große Entwicklungsperioden sind aus der Statistik herauszulesen, eine erste von 1870-1S80 mit 43,1\% und eine zweite von 1888 bis 1900 mit 111,9\% Zunahme der Bevölkerung. Den zweiten enormen Aufschwung brachte der Bau der Eisenbahn (Landquart - Klosters 1889, Klosters - Davos 1890, Davos - Filisur 1909). Innerhalb von 40 Jahren entstand an der Stelle der paar Dutzend Fläuser von Dörfli und Platz ein Kurort mit über 6000 Einwohnern. Im 20. Jahrhundert nahm die Einwohnerzahl nicht mehr stark zu. Neben den Kranken kamen immer mehr Wintersportgäste und in viel kleinerem Maße auch Sommergäste nach Davos. Daraus resultierte eine gewisse Umstellung als Fremiden- und Sportort, der Davos eine neue Note gibt (Bau einer Eisbahn, Parsennbahn, Skiliftc, Sprungschanze usw.). Davos wird immer stärker auch abhängig von Konjunktur und Krisenperioden in der intcrnationalen Wirtschaft, was sich deutlich in der Kurve der Logiernächte zeigt ${ }^{144}$. In der Davoser Wirtschaftslage entsteht ein Ausgleich. Die Sanatorien bilden gewissermaßen einen Grundstock, auf den sich saisongebunden im Winter und Sommer der Fremden- und Sportbetrieb aufbaut.

$1+2$ Vergleiche auch Weiss: BM 1941, Nr. 1.

$1+3$ Vergleiche die Tabelle im Kapitel Bevölkerung.

itt Vergleiche Fig. 2. 


\section{Die Genossenschafts-Sennerei.}

Mitte des letzten Jahrhunderts erwachte auch in Davos der Genossenschaftsgedanke in der Milchverwertung. Als erster schloß ein Zürcher (Hauser) mit den Nachbarn von Spina einen 4-jährigen Vertrag, indem er die Milch zum Buttern und Käsen für 4 Blutzger pro Maß kaufte $\left(1 \mathrm{Ma}=1 \frac{1}{2}\right.$ Liter, 4 Blutzger $=$ 9,2 Rp.). Es folgten andere Zürcher Käufer (Gebrüder Jakob und Rudolf Greuter, Müller) die an verschiedenen Orten der Landschaft die Milch aufkauften. Im Laufe der Zeit entwickelten sich in Davos drei Formen der gemeinschaftlichen Sennerei ${ }^{145}$.

1. Genossenschaitssennerei: Für die Milch wird kein bestimmter Preis festgelegt, sondern der Wert nach dem Verkauf der Produkte und nach den Gesamtkosten berechnet. Der Senn wird von der Genossenschaft für einen festen Lohn angestellt.

2. Sennereien, die von Übernehmern geführt werden. Die Bauern übergeben Lokal und Geräte einem Sennen. Dieser kauft die Milch. Die Bauern tragen so keine Verantwortung.

3. Die Bauernsennerei: Eine Anzahl Bauern richten ein Sennerei ein und stellen einen Senn an, dem sie Kost und Lohn geben. Die Beteiligten rehmen die ihnen zukommenden Produkte nach Hause ${ }^{146}$.

Die Sennereien wurden auf den Alpen wie im Tale meistens in einem leer stehenden Hause eingerichtet oder sogar nur bei einem Nachbarn, der genug Platz besaß. Sie waren daher äußerst primitiv eingerichtet.

Talsennereien: (Winter).

Monstein : 1902 ein neues, modernes Gebäude im Dorf.

Glaris: Unterhalb der Kirche auf der rechten Seite des Landwassers.

Langmatte: Dellenhaus.

Frauenkirch: In einer frühern Schmiede, heute Bäckerei und Handlung.

Davos-Dorf: Die erste Wintersennerei der Landschaft in der Sonne, von G. Jegen aus Seewies (Prättigau) geführt. Sie ging aber schon 1884 an Milchmangel wieder ein.

Auf vielen Alpen baute man später neue Steinhäuser mit Kühlräumen und Zementtrögen und führte das Abkühlungsverfahren in der Milchverarbeitung ein ${ }^{14 \bar{\tau}}$.

Gemauerte Alpsennhütten: 1881 Stafelalp, 1882 Chumma-Alp, gemeinsam Rieber-/Riederalp, 1886 Bärentalalp, 1895 Sertig, vorerst an der Stelle des heutigen Kurhauses, später eine zweite in den Kleinalpen (heute ein Ferienhaus).

Mit dem Übergang zur gemeinschaftlichen Sennerei und den guten Absatzmöglichkeiten in dem ständig wachsenden Kurort stiegen die Milchpreise. Zwei verschiedene Milchpreise liefen parallel neben einander, einmal der Sennereipreis, der seit 1860 durchschnittlich $11,5 \mathrm{Rp}$. betrug und auch später wenig anstieg, dann der Konsummilchpreis:
1838: $9,4 \mathrm{Rp}$.
1848: $11,3 \mathrm{Rp}$.
1858: 12,0 Rp.
1868: $18 \mathrm{Rp}$.
1878: $20 \mathrm{Rp}$.
1905: $22 \mathrm{Rp}$.
1907: $25 \mathrm{Rp}$.
1910: 27 Rp.

148

Die Oberschnitter Bauern verkauften immer mehr Milch an den Kurort. Sie besaßen alle ihre festen Kunden, die sie das ganze Jahr belieferten. Es kam die Zeit, da ihre Milch nicht mehr reichte. Wie früher die Zürcher, waren es jetzt einzelne Bauern aus dem Platz, die zur Befriedigung ihre Kunden mit den Sennereien auf

$1 \pm j$ Vergleiche SchatzMnNN: BM 1871, S. j.

146 Die Reihenfolge bestimmt ungefähr die Häufigkeit ihres Vorkommens.

$1+7$ Schatzmannsche Theorie der Wasserkühlung.

148 Himmei.: Die Milchversorgung des Kurortes Davos. S. 20. 
der Langmatte, in Glaris, in Spina und in Monstein Handelsverträge abschlossen (Prader, Branger, Ardüser, Buol usw.). Immer mehr drängte sich für die Versorgung des Kurortes mit Milch ein gemeinsames Projekt auf 1895 versandten Himmel, Chr. Meißer-Michel und Salomon Michel-Baldini einen Fragebogen für eine projektierte Milchversorgung und Kontrolle an die Bauern. Noch war es zu früh; eine Entrüstung brach unter der Bauernschaft aus ${ }^{149}$.

«Man befürchtete durch Zwischenhandel eine Verteuerung der Milch und nachher keinen Absatz mehr. Von unbekannter Stelle werde weniger Milch gekauft als vom vertrauenswürdigen Bauern. Die Existenzbedingungen für eine Molkerei seien nur an Orten mit Milchüberfluß vorhanden. Der Arbeitsaufwand und Milchverschleiß lohne sich nicht ». Eine Bauernversammlung im Dorf unterstützte die Vorschläge von Himmel. Sie wollte eine Viehversicherung einführen ${ }^{150}$, gemeinsam Futtermittel beziehen, die Viehzucht heben. Gegenüber einem Milchhandel war sie jedoch skeptisch. Sie glaubte nicht an eine Besserung, sondern an eine Entwertung der Milch durch Verunreinigung und Entrahmung beim längern Weg, den die Milch über eine Zentrale machen mußte. Die Glariser Bauern waren sachlich eingestellt, sie sahen Vor- und Nachteile und wollten abwarten. So entstand vorerst nur ein kleines privates Unternehmen unter der Leitung von Himmel. Doch mit jedem Jahr wurden weitere Kreise in die direkte Milchversorgung von Davos einbezogen (Glaris 1898). 1899 verlangten die Bauern plötzlich einen übersetzten Milchpreis von 25 Rappen. Die Konsumenten wehrten sich, ein Alpbesitzer von Gotschna (Klosters) offerierte sofort Milch für 18 Rappen und hoffte, ein gutes Geschäft zu machen 151. Es mußte eine Lösung gefunden werden. Im gleichen Jahr drang auf der Landsgemeinde ein Gesetz durch, das eine amtliche Milchkontrolle einführte. Dazu wurde ein Milchchemiker angestellt, Craandyk, der früher das bekannte Laboratorium der Molkerei Dr. Gerber in Zürich führte. Damit war der erste Schritt getan. Drei Jahre später beschloß die Bauernschaft die Gründung einer zentralen Molkerei in Davos-Platz.

\section{MILCHWIRTSCHAFT ZUR VERSORGUNG DES KURORTES}

\section{Allgemeine Davoser Kontroll- und Zentralmolkerei ${ }^{152}$.}

Am 15. September 1905 eröffnete die Molkereizentrale der Landschaft ihren Betrieb, deren Leitung der Inhaber der schon seit 1895 bestehenden Molkerei, C. Himmel, übernahm. Die Aktiengesellschaft begann mit 199 Aktien und ca. 135 Lieferanten, doch schon 1910 waren es 170 Milchlieferanten und 215 Aktien (1923: 182 Lieferanten, 1930: 193 Lieferanten). 1916 Beitritt zum Nord-Ostschweizerischen Käse- und Milchverband. 1947 Umwandlung der Aktiengesellschaft in eine Genossenschaft. 1950 besitzt diese 199 Milchlieferanten: DavosPlatz und Brüche 36, Dorf und Dischma 41, Glaris, Spina und Hitzeboden 38, Frauenkirch, Clavadel und Sertig 60, Monstein, Schmelzboden 12, Laret, Wolfgang 12. Bis auf zwei oder drei Bauern sind heute alle der Milchgenossenschaft angeschlossen ${ }^{153}$.

${ }^{149} \mathrm{DZ} 1895$, 6. Februar.

150 Monstein führte 19110 als erste Fraktion der Landschaft eine freiwillige Viehversicherung ein, der sofort alle Bauern beitraten. Jeder Bauer war berechtigt, alle seine Kühe, welche er überwinterte, zu versichern. Die Prämien waren so angesetzt, daß der Bauer $1 / 2 \%$ der Schatzungssumme zahlte, dazu gab die Fraktionskasse noch einen Beitrag von einem halben Prozent. Die Versicherung zahlte an tierärztliche Kosten $50 \%$ und an Unfall $70 \%$ der Kosten.

${ }_{1 \overline{1}} 1 \mathrm{DZ} 1899,25$. Juli.

152 Dieses Kapitel soll nur einen zusammenfassenden Überblick geben. Diese Fragen sind ausführlich in der Dissertation von CHR. Jost enthalten, die er mir freundlicherweise als Manuskript zur Einsicht überließ.

${ }_{153}$ Diese Zahl schließt auch einige Sommerlieferanten ein. Fremde Bauern, die in Davos Alpen besitzen. Davoser Lieferanten $=193$. 
„Die Gesellschaft will eine rationelle Verwertung der von den Mitgliedern produzierten Kuhmilch, Handel mit Milch- und Milchprodukten, die Versorgung des Kurortes Davos mit hygienisch einwandfreier Milch. - Die Mitglieder haben sämtliche produzierte Milch, ausgenommen die für den eigenen Konsum nötige, an die Molkerei abzuliefern und die. Anordnungen der inspirierenden Beamten, Inspektoren und Tierarzt zu respektieren. - Die Milch muß von gesunden, reinlich gehaltenen und in ausreichendem Maße mit unverdorbenem Futter genährten Kühen stammen. Sie soll in Bezug auf Farbe, Geruch, Geschmack und sonstiges Verhalten alle diejenigen Eigenschaften haben, welche durch die geïbten Sinne eines erfahrenen Fachmannes als die richtigen bezeichnet werden müssen. ${ }^{154}$

Die frühern Mißstände ließen das neue Unternehmen äußerst rasch entwickeln. Anfänglich war zwar der Hausverbrauch noch sehr groß, bei vielen Bauern über die Hälfte der produzierten Milch.

1909: A besaß im Winter 5, im Sommer 7 Kühe. Er lieferte im $_{2}$ Winter 715 Liter in die Molkerei. Ungefähr 1800 Liter verbrauchte er im Haus, ca. 1200 Liter für die Aufzucht von Kälbern.

Für die ganze Landschaft war der Selbstverbraucheranteil 20,1\%.

$\begin{array}{ll}\text { Milchliefermenge in die Molkerei } & 18901851 \\ \text { Von } 159 \text { Bauern wurde im Haushalt verbraucht ca. } & 2447501 \\ \text { für Kälber } & \text { ca. } 232600 \text { l }\end{array}$

Die Alpsennereien blieben vorerst noch bestehen, die Milcheinlieferungen begannen mit dem 1. August. Jedoch schon 1909 brachten diejenigen Alpkorporationen mit guten Fahrwegen auch im Sommer die Milch in die Zentralmolkerei. Die Alpsennhütten dienten nur noch als Sammelstelle und Kühlraum. Einzig der Kriegsausbruch 1914 brachte vorübergehend noch einmal die alten Zustände. Die Bärental-, Kumma-, Stafel- und Hauptalp butterten noch einmal einen Sommer selber.

Die Entwicklung des Molkereibetriebes ist aus dem Diagramm ersichtlich. Die Gesamteinlieferung erreicht 1912 einen Höhepunkt, um dann im ersten Weltkrieg stark abzufallen, aber bis 1918 sich rasch wieder zu erholen. Die Nachkriegsjahre sind Krisenjahre, aber dann beginnt ein ungeheurer Anstieg, der in den dreißiger Jahren zur Milchschwemme führt. Davos kontingentiert die Milch. Jeder Bauer darf nur noch für so viel Kühe Milch abliefern, als er auch überwintert. Die nachfolgenden Jahre bringen einen andauernden, langsamen Abfall bis zum Kriegsende 1945. Von da an folgt wieder ein Anstieg in der Milcheinlieferung. Die Kurve der Logiernächte $\mathbf{1 5 5}$ und des Konsummilchverbrauchs laufen ungefähr parallel, ein Zeichen, wie mit dem Steigen und Fallen der Fremdenindustrie auch der Ertrag der Molkereigenossenschaft $\mathrm{zu}$, und abnimmt. Der direkte Milchverkauf ist die beste Milchverwertung, je größer die Verarbeitungsquote an Milch, desto schlechter ist die Rendite. So kann uns auch eine Relation Konsummilch zu Gesamteinlieferung Aufschluß über die wirtschaftliche Lage der Davoser Bauernschaft geben.

$\begin{array}{ccccc}\text { Konsummil:h in Prozenten der Gesamtlieferung. } & & \\ 1920: 93 & 1926: 80 & 1932: 60 & 1938: 66 & 1944: 86 \\ 1922: 69 & 1928: 74 & 1934: 63 & 1940: 58 & 1946: 90 \\ 1924: 85 & 1930: 70 & 1936: 61 & 1942: 80 & 1948: 87\end{array}$

Die Fabrikation richtet sich nach dem Bedarf und der Gesamteinlieferung; sind sie ausgeglichen, so bleibt auch nicht viel für die Verarbeitung übrig. Bedingt durch ausgesprochene Spitzenzeiten im jährlichen Milchverbrauch, Januar, Februar, März und August ist es beinah unmöglich, ohne Reguliermilch auszukommen. Dazu kommt noch, daß gerade der August mit dem Beginn der Laktationsperiode zusammenfällt. Der September zeigt jedes Jahr die kleinste Milcheinlieferung. Um die Milchproduktion im Sommer zu fördern und einen Ausgleich zu schaffen, wird für die Milch vom 15. Juli bis 15 . November 4 Rappen mehr pro Liter bezahlt.

1ijt Aus den Statuten der Davoser Kontroll- und Zentralmolkerei Davos AG.

${ }^{105} \mathrm{Da}$ in beiden Weltkriegen viele Internierte in Davos untergebracht waren, nimmt die Zahl der Logiernächte in dieser Zeit kaum ab. 


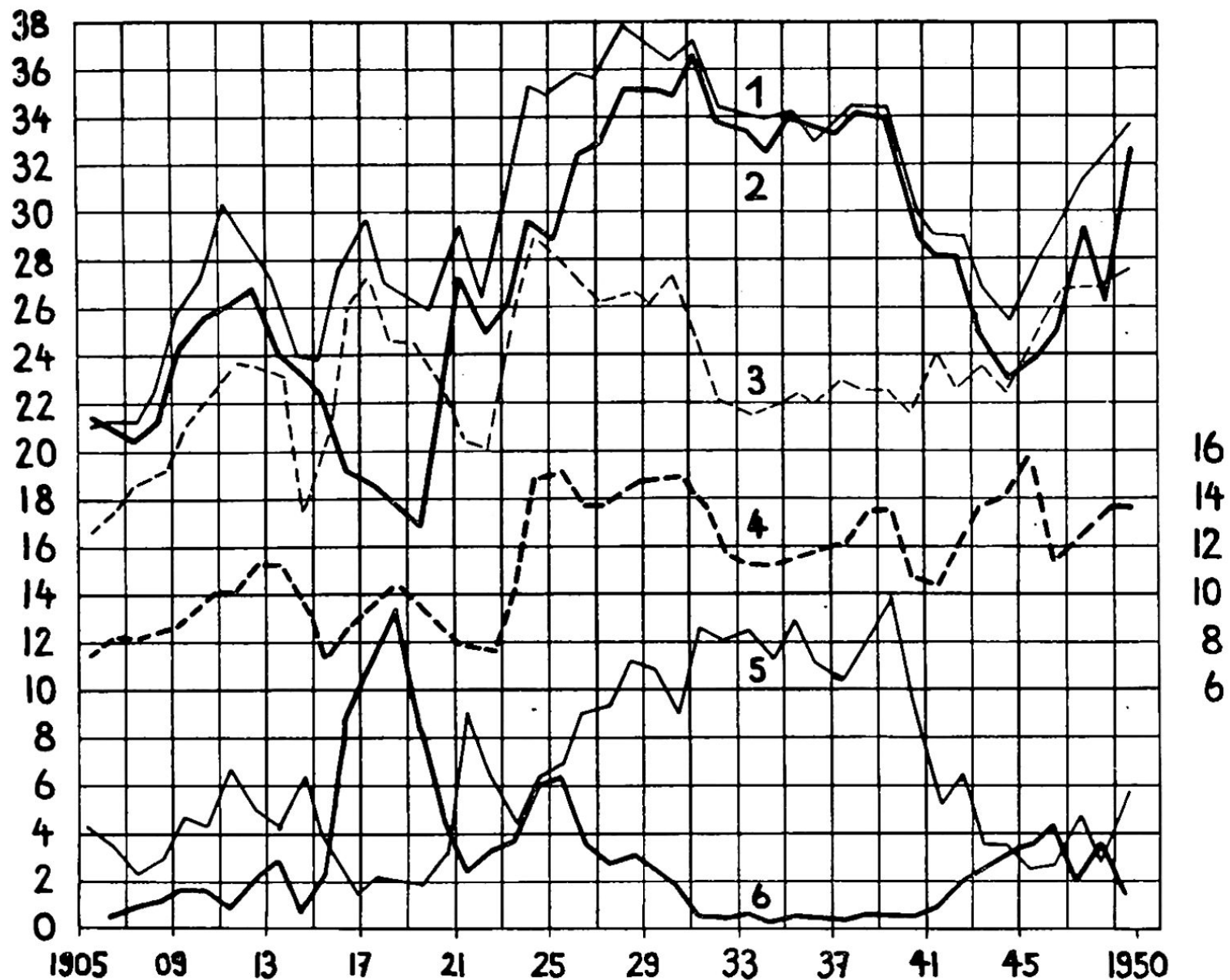

Fig. 2 Die Milchwirtschaft der Molkereigenossenschaft Davos in 100000 . 1 Gesamte Milcheinlieferung (Liter), 2 Einlieferung der Mitglieder (Liter), 3 Konsummilchverkauf (Liter), 4 Logiernächte des Kurortes (Scala rechts), 5 Reguliermilch (Liter), 6 Fabrikationsmilch (Liter),

Der Bauer kann es nun einrichten, daß ein Teil seiner Kühe erst sehr spät kalbert, cin anderer Teil sehr früh. Die Reguliermilch kam 1918 von Cham, 1920 von Wädenswil, dann ab Station Schmerikon und heute von Rüti (Zürich). Umgekehrt konnte Davos auch immer wieder aushelfen. 1911 bestand ein Kurmilchdepot in St. Moritz. Während dem 1. Weltkrieg lieferte es im Sommer 2-300 Liter täglich nach Schuls, 1931 und 1932 sogar nach Chur und Zürich.

Der Molkereizentrale in Davos-Platz ist ein Laboratorium angegliedert. Dort wurden 1948/49 24201 Proben gemacht, über Wässerung, Entrahmung, Fettgehalt, Säuregehalt, Reduktionszeit, verschiedene Milchqualitäten, Sauberkeit usw., im gesamten 13 Eigenschaften. 249 Proben wurden beanstandet. $\mathrm{Zu}$ diesen Proben kommen noch chemisch-physikalische und hygienische Untersuchungen, die täglich durchgeführt werden. Jährlich werden so über 100000 Proben und Untersuchungen gemacht. Durch Stallinspektionen und Beratung wird versucht, die hygienischen Verhältnisse zu heben. Mit Milchprämien wird die Qualität gesteigert. (1948/49 erhielten 20 Bauern einen halben Rappen mehr pro Liter eingelieferter Milch, 47 Bauern 1/4 Rappen mehr, 44 Bauern 1/i0 Rappen mehr und nur 75 Bauern, 39,2\%, gingen leer aus.) Diese große Arbeit zeitigte auch ihre Früchte. Den hygienischen und qualitativen Anforderungen einer Milch für Kranke kann so entsprochen werden. Dabei wird besonders noch eine teurere Kurmilch ausgeschieden, dic nur aus ganz bestimmten Stallungen kommt, welche die höchsten Milchqualitäten erreichen (1949/50: 12294 Liter Kurnilch 0,36\% des gesamten Milchumsatzes). 
Die 'Tiere sind sehr gesund, das zeigt die statistische Übersicht über notgcschlachtete Tiere der Rindvieh-Versicherungsanstalt Davos.

\begin{tabular}{llllllr} 
& 1940 & 1942 & 1944 & 1946 & 1948 & 1949 \\
\hline Total der verlorenen Tiere & 65 & 56 & 48 & 46 & 43 & 36 \\
an Tuberkulose & 17 & 20 & 8 & 7 & 1 & 0 \\
in \% der versicherten Tiere & 1.85 & 1.0 & 0.42 & 0.37 & 0.05 & -
\end{tabular}

Die Handelstätigkeit beschränkt sich nicht nur auf den Verkauf von Milchfabrikaten. Schon seit dem Bestehen der Zentralmolkerei dient sie auch zur Vermittlung von Kunstdünger, Futtermittel und Heu.

Handelstäligkeit der Molkerei :

\begin{tabular}{lrrr} 
& $1946 / 47$ & $1947 / 48$ & $1948 / 49$ \\
\hline Käse in kg. & 81739 & 69466 & 62379 \\
Butter in kg. & 91735 & 92782 & 95690 \\
Eier in 1000 Stück & 225 & 292 & 225 \\
Mineralwasser in Fr. & 28400 & 26500 & 24500 \\
Futtermittel in kg. & 175445 & 485757 & 901222 \\
Kunstdünger in kg. & 56900 & 61350 & 54100
\end{tabular}

Von der ausschließlichen Viehzucht trat im 20. Jahrhundert eine Verschiebung zu einseitiger Milchwirtschaft ein. Wohl warnten in den dreißiger Jahren, der Zeit des Milchüberflusses, weitsichtige Männer. Der Davoser hatte sich schon zu stark angepaßt. Nur mit großer Anstrengung wird immer wieder versucht, auch die Viehzucht zu fördern. Solange jedoch die internationale Lage auf dem Viehmarkt so schlecht ist, und das Gewinnrisiko bei der Aufzucht so groß, wird der Davoser Bauer bei der Milchwirtschaft bleiben. I)ie folgenden drei Tabellen zeigen diesen Wandel.

Jungvieh in Prozenten des Kuhbestandes:

$\begin{array}{cccccc}1805 & 1860 & 1870 & 1901 & 1931 & 1949 \\ 128 & 72 & 95 & 56 & 31 & 31.6 \\ \text { unter } 50 & \text { Milchproduktion, ungenügende Nachzucht } & \\ 50-75 & \text { Milchproduktion, genügende Nachzucht } & \\ 75-100 & \text { Milchproduktion, gelegentlicher Verkauf von } & \text { Tieren } \\ 100-150 & \text { Kombinierte Rindviehhaltung } & & \\ \text { ïber 150 } & \text { Eigentliche Aufzucht } & \end{array}$

Durchschnittliches bä̈erliches Einkommen aus der Milchwirtschaft (in Franken):

$\begin{array}{lllllll}1905 & 1915 & 1925 & 1930 & 1940 & 1945 & 1949 \\ 2200 & 2700 & 5600 & 6000 & 5000 & 4600 & 620015 \pi\end{array}$

1920 sind in Graubünden 1342 Mitglieder dem Verband nordostschweizerischer Käserei- und Milchgenossenschaften angeschlossen. In Davos sind es 222 Mitglieder mit einem Kuhbestand von 1120. Vergleichen wir dazu ein Viehzuchtgebiet, das Oberengadin : 352 Mitglieder mit 901 Kühen. ${ }^{158}$

Mit der Gründung der Zentralmolkerei fand in jeder Hinsicht eine entscheidende Wandlung in der Davoser Alpwirtschaft statt. Die ganze Bauernschaft ist nun in einer gemeinsamen Organisation zusammengeschlossen und kann damit ihre Grundsätze verteidigen und Krisen entgegentreten. Die ganze Wirtschaft wird durch diese Zentrale geordnet und gesteucrt. Trotzdem ist sie keine diktatorische Macht, denn sie entspringt aus dem Willen jedes einzelnen Bauern und paßte im Laufe der Zeit ein altes, schlechtes Milchverarbeitungssystem einer modernen und rationellen Methode an. S. 29.

150 Vergleiche Hösı.. : Glarner Land- und Alpwirtschaft, S. 49. Sımmen: Puschlaver Alpwirtschaft, schaft Davos.

158 Die Übersicht der Viehbestände folgt im Anhang. 
Die Wandlungen zu Beginn des 20. Jahrhunderts führten zu einer starken Intensivierung der Landnutzung. Im Tal bestanden noch große Flecken von Magerwiesen. An Bachläufen, Straßen, sumpfigen Stellen konnten noch viele kleine Stücke in die Nutzung einbezogen werden. Da war die höchste Nutzungsgrenze noch nicht erreicht. Auch die Alpen wurden verbessert. Mehr Weide! Das führte zu einer Entwicklung, die nach heutigem Ermessen gerade falsch war. Große Teile der Mäder über der Waldgrenze wurden umgewandelt in Weide; Extensivierung statt Intensivierung. 1899 kaufte die Riederalp für Fr. 3100.- die Jaz- und Wangmäder aus. Es folgten ihr die Rieberalp mit dem. Schönboden und die Chummaalp mit einem Teil der Chummamäder. Ebenfalls in Weide umgewandelt wurden: Alpwiesen im Bärental, Fanetz- und Inncralpmäder in Monstein, Wytimäder im Sertigtal, Mäder im Dischma- und Flüelatal, Dorfbergmäder, Parsennmäder.

Wieviele Verbesserungen in den Davoser Alpen ausgeführt wurden, zeigt eine Liste, die nach den Angaben des kantonalen Meliorationsamtes zusammengestellt ist.

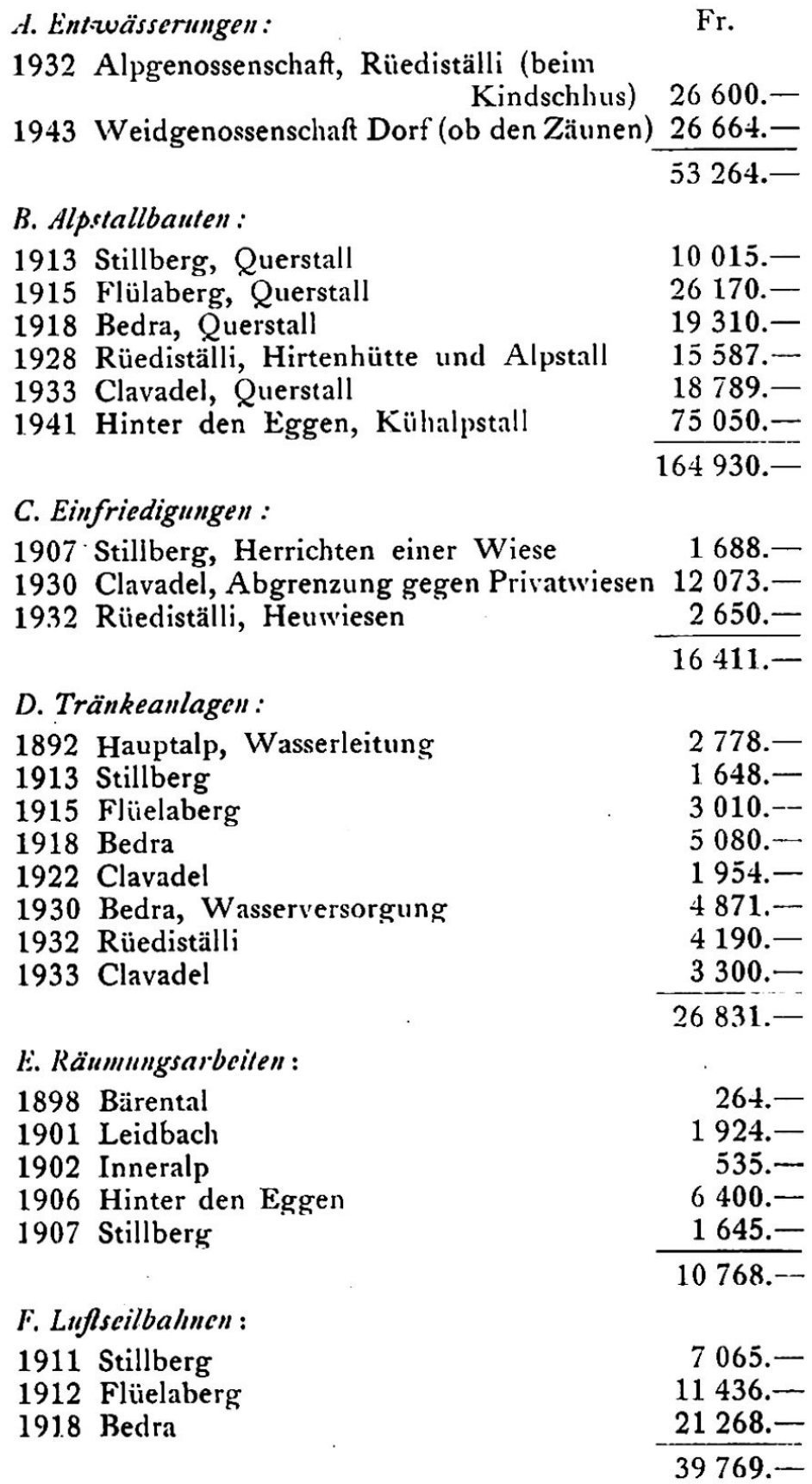




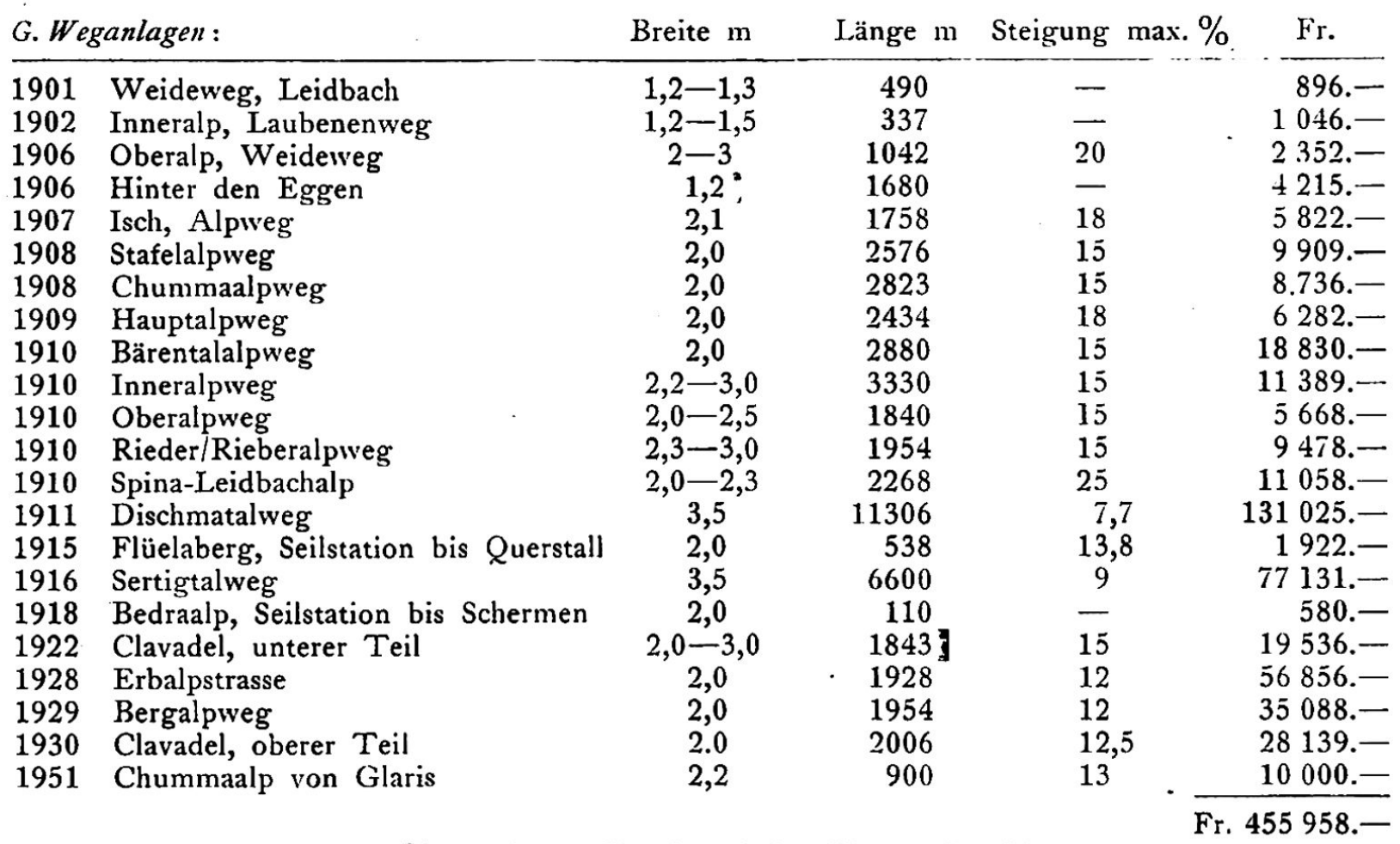

Durchschnittlich wurden $40 \%$ durch den Bund und den Kanton bezahlt.

III. Teil

\section{Die heutige Alpwirtschaft}

\section{Der Ackerbau.}

\section{DIE LANDNUTZUNGSFORMEN ${ }^{1}$}

Die Landschaft Davos befindet sich an der obern Grenze des möglichen Akkerbaus ${ }^{2}$. Die höchsten Getreideäcker liegen 1949 auf 1800 m (Waldalp 1810 m, Gaschurna und Bäbi, Sertig $1840 \mathrm{~m}$ ), die höchsten Kartoffeläcker an der gleichen Stelle. Während des. Krieges gab es einen Versuchsacker mit Kartoffeln an der Waldgrenze in einer geschützten Ecke auf der Clavadeleralp in $1980 \mathrm{~m}$ Höhe ${ }^{3}$ und auch in der Oberalp wurden auf $1870 \mathrm{~m}$ ü. M. Kartoffeln angebaut. Diese Äcker sind jedoch wieder aufgegeben worden. Im Oberschnitt sinkt die obere Anbaugrenze parallel zur Dauersiedlungsgrenze: Dischma (Gulrigenhus $1730 \mathrm{~m}$ ), Flüelatal nur während des Krieges (Bedra $1770 \mathrm{~m}$ ), Wolfgang $1660 \mathrm{~m}$ und Laret $1550 \mathrm{~m}$ ü. M.

Die klimatische Untersuchung von W. Sch ÜEPP 4 über den Kartoffelanbau in Davos gibt uns für 8 Zonen die Vegetationszeit an und damit die Möglichkeit des Anbaus. Diese Zonen wurden auf Grund der Frosthäufigkeit und des Erfrierungsgrades der Kartoffelstauden bestimmt.

\footnotetext{
Zone $0 \quad 1680-1900 \mathrm{~m}$ ü. M.

Zone 3-6 1550-1560 m

Zone 1 1620-1680 m, 1900-1950 m Zone 7 1550-1560 m, die Kälteinseln im Talboden. ${ }^{5}$ Zone 2 1590-1620 m

${ }^{1}$ Die Angaben stützen sich auf die Kartierungen im Jahre 1949, Siedlungs- und Nutzungskarte im Maßstab 1:10000.

2 Bei der Station Monstein liegen die tiefsten Äcker auf $1350 \mathrm{~m}$ Meereshöhe.

3 Der Versuch fiel ertragsmäßig in den damals klimatisch günstigen Jahren positiv aus. in Davos.

- SCHUEP: Frostverteilung und Kartoffelanbau in den Alpen auf Grund von Untersuchungen
} 


\begin{tabular}{lcccccccc} 
Zone & 0 & 1 & 2 & 3 & 4 & 5 & 6 & 7 \\
\hline Beginn & -20.5 & 20.5 & 25.5 & 1.6 & 10.6 & 20.6 & 25.6 & 1.8 \\
Ende & 10.10 & 5.10 & 29.9 & 15.9 & 10.9 & 1.9 & 20.8 & 20.8 \\
Dauer (Tage) & 143 & 138 & 123 & 107 & 92 & 72 & 57 & 20
\end{tabular}

Die Grenze des wirtschaftlich lohnenden Anbaus liegt zwischen 80 und 100 Tagen Vegetationszeit, damit in den Zonen 0-4. In den Zonen 5-7 kann nur in besonders günstigen Jahren ein lohnender Ertrag geerntet werden. Diese Untersuchungen rücken die oberste Grenze des möglichen Kartoffelanbaus sehr hoch, in $1900 \mathrm{~m}$ ü. M. bezeichnen sie noch sehr günstige Lagen. Höher folgen dann die einzelnen Zonen eng aneinander, je nach den topographischen Verhältnissen, und schon bei $1950-2000 \mathrm{~m}$ erreichen wir die Zone 7. Die Zone 0 liegt auf $1880-1900 \mathrm{~m}$ Höhe und nach unten gelangen wir durch alle Zonen bis auf den Talboden, wo kein Kartoffelanbau mehr möglich ist. Wie stark kommen hier die besondern klimatischen Verhältnisse cines Hochtales zum Ausdruck! Zur Bewertung der Frosthäufigkeit eines Ackers müssen folgende Gesichtspunkte berücksichtigt werden:

1. Länge und Neigung der Talsohle.

2. Lage der Pflanzstelle zum Tal. (Hanglage, Gefälle, Mulde, Kuppe).

3. Höhe der Pflanzstelle über der Talsohle.

4. Oberflächenbeschaffenheit in der Umgebung der Pflanzstelle. (Wiese, Wald, Gebüsch, Häuser, See).

5. Verschiedene Lokaleffekte. (Anbau in Terrassen, welliges Gelände).

Für Davos kommt SchüEPP zu drei Feststellungen:

1. In ungünstigen Lagen können in Davos nur ausnahmsweise Kartoffèln gedeihen.

2. Die Vegetationszeit schwankt an gewissen Orten der Landschaft in großem Maße von Jahr zu Jahr.

3. Günstige Lagen in Davos sind von Ende Mai bis Anfang Oktober frostsicher.

Der Kartoffel- und Getreideanbau beschränkt sich hєute vorwiegend auf den Unterschnitt. Früher, und während der Kriegsjahre mit Anbaupflicht, bestanden auch im Obersclınitt zahlreiche Äcker, doch traten sie gegenüber dem Unterschnitt immer zurück. Eine Zone muß seit jeher ausgeschlossen werden, weil sie unter der klimatischen Grenze liegt. Das ist der Talboden vom Davosersee bis zum Wildboden und die anliegenden Talhänge bis zu einem Niveau von $10-30 \mathrm{~m}$ über dem Talboden. Auch der flache vorderste Teil des I)ischmatales bis Kaisern ist dazu zu rechnen. Hier bilden sich Kaltluftseen, welche die Vegetationszeit im Frühling und Herbst stark einschränken. Die Äcker liegen an den Süd-Südost exponierten Hängen (Sertigtal, Spina, Monstein, Frauenkirch, Langmatte, Kumma, Hitze. boden). Diese Lage hatte vor allem früher bei vermehrtem Getreidebau seine Geltung. Der heute leitende Grundsatz ist, so wenig als möglich günstiges Land für den Ackerbau herzugeben. Der Bauer wählte daher auch bei der Neuanlage von Äckern im letzten Weltkrieg die schlechtesten, entferntesten, steilsten Hänge (womöglich Magerwiese) und berücksichtigte die Exposition erst in zweiter Linie. 1949 nimmt die Fläche des Ackerlandes bei der landwirtschaftlichen Bevölkerung 2154 Aaren ein 7.

Mittlere Anbaufäche pro Bauer:

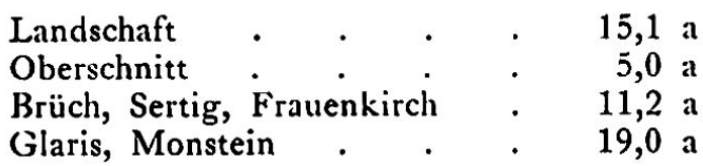

"Die Zonen gelten für Davos. Schúepp, S. 48.

"SCHÓEP, S. 54.

7 Die ganze Landschaft mit den Kleinpflanzern geschätzt ca. 2500 Aren. 


\begin{tabular}{lcccc} 
Ackerland in Arcn: & Gerste & $\begin{array}{c}\text { Hafer, Gerste } \\
\text { grün geschnitten }\end{array}$ & Kartoffeln & Kunstwiese \\
\hline Frauenkirch/Brüch & $-\cdots$ & 31 & 406 & 30 \\
Glaris/Spina & 52 & 48 & 595 & - \\
Monstein & 26 & 8 & 191 & 11 \\
Sertig & 22 & 11 & 217 & 12 \\
Laret/Wolfgang & 3 & 14 & 72 & 126 \\
Davos/Dischma & 18 & 35 & 113 & 179 \\
& $180^{8}$ & $147^{9}$ & 1594 & 8,5
\end{tabular}

Beide Tabellen zeigen die Abnahme der Ackerfläche mit der Talhöhe und das Überwiegen des Ackerbaues in Unterschnitt. Der Anbau von Kunstwiese ist unbedeutend (in Davos-Dorf liegen 100 a in einem Betrieb). Von der Getreidefläche wird ungefähr die Hälfte aufgegeben. Im ersten Jahr schneidet man den Hafer und die. Gerste grün und verfuttert sie. Im zweiten Jahr werden Gräser und Klee eingesät und im dritten Jahr geht der Acker in Wiese über. Jedes Jahr nimmt die Ackerfläche seit dem Kriege ab ${ }^{10}$. Die Anbaustatistik 111945 gibt noch eine Totalfläche von 7808 a Ackerland an (1771 a Getreide, 4464 a Kartoffeln, 602 a Futterrüben, 1571 a Gemüseland). Innerhalb von 4 Jahren ist also ein Rückgang von $60 \%$ des Ackerlandes zu verzeichnen. Daher beschloß der Bundesrat zur Förderung des Ackerbaus bei Gerste, Roggen und Hafer für das Jahr 1951 über 1000 m Meereshöhe Fr. 280.- pro Hektare Anbauprämien zu bezahlen.

Die Gründe für diesen Rückgang sieht STACHER ${ }^{12}$ vor allem in der persönlichen Einstellung des Bauern. Der Arbeitsaufwand stehe in keinem Verhältnis zum Ertrag, ist das Hauptargument des Bauern. Er verzichtet lieber auf die Selbstversorgung und kauft sich das Brot und die Kartoffeln. Für die Abwendung sind nicht die Natur und die Witterung schuld, sondern die unzulängliche Ackerbaumethode und die Preisansätze.

1. Der Acker liegt immer an der gleichen Stelle.

2. Die große Arbeit zum Umbruch von Neuland wird gescheut.

3. Der Bauer opfert nicht gern sein Grasland.

Eine Verbesserung muß also beachten :

1. Eine Änderung der Arbeitsmethode. Die Hacke muß so weit wie möglich durch den Pflug mit Seilwinde ersetzt werden. Dazu ist eine Zusammenlegung von kleinen Parzellen zu großen einheitlichen Äckern notwendig.

2. Mit der Einführung des Pfluges verkleinert sich der Arbeitsaufivand. Es besteht die Möglichkeit zu Neuumbruch und Bodenverbesserung. ${ }^{13}$

3. Durch zweckmäßige Auswahl der Kartoffelsorte kann der Ertrag gesteigert werden. (Der Kartoftelsaatgutanbau würde sich für diese Höhenlage eignen.)

4. Zweckmäßige Düngung auch mit Kunstdünger. (Für Davos in den meisten Fällen Kalksalpeter.)

5. Durch Vorkeimen des Saatgutes kann der Acker später bestellt werden und entgeht dadurch den Maifrösten.

Fin Rentabilitätsvergleich fällt zu Gunsten des Kartoftelanbaues aus.

Heu und Emd pro Are $80 \mathrm{~kg}(100 \mathrm{~kg}$ zu Fr. 20.-)

Erntespesen

Gewinn

$$
\begin{aligned}
& \text { Fr. 16.- } \\
& - \text { 4. } \\
& \hline \text { Fr. 12. }
\end{aligned}
$$

81940 wurde aus Glaris eine standfeste, frühreife, zweizeilige Gerste von der Molkerei gekauft und als Saatgut ausgegeben. Versuche mit Isaria-, Kenia- und Savogninergerste mißlangen.

9 Außer Gerste wurden 1944 noch 7 a Winterweizen, 55 a Sommerweizen, 60 a Roggen, 18 a Mischel, 81 a Hafer und 8 a Körnermais angepflanzt. Der Winterweizen wird im September gesät. Vorfrucht: Frühkartoffeln, die Ende August, Anfangs September geerntet werden können.

101951 hat die Ackerfläche ihren Tiefstand erreicht und wird von jetzt an stagnieren.

11 Statistik der Davoser Ackerbau-Kontrollstelle.

12 STACHER O.: In Jahresbericht der Molkerei 1942/43.

18 Das Ackerland wird 10-20 Jahre benutzt, vorübergehend ist es Wiese, um dann wieder umgebrochen zu werden. Ein unregelmäßiger Fruchtwechsel findet dort statt, wo noch Gerste angepflanzt wird. 


$\begin{array}{lc}\text { Kartoffeln, Mittelernte pro Are } 250 \mathrm{~kg}(100 \mathrm{~kg}=\text { Fr. 23.- }) & \text { Fr. } 57.500^{14} \\ \text { Saatgut und Arbeitsspesen } & \frac{\# 25 .{ }^{14}}{\text { Fr. } 32.50} \\ \text { Gewinn }^{15} & \end{array}$

Der Ackerbau nahm früher einen viel größern Raum ein. Er genügte weitgehend der Selbstversorgung, die sich damals viel einseitiger auf wenige Produkte beschränkte. KarSTHOFER ${ }^{16}$ schreibt 1822 von der Siedlung Hoffnungsau 17 (Monstein-Schmelzboden $1350 \mathrm{~m})$ : «Dort wachsen im Garten Kohl, Möhren, Flachs, Hanf und Erbsen, auch Frühbirnen und Äpfel bilden kräftige Triebe und reife Früchte. Flandrisch Klee ist hier von dem tätigen Verwalter mit bestem Erfolg gesät worden und so auch Winterroggen, der gut gedeiht ${ }^{18}$ ».

Die vielen abgebrochenen Speicher und Mühlen weisen ebenfalls auf vermehrten Getreidebau hin ${ }^{19} .1949$ stehen noch 58 Spycher in der Landschaft Davos (Sertig 8, Sertig-Dörfli 1, Frauenkirch 13, Glaris 13, Monstein 22, Meyerhof-DavosDorf 1). Die Bauweise der Spycher unterscheidet sich kaum von derjenigen des Wallis. Es fehlen die Steinplatten zwischen dem getrennten Ober- und Unterbau, da geeignetes Steinmaterial in Davos nicht vorkommt (Gneis- oder Quarzitplatten). Auf der Seite unter dem vorspringenden Dach ist ein Gerüst zum Aufhängen und Ausreifen des Getreides angebracht ${ }^{20}$. Monstein besitzt 10 Bauernbetriebe und 22 Spycher. Darum stehen viele Spycher leer oder werden als Remisen gebraucht. Durch die Zusammenlegung der Güter im letzten Jahrhundert hat der Monsteiner heute sogar halbe Anteilsrechte an Spychern (2 1/2 Spycher). Das Getreide wird mit besondern Dreschflegeln gedroschen und die Spreu mit einfachen Windfegen entfernt. Der Dreschflegel besteht aus einem 40-50 cm langen Schlagholz (Querschnitt $8 \times 8 \mathrm{~cm})$, in dessen hintere Hälfte schräg ein Loch gebohrt wird, darin sitzt der unbewegliche Stiel.

Die Angaben der Ackerbaustatistiken zeigen das Ansteigen der Nutzfläche in Kriegszeiten und das Zurücksinken auf eine bleibende Fläche von 10-20 Hektaren.

Ackerbau in Aren, in Klammer Anzahl der Pflanzer:

\begin{tabular}{rrrrrrrrr} 
& \multicolumn{2}{c}{$\begin{array}{c}\text { Ackerland } \\
\text { Total }\end{array}$} & \multicolumn{2}{c}{ Getreide } & \multicolumn{3}{c}{$\begin{array}{c}\text { Hackfrüchte } \\
\text { Kartoffeln }\end{array}$} & Gemüse \\
\hline 1917 & 2444 & $(409)$ & 228 & $(49)$ & 1427 & $(176)$ & 789 \\
1919 & 3630 & & 370 & & 2590 & & 670 \\
1926 & 1729 & $(298)$ & 175 & $(52)$ & 1378 & $(172)$ & 176 \\
1929 & 3473 & $(253)$ & 133 & $(24)$ & 3247 & $(128)$ & 93 \\
1934 & 1535 & $(234)$ & 52 & $(13)$ & 1283 & $(134)$ & 200 \\
1939 & 1314 & $(149)$ & 42 & $(16)$ & 1172 & & 100 \\
1940 & 1851 & & 40 & & 1679 & & 141 \\
1941 & 3012 & $(231)$ & 266 & & 2100 & & 646 \\
1942 & 3950 & $(229)$ & 340 & $(93)$ & 2210 & $(213)$ & 1400 \\
1943 & 5442 & & 810 & & 2870 & & 1762 \\
1944 & 6690 & & 1450 & & 3420 & & 1820 \\
1945 & 7808 & & 1171 & & 4464 & 21 & 1571 \\
1949 & 2500 & & 327 & $(58)$ & 1594 & $(143)^{22}$ &
\end{tabular}

14 mit Gebirgszuschlag.

${ }^{15}$ Das schweizerische Bauernsekretariat rechnet einen mittleren Ertrag von $70 \mathrm{~kg} \mathrm{Heu} /$ Are und $200 \mathrm{~kg}$ Kartoffeln (hohe Erträge $300 \mathrm{~kg}$ ).

${ }_{16}$ Zitiert in Ferdmann, die Anfänge des Kurortes Davos. S. 70.

17 Bergwerkssiedlung mit den Gruben am Silberberg. Blütezeit: 1513-1648. Letzte Ausbeute 1837. Gewinnung von Zinkblende und Bleiglanz.

${ }^{18}$ Diese Beschreibung mutet uns heute unglaublich an. Sicher war es nur ein Einzelversuch dieses Verwalters. Vielleicht sind auch bessere klimatische Verhältnisse für jene Zeit anzunehmen?

${ }^{10}$ Vergleiche S. 299.

20 In Davos auch „Aschma“ genannt.

${ }^{21}$ Während des Krieges bebaute die Gemeinde Davos 8-9 ha Land mit Saatkartoffeln. (Zügen, Wildboden, beim Spital, Golfplatz, Wolfgang.)

${ }^{22}$ Von 185 hauptberuflichen Landwirten. 


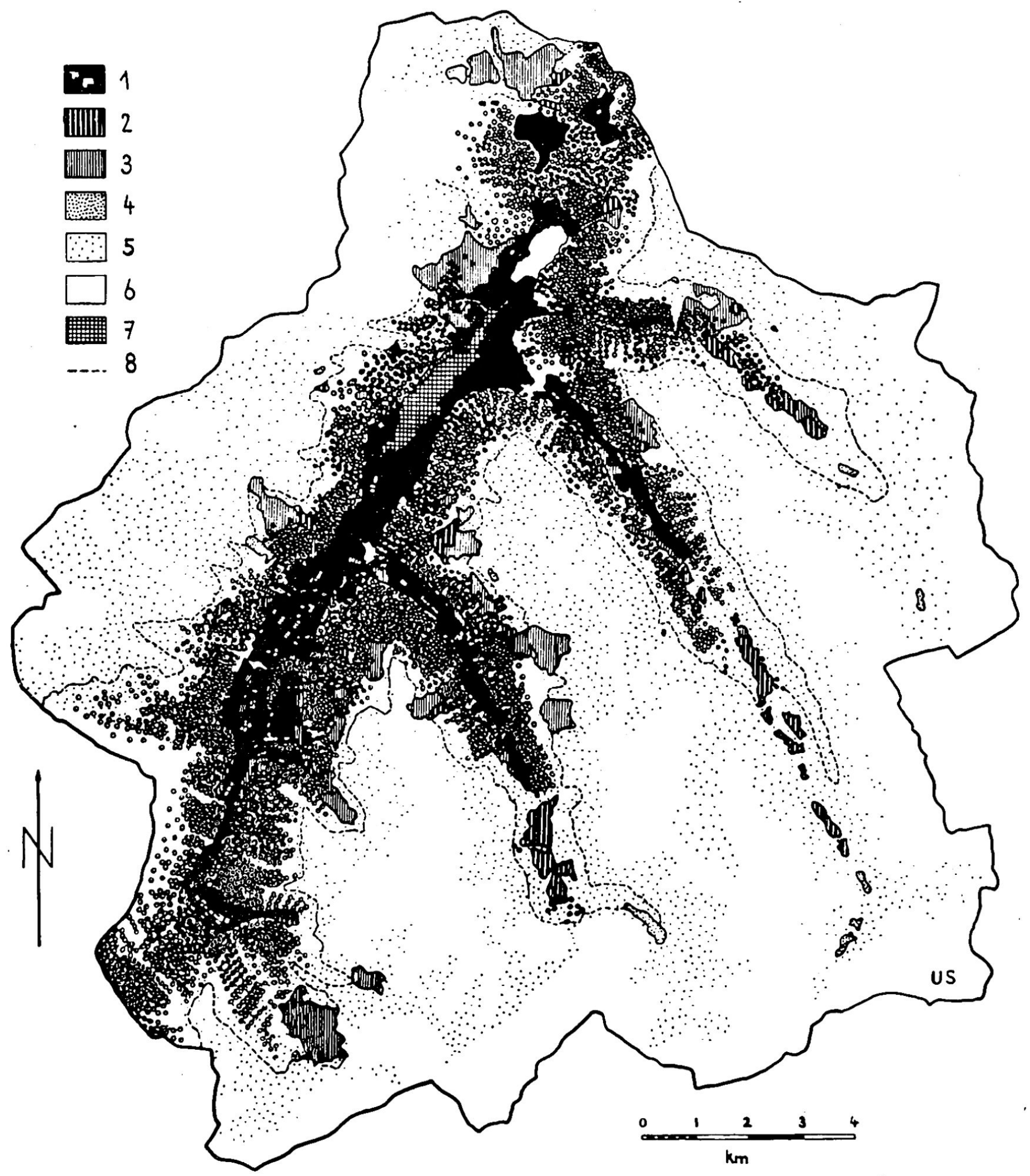

Fig. 3 Landnutzung, 1. Talfettwiesen mit Äckern, 2. Alpwiesen, 3. Magerwiesen (Usörter und Mäder). 4. Wald, 5. Weide, 6. Fels, Geröll; Davoser- und Schwarzsee, 7. Kurort Davos, geschlossenes Siedlungsgebiet, 8. Grenze zwischen offener Alpweide und bestockter Weide.

Wiesen.

Das Wiesland nimmt den ganzen Talboden ein und steigt auch an den Talflanken noch hoch hinauf. Es bildet die Futterbasis für den Winter. Wir unterscheiden in Davos drei Arten von Wiesen, die sich in ihrem Ertragswert und ihrer Lage voneinander unterscheiden: 
Die Talfettwiesen: Es sind Wiesen, die jedes Jahr gedüngt werden und zweimal genutzt, ein erstes Mal geheut und ein zweites Mal geemdet oder geweidet (Emdweide). Der Ertrag wird in Kuhwinterungen (KW) gemessen. Es ist das jene Menge Heu, die nötig ist, eine Kuh überwintern zu können, d.h. für Davos, 260 Tage füttern. ${ }^{23}$ Einer Kuhwinterung entsprechen $60-120$ Aren Talfettwiese.

Alpwiesen, Alpfett-wiesen: Es sind jedes zweite oder dritte Jahr gedüngte Wiesen, die einmal gemäht werden. Jede Alp besitzt anschließend noch ein Stück Wiesland, das mit dem anfallenden Alpmist gedüngt wird. Bei großen Alpwiesen reicht der Mist jedes Jahr nur für einen Teil der Fläche. (Sertig-, Flüela-, Dischmatal.) Bis zum letzten Weltkrieg führte man den Mist in einzelnen Alpen (Stafel) im Winter in hart gefrorenen Blöcken (Mischtplätsche) zu Tal und verteilte sie im Frühling auf die Wiesen. Heute kommt dieser mit „Gülleverschlauchungsanlagen“ auf die Weide. Die Alpwiesen liefern Heu für Schneetage, wenn das Vieh in den Ställen bleibt, und Futterzusatz am Äbend bei schlechten Weidetagen. Im Sertig, Dischma und Flüela wird das Heu als Vorwinterung ${ }^{24}$ aufgebraucht. In andern Fällen holt man das restliche Heu im Winter auf Schlitten ins Tal. Der Ertrag der Alpwiesen schwankt sehr stark je nach Höhenlage und Düngung. Fläche für eine KW: Engialp $1820 \mathrm{~m}$ ü. M.: 1,2 ha, Rieberalp $1850 \mathrm{~m}$ : 2,0 ha, Sertig $1860 \mathrm{~m}$ : 1,5-1,7 ha, Hauptalp $1980 \mathrm{~m}: 3,0$ ha, Clavadel $2030 \mathrm{~m}: 1,3$ ha.

Magerwiesen: a) Mäder sind abgegrenzte ungedüngte Wiesen über der Waldgrenze, die jedes zweite Jahr von der Alp aus geheut iverden. b) „Usörter“ (Außenorte) sind vermarchte, ungedüngte Wiesen, an die Talfettwiesen anschließend, die jedes zweite Jahr vom Heimgut aus geheut werden. Die Usörter liegen meistens im offenen Lärchenwald, sind also Magerwiesen in einer Doppelnutzung (Wald - Wiese).

Jedes Jahr wird nur die Hälfte gemäht, das nächste Jahr die andere. So entsteht durch die absterbenden Pflanzenteile eine Naturdüngung. Fläche für eine KW: Wytibergmäder $2100-2300 \mathrm{~m}$ ü. M. : 5-7 ha, Parsennmäder $1800-2200 \mathrm{~m}$ : 5-9 ha, Dorfberg $1700-2100 \mathrm{~m}: 7-8$ ha, Fanezmäder $2200-2300 \mathrm{~m}: 10-12$ ha.

Der Vergleich des Ertrages der einzelnen Wiesen zeigt einen fließenden Übergang von den am intensivsten bewirtschafteten Talwiesen bis $z u$ den höchst gelegenen Mädern.

$\begin{array}{lc}\text { Talfettwiesen } & 0,7-1,2 \text { ha } \\ \text { Alpfettwiesen } & 1,2-3,0 \text { ha } \\ \text { Magerwiesen 's } & 5-12 \text { ha Land pro Kuhwinterung. }\end{array}$

Kulturland der Landschaft Davos:

\begin{tabular}{lrrr} 
Magerwiesen und Alpfettwiesen & 1382 ha & $48,2 \%$ \\
Fettwiesen & 1436 ha & $51,0 \%$ \\
Ackerland 1949 & 25 ha & $0.8 \%$ \\
\cline { 2 - 2 } Kulturland & 2843 ha
\end{tabular}

2818 Hektaren Wiesland entsprechen ca. 1900 Kuhwinterungen Land. Für ein Kuhland ergibt sich damit eine Fläche von 1,43 ha. Der Davoser Viehstand, der überwintert wird, beträgt umgerechnet in Kuheinheiten (Kuhrechte) ca. 2100 25. Mit $1900 \mathrm{KW}$ sollten $2100 \mathrm{Kühe}$ gefüttert werden. In der Landschaft muß also noch jeden Winter Heu und Futtermittel zugekauft werden. Etwa 240 Kuheinheiten fallen auf die Pferde, die das ganze Jahr Futter benötigen ${ }^{26}$. Die vorhandene Wiesfläche bestimmt die Viehzahl der Landschaft Davos. Ein Viehstand mit gekauftem Futter zu überwintern, ist wahrscheinlich untragbar. Der Viehbestand ist deshalb wohl ausgewogen mit dem vorhandenen Futterertrag. Folgen sich eine Reihe schlechter Heujahre, so sinkt jener, und nur bei einzelnen Mißernten' wird versucht, durch Zukauf von Heu den Kuhbestand durchzuhalten.

${ }^{29} \mathrm{KW}$ wurde zu einem festen Maß, das auch zur Einschätzung des Bodenwertes benutzt wird. Da die Ertragswerte pro Hektare stark schwanken, besitzt das Flächenmaß keinen praktischen Wert.

24 Nach der Emdweide auf den Wiesen des Talgutes, kehrt das Vieh noch einmal zurück in den Alpstall und braucht dort das Heu auf.

${ }_{25} \mathrm{Kuh}, \mathrm{Rind}=1 \mathrm{KR}$, Mese $(1-2$ jährig $)={ }^{3} / 4 \mathrm{KR}, \mathrm{Kalb}=1 / 2 \mathrm{KR}$, Ziegen, Schafe $=1 / 8 \mathrm{KR}$, Ochsen und Pferde $=2 \mathrm{KR}$.

${ }_{20}$ Der landwirtschaftliche Produktionskataster von Davos gibt für 50-60 Landwirte einen Heukauf von 500 Tonnen und 200 t Stroh für die Zeit vor dem Kriege an. 
Weide.

Eine $F$ läche von rund 12000 ha (produktive Weidefläche), $47 \%$ der gesamten Gemeindefläche wird als Weide genutzt. Es ist dasjenige Areal, in welchem sich das Vieh zur Gewinnung von Futter unter Aufsicht oder frei herumtreibt. Alpweiden sind Nutzungsräume, die wegen ihrer Höhenlage ausschließlich in den Sommermonaten der Atzung unterliegen ${ }^{27}$. Für die Verhältnisse in Davos unterteile ich die Alpweide nach Vegetations- und Lageunterschieden:

Die offene Alpweide:

Regelmäßig von Groß- und Kleinvieh genutzter Naturrasen über der alpinen Ericaceenheide. ${ }^{28}$

Die bestockte Weide, Wytrveide, Waldweide:

Diese schließt die Stufe der alpinen $Z$ wergstrauchformation, des Lockerwaldes an der Kampfzone und alle Weidefläche im Wald bis an die Grenze der Wiesen ein.

Läger:

Es sind ebene Plätze um die Sennhütte herum oder auf offener Weide, wo durch regelmäßiges Zusammenkommen und Lagern des Viehs der Boden überdüngt ist und eine hochstenglige vom Vieh verschmähte Unkrautflora nährt. ${ }^{29}$

In den Jungviehalpen (Großalp, Carlimatte, Stützalp, Rüediställi) wird am Abend das Vieh auf flachen Böden zusammengetrieben. Dort entsteht dann eine üppige Lägerflora (Sauerampfer, Eisenhut). Leider wird der anfallende Mist meistens nicht verteilt, soda $\beta$ er Geilstellen verursacht. Das Galtvieh der andern Alpen übernachtet weniger auf bestimmten Plätzen. Jedoch haben einige Alpen noch Melkplätze, dort entstehen auch Läger. Sie lassen die Kühe auch nachts im Freien und treiben sie nur bei ganz schlechtem Wetter in die Ställe. Jeden Morgen und Abend geht der Bauer mit der Milchtanse zum Melkplatz und nimmt damit dem Vieh ein Stück des Weges ab. (Grünialp, Dürrboden, Stützalp, Bergalp, früher auch die Kühalp, bevor man den Schermen baute.) ${ }^{30}$

Diese Unterteilung drängt sich aus Ertrags- und wirtschaftlichen Gründen auf. Die offene Alpweide liegt über der Waldgrenze. Der Ertrag wird durch pedologische und klimatische Verhältnisse, insbesondere aber durch die Höhenlage bestimmt. Die Ericaceenheide schließt an den Wald an und nimmt die Fläche der Kampfzone des Waldes ein. Sie bildet die schlechteste Weide und ist nur beschränkt nutzbar. Die Waldweide nimmt, bedingt durch die historische Entwicklung in Davos, eine große Fläche ein. Durch die tiefere Lage ist hier die Vegetation reicher und liefert auch in trockenen Jahren reichlich Futter ${ }^{31}$. Die Temperaturen sind höher und verlängern die Vegetationszeit im Frühling und Herbst. Auch wirtschaftlich nehmen die Waldweiden eine eigene Stcllung ein. Sie dienen als Frühlings- und Herbstweide, wenn auf den Alpen zu wenig Gras wächst. Es sind die der Alp nahe gelegenen Wetterflucht- und Ruheweiden 22.

Die obere Weidegrenze wird durch natürliche und wirtschaftliche Faktoren gebildet. Die Ausdehnung der Grasnarbe ist durch klimatische Verhältnisse eingeschränkt. Die Vergandung setzt je nach der Gesteinsunterlage verschieden stark

\begin{tabular}{lccc} 
& $\begin{array}{c}\text { Höhendifferenz } \\
\mathrm{m}\end{array}$ & $\begin{array}{c}\text { Entfernung } \\
\mathrm{m}\end{array}$ & $\begin{array}{c}\text { Einfache Wegzeit } \\
\text { des Viehs in Stunden }\end{array}$ \\
\hline Stafelalp & 660 & 4000 & $4-5$ \\
Waldalp & 600 & 2500 & 4 \\
Dürrboden & 500 & 3000 & $3-4$ \\
Leidbachalp & 700 & 2500 & $3-4$ \\
Bedra (Schermen) & 300 & 1200 & $1-2$
\end{tabular}

27 Simmen, G.: Puschlaver Alpwirtschaft, S. 33

28 SchrOTER, C.: Kleiner Führer durch die Pflanzenwelt der Alpen, S. 16.

20 SCHRÖTER, S. 17.

${ }^{30}$ Diese Wirtschaftsform ist ein Überrest aus früherer Zeit, als die Kühe um $17.00 \mathrm{Uhr}$ gemolken wurden und nachher weiter weideten. Vergleiche Anmerkung ${ }^{136}$. Teil II.

${ }^{81}$ In den trockenen Sommern 1947 und 1948 litten die ganz im Walde gelegenen Sömmerungsweiden wie Kaisern- oder Wildiatzung keinen Mangel, im Gegensatz zu vielen Alpweiden, die ausgedörrt waren und die Tränkstellen ausgetrocknet. getrieben.

${ }_{82}$ An bestimmten Tagen wird das Vieh zum Ausruhen in die mahegelegenen Weideplätze 


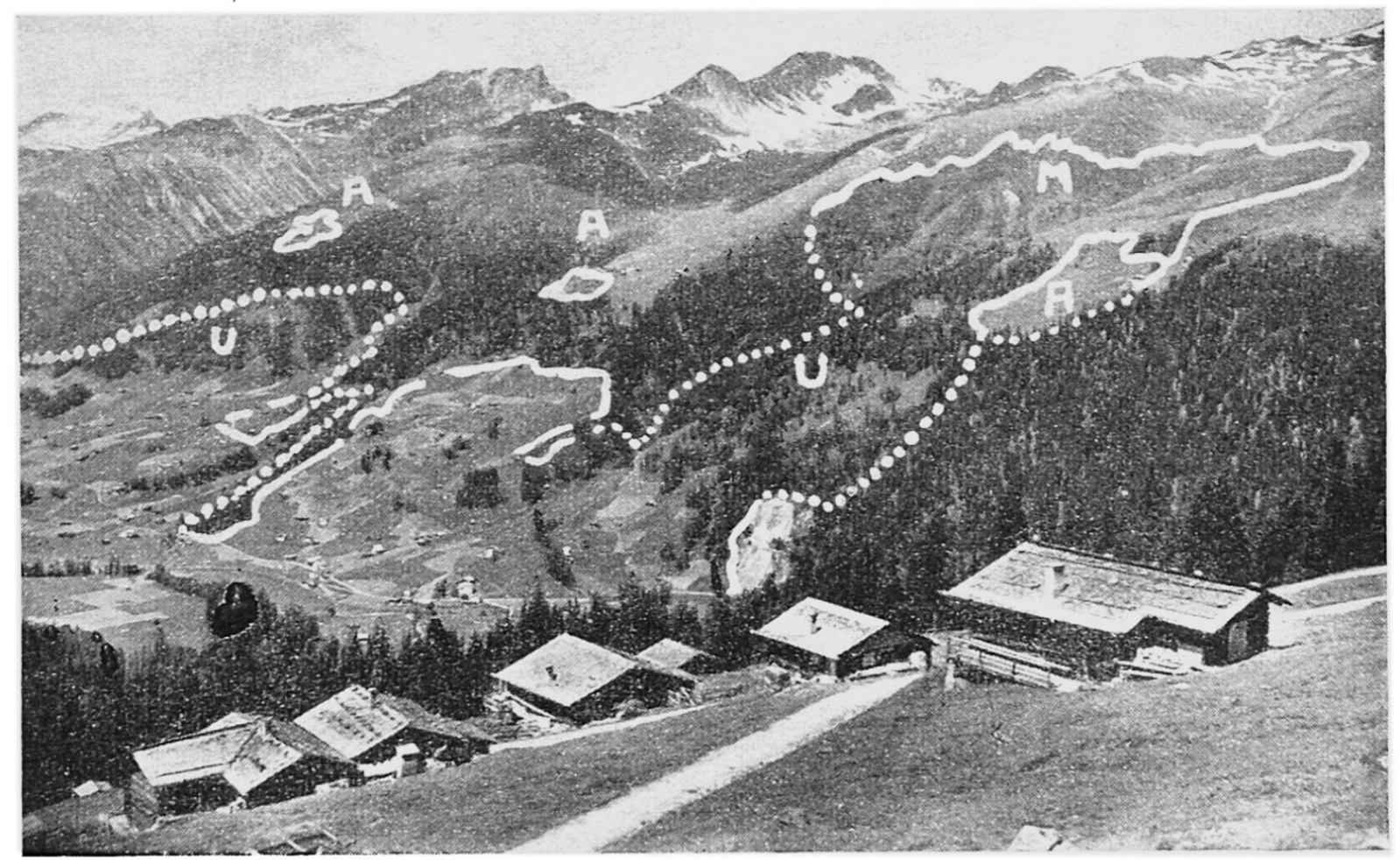

Abb. 4 Wies-Weidegrenze. Blick von der Alp Clavadel auf Frauenkirch. Über der Waldgrenze von links nach rechts Chumma-, Stafel- und Erbalp. Die weiße Linie trennt das Weideland ron der Wiesfläche. $\mathrm{A}=$ Alpwiesen, $\mathrm{M}=$ Mäder, $\mathrm{U}=$ Usörter. Aufnahme H. TraUfFr

ein 33. Weit entfernte Weideplätze können von den Kühen, die jeden Tag wieder zurück in den Stall kehren, nicht mehr erreicht werden.

Diese müssen daher vom Galtvieh, das den ganzen Sommer im Freien bleibt, oder von Ziegen und Schafen genutzt werden. Auch die Steilheit des Geländes setzt der Weidenutzung eine Grenze (Kühe 20-30 Grad, Schmalvieh 30-40 Grad Neigung) 34. Berggewohnte Mesen überschreiten auch diese Grenzen, und das Schmalvich weidet je nach örtlichen Verhältnissen noch an steilern Hängen.

Die untere Weidegrenze ist eine klare, da die Weide immer an intensiver genutztes Land stößt. Durch die ganze Landschaft zieht sich in vielen Einbuchtungen der umlegbare Zaun, der die Weide von der Wiese trennt. An vielen Stellen greift die Weide schlauchartig hinunter bis ins Tal. Das sind die Weidestraßen, auf denen früher das Vieh die Allmend erreichte, und später das Heimvieh die Weide. Sie ziehen in lockern Lärchenwäldchen den Bachläufen entlang (Kumma, Frauenkirch) oder bilden sogar einen Durchgang auf die andere Talseite (Sertig). Am Eingang ins Dischmatal mündet die Weide in die Straße, auf der das Vieh bis hinein nach Davos-Dorf getrieben werden kann.

An drei Punkten setzt der Rückgang der Weide ein: 1. Durch Vergandung an der obern Weidegrenze. 2. Durch Überwuchern und Vordringen der alpinen Zwergstrauchformation (Alpenrosen, Erika, Heidel-, Preisel-, Rauschbeere, Wachholder). 3. Aufgabe von steilen und entfernten Gebieten ${ }^{35}$.

33 Vergleiche Seite 269.

34 WEIss: Das Alpwesen Graubündens, S. 52.

35 Hier muß an die Waldweiden erinnert werden, die im Zusammenhang mit den Servitutsablösungen aufgegeben wurden: Gemeindewälder. Die meisten Weidegebiete der Zügenschlucht am Altein bis nach Glaris. Rüti war zu Beginn des 19. Jh. noch ein dauernd bewohnter Hof. Dann wurde er zur Alp. Die Ziegen trieben sich in den steilen Halden des Alteins herum. Seit 10 Jahren wird nicht mehr geweidet, nur noch das Gras gemäht und das Heu im Vorwinter aufgefüttert. Rüti ist damit ein Maiensäß geworden. 
Der Ertrag der Weide wird in Kuhweiden, Kuhrechte oder Stößen angegeben. Sie entspricht der Weidefläche, die nötig ist, um eine Kuh zu sömmern, d. h. für Davos 100 Tage ( 1 Sto $\beta=4-4,5$ ha produktive Weidefläche) ${ }^{36}$. Für alle Alpen wurde zu Beginn dieses Jahrhunderts die Stoßzahl in den Statuten gesetzlich verankert, sie bestand jedoch seit der Abgrenzung der einzelnen Alpen im 14. und 15. Jahrhundert ${ }^{37}$. Sie ist meistens zu hoch angesetzt und wird von den Bauern aus der Erfahrung heraus anders geschätzt. Alle Alpen der Landschaft Davos besitzen nach den Angaben der Bauern zusammen 2777 Kuhrechte, gesetzlich $3112 \mathrm{KR}$, davon sind 19492425 Weiden bestoßen. Die Weidefläche ist noch nicht voll ausgenützt. Dabei kann gerade diese auch noch verbessert und intensiviert werden, im Gegensatz zur Wiesfläche, die bald ihre Kapazität erreicht hat. Etwa 20-30 Stück Vich werden von Bauern ohne Alpen den gößten Teil des Sommers im Stall durchgefüttert und nur im Frühling und Herbst nach dem System der Koppelweide 38 auf die Wiesen getrieben. Dazu kommen die 120 Pferde der Landschaft, die heute auf den wenigsten Alpen noch Weiderechte besitzen und dann nur am Abend etwas ausgelassen werden ( $5-10$ Pferde, welche die Milch von der Alp führen). Alle andern werden im Tale gebraucht und über. Nacht im Stall gehalten. Der größte Teil der Pferde fällt übrigens nicht auf die Bauernschaft, sondern auf Fuhrhalterei und Gewerbe in Davos.

\section{Verbesserung und Intensivierung der Landnutzung.}

Mit der enormen Intensivierung der Landwirtschaft seit der Gründung der Zentralmolkerei wurden viele Reformvorschläge angenommen und durchgeführt, es wird jedoch immer möglich sein, noch etwas zu verbessern.

a) Weideverbesserung.

1. Vergrößerung der produktiven Weidefläche.

Große Gebiete können wegen Verstrauchung nur eingeschränkt genutzt werden. Durch Roden und Brennen könnte man die Stauden entfernen. Nachher muß jedoch der Boden noch entsäuert und umgewandelt werden, bis ein dauernder Erfolg eintritt. Das geschieht durch Kalk- und Volldüngung und nachheriger Graseinsaat. Auch durch Schafpferchen ${ }^{39}$ werden die Sträucher vertilgt. Der Dünger fällt in den Nächten an und muß nur noch eingeeggt oder gewalzt werden. Auch hier ist zum Ausgleich noch Kalk nötig. - Durch Räumung von Steinen könnte man immer wieder kleine Flächen neu schaffen.

\section{Intensivierung.}

Seit dem letzten Weltkrieg fand das Düngen der Weide Eingang in Davos. Einzelne Alpen kauften sich Verschlauchungsanlagen und Pumpen. Am einfachsten ist die Verschlauchung der Jauche bei genossenschaftlichen Schermen. Hier kann die Pumpe fest eingebaut werden (Kühalpschermen Sertig seit 1941, Alpstall des landwirtschaftlichen Betriebes der Zürcher Heilstätte Clavadel). Die andern Schermen besitzen bis jetzt nur eine Verschlauchungsanlage, mit deren Hilfe sie den verwässerten Mist wenigstens auf die tiefer liegenden Weiden führen können (Bedra, Flüelaberg, Rüediställi, Podestatenalp Clavadel-Genossenschaftsschermen). Die Atzungsgenossenschaft Stafelalp kaufte 1945 eine bewegliche Motorpumpe mit

36 Vergleiche SENN: Diplomarbeit, S. 31.

37 Die Festlegung geschah wahrscheinlich auf der Basis der Erfahrung, daß eine bestimmte Anzahl Kühe genug Futter findet und nicht auf Grund des Wiesenbesitzes im Tal.

${ }_{38}$ Das Vieh weidet in eingezäunten Arealen (Koppeln) und wechselt, sobald die Wiese aufgebraucht ist, um nach einer bestimmten. Zeit wieder auf die 1 . Koppel zurückzukehren, auf der in der Zwischenzeit das Gras wieder nachgewachsen ist.

${ }^{39}$ Schafe werden noch auf der Engialp gepfercht. Auf den drei andern Atzungen, auf denen sich noch Schafe befinden, laufen sie den ganzen Sommer frei herum. (Gulrigenberg, Carlimatte, Hinter den Eggen.) 
Verschlauchung, die nicht nur auf der Alp, sondern auch im Tal von den einzelnen Alpgenossen gebraucht werden kann. - Sumpfige Stellen müssen entwässert werden. Große Drainageanlagen sind im Gebirge sehr teuer, durch einfache und natürliche Abzugsgräben könnte man auch da verbessern.

\section{Weideschonung.}

Durch Übernutzung und fehlende Düngung. der Weide tritt eine starke Rohhumusbildung ein. Das Borstengras 40 (nardus stricta) erscheint. Blätter und Stengel verfaulen schwer, durch Wassermangel, Luftabschluß und niedrige Temperaturen ist die zersetzende Tätigkeit der Bakterien gehemmt. Es folgen als nächste Ansiedler sauren Boden liebende Pflanzen, wie Alpenrosen und Erika. Die Anlagen und günstigen Verhältnisse für eine starke Rohhumusbildung bestehen ohnehin in den Alpen. Darum muß dagegen gewirkt werden, durch Düngung der Weide- und Verhinderung vor Übernutzung. Die Alp soll in Weidebezirke eingeteilt sein, die dem Ablauf der Vegetationszeit in den verschiedenen Höhenlagen entsprechen.

\section{Bessere Ausnützung.}

Die größte Hilfe für viele Davoser Alpen wäre der Bau eines Schermens in höherer Lage und der Übergang zu einer Stafelwirtschaft. Durch das Hinaufsetzen des Wirtschaftsbetriebes ins Zentrum des Weidegebietes wird die Weide besser ausgenützt und vor allem der Weg für das Vieh abgekürzt ${ }^{41}$. Damit werden die Milcherträge heraufgesetzt, was das Beispiel der Flüelabergalp zeigt.

Die Bauern der Flüelabergalp treiben ihr Vieh vom 5.-14. Juli von den Uslohställen im Flüeladörfli aus in den Wald. Dabei legen die Kühe ziemlich große Distanzen zurück, das Gelände ist steil und unwegsam. Nachher bestoßen sie die Alp; der Schermen liegt über der Waldgrenze mitten im Weidegebiet.

\begin{tabular}{ccc} 
Milchertrag & \multicolumn{2}{c}{ Flüela Landschaft: Gesamteinlieferung Molkerei } \\
\hline 5.-14. Juli & $3948 \mathrm{~L}$ & $63323 \mathrm{~L}$ \\
15.-24. Juli & $4224 \mathrm{~L}$ & $58162 \mathrm{~L}$ \\
& $+275 \mathrm{~L}$ & $-5161 \mathrm{~L}$ \\
& $+6,9 \%$ & $-8,1 \%$
\end{tabular}

Die Differenz und Ertragssteigerung machten also in diesem Einzelfall 15 Prozent aus. ${ }^{+2}$

Durch vermehrte Haltung von Schmalvieh würde sicher auch die Nutzung der entfernten und unzugänglichen Weiden heraufgesetzt. Hier bleibt jedoch die Frage offen, ob nicht andere Nachteile (Winterung, Schaden) diesen Nutzen aufwiegen?

b) Verbesserung der Wiesfläche:

Der Heuertrag kann nur noch durch bessere Düngetechnik heraufgesetzt werden. Durch bessere Ausnützung des Düngers ist es möglich, noch einzelne Magerwiesen in Fettwiesen umzuwandeln. Dies geschieht durch Jauchedüngung. 1949 bestehen (mit den Alpen) 17 Verschlauchungsanlagen in Davos. Die Molkereigenossenschaft besitzt eine zum Vermieten; teilweise wurden die Maschinen von einigen Bauern zusammen angeschafft. So wird in den letzten Jahren immer mehr Magerwiese gedüngt und die Fettwiesenfäche ausgedehnt ${ }^{43}$.

40 walserdeutsch Soppa.

41 Dem stehen heute besonders die großen Baukosten entgegen. Zum Schermen muß auch eine neue Straße angelegt werden. Die Entfernung zur Molkerei nach Davos-Platz wird größer und damit erhöhen sich die Fuhrlöhne.

42 Jahresbericht der Molkereigenossenschaft 1922/23.

. 48 Trotz anfänglichem Mißtrauen scheint sich das Güllen durchzusetzen. Es ist eine große Arbeitsersparnis, verlangt jedoch die gegenseitige Hilfe (Transport der schweren Pumpe). Die Schwierigkeit liegt bei den hohen Anschaffungskosten für einen Bergbauern. Darum wird man auch in Zukunft in der Landschaft Davos nocls das mühsame und Zeit raubende "Anlegen des Mistes“ im Frühling und in Herbst antreffen. 
Weide ist für den Davoser Viehbestand genügend vorhanden. Der Futterertrag der Wiesen setzt die Grenzen. Daher sind zwei Fälle interessant, wo Weide zur Wiesfläche wurde.

Schatzalp:

Ein ursprünglicher Bauernbetrieb mit Alp und Heimgut wurde durch Erbschaft in zwei selbständige Betriebe gespalten. Die Alp besitzt durch die Nähe des Sanatoriums Schatzalp einen dauernden Milchabnehmer und gute Zufahrtsstraßen (Schatzalpbahn). So entstand ein selbständiger Betrieb mit einer Fettwiesenfläche von acht Kuhwinterungen. An die Wiesen schließt direkt die Alpweide an, die 35 Stöße besitzt. Das Vieh wird im Sommer von einem höher liegenden, an die Wiese angrenzenden Alpstall in die Weide getrieben ${ }^{44}$.

Clavadel:

Der Landwirtschaftsbetrieb der Zürcher Heilstätte arbeitet seit 1919 mit vielen Versuchen an der Verbesserung ihres Landes. Eine richtige und angepaßte Kunstdüngerverwendung (zuerst in kleinen Stücken) führte innerhalb weniger Jahre zu einer Ertragssteigerung um das Doppelte ${ }^{45}$ (Schwendimad: Düngung mit Holzasche, Ertrag 1919: 3 Burdenen, 1920: 12, 1922: 13). Der Heuertrag wuchs pro Are auf $102 \mathrm{~kg}$ Dürrfuttergewicht, das Emd auf $38 \mathrm{~kg}$, das entspricht einer Jahresernte von $14000 \mathrm{~kg}$ auf einer Meereshöhe von $1680 \mathrm{~m}^{46}$. 1926 baute die Zürcher Heilstätte auf $2028 \mathrm{~m}$ Höhe einen vorbildlich, modern eingerichteten Stall und führte Räumungen, Reutungen und Entwässerungen durch. Heute besitzt der Betrieb $10 \mathrm{KW}$ (ca. $10 \mathrm{ha}$ ) im Tal und $14 \mathrm{KW}$ (ca. $19 \mathrm{ha}$ ) auf der Alp, in einer Höhe von $1850-2120 \mathrm{~m}$, gedüngte Fettwiesen. Die Wiese auf der Alp kann jedoch nur in besonders günstigen Jahren zweima! geschnitten werden ${ }^{17}$.

\section{Der Wald.}

\section{Gemeindewald:}

Die Gemeinde Davos konnte bis jetzt drei größere Waldstücke erwerben. Den Zügenwald (218 ha) kaufte 1807 die Bergwerksgesellschaft Monstein-Silberberg von der Fraktion Monstein. Nach dem Zusammenbruch des Unternehmens kam er in verschiedene Hände, bis ihn 1934 die Landschaft erwarb. Den Aebiwald am Ausgang des Sertigtales kaufte die Gemeinde 1938, und 1947 erwarb sie auch noch 31 Lose des Kircherbannwaldes ( 39 Lose $=41,5 \mathrm{ha}$ ), wovon immer noch 8 Lose in Privatbesitz sind. In zwei großen Aufforstungen am Albertibach (57 ha, Beginn 1909) und Schiahorn-Dorfberg (26 ha, Beginn 1924) kämpft die Gemeinde gegen Lawinen und Zerstörungen der Erosion. Wie wichtig eine planmäßige Aufforstung ist, zeigen die Lawinenschäden des Winters 195148 :

\section{Zerstörte Waldfäche:}

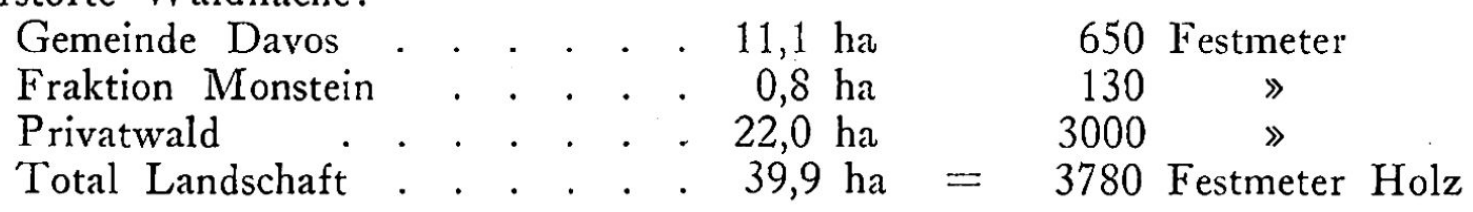

Monstein ist die einzige Nachbarschaft, in der der Wald nicht aufgeteilt wurde, sodaß alle Nachbarn gleichmäßig ihren Gewinn oder Holzanteil erhielten (598 ha). Davos-Dorf besitzt im Wehriwald und Bannwald noch zwei Parzellen.

${ }^{44}$ Höhe des Hauses mit Heimstall $1915 \mathrm{mu}$ u. M., Alpstall und obere Wiesengrenze $1980 \mathrm{~m}$, untere Wiesengrenze $1850 \mathrm{~m}$.

45 Vergleiche "Der Bündner Bauer “ 1924, Nr. 30-33, Kell.er, G., Verwalter von Clavadel.

46 Nach den Angaben der Versuchsanstalt Oerlikon sind $4000 \mathrm{~kg}$ ein schwacher, $8000 \mathrm{~kg}$ ein mittlerer und $14000 \mathrm{~kg}$ ein hoher Ertrag.

${ }_{47}$ Die Alpgenossenschaft Clavadel besteht aus 4 Bauern mit $37 \mathrm{KR}$ und der Zürcher Heilstätte mit $20 \mathrm{KR}$. Sie besitzt einen Schermen auf $2141 \mathrm{~m}$ Meereshöhe.

${ }_{48}$ Freundliche Mitteilung von Herrn Gregorı, Kreisförster. 
Neben der Gemeinde als Trägerin des Forstschutzgedankens besteht am Wolfgang im Totalbergsturzgebiet noch eine private Dälenschutzwaldgenossenschaft (Dälen, Dellen = Föhren). Zeigt das nicht, wie stark die ganze Davoser Wirtschaftsgliederung auf einer historisch entwickelten Privatinitiative aufgebaut ist!

\section{Genossenschaftswald:}

Ein großcr Teil der Waldungen, vor allem im Unterschnitt, wurde nicht ganz aufgeteilt, sondern blieb als Genossenschaftswald (Löserwald) erhalten:

Chummerlöser - Glaris, 12 Lose (9). Dunkelschlucht-Glaris (4). Jaztobelwald-Glaris, Spina (5). Büschenwald-Spina (6). Zäunenwald-Spina (7). Hellentobelwald-Frauenkirch (5). Kientobelwald-Frauenkirch, 20 Lose (11). Äußerer Würzenwald-Frauenkirch, 31 Lose (13). Innerer Würzenwald-Frauenkirch (15), Seitenwald-Frauenkirch, 91 Lose. (In Klammer: Anzahl der Losbesitzer.)

Die Aufteilung der Wälder fordert die Abgrenzung von vielen Einzelparzellen. Diese Arbeit fällt beim Löserwald weg. Hier wird das Holz (früher Gmeiwärch) gefällt und aufbereitet und nachher an die Losinhaber verteilt, welche auch die Kosten des Fällens tragen.

Waldverteilung in der Landschaf:

\begin{tabular}{|c|c|}
\hline $\begin{array}{l}\text { Semeindewald } \\
\text { raktionswald: Monstein, Dorf } \\
\text { Canton, andere Gemeinden usw. } \\
\text { rivatwald }\end{array}$ & $\begin{array}{r}290 \text { ha }( \\
610 \text { ha } \\
30 \text { ha } \\
3350 \text { ha }\end{array}$ \\
\hline indschaft $\mathrm{Da}$ & 280 ha (c \\
\hline
\end{tabular}

dreal-verlcilung in der Landschafl $:^{\text {t9 }}$

\begin{tabular}{lrr} 
Offenes Weideland & $11240 \mathrm{ha}$ & $44,4 \%$ \\
Unkultivierbar & $6390 \mathrm{ha}$ & $25,3 \%$ \\
Wald & $4280 \mathrm{ha}$ & $16,8 \%$ \\
Kulturland (Wiesen, Äcker) & $2818 \mathrm{ha}$ & $11,1 \%$ \\
Gebäude, Straßen, Anlagen & $380 \mathrm{ha}$ & $1,5 \%$ \\
Gewässer & $232 \mathrm{ha}$ & $0,9 \%$ \\
\cline { 2 - 3 } Fläche der Lindschaft Davos & $25340 \mathrm{ha}$ &
\end{tabular}

\section{Gebäucle:}

\section{DER LANDWIRTSCHAFTLICHE BETRIEB}

Das alte Davoserhaus ist ein einfacher, geschlossener Strickbau aus unbehauenen Holzbalken. Die Giebelseite schaut ins Tal. Gemauert ist im vordern Teil der Unterbau, hingegen seltener auch der Küchenteil 50. Vorne befindet sich dic Stube mit zwei kleinen Fenstern an der Giebelfront und einem an der Längsfront, daneben eine Kammer. Die hintere Fälfte nimmt die Küche ein mit dem offenen Kamin und der Herdstelle, die zentral an die Stube angrenzend liegen, hinten ein kleines Vorratskämmerchen oder Holzschopf. Über der Stube liegt die Kammer, eine zweite kleinere befindet sich über der Küche, meist bergwärts mit einer Lichtluke. Steinhäuser gab es nur wenige ${ }^{51}$. Im 17./18. Jahrhundert begann man die Blöcke zu behauen 52. Die Häuser wurden sehr oft zu Doppelhäusern vergrößert mit einem durchgehenden, zentralen Gang, der den bergwärts liegenden Küchentrakt vom Wohnteil trennte. In der Küche lag nun der Herd bergwärts, der getrennte

4y Die Vermessung der Landschaft Davos ist 1951 noch nicht abgeschlossen. Es fehlt das Flüelatal, für das geschätzte Werte verwendet wurden. Für die Arealangaben danke ich Herrn Joos, Vermessungsingenieur.

50 Alte Häuser finden wir auf dem Meyerhof, auf Bedra, je ein halb zerfallenes in Monstein und auf Spina.

51 BüHl\&R zitiert für Campells Zeit 4 Steinhäuser. Bd. I, S. 189.

52 In Monstein sind die meisten Häuser aus behauenen Blöcken und tragen Jahrzahlen aus dem Beginn des 18. Jahrhunderts. 


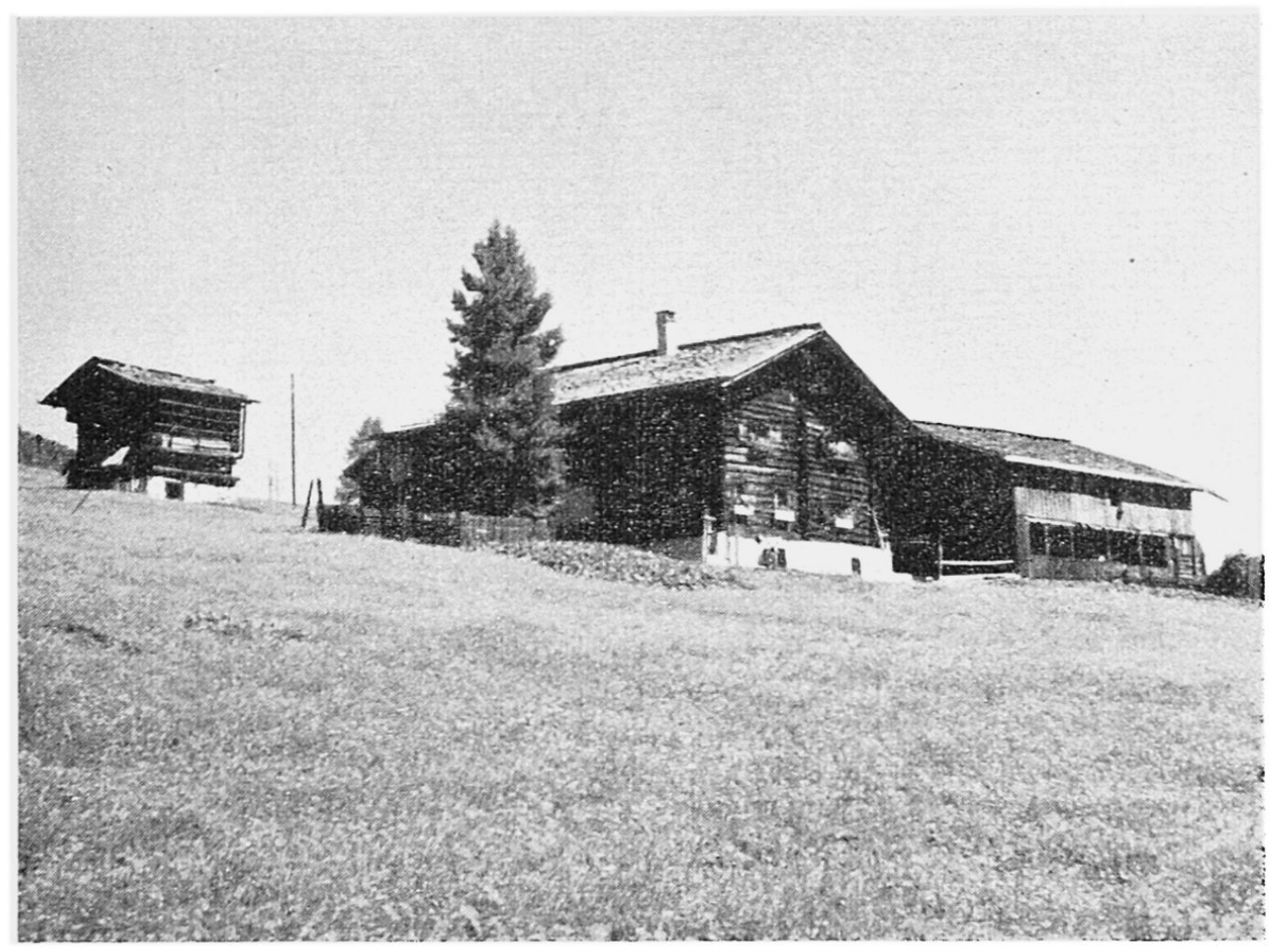

Abb. 5 Bauernhof auf der Langmatle, Frauenkirch. Doppelhaus mit Umbaustall und Spycher. Vor dem Garten „Blaktenfeld“ (rumex alpinus) als Schweinefutter. Aufnahme H. Skxx

Stubenofen konnte vom Gang aus geheizt werden. Im 19. Jahrhundert kleidete man die Holzhäuser teilweise oder auch ganz mit einem Mauermantel ein.

"Seit etwa 15 Jahren ist in Davos sehr in Aufnahme gekommen, die gestrickten und auch Blockhäuser in zeblenda, das heißt selbe, auf die vorstehende Mauer des Erdgeschoßes und seitwärts an die Vorstöße gelehnt, mit einem Riegelgerippe zu überspannen, selbes auszumauern und dann mit gewöhnlich hiebei verbundener beträchtlicher Vergrößerung der Fenster, das Haus als gemauertes darzustellen." 53

So finden wir heute in Davos die folgenden Haupttypen: Das Holzhaus mit Rundlingen und den Strickbau mit den behauenen Balken als einfachen Block oder als Doppelhaus, den Holzbau mit teilweiser und mit ganzer Steinummantelung.

Der ursprüngliche Stall stand neben dem Haus in Giebellage zum Berg. Der untere Teil, ein geschlossener Strickbau, enthält die Stallung, der obere offene Strickbau den Heustock. Letzteren erreicht man auf einer Brücke vom Berg her. Der Eingang zum Stall liegt vorne. Je nach Größe bestehen ein oder zwei Brücken ${ }^{54}$ mit einem seitlichen oder zentralen Mistgang. Im hintern Teil befindet sich bei einzelnen Ställen eine Luke (Rüschla) zum Heustock, durch die das Heu heruntergelassen wird. Bei den meisten Ställen wird jedoch das $\mathrm{Heu}$ in «Zummen » um das Gebäude herum geholt ${ }^{55}$. Alle neuern Ställe sind Doppelställe mit der Traufe zum Berg gebaut ${ }^{56}$. Über dem gemauerten Misthaus liegt ein gedeckter Vorraum. Von diesem aus tritt man in die beiden getrennten Ställe ${ }^{57}$, in den Mittelgang, der quer zum Berg hin verläuft, und an dem auf beiden Seiten die Brücken liegen. Vom

53 BüHLER: Davos in seinem Walserdialekt, Bd. I, S. 189.

54 Walserdeutsch Brügi, rohgezimmerter Bretterboden auf dem die Kühe stehen und der erhöht ist gegenüber dem „Mischtgraba “ und dem Mittelgang.

${ }^{55}$ Die "Uslohställe" sind so gebaut. Sie liegen an der Wies-Weidegrenze. Von hier aus wird das Vieh in die Waldweide ausgelassen.

56 Dieser Typ ist auch im Prättigau überall verbreitet. Abb. 5.

57 Haupt- und Zustall. 


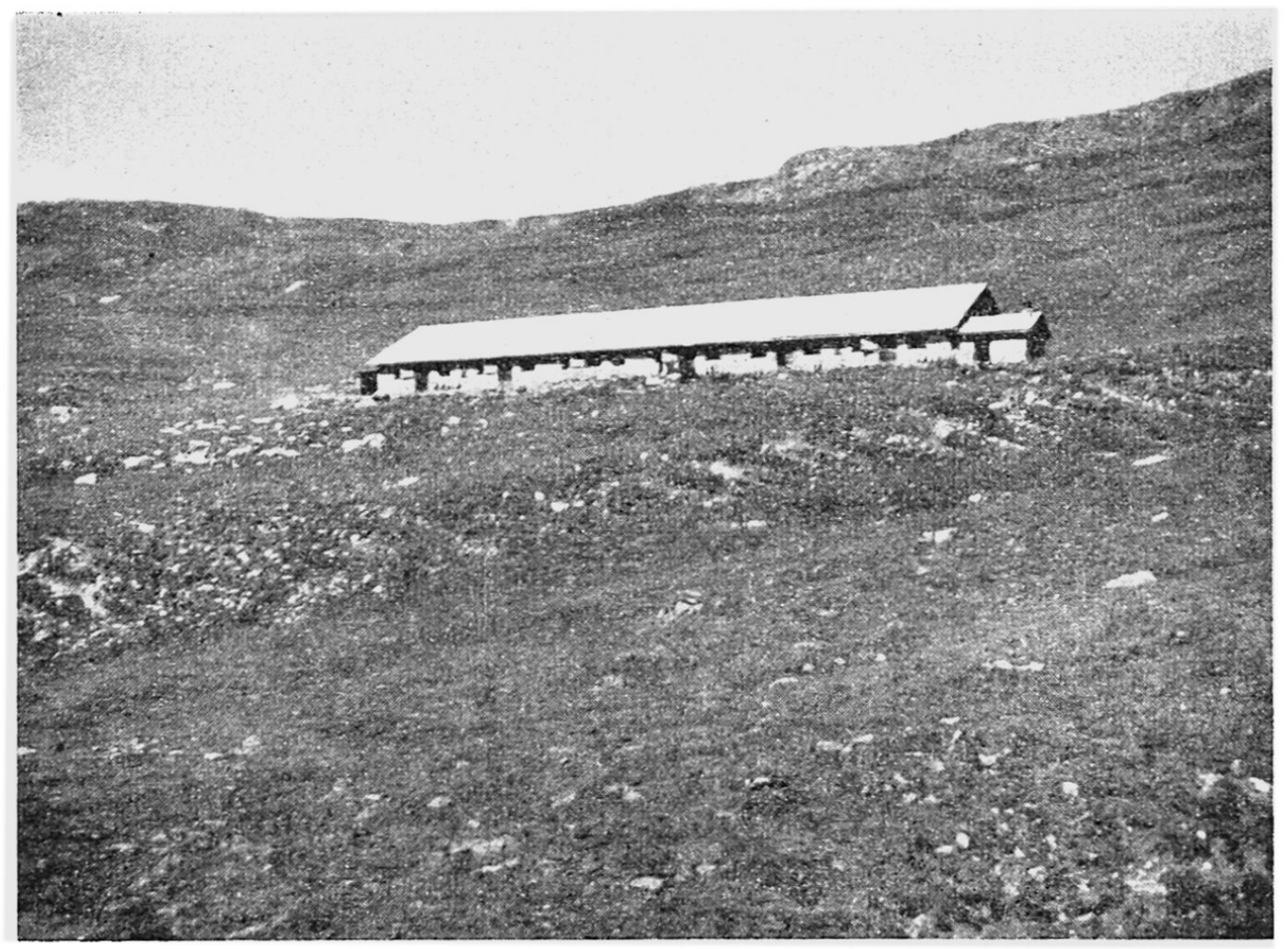

Abb. 6 Alpschermen Fliielaberg. Aufnahme U. SENN

Vorraum aus führt eine Treppe hinauf zum Heustock, der geteilt ist durch einen Quergang und über den Ställen liegt. Das Heu wird von hinten in dieses Tenn eingefahren oder in die beiden Heustöcke getragen.

Die Alphütte besteht aus einem Stallteil und einem Küchenteil. Letzterer reicht bis unter das Dach und diente früher als Verarbeitungsraum für die Milch. Über dem Stall liegen die Wohnstube und ein oder zwei Kammern. Alle Alphütten sind Blockhütten, meistens die Giebelfront ins Tal gerichtet. Sie besitzen noch die kleinen Fensterchen und zeigen die alte, ursprüngliche Bauart.

Das Madställi (sprich Madstelli) oder Madhüttje ist ein offener, kleiner Blockbau, in dem das Heu in den Mädern oder «Usörtern» aufbewahrt wird.

Ein vollständiger Davoser Bauernbetrieb besitzt im Minimum 7 Gebäude (Haus, Stall, Spycher, Uslohstall 55, Alphütte und 2 Madställi). Die durchschnittliche Gebäudezahl liegt aber höher. Meistens hat der Bauer mehrere Ställe, 2-10 Madställi, in Monstein eine ganze Anzahl Spycher und vielleicht auch ein oder zwei Häuser, die er vermietet 58 .

Eine Auszählung der Kuhställe, in denen auch gefüttert wird, ergibt: 13 Bauern besitzen 1 Stall (Bauern ohne Alp), 32 mit 2 Ställen (besitzen keinen Uslohstall), 38 mit 3 Ställen, 44 mit 4 Ställen, 26 mit 5 Ställen, 17 mit 6 Ställen, 9 mit 7 Ställen, 2 mit 8 Ställen und ein Großbetrieb mit 16 Ställen, wo jedoch in verschiedenen gleichzeitig gefüttert wird. Das Heu wird im Winter aufgebraucht, das Vieh wandert von Stall zu Stall. ${ }^{59}$

Näher beim Kurort Davos nimmt die Gebäudezahl ab. Der Bauer ist dort eher besser gestellt und hat sich einen neuen, größern, den hygienischen Verhältnissen besser angepaßten Stall gebaut und den alten abgerissen ${ }^{(0)}$. Aber auch in Frauen-

58 In Monstein : 1 Betrieb mit 36 Gebäuden, ein anderer mit 20. Ein Großbetrieb in DavosDorf (ursprünglich 10 Heimwesen) mit 74.

50 "Hüt tüan mar stella “. Heute wechselt das Vieh den Stall. Mittelhochdeutsch stellen. Althochdeutsch stallja $=$ in den Stall tun. Vergleiche BüHLER, Bd. I, S. 138.

${ }_{60}$ Leer stehende Gebäude wurden durch den wachsenden Kurort beansprucht und umgebaut. 
kirch, Glaris und Monstein baute man Lüftungen und größere Fenster in die Ställe ein, die Stallungen wurden geweißelt, um den Forderungen der Zentralmolkerei gerecht $\mathrm{zu}$ werden. Die große Stall- und Gebäudezahl ist geblieben. Sie stammt aus dem letzten Jahrhundert. Sicher bestehen Vorteile (kurzer Weg beim Heu tragen) ${ }^{61}$; die Nachteile, die großen Kosten des Gebäudeunterhaltes und Versicherung wiegen jene jedoch auf.

\section{Betriebsgröße.}

Im Vergleich zu einem kantonalen oder schweizerischen Mittelwert, muß die mittlere Betriebsgröße in Davos höher liegen. Durch die Höhenlage und kürzere Vegetationszeit sinkt der Ertrag, entsprechend steigt die Produktionsfläche. Von den 185 Bauern, deren Verhältnisse ich 1949 untersuchte, besitzen ${ }^{62}$ :

\begin{tabular}{rcccrr} 
Bauern & $\begin{array}{c}\text { Land } \\
\text { in KW }\end{array}$ & $\begin{array}{c}\text { in ha umgerechnet } \\
\text { KW }=1,43 \text { ha }\end{array}$ & & 1929 & 1939 \\
\hdashline 16 & $2-4$ & $2,80-5,70$ & Betriebe : & 245 & 240 \\
35 & $5 \mathrm{u} .6$ & $7,15-8,60$ & Hauptberuf: & 199 & 189 \\
91 & $7-10$ & $10,00-14,30$ & $-5 \mathrm{ha}$ & 36 & 58 \\
32 & $11-15$ & $15,70-21,45$ & $5-10 \mathrm{ha}$ & 42 & 37 \\
6 & $16-28$ & $22,90-40,00$ & über 10 ha & 167 & 145 \\
1 & 104 & 148,70 & & &
\end{tabular}

Die Hauptgruppe besitzt $10-15$ ha Land. Das entspricht einem Viehstand von 7-10 Kühen. Der Vergleich von 1929 mit 1939 zeigt eine Verkleinerung der Betriebe. Heute kann ein Bauernbetrieb unter $5 \mathrm{KW}$ Land nicht mehr ohne Nebenerwerb bestehen, es ist darum auch zu verstehen, daß 1949 nur noch etwa $20 \mathrm{Be}$ triebe unter 5 ha bestehen gegenüber 58 im Jahre 1939. Zur Sanierung der Bergbauernbetriebe schlägt STACHER 63 vor:

- Bereitstellung von genügend Produktionsfläche pro Betrieb.

- Sistierung zu kleiner Betriebe.

- Einführung intensiverer Bewirtschaftung mittelst Fachberatung.

- Entschuldung finanziell überlasteter Betriebe.

- Güterzusammenlegung.

- Gesetzliche Abschaffung der Erbteilung für Kulturland.

- Schaffung differenzierter Produktionspreise in Berggebieten und sicherung der Absatzmöglichkeiten.

- Schaffung von geeigneten Nebenverdienstmöglichkeiten (Heimarbeit).

Einteilung der Betricbe:

1. Betriebe mit absoluter Lebensfähigkeit, mit genügender Produktionsfläche, geordneter finanzieller Situation und guter Bewirtschaftung.

2. Betriebe mit genug Produktionsfläche ohne Lebensfähigkeit wegen Überschuldung, mangelhaften Bewirtschaftungsmethoden oder enormer Zersplitterung der Produktionsfläche. ${ }^{64}$

3. Betriebe mit zu wenig Produktionsfläche, aber geordneter finanzieller Lage und guter Bewirtschaftung ohne Möglichkeit, die Produktionsfläche durch Pacht oder Zukauf zu vergrößern.

4. Betriebe mit zu wenig Produktionsfläche, schlechter finanzieller Situation und schlechter Bewirtschaftung.

\section{Sanierungsmaßnahmen:}

1. gut, 2. sanierungsbedürftig, 3. mehr Produktionsfläche, 4. müssen aufgelöst werden.*

${ }^{61}$ Das Heu wird in Burdenen, die aus einer Anzahl „Wüschen “ bestehen, auf dem Rücken eingetragen. ( 1 Wüsch sollte hinreichen, eine Kuh innerhalb 24 Stunden zweimal zu füttern.) Der Heuertrag wird in Burdenen oder Seileten (was ein Heuseil umfaßt) angegeben, das sind $40-60 \mathrm{~kg}$ je nach den Kräften des Mannes, der sie auf den Heustock trägt. 90 Seilete entsprechen einer KW also $4000-5000 \mathrm{~kg}$ Heu.

${ }^{62}$ Die Zahl entspricht den hauptberuflichen Landwirten der Statistik.

${ }^{03}$ In Jahresbericht der Molkerei 1943/44.

64 Die Betriebsfläche ist infolge der natïrlichen Güterzusammenlegung im letzten Jahrhundert in Davos verhältnismäßig gut arrondiert.

* Es ist leider nicht möglich, für das Vorkommen der verschiedenen Betriebstypen Zahlen zu bekommen. $70-80 \%$ der Bauernbetriebe sind mit Hypotheken belastet. 
Die letzten 10 Jahre brachten eine starke Mechanisierung des Davoser landwirtschaftlichen Betriebes, wenn auch bis jetzt erst ein Anfang erreicht wurde. Es galt, das Vorurteil zu überwinden, im steilen und kupierten Gelände eines Bergbauernbetriebes sei es unmöglich, Maschinen wirtschaftlich einzusetzen. Für große Teile wird dieser Grundsatz vorläufig auch weiter bestehen, in vielen andern ist es aber möglich, das Gras mit dem Motormäher zu schneiden, den Kartoffelacker mit der Seilwinde «aufzuherden » ${ }^{65}$, zu misten und pflügen, um nur zwei Verbesserungen $z u$ nennen.

Landwirtschaftiche Motoren und Maschinen $19+9:{ }^{60}$

Motormäher

Mähmaschinen (Pferd)

Wender

Futterschneidemaschine

Kunstdüngermaschine

Mistanlegemaschine

Heuaufzüge, Elevatoren in Ställen
Motoren
$10 \quad(3)$

16 (2)

14

6

7

1

1

6
Verschlauchungsanlagen

Pflüge

Seilivinden

Traktoren

Jeep

Lastautos

Boiler (im Stall zur 'Temperierung des Wassers im Winter)

\begin{tabular}{lccc} 
Silo: & Betriebe & Anzahl & $\begin{array}{c}\text { Fassungsvermögen } \\
\text { in Kubikmetern }\end{array}$ \\
\hline 1939 & 3 & - & 79 \\
1946 & 8 & 17 & 193 \\
1949 & 15 & 33 & 380
\end{tabular}

Die Entwicklung der Silowirtschaft steht still, da die Silomilch in der Käisefabrikation nicht erwünscht ist.

Die heutige Landwirtschaft besitzt nicht genug eigene Arbeitskräfte, die Arbeitsspitzen, wie z. B. die Heuernte, verlangen die Einstellung von einem Knecht oder einer Magd. Die Familien sind nicht mehr so kinderreich, wie früher. Die heutigen wirtschaftlichen Erkenntnisse bedingen eine rasche Ernte, sobald das Gras reif ist, im Gegensatz zu frühern Zeiten, wo auch ein überreifes Feld noch warten konnte und die Kartoffelernte oft in den ersten Schneefall hinein reichte. Die meisten Davoser Bauern sind gezwungen, Arbeitskräfte einzustellen, dabei sinkt die Rentabilität der Betriebe stark. Es sind ausschließlich ausländische Arbeiter, Südtiroler und Italiener.

1949 von 185 hauptberuflichen Landwirten: Arbeitskräfte :

$\begin{array}{ll}\text { dauernd: } & \text { männlich 47, weiblich 5, bei } 29 \text { Bauern } \\ \text { nur im Sommer : männlich 196, weiblich 37, bei } 124 \text { Bauern } & \text { 1it }\end{array}$

Beispiel eines landwirtschaftlichen Betriebes ${ }^{68}$.

Franenkirch $19+9$ :

Gebäude:
3 Wohnhäuser
2 Alphütten
7 Ställe
4 Madställe
1 Spycher
Kulturland:
16 a Kartoffeln

9a Gerste (etwas Huronweizen)

4 a Grünfutter (Hafer)

1 a Gemüse

42-43 a Ackerland wurde seit 1945 auf gegeben

$11 / 2 \mathrm{KW}$ Magerwiese, machen die halbe Wiesfiäche aus

$71 / 2$ KW Fettwiese

65 , aufherden “ = die Erde hinaufbringen. Jeden Frühling muß unten am Acker ein Graben von $60-80 \mathrm{~cm}$ Breite und $40-60 \mathrm{~cm}$. Tiefe ausgehoben, und die Erde mittelst eines Flaschenzuges und zwei "Bära " (Zugkarren) an den Oberrand des Ackers geführt werden. Durch das fünfmalige Umhacken (Mist einhacken, Kartoffel stecken, zweimal schürfen, d. h. Unkraut entfernen und ernten) und abschwemmen der Erde wird der Graben wieder ausgefüllt.

$11^{36}$ In Klammer: Die Anzahl 1939 nach der eidg. Betriebsstatistik.

67 Eidg. Produktionskataster 1945: 30 Betriebe dauernd fremde Arbeitskräfte, 150 Betriebe mit Saisonarbeitern.

68 SenN: Leben und Umwelt. Juli 1951. Beispiel eines Monsteiner Betriebes. 


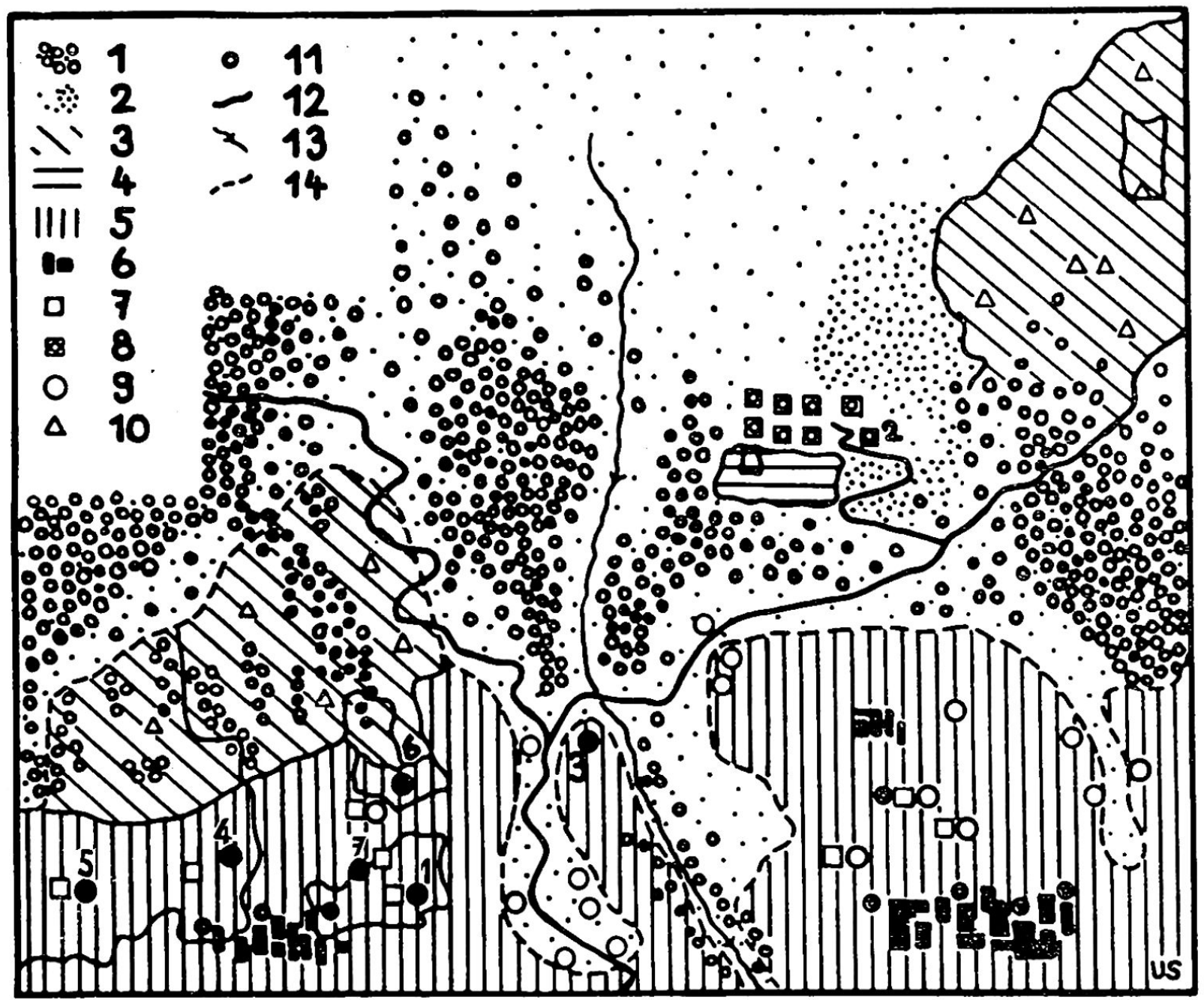

Fig. 4 Wirtschaflskärtchen. 1 Wald - Weide, 2 Weide, gedüngte Weide, 3 Magerwiese, 4 Alplettwiese, 5 Talfettwiese, 6 Acker, 7 Häuser, 8 Alphütte, 9 Stall, 10 Heuhüttchen, 11 Spycher, 12 Alpstraße, 13 Bach, 14 Wies - Weidegrenze. $1-7$ bezeichnen die Ställe des erwähnten Bauern. Wegzeit von Heimstall 1 nach : $5=10 \mathrm{~min} ., 6=10 \mathrm{~min} ., 3=12 \mathrm{~min} ., 2=45 \mathrm{~min}$., Miider $=$ $75 \mathrm{~min}$.

Wald:

13 Lose in 3 verschiedenen Waildern und etwa eine Hektare privat.

Viehstand:
8 Kühe
1 Rind
1 Mese
1 Kalb
4 Ziegen

2 Schweine

20 Hühner

3 Völker Bienen

\section{Maschinen :}

Anteil an der Gïlleverschlauchung der Alpgenossenschaft

Alp : zwei Alprechte mit $8 \mathrm{KR}$ und $7 \mathrm{KR}$

Der Jahresgang des Viehs: ${ }^{60}$

Stallfütterung :

1. Oktober-15. Dezember

15. Dezember-20. Januar

20. Januar-25. März

25. März-5. Mai

5. Mai-5. Juni

Frühlingsweide: 5. Juni ca. eine Woche auf der

$\begin{array}{ccc} & \text { Wiese } & \text { Uslohstall } 3 \\ 14 \text { Tage auf der Waldweide } & \text { Uslohstall } 3\end{array}$

Stall 5

Stall 4

Heimstall 1

Stall 6

Stall 4

69 Alle Zeiten können sich verschieben. Feste Daten sind: 5. Juni frühestes Datum zum Alpauftrieb. 25. September Hirtenentlöhnung in der ganzen Landschatt. 


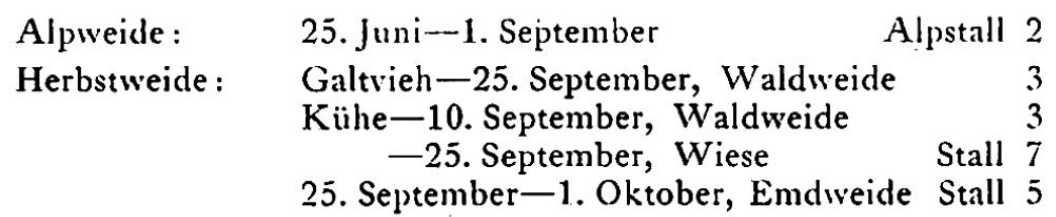

Die Arbeiten des Bauern im Jahresablauf:

Sommerarbeiten:

Misten: Anfangs April nach der Schneeschmelze.

Acker : Aufherden, misten, Mist unterhacken, Gerste säen, Kartoffeln stecken, bis Mitte Mai. Wiesen aufräumen, Erstellen der Zäune, Verbesserungen an Gebäuden, Kartoffeln hacken (Unkraut), Gmeiwärch.

Heuen : Anfangs Juli, Wiesen, Usörter, Mäder von der Alp aus Anfangs August.

Emden: Nach ungefähr einer Woche Zwischenraum bis Anfang September. Die Frauen suchen in dieser Woche von der Alp aus Beeren.

Ernte: Gerste, Kartoffeln im September.

Bis zum Schneefall : Aufherden der Äcker, misten der Wiesen.

Winterarbeiten :

- Reparaturen an Häusern, Holzarbeiten, Heu holen von den Usörtern und Mädern. ${ }^{\mathbf{} 0}$

Der Davoser Bauer befindet sich heute nur noch kurze Zeit mit der ganzen Familie auf der Alp, wenn er die Mäder mäht und die Zwischenzeit bis zum Emden (14 Tage bis 3 Wochen im August). Länger sind die Bauern des Flüela-, Dischma- und Sertigtales dort, da sie große Alpwiesen zu mähen haben.

\section{DIE ATZUNGSTYPEN (ENTWICKLUNGSTYPEN)}

\section{Die Weidgenossenschaft Dorf.}

Genossenschafter sind die Besitzer von Wiesboden innerhalb der ehemaligen Nachbarschaft Seewer sonnen- und litzihalb, so heißt es heute noch in den Statuten dieser Atzung. Das Weidegebiet umfaßt die Waldweide vom Ausgang des Dischmatales bis zum Flüelatal und ein Stück am Davosersee an den Hängen des Seehorns. Früher gehörte auch noch die Waldweide auf der rechten Talseite dazu, die Stockenweide, die jetzt in Privatbesitz übergegangen ist. Das Weideareal entspricht demnach dem alten Allmendbesitz der Nachbarschaften. Auch heute noch ist jeder Landbesitzer innerhalb dieser Grenzen (entspricht der Fraktion DavosDorf ohne Wolfgang, Laret und Flüela) weideberechtigt ${ }^{71}$. Die Weiderechte richten sich nach dem Wiesboden.

$$
\begin{aligned}
& 50 \text { Aren Fettboden . . . . . = } 1 \text { Kuhland } \\
& 5 \text { Aren Fettboden . . . . . } \Rightarrow 1 \text { Burde } \\
& 100 \text { Aren Halbfettboden . . . = } 1 \text { Kuhland } \\
& 10 \text { Aren Halbfettboden . . . }=i 1 \text { Burde }
\end{aligned}
$$

Wer eine Kuh weiden läßt, muß + Kuhland (2 ha) Wiese besitzen. Er darf keine Rechte von einem andern Wiesenbesitzer pachten und nicht mehr als 5 Kühe auftreiben, desto weniger Weidezins muß der einzelne Bauer zahlen. 1949 waren weiden. Die nicht bestellte Weide ist jedes Jahr mit Fr. 2.50 pro Kuhweide zu verzinsen. Je weniger leere Weiden also zurückbleiben und je mehr Bauern ihr Vieh auftreiben, desto weniger Weidezins muß der einzelne Bauer zahlen. 1949 waren $323 / 4$ Weiden bestoßen. Sie verteilten sich auf 9 Besitzer von $\mathrm{W}^{r}$ iesland (1 Metzgermeister und ein Viehhändler ohne Alp, 2 Baucrn ohne Alp), die andern hielten nur ein oder zwei Heimkühe dort ${ }^{73}$. Die Beschlußfassung über Kauf und Erwerb von

${ }^{70}$ Es wird in „Stückli “ (Heuballen) $50-80 \mathrm{~kg}$., 2-4 hintereinander gekoppelt auf Schlitten oder speziellen Heubrettern ins Tal geführt. Das Heubrett ist vorne aufgebogen, $100-150 \mathrm{~cm}$ lang und $40-80 \mathrm{~cm}$ breit und wird als Kufe unter die Heuballen gelegt.

71 Vergleiche Fig. 1.

72 Ausnahmen darf die Genossenschaftsversammlung beschließen. Da heute nur noch ein paar Bauern ohne Alp ihr Vieh dort weiden lassen, dürfen diese ihren ganzen Bestand auftreiben.

${ }_{78} \mathrm{Mehr}$ aus Pflichtbew'ustsein gegenüber den andern, als aus Notwendigkeit eine Heimkuh am Land zu haben. 
Boden und Liegenschaften müssen von der Genossenschaftsversammlung bestätigt werden. Der Landwirt besitzt damit eine Kontrolle gegen Bodenspekulationen, die gerade am Rand des Kurortes Bedeutung gewinnt. Heute teilen sich 61 Teilhaber in 1340 Aren Wiesland, das 314 Kuhland und 6 Burden entspricht, damit hätten theoretisch 74 Kühe Weiderecht, was nicht mehr dem geschätzten Nutzungswert der Bauern (40 KR) gleich kommt. An der Wies-Weidegrenze stehen keine Uslohställe. Das Vieh wird vom Heimstall aus auf der Straße nach der Weide getrieben.

\section{Die Kaisernatzung:}

Sie -besitzt die Waldweide am linken Talhang im Dischmatal gegenüber Kaisern. Dazu kommit noch ein Stück über der Waldgrenze, das früher der Gemeinde Conters als Schafalp gehörte. Die Kaisernatzung entstand aus einem Teil der alten «Gemeinen Weide Dischma». Die Allmend ist aufgeteilt, bestimmte Bauern besitzen bestimmte Nutzungsrechte. Sie umfaßt heute 21 Stöße, die auf drei Bauern in den angrenzenden Höfen Kaisern $\left(9 \frac{1}{2} \mathrm{KR}\right.$ und $\left.8 \mathrm{KR}\right)$ und in den Büelen $(3 \mathrm{r} / 2$ KR) verteilt sind. Gewöhnlich sind 15-17 Weiden bestellt. Schmalvieh darf keines weiden. Auf der linken Talseite am Waldrand stehen die Uslohställe, von denen aus das Vieh den ganzen Sommer in den Wald getrieben wird.

Genau gleich aufgebaut sind die anschließenden Wildi- und die Wildbodenatzung. Letztere umfaßt zwei durch das Sertigtal getrennte Weiden, wobei die eine noch etwas über die Waldgrenze hinausreicht. Dort wurde im letzten Jahrzehnt auf $2000 \mathrm{~m}$ Höhe eine Nothütte für das Galtvieh gebaut.

Ebenfalls aus einer gemeinen Weid entstanden, sind die Sonderweiden und drei Frühlings- und Herbstwreiden.

Die Sonderweiden sind entweder 'Teilstücke der Allmend (sicher Stockenweid) oder später von der aufgeteilten, gemeinen Weide abgetrennte Weiden, heute Sondereigen, d. h. Einzelbesitz. In den andern Fällen kann nur schwer entschieden werden, zu weichem Zeitpunkt sie sich ablösten (Lusiweide-Laret, BleiktenwaldWolfgang, Schiatobel, Mattenwald-Platz, Spinabad). Die Sonderweiden sind klein und grenzen an das eigene Wiesland. Sie werden vom Heimstall oder besondern Uslohställen aus bestoßen.

Das Waldje am Ausgang des Flüelatales besitzt eine große, aber sehr steile und schlechte Weide, die auch etwas über die Waldgrenze hinaus reicht. Die Weide schließt nicht direkt an das Heimgut an. Noch zu Beginn dieses Jahrhunderts war das Waldje ein dauernả besiedelter Hof mit Haus, Stall und Wiesen, von dem aus das Vieh im Sommer in den angrenzenden Wald gelassen wurde. Heute nimmt es eine Zwischenstellung ein, vergleichbar mit einem Uslohstall.

Die Junkersboden-, Hitzeboden- und Staflerweide (die letzten beiden fälschlicherweise Sonderweide genannt ${ }^{74}$ sind gemeine Weiden, die nur im Frühling und Herbst genutzt werden und in welchen die angrenzenden Höfe Rechte besitzen. Sie sind alle in Kuhweiden aufgeteilt und werden vom Üslohstall bestoßen.

\section{Monstein:}

Bei den drei Monsteineralpen Inneralp, Oberalp und Haupter-, Haupt- oder Haudalp ging die aufgeteilte Allmend in den Besitz der Alpen über. $Z u$ jeder gehört das unten anschließende Waldareal zur Nutzung, das in den Alprechten eingeschlossen ist und keine besondern Weiderechte mehr hat. Monstein kennt keine Uslohställe. Schon sehr früh (anfangs Juni) kommt das Vieh auf die Alp und weidet von dort aus abwärts bis zur Wiesengrenze in den Wäldern. Es nimmt damit eine Sonderstellung ein, die wohl durch die nahe Lage der Heimgüter an der Weide zu erklären ist. Diese dringt dem Bach entlang bis an die obersten Häuser

it Vergleiche S. 284. 
der Dorfgasse. Früher zog das Vieh jeden Tag aus den Heimställen durch die Gasse auf die Weide ${ }^{75}$.

Bärental-Alp (Abb. 7).

Auch bei der Bärentalalp ist die gemeine Weide in den Besitz der Alp übergegangen. Sie unterscheidet sich von den Monsteineralpen nur durch die Uslohställe an der Wies-Weidegrenze, die im Frühling und Herbst benutzt werden. Wie die Bärentalalp sind die meisten Davoser Alpen aufgebaut. Sie gehören entweder einer Anzahl Bauern, die sich zu einer Privat-Korporation zusammengeschlossen haben, oder einem Einzelnen. Die Stillbergalp (Dischma) und Stützalp (Wolfgang) bauten zu Beginn dieses Jahrhunderts gemeinsame Alpschermen an die Stelle der vielen, privaten Alphütten.

Flüelaberg-Atzungsgenossenschaft (Abb. 6).

Die Geschichte der Alp Flüelaberg durchläuft drei Stadien. 1. Das Flüela-Dörfli 76 ist das ganze Jahr bewohnt. Von den Uslohställen weidet das Vieh im Sommer zuerst die nähern und dann die entferntern Weiden über der Waldgrenze ab. 2. Das Flüela-Dörfli wird zur Alpsiedlung und ist nur noch im Sommer bewohnt (Frühestens Ende 17. Jahrh., wahrscheinlich aber erst im 18. Jahrhundert). 3. 1915 nimmt die Flüelaberg-Atzungsgenossenschaft den Alpschermen über der Waldgrenze auf $2257 \mathrm{~m}$ Höhe in Betrieb. Schon 1912 wurde zum Bau eine Luftseilbahn erstellt, die weiter bestehen blieb und heute statt einer Alpstraße die Verbindung von der Alp zur Flüelastraße aufrecht erhält. Ganz analog entwickelte sich Bedra (Seilbahn und Schermen 1918) und Rüediställi (Alpstall 1928 mit Alpweg).

Clavadeler-Atżungsgenossenschaft (Abb. 4).

Die Entwicklung der Alp Clavadel ist die gleiche, wie diejenige der Bärentalalp. 1933 baute man jedoch auf $2141 \mathrm{~m}$ Höhe noch einen Alpschermen, sodaß Clavadel heute zwei Stafel besitzt 77: Die alte Alp, die kurze Zeit gebraucht wird und den Schermen. Das gleiche machten auch die Bauern der Kühalp 1941 (ein Teil der Atzungsgenossenschaft Hinter den Eggen), der privaten Büschalp (Davos-Dorf) und der verpachteten Podestaten oder Schatzalp. Die Podestatenalp besitzt sogar zwei Schermen, einen an der Stelle der Alphütten auf 1990 m Höhe und den andern in einer Höhe von $2260 \mathrm{~m}$.

\section{ALPWIR'TSCHAFT}

Der. Alpbegriff.

Nach der Definition von Hösli ${ }^{78}$ ist eine Alp ein Bergareal, das ausschließlich von einem vom Heimbetrieb getrennten, temporären Weidebetrieb allein, oder von mehreren gemeinsam bewirtschaftet wird 79 .

Die Alp ist ein temporärer Teilbetrieb der alpinen Landwirtschaft und je nach Ortlichkeit wirtschaftlich enger oder weniger stark auch im Sommer mit dem Heim-

75 Monstein trägt heute den Charakter einer Dorfsiedlung, trotzdem es von Walsern als Streusiedlung angelegt wurde. Bedingt durch die topographisch günstige Lage (aufgeschüttete Terrasse in den postglacialen Davoser-Großsee) verdichtete sich die Siedlung durch Anlage neuer Höfe zu einem Dorf. Das gleiche gilt auch für Laret. Vergleiche den selben Vorgang für Nufenen bei IssLER: Geschichte der Walserkolonie Rheinwald, S. 43.

${ }_{76}$ Das Dörfli ist eine Hofsiedlung und besitzt nicht den Charakter eines Dorfes. Dörfli nannten die Walser die wichtigsten Hofgruppen nach dem Hauptzentrum, dem Platz.

77 Von Stafelwirtschaft spricht man, wenn vom gleichen Betrieb Weiden in verschiedenen Höhenlagen im Turnus gemäß dem jeweiligen Stand der Vegetation genutzt werden, und neben dem Vieh auch das Alppersonal die Wanderung mitmacht, was ihm durch Bestehen geeigneter Gebäude auf den verschiedenen Stufen möglich ist. - SIMMEN : Puschlaver Alpwirtschaft, S. 87.

78 HösLI: Glarner Alp- und Landwirtschaft, S. 209 f.

79 Vergleiche auch die Definition von Werss: Das Alpwesen Graubündens, S. 53. 


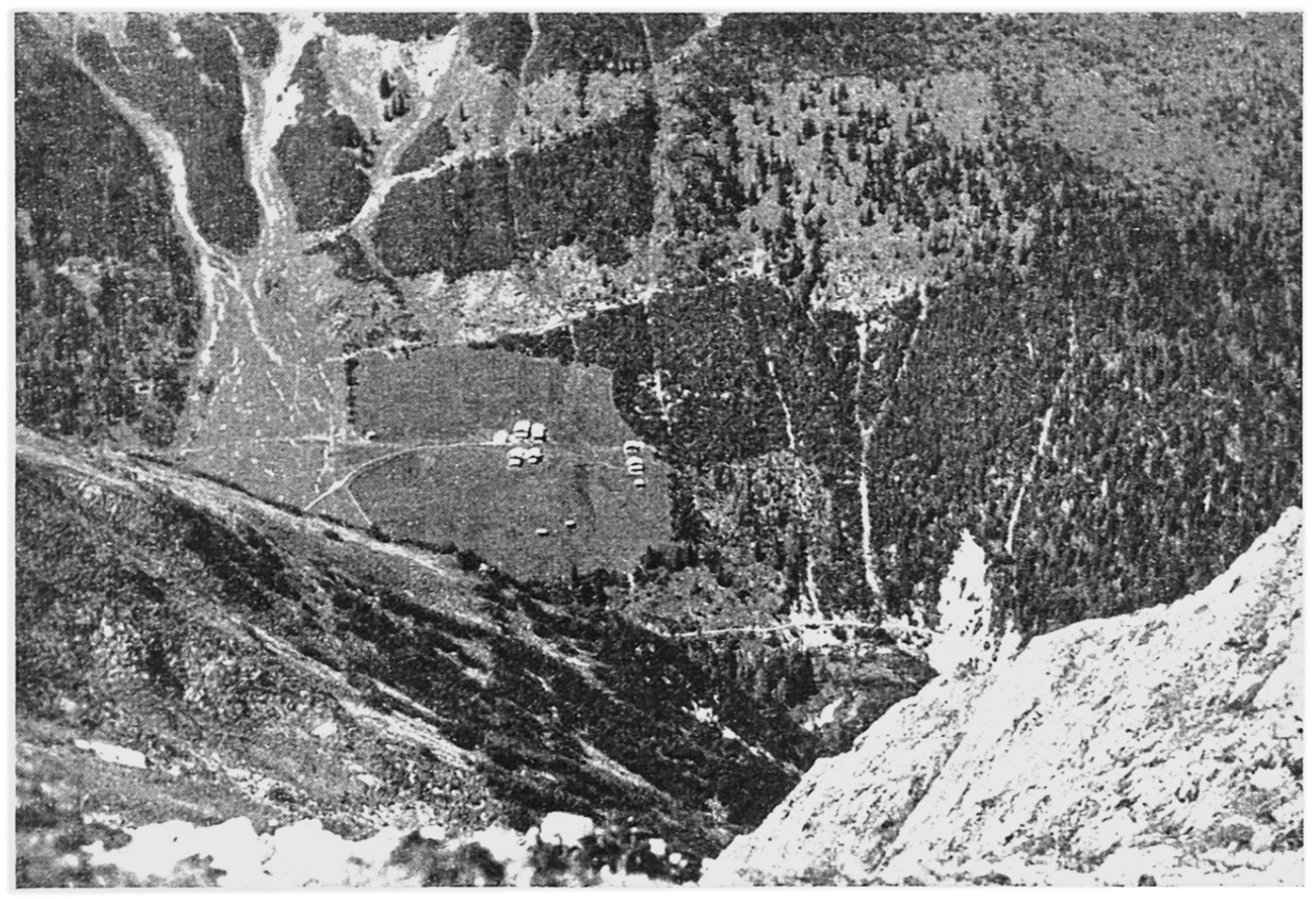

Abb. 7 Bärental-Alp. Im Lawinenzug, linke Bildhälfte, sind die Stein-Lesehaufen im Weidegebiet gut erkennbar. Aufnahme H. SEN.

betrieb verbunden. In Davos sind die wirtschaftlichen Bindungen so stark, daß überhaupt nicht von einem getrennten Betrieb gesprochen werden kann. Jeden Morgen kehrt der Bauer wieder ins Tal zurück, und jeden Abend steigt er auf die Alp, um sein Vieh zu besorgen. Eine Trennung besteht insofern, als die Sömmerung nicht vom Heimstall ausgehen darf, sondern von einem eigenen Stall, sonst spricht man von einer Heimweide. Heimweiden sind demnach viele Sonderweiden. Alle Sonderweiden, die von einem Uslohstall aus bestoßen werden und ebenso der Typ der Kaisern-Atzung könnten nach dieser Definition als Alpen angesprochen werden. Die Frühlings- und Herbstweiden, Typ Hitzeboden, sind untergeordnete Gebiete, da für die ganze Sömmerung noch eine andere Weide nötig ist. In Davos würde niemand von einer Alp Lusiweid (Sonderweid) sprechen, auch die naheliegende Weide von Kaisern wird als Atzung und nicht als Alp bezeichnet. Zwischen einer Alp und dem Heimgut muß eine gewisse Distanz liegen, bis man von Alp spricht. Aber vor allem muß die Atzung in den Raum der alpinen Gebirgsweide (offene Weide) hinein reichen, in die Alpzone ${ }^{80}$. Mit dieser entscheidenden Forderung können wir alle Heimweiden und Atzungen von der Alp trennen, diese entsprechen nun auch der Vorstellung und Auffassung des Bauern von einer Alp. Für Davos gilt:

Eine Alp ist ein Bergareal, das größtenteils über der obern Waldgrenze liegt, und ausschließlich im Sommer von einem vom Heimgut örtlich getrennten, temporären Weidebetrieb allein, oder von mehreren gemeinsam bewirtschaftet wird.

Damit fallen als Alpen alle Sonderweiden, die Frühlings- und Herbstweiden und Atzungen wie Kaisern, Wildi, Wildboden und Waldje weg. Die letzteren neh-

${ }^{80}$ Die Alpzone ist der Raum der Gebirgshochweiden, der dem Vieh als Sömmerung dient und vielfach als Nebennutzung den Ertrag von Berggütern und Wildheuplanken abwirft. SIMMEN: Die Puschlaver Alpwirtschaft, S. 13. 
men eine Zwischenstellung ein, da sie auch etwas in die Alpzone hinein reichen. Die zugehörigen Uslohställe befinden sich jedoch so nahe am Heimbetrieb, daß man sie zu den Sömmerungsweiden zählen muß, was auch die Bezeichnung Atzung angibt ${ }^{81}$.

Der sömmerliche Weidebetrieb besitzt eine bestimmte Organisation und Wirtschaftsform, er wird ergänzt durch die winterliche Stallfütterung. Daher kann man auch im engern Sinne den sömmerlichen Weidebetrieb in Berggebieten als «Alpwirtschaft » bezeichnen. Der Begriff Alpwirtschaft als alpine Landwirtschaft, oder Landwirtschaft des Bergbauern, grenzt jedoch noch andere Wirtschaftsformen mit ebenfalls zeitlich genutzten getrennten Weideflächen $a b$, die Transhumanz und den Nomadismus 82. Die Alpwirtschaft besitzt als Unterscheidungsmerkmal zu diesen, die winterliche Stallfütterung.

$E_{s}$ ist eine Viehwirtschaft mit einem sömmerlichen Weidebetrieb in der Alpzone und Stallfütterung in einer. Wintersiedlung, wo auch im Sommer das Heu fïr die Winterung gequonnen wird.

Diese Definition trennt die Alpwirtschaft vom Nomadismus und der Transhumanz. Durch die örtliche Festlegung des sömmerlichen Weidegebietes in die Zone der Hochgebirgsweiden, wird auch eine Weidewirtschaft (Koppelweiden, Sömmerungsweiden), wie wir sie in Mitteleuropa oder im schweizerischen Mittelland finden, ausgeschieden ${ }^{83}$.

\section{Dic Atzungsgenossenschaft Stafelalp (Alporganisation) (Abb. 8).}

Wie der Alp- und Murmendenbrief der Leidbachalp 84 zeigt, war die Organisation der Alpen im 16. Jahrhundert in ihren Hauptzügen festgelegt. Es folgten nur noch Verbesserungen und Zusätze bei Veränderungen oder Neuerungen. Auch für die Stafelalp läßt sich das feststellen. 1655 legt ein Spruchbrief ${ }^{85}$ einen Streit bei, den die Genossen der Stafleralp um die Sonderweide von Foppa und Rongg ausfechten. Beides sind ehemalige Allmenden und dann gemeine Weiden, Foppa gehörte in den Bereich der Nachbarschaft Langmatte und Rongg in diejenige der Siebelmatte. Die Genossen setzten sich aus den beiden Nachbarschaften zusammen (noch heute). Das Überstellen der Weide gab einmal mehr den Anlaß zum Streit; weiter hatten sich im Laufe der Zeit die Weiderechte verschoben, sodaß Nachbarn der Siebelmatte Weiderechte auf der Foppa besaßen und umgekehrt. Man entschied sich, die Weiden wieder abzulösen, am besten umzutauschen ${ }^{86}$. Die Langmattener dingten sich noch ein Sonderrecht aus, daß sie nämlich bei Schneefall in die tiefer liegende Weide der Siebelmatte (Rongg) durften, die andern dafür nachher dic entsprechende Zeit hinauf in die Foppa ${ }^{87}$. Die untere Weide («Sonderweide»)

81 Der Begriff Atzung wird in Davos auch für Alpen gebraucht. Wahrscheinlich aus dem Empfinden, daß die Haupttätigkeit auf der Alp heute die Weidenutzung. ist, seit die Milch nicht mehr auf der Alp verarbeitet wird. Von diesem Gesichtspunkt aus könnte man alle Alpen in Davos in Frage stellen. Da aber Jungviehalpen auch keine Milch verarbeiten und alle Davoser Alpen früher sennten, so wird die Bezeichnung Alp weiterhin zutreffen.

82 Vergleiche B๔sch. H.: Nomadismus, Transhumanz und Alpwirtschaft. Die Alpen, Juni 1951, S. $202-207$.

83 Klare Definitionen zur Abgrenzung der 3 Wirtschaftsformen gibt Blaches: Nomadismus : Déplacement du troupeau de pâturage en pâturage avec toute la population. Transhumanz: Déplacement du troupeau de pâturage en pâturage avec des bergers. Alpwirtschaft: Déplacement du troupeau vers un pâturage écarté après une période de stabulation.

84 Vergleiche Seite 287.

85 Davoser Archiv Brief 84 vom 15. Obtober 1655.

${ }^{80}$ Heute besitzen die meisten Bauern auf der innern (Rongg-Siebelmatte) und äußern (FoppaLangmatte), untern Weide Rechte. Hingegen weiden ganz bestimmte Bauern auf der äußern oder innern Weide. Innere, untere Weide : 8 Bauern (2 davon wohnen in der Nachbarschaft Langmatte). Äussere, untere Weide: 5 Bauern, alle aus der Nachbarschaft Langmatte.

87 Vergl. Grass: Beiträge zur Rechtsgeschichte der Alpwirtschaft. Schneefluchtrecht, S. 121. 
schien stark übernutzt gewesen zu sein. Besaß ein Bauer Lösvieh ${ }^{88}$, so mußte er dieses bei Schneefall, wenn das andere hinunter auf die Schneefluchtweide (untere Weide) getrieben wurde, in Stall behalten. Verschiedene andere Grundsätze wurden damals festgelegt und erscheinen heute wieder in den Statuten der Alpgenossenschaft. Die Statuten geben uns Auskunft über die Organisation einer Alp. Diejenige der Stafelalp möge als Beispiel dienen, andere aus weitern Davoser Alpen sind ähnlich. Die heutigen Statuten stammen aus dem Jahre 1934 und fußen auf einem Beschluß des großen Landrates vom 6. Juni 1933, der verlangte, daß Statuten und Verzeichnisse der Weidberechtigten jeder Alp erstellt werden sollten ${ }^{89}$. Sie wurden auf Grund der alten Weidbücher und des Gewohnheitsrechtes ausgeführt und geben nichts Neues, sondern legen fest, was sich durch Jahrhunderte entwickelt hat.

\section{Statuten der Stafler-Atzungsgenossenschaft: ${ }^{90}$}

1. Unter dem Namen Stafler-Atzung besteht eine Atzungsgenossenschaft mit 153 obern, 91 untern, äußern und 73 untern, innern Kuhweiden, welche sich gegenwärtig auf 13 Bauern verteilen. ${ }^{91}$

3. Die Veräußerung von Teilrechten kann nur durch eine schriftliche Abtretungserklärung auf dem Anteilschein oder in einem Vertrag erfolgen. Ganze Teilrechte dürfen nicht mehr unterteilt werden.

5. Die Organe der Genossenschaft sind: Die Hauptversammlung, der Vorstand und zwei Alpmeister, die Rechnungsrevisoren und der Sennereivogt. ${ }^{92}$

6. Das Einzählen findet an der Hauptversammlung statt, am 13. Juni auf der Egga in Frauenkirch, vormittags um 9 Uhr. Fällt dieses Datum auf einen Sonntag, so ist der darauf folgende Montag zu bestimmen. Es wird für jede der drei Abteilungen separat eingezählt, wobei der Vorstand die Alpweiderechnung und die Alpmeister die Sonderweiderechnung vorzulegen haben. Das Rechnungsjahr läuft vom 1. Juni bis 31 . Mai des folgenden Jahres.

8. Der Vorstand besteht aus Präsident (zugleich Kassier), Aktuar und den beiden Alpmeistern. Die Erneuerungswahl für Präsident und Aktuar findet beim Einzählen für eine dreijährige Amtsdauer statt. Wiederwahl ist gestattet, dagegen ist keiner verpflichtet, sich für zwei aufeinander folgende Amtsperioden wählen zu lassen. Präsident und Aktuar vertreten gemeinsam die Atzungsgenossenschaft nach außen.

11. Zur Übernahme der Alpmeisterschaft ist jeder Alpgenosse innerhalb den Grenzen der streng innehaltenden Kehrordnung verpflichtet, auch dann, wenn er im entsprechenden Sommer kein Vieh auftreiben würde.

12. Die Alpmeister dingen die Hirten, verschaffen ihnen Logis, erteilen ihnen die nötigen Weisungen und verteilen die Hütlöhne.

13. Der äußere Alpmeister legt im Herbst den gemeinsamen Zaun nieder und ist dafür im Frühling vom Gemeinwerk befreit.

14. Die Hirtenlöhne sind folgendermaßen verteilt: a. Der Lohn für Kuh- und Galtviehhirt verteilt sich gleichmäßig auf die Zahl der Kühe und des Galtviehs. Zudem erhält der Kuhhirt für jedes bei den Kühen gehaltene Kalb einen Franken extra. b. Für die Ziegen wird der Hütlohn auf die gleiche Art berechnet.

15. Für das Instandhalten des gemeinschaftlichen Zaunes in der äußern Sonderweide, sowie für Verbesserungen der Wege und Stege und Räumen der Weide, ist für jede obere und jede untere hestellte Weide ein Franken \%u bezahlen. Es steht jedoch jedem Weidgenossen frei, diese Bezahlung im Gemeinwerk abzuverdienen, aber nur durch erwachsene Personen, wobei die Stunde Arbeitsleistung mit einem Franken berechnet wird. Das Gemeinwerk findet in den Sonderweiden im Frühling am letzten 'Tag vor dem Auslassen und in der Alp an dem, bei der Einzählung gemeinsam bestimmten 'Tag statt. (Wer zwei Weiden hat soll im Gmeiwärch erschinen, sonst verfällt er in Buß, wer weniger als zwei Weiden hat ist nit schuldig ze zäunen.) ${ }^{93}$

16. Das in der Alp benötigte Brenn- und Zaunholz wird durch den Förster angewiesen, sofern nicht dürres Holz dazu vorhanden ist. Das Brennholz wird auf gemeinschaftliche Rechnung gerüstet und daun verteilt. (Wiınn es aber käme, daß einer oder der andere Nachbar von Nöten zu bessern

${ }^{88}$ Gepachtetes Vieh für übrig bleibende Nutzungsrechte. Der Bauer bekommt für eine Kuh den Milchertrag und zahlt dem Besitzer 22-23 Rp. pro Liter Milchertrag, somit bleiben ihm etwa 22 Rp. pro Liter. Davon gehen noch Fr. 60 bis 70.- für Hütlohn, Weidezins und Futter am Abend ab. Die Rendite ist sehr klein. Für ein Rind bekommt der Bauer vom Besitzer Fr. 50. - bis 80.-

${ }_{89}$ Amtliche Gesetzessammlung der Landschaft Davos. III, G 5, Art. 1-4.

90 Weniger wichtige Artikel und Sätze wurden weggelassen, die Numerierung der Abschnitte aber gleich beibehalten.

${ }_{01}$ Stand 1951, 16 Alprechte, da je 2 Bauern 2 Alprechte besitzen und einer das seinige nicht benützt.

92 Der Sennereivogt sorgt heute für den Milchfuhrmann.

"3 In Klammern jeweils die Verordnungen aus dem Jahre 1655. 


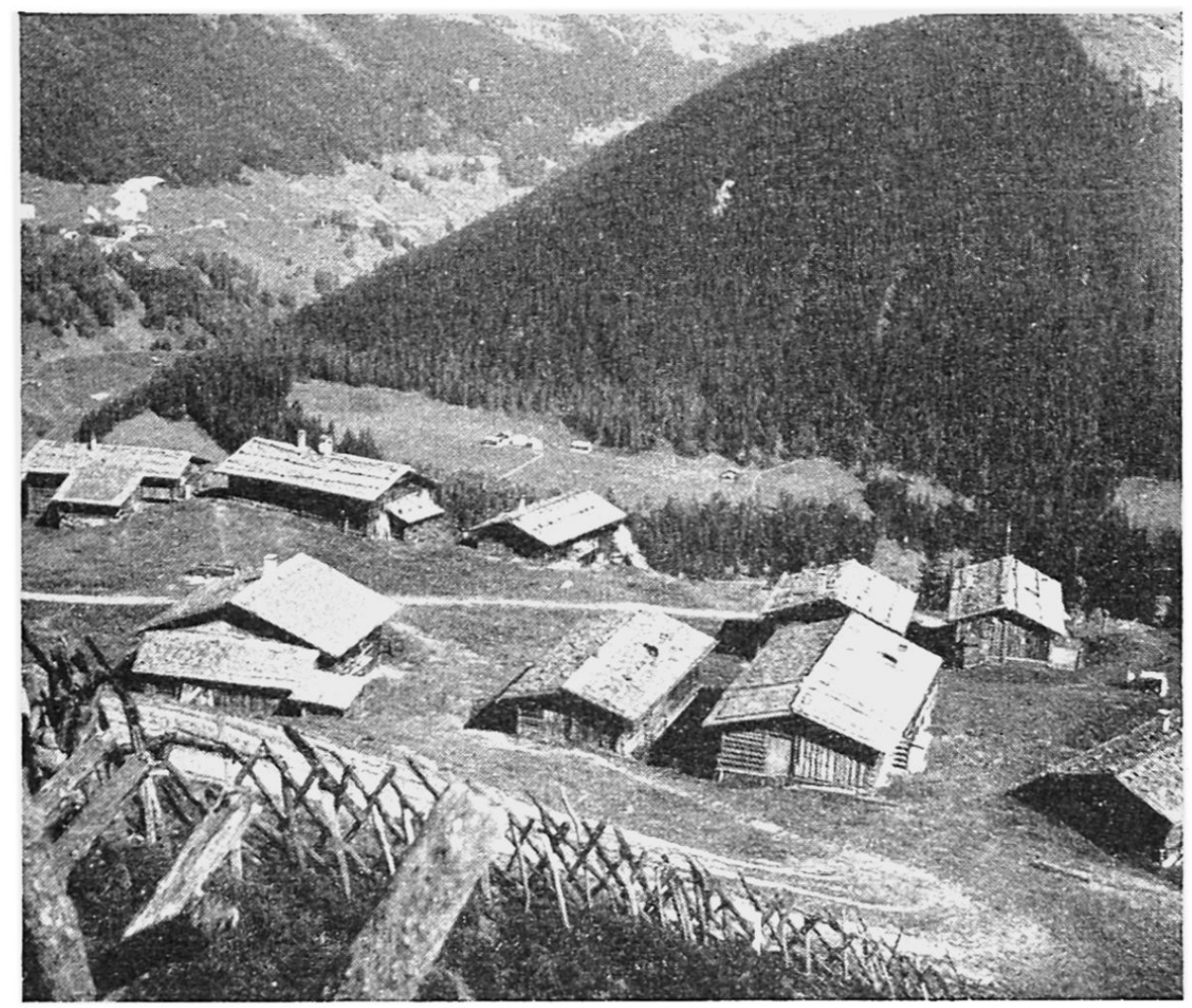

Abb. 8 Stafelalp. Alpdörfchen, im Vordergrund typischer umlegbarer Zaun. Blick auf den Junkersboden und ins Sertigtal. Aufnahme H. SENN

39. Es dürfen am Abend nach dem Heimtrieb keine Tiere mehr weiden, und am Morgen früh dürfen sie nicht vorher ausgelassen werden, als der Hirt den Befehl dazu gibt.

41. Solche, die es vernachlässigen, am Stafel den pflichtigen Zaun zu erstellen und die ihnen durch das Los zugeteilte Straße in guter Ordnung zu halten, soll der Vorstand nach fruchtlos gebliebener Mahnung dieselbe in Stand stellen lassen und hiefür ergangene Kosten eintreiben lassen. 42.-44. Festlegung der Bußen. Gegen denjenigen, der die Anordnungen nicht befolgt, kann polizeilich vorgegangen werden.

45. Statutenänderungen, sowie Änderungen in der Gesamtzahl der Teilrechte bedürfen zu ihrer Gültigkeit der Genehmigung des kleinen Rates. Für die Statutenänderung ist eine Mehrheit von $2 / 3$ der Alpbesitzer erforderlich.

Die ersten allgemeinen Verordnungen der Gemeinde Davos stammen aus dem Jahre 1898 101. Die Gesetze richten sich gegen das Überstellen der Weiden und bestimmen, daß jede Atzung das Recht hat, die Besatzlisten seiner Nachbaratzung einzusehen. Damit kontrollieren sich die Alpgenossenschaften gegenseitig. Für Alpauftrieb und Entladung ist kein festes Datum festgesetzt, sie richten sich nach den Weidbüchern. Der unbehirtete Weidgang und das Heuen innerhalb den Grenzen des Waldareales wird vom 1 . November bis 1. Mai untersagt.

Gewöhnlich finden wir bei den Davoser Alpen die Form der Privatkorporation. Es ist ein Zusammenschluß von Bauern, einzelne Arbeiten werden gemeinsam erledigt. Alles Alpeigentum (Alphütte) gehört jedem privat. Die Alpweide ist der Atzungsgenossenschaft unterstellt, wobei die einzelnen Alpgenossen Anteilrechte besitzen 102. Durch die vielen privaten Alphütten entstehen bei großen Alpen ganze Alpdörfchen, die als spezifisches Merkmal den Walsern zugeschrieben werden ${ }^{103}$.

101 Amtliche Gesetzessammlung. III G 4, Art. 1-11.

102 Es sind persönliche Rechte (Mitgliedschaftsrechte) mit verstärkter, dinglicher Wertung, ähnlich der Aktie. Vergleiche Weiss: Das Alpwesen Graubündens, S. 168.

${ }^{103}$ Sie sind Ausdruck von Einzelsennerei und Privatkorporation und kommen überall dort vor, wo diese Wirtschaftsformen bestehen oder bestanden haben. Die Alpdörfchen müssen also gar nicht auf die Walser beschränkt sein. 
Genossenschaftlich organisiert ist die Atzung, der Milchtransport, Straßen- und Zaununterhalt, die Betreuung des Alpwaldes, das Düngen der Weide mit Verschlauchungsanlagen und Weidverbesserungen.

Mit der Gründung der Zentralmolkerei organisierten sich in der Landschaft die einzelnen Bauern und Alpgenossenschaften für den Transport der Milch. Jeden Morgen stauen sich Wagen und Autos, mit Milchkannen beladen, vor der Molkereizentrale in Davos-Platz zur Ablieferung der Milch. Im Sommer sind es die Alpgenossenschaften, im Winter einzelne Regionen, die gemeinsam einen Milchfuhrmann anstellen. Dieser wird von den Bauern bezahlt, die Kontrolle und Abrechnung der Milch geht über die Molkerei. Je nach Distanz wechselt der Fuhrlohn. 1924 z. B. Inneralp, Monstein 6,3 Rp., Chumma-Alp 5 Rp., Rieder - Rieberalp 4 Rp., Sertig $2 \frac{1}{2}$ Rp., Flüela und Bedra 2 Rp., Stafel $3 \frac{1}{2} \mathrm{Rp}$. (heute 3,75 Rp.) pro Liter geführter Milch. Versuche mit der Bahn für die entferntesten Gegenden lohnten sich wegen der hohen Bahntarife nicht ${ }^{104}$. Die Milch aus den drei Monsteiner Alpen kommt im Sommer (1949: 1. April-20. Juli) in die Käserei Monstein (Ablage der Molkereizentrale Davos-Platz) und wird dort zu vollfettem Alpkäse verarbeitet. Die drei großen Sanatorien Clavadel, Schatzalp und Wolfgang beziehen die Milch direkt von den umliegenden Bauern, die Abrechnung geht aber auch durch die Molkereizentrale.

Die Alpstraßen in Davos werden täglich vom Milchfuhrwerk benützt, eine gute Straße ist Vorbedingung für den regelmäßigen Absatz der Milch. Die Liste der subventionierten Alpstraßen umfaßt praktisch alle Alpen. Einige besitzen aber auch heute noch keine richtigen Fahrwege (Stadel und Wyti von der Alp bis zur Sertigtalstraße). Bedra, Flüelaberg, Stillberg und Seltenüb führen die Milch mit Seilbahnen von der Alp bis zur Talstraße. Von dort aus wird sie im Sertig, Dischma und Flüela auf ein Auto geladen, das von allen Alpen der Talschaft die Milchkannen einsammelt.

\section{Die Atzungsgenossenschaft Hinter den Eggen, Sertig (Abb. 2).}

Es ist die größte Atzungsgenossenschaft der Landschaft mit 300 Kuhweiden und teilt sich eigentlich in verschiedene Alpen auf, was auch die innere Organisation noch widerspiegelt. Das Sertig-Dörfli nimmt gegenüber den andern Alpen (Sand-, Groß-, Klein-; Wasserfallalp) eine eigene Stellung ein. Das Dörfli war eine Dauersiedlung und besitzt seit 1699 ein eigenes Kirchlein. Die Alpgenossen zahlen Kirchensteuer, die Alpgenossenschaft verwaltet ein Pfrundenkapital 105. Das Weidegebiet liegt so nahe, daß keine Úslohställe nötig waren. Heute unterscheidet sich Sertig nur noch durch die großen, zugehörigen Wiesenflächen und die Trennung von Stall und selbständigem $\mathrm{H}$ aus von den andern Alpen.

Organisation der Atzungsgenossenschaft Hinter den Eggen :

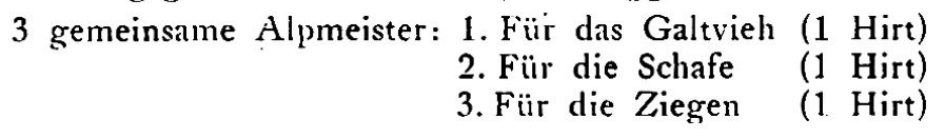

1. Waldrogt

2. Für die Schafe

(1. Hirt)

Die Kuhalpen sind aufgeteilt:

A. Kühalpgenossenschaft. 1 Obmann. Sie besitzt einen Schermen im Kühalptal.

104 Heute kommt nur die Milch aus Laret ${ }^{-}$und Monstein im Winter mit der Bahn. Eine Ausnahme machen große Schneefälle, wenn die Straße gesperrt ist, die Bahn aber fährt. Sind die Bauern wegen Lawinengefahr abgeschnitten, so sammelt sich die Milch an, bis keine Gefäße mehr vorhanden sind. Das kann, wie der Winter 1951 zeigte, zu Katastrophen führen und beweist die enorme Umstellung innerhalb eines halben Jahrhunderts, daß nicht einmal mehr die Geräte da sind, die Milch selber zu verarbeiten.

${ }^{105}$ Der Besitzer des obersten Heimes in der Bäbi (eine Vorwinterung) zahlt ebenfalls Kirchensteuer in Sertig. Dies ist wieder ein Beweis für die frühere Gleichwertigkeit der Heimwesen im Sertig und in der Bäbi als Dauersiedlung. 
Dazu gehören :

Wasserfallalp 2 Bauern (3 Alprechte) 1 Hirt

Kleinalp 2 Bauern (3 Alprechte) 1 Hirt

Großalp 3 Bauern (4 Alprechte) 1 Hirt

Sand 5 Bauern (7 Alprechte) 1 Hirt

B. Dörfli. 1 Obmann. 7 Bauern (8 Alprechte) 1 Kuhhirt mit Knabe

Die Kuhherde der Kühalpgenossenschaft wird gemeinsam von den vier Hirten gehütet, und nur auf der Ruheweide sind sie getrennt. Jeder Bauer besitzt Anrechte in der zugehörigen Kuhalp und solche auf dem gemeinsamen Galtviehberg.

Das Weidegebiet Hinter den Eggen schließt zwei Seitentäler, das Kühalptal und das Ducantal mit ein, und dehnt sich auf einer Fläche von 2000 ha über eine Höhe von $1800-2800 \mathrm{~m}$ aus. Es umfaßt flache und steile, saftige und steinige Weiden mit ganz verschiedenen Vegetationszeiten. Das Weidegebiet ist uneinheitlich und gliedert sich natürlich in verschiedene Zonen auf. In einem bestimmten 'Turnus wird während des Sommers die ganze Fläche genutzt, er ist nicht in Weidbüchern festgehalten, aber vererbt sich von Generation zu Generation. Jeder Hirt übernimmt wieder die alte Tradition, keine konservative Tradition, sondern eine, die immer wieder angepaßt wird nach den jährlichen Beobachtungen der Hirten und Bauern. Der Weideplan von Sertig hält nur eine grobe Ordnung fest, die im Einzelnen noch unterteilt ist (Fig. 5). Die Ruheweide wird in Frühling 1-2 Tage und im Herbst 14 'Tage bestoßen und mit Ausnahme des Dörfili nicht mehr in ihrem ursprünglichen Sinne genutzt. Im Kühalptal übernehmen die Weideflächen rund um den Schermen die Funktion der Ruheweide ${ }^{106 .}$

Die große Wiesenfläche im Sertig, teilweise $2-3 \mathrm{KW}$, ermöglicht es den Bauern, nach der Endweide anfangs Oktober auf dem Heimgut, noch einmal ins Sertig zurückzukehren und bis anfangs Dezember dis Heu im Alpstall aufzubrauchen. Wegen der großen Distanz lassen jedoch die meisten Bauern einen Teil der Tiere im Sertig, bis das Heu aufgebraucht ist und nehmen nur 2-3 früh kalbernde Kühe zur Emdweide ins Tal, andere verzichten auf die Emdweide.

Bei der Besitznahme der Alpen im 14. und 15. Jahrhundert bekam jeder Hof die ihm am nächsten liegende Alp. Doch schon bald änderte sich diese natürliche Ordnung durch Erbgang und Kauf, wenn auch jeder Bauer versuchte, möglichst auf der nächsten Alp seine Rechte zu besitzen. Die Zusammenstellung für Sertig ergibt 1949: Die Bauern besitzen ihr Heimgut: Auf Bolgen (Davos-Platz), Hof (Brüch), 4 in den Brüchen, Langmatte, Furra (Frauenkirch), Suzi (Frauenkirch), 3 in Frauenkirch, Wildboden, 2 in Clavadel und + im Sertigtal. - Die Heimwesen der Besitzer der Hauptalp Monstein stehen in Ardüs und 2 in Glaris. Das Beispiel eines einzelnen Bauern zeigt, wie stark oft der Wechsel innerhalb der Alpen sein kann. Er besaß bis 1918 Alprechte im Sertig. 7 Jahre auf der Bedra-Alp (Flüela), 10 Jahre im Dischmatal, 3 Jahre auf der Riederalp (Glaris) und heutc ist er auf der Gadmenaip im Dischma ${ }^{10 i}$.

Dir Alpen und Weiden der Landschaft Dav'os.

Eine Einteilung der Alpen kasnn von verschiedenen Gesichtspunkten ausgehen. Einteilung nach Stufen:

Der geringe Höhenunterschied von den Talgütern жur Alp läßst in Davos dic Maiensälßzone ausfallen. ${ }^{108}$

1116 Der Schermen bietet 140 Kühen Plat\%, die in 8 Abteilen $\%$ je 18 Ständen untergebracht sind. Er besitzt eine Hirtenwohnung und eine Schlatstätte für 18 Personen. Fine Milchkühlanlage und eine $W$ ascheinrichtung für das Milchgeschirr sind eingebaut. Der anfallende Dünger kann mit einer Verschlauchungsanlage den naheliegenden Weiden zugeführt werden.

${ }^{107}$ Die Karte III Alp-Heimgut in meiner Diplomarbeit gibt für alle Alpen der Landschaft den Standort des Heimgutes an.

${ }_{108}$ Als Maiensïße in Daros können nur Rüti (Glaris), Obermatte (Chumma) und die drei letzten Höfe des Sertigtals (in der Bäbi) bezeichnet werden. 


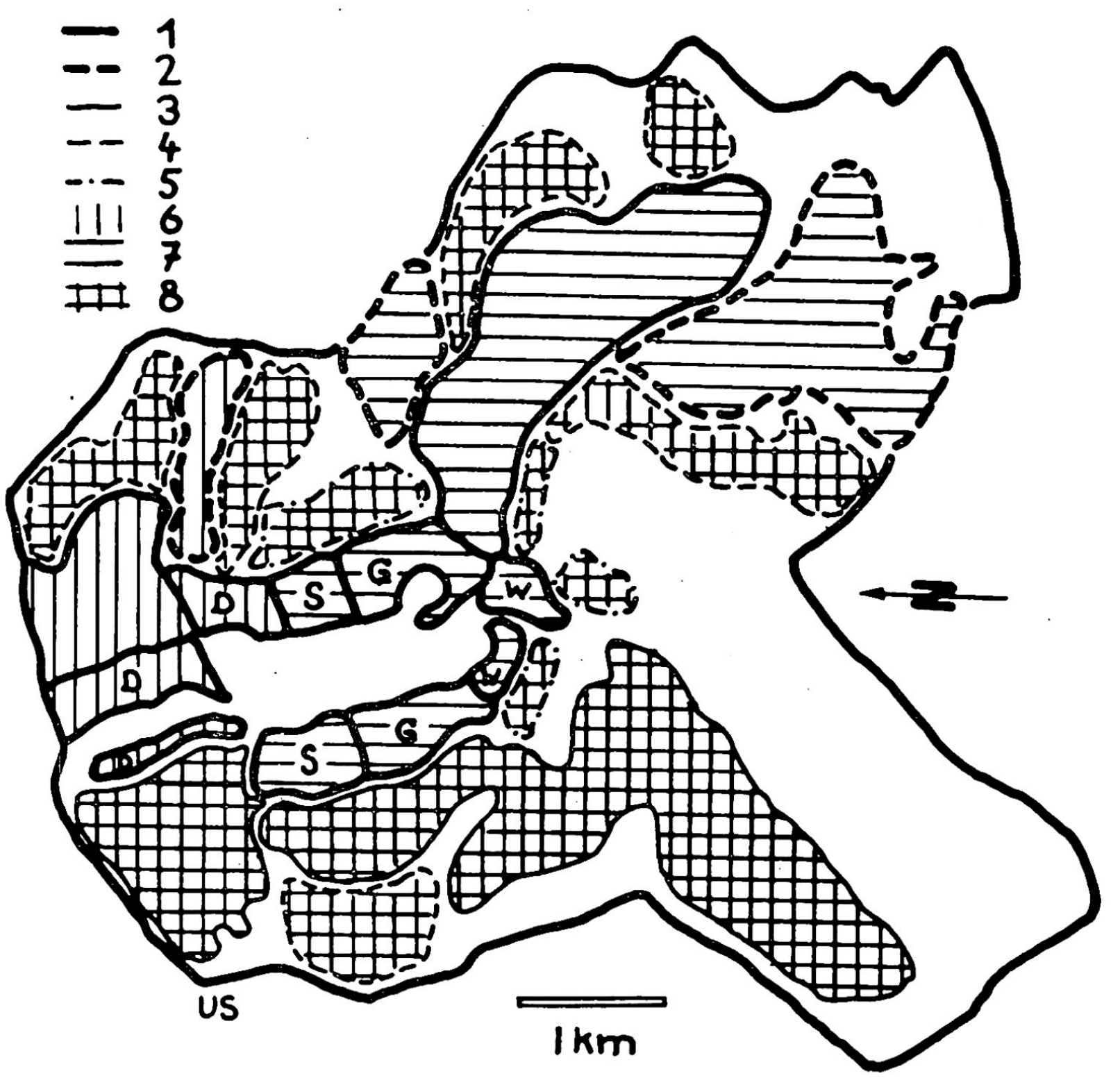

Fig. 5 Weidezonen Atzungsgenossenschaft Hiuter den Eggen. 1 Kuhalpen, Alpgrenze, 2 Kuhweiden ab 1. August stoßbar, 3 Galtviehweiden, 4 Schafweiden, 5 Ziegenweiden, 6 Atzungsgenossenschaft Dörfli, 7 Atzungsgenossenschaft Kühalp, 8 Gemeinsame Jungvieh- und Schmalviehweiden. Ruheweiden :

$\mathrm{D}=$ Dörfli, $\mathrm{S}=$ Sand, $\mathrm{G}=$ Großalp (Kleinalp mit einbezogen), $\mathrm{W}=$ Wasserfallalp.

Eine Stufe:

A. Winterung in den Talgütern.

Sommerweide von den Uslohställen aus.

(Sonderweiden, Kaisern, Wildi, Wildboden.)

Zwei Stufen :

B. Winterung in den Talgütern.

Sömmerung auf der Alp. (Alpen von Monstein)

C. Winterung in den Talgütern.

Frühlings- und Herbstweide vom Uslohstall. ${ }^{109}$

Sömmerung auf der Alp. (Typ Bärental)

Drei Stufen :

D. Winterung in den Talgütern.

Frühlings- und Herbstweide vom Uslohstall.

Sömmerung von der Alp aus.

Sömmerung vom Schermen aus.

(Clavadel, Kühalp, Schatzalp, Büschalp, Bedra, Flüela, Rüediställi)

${ }^{109}$ Um den Vergleich mit andern schweizerischen Alpen zu ermöglichen, wird die Frühlingsund Herbstweide von den Uslohställen aus nicht als eigene Stufe gerechnet. 


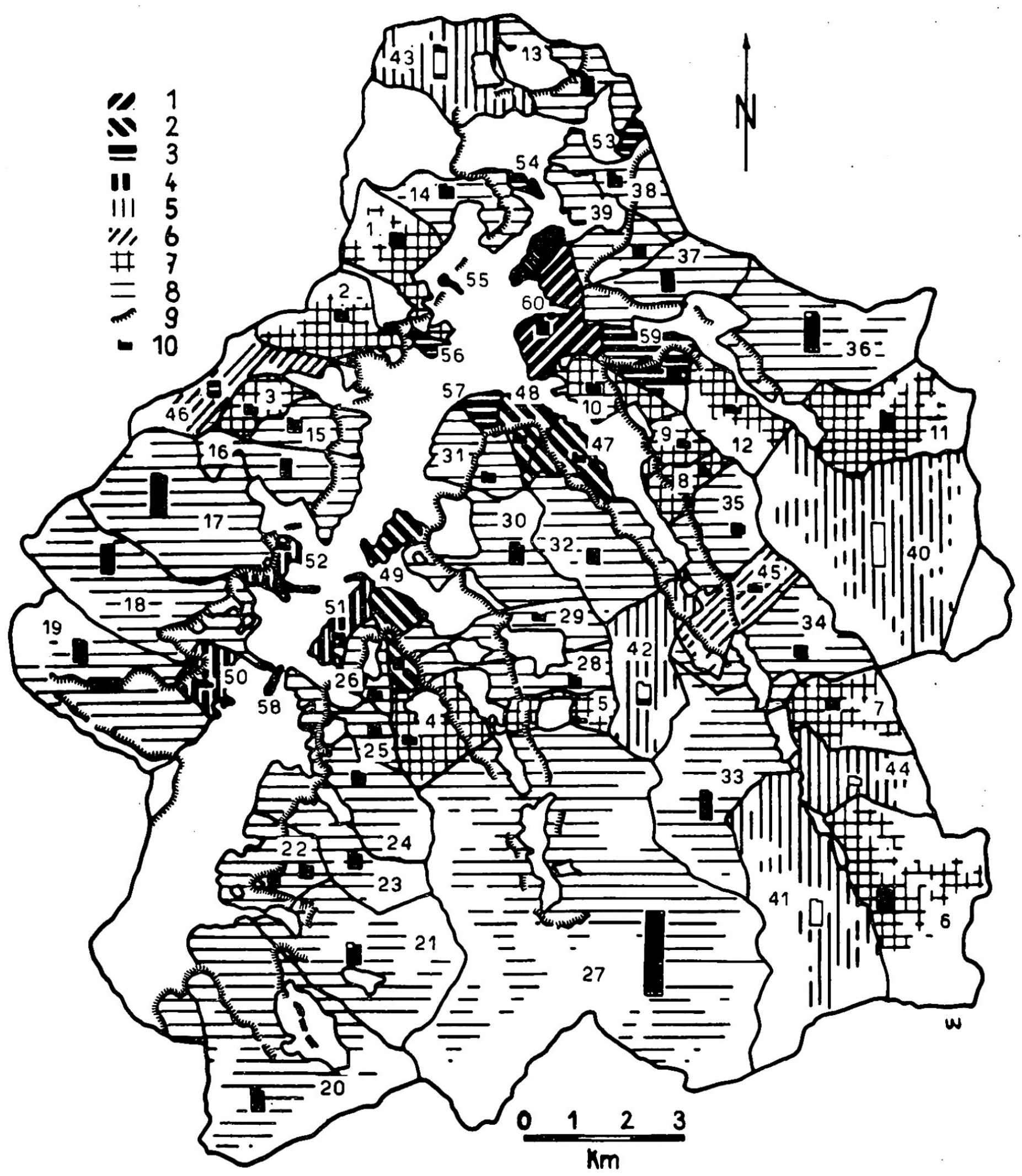

Fig. 6 Dic Alpen der Landschaft Davos. 1 Dorfweide, 2 Atzungen, 3 Sonderweiden, 4 Frühlingsund Herbstweiden, 5 Fremde Alpen, 6 Pachtalpen, 7 Privatalpen, 8 Privatkorporationsalpen, 9 Waldgrenze, 10 Stoßzahl der Alpen (11 Stölse), Alp mit Schermen. Die Numerierung der Alpen entspricht derjenigen im Text.

Nach Besitz und rechtlichen Ierhältmissen: ${ }^{110}$

A. Private Alpen:
1. Büschalp $(\mathrm{H})$
2. Strela-Alp (H)
3. Lochalp (H)
4. Seltenüib (S)
5. Gaschurna (S)
6. Dürrboden (D)

110 Stand 1951. Die Nummern entsprechen denjenigen auf der Karte. $H=-$ Haupttal, $M=$ Monstein, $\mathrm{S}=$ Sertigtal, $\mathrm{D}=$ Dischmatal, $\mathrm{F}:=$ Fliielatal. 
7. Wiesenalp (D)

8. Lukschalp (D)
9. Berg-Alp (D)

10. Alp Infang (D)
11. Tschuggen $(F)$

12. Engi (F)

B. Privat-Korporationsalpen :
13. Schwarzsee $(\mathrm{H})$
14. Salez-Alp $(\mathrm{H})$
15. Grüni-Alp (H)
16. Erbalp (H)
17. Stafelalp $(\mathrm{H})$
18. Chumma-Alp (H)
20. Inner-Alp (M)
21. Ober-Alp (M)

22. Hauptalp (M)

23. Leidbachalp $(\mathrm{H})$

31. Isch-Alp (H)

24. Rieberalp (H)

25. Riederalp $(\mathrm{H})$

32. Stillbergalp (D)

26. Waldalp $(\mathrm{H})$

27. Hinter den Eggen (S)

28. Wyti-Alp (S)

29. Stadel-Alp (S)

30. Clavadeler-Alp (S)

33. Alp am Rhin (D)

34. Gadmen-Alp (D)

35. Gulrigenberg (D)

36. Flüelaberg (F)

37. Bedra-Alp (F)

38. Außer-Drusatscha (H)

C. Fremde Alpen:

40. Carlimatte (F) Jungviehalp der Gemeinde Luzein. (Schon im 17. Jh. von Sererhard als zu Luzein gehörig genannt.)

41. Großalp (D) Jungviehalp der Gemeinde Luzein. (1878 besaß sie schon einen Teil und kaufte 1901 den Rest der Weide.) ${ }^{\mathbf{1 1 1}}$

42. Rüediställi (D) Jungviehalp der Viehzuchtgenossenschaft Altstätten (Rheintal), 1924 gekauft.

43. Parsenn oder Stützalp (H) Jungviehalp der Gemeinde Conters. (Sie kaufte die Alp von einem Rheintaler Tischhauser, der sie 1918 von einem Davoser erwarb.) ${ }^{112}$

44. Jenatschalp (D) Kuhalp eines Bauern aus Furna. ${ }^{113}$

D. Gepachtete Alpen:

45. Alp Kindschhus (D), Privatalp.

46. Podestaten- oder Schatzalp (H). Von einem Davoser und Klosterser vom Sanatorium Schatzalp gepachtet.

E. Sömmerungsweiden von Privatkorporationen :

47. Kaisern-Atzung (D), 48. Wildi-Atzung (D), 49. Wildboden-Atzung (H).

F. Frïhlings- und Herbstweiden im Besitz von Privat-Korporationen :

50. Hitzeboden $(H), 51$. Junkersboden $(H)$, 52. Stafel-Sonderweid $(H)$.

G. Sonderweiden :
53. Lusi $(\mathrm{H})$
56. Schiabach $(\mathrm{H})$
59. Waldje (F)
54. Bleikten $(\mathrm{H})$
57. Mattenwald $(\mathrm{H})$
55. Stocken $(\mathrm{H})$
58. Spinabad $(\mathrm{H})$

H. Sömmerungsweide im Besitz von Nachbarschaften : 60. Weidgenossenschaft Dorf $(\mathrm{H})$.

\begin{tabular}{lcccc} 
& Anzahl Bauern & Alp & $\begin{array}{c}\text { Höhe über Meer in } \begin{array}{c}\text { Metern } \\
\text { Schermen }\end{array} \\
\text { Weidegebiet }\end{array}$ \\
\hline Büschalp & 1 & 1962 & $\cdots$ & $1600-2600$ \\
Strela-Alp & 1 & 1980 & 1980 & $1800-2600$ \\
Lochalp & 1 & 2010 & & $2010-2500$ \\
Seltenüb & 1 & 2030 & & $1760-2500$ \\
Gaschurna & 1 & 2061 & & $1750-2600$ \\
Dürrboden & 1 & 2011 & & $2011-2700$ \\
Wiesenalp & 1 & 1922 & & $1922-2700$ \\
Lukschalp & 1 & 1870 & & $1740-2550$ \\
Berg-Alp & 1 & 1870 & & $1850-2550$ \\
Inschlag & 1 & 1850 & & $1700-2500$ \\
Tschuggen & 1 & 1940 & & $1940-2700$ \\
Engi & 1 & 1855 & & $1850-2500$ \\
Schwarzsec & 2 & 1868 & & $1500-2300$ \\
Salez. & 3 & 1990 & & $1650-2400$ \\
Grüini & 3 & 1968 & &
\end{tabular}

111 Freundliche Mitteilung von Herrn ${ }^{-}$Fü̈HMANN, Grundbuchverwalter.

112 Auf der Stützalp besitzt noch ein Davoser Bauer 13 Weiden, die er benutzt.

${ }_{113}$ In der Flüelabergalp besitzt ein Serneuser $13 \mathrm{KR}$ und ein Gut auf dem Wolfgang, in der Oberalp ein Bauer aus Klosters $13^{1 / 2} \mathrm{KR}$. 
Höhe über Meer in Metern

Anzahl Bauern Schermen

Weidegebiet

\begin{tabular}{|c|c|c|c|c|}
\hline Erb & 4 & $1860-1922$ & & . $1560-2250$ \\
\hline Stafel . & 13 & 1934 & & $1600-2600$ \\
\hline Chumma & 9 & 2020 & & $1.500-2700$ \\
\hline Bärental & 5 & 1829 & & $1500-2600$ \\
\hline Inneralp & 7 & $1860-1996$ & & $1600-2600$ \\
\hline Oberalp & 5 & 1910 & & $1700-2600$ \\
\hline Hauptalp & 3 & $1870-2030$ & & $1600-2400$ \\
\hline Leidbach & 3 & 1780 & & $1650-2430$ \\
\hline Rieber & 4 & 1820 & & $1750-2500$ \\
\hline Rieder & 4 & 1760 & & $1600-2500$ \\
\hline Waldalp & 2 & 1836 & & $1800-2500$ \\
\hline Hinter den Eggen & 19 & 1860 & 2100 & $1800-2800$ \\
\hline Wyti & 4 & 1994 & & $1700-2670$ \\
\hline Stadel & 3 & 2069 & & $1650-2630$ \\
\hline Clavadel & 5 & 1930 & 2141 & $1700-2600$ \\
\hline Isch & 3 & 1885 & & $1600-2450$ \\
\hline Stillberg & . 4 & 1971 & & $1900-2600$ \\
\hline Am Rhin & 6 & 1860 & & $1860-2700$ \\
\hline Gadmen & 2 & 1832 & & $1830-2600$ \\
\hline Gulrigenberg ${ }^{114}$ & 4 & 1703 & & $1700-2500$ \\
\hline Flüelaberg & 8 & 1800 & 2254 & $1800-2700$ \\
\hline Bedra & 2 & 1740 & 2249 & $1740-2500$ \\
\hline Außer Drusatscha & 2 & 1740 & & $1580-2450$ \\
\hline Inner Drusatscha & 2 & 1740 & & $1580-2450$ \\
\hline Carlimatte & & & & $1950-2600$ \\
\hline Großalp & & 1902 & & $1900-2600$ \\
\hline Rüediställi & & 1710 & 2158 & $1700-2600$ \\
\hline Parsenn & & & 1920 & $1650-2500$ \\
\hline Jenatsch & 1 & 1925 & & $1925-2700$ \\
\hline Kindschhus & 1 & 1734 & & $1730-2700$ \\
\hline Podestatenalp & 2 & 1990 & 2263 & $1900-2500$ \\
\hline Kaisern & 3 & & & $1600-2400$ \\
\hline Wildi & 2 & & & $1600-2300$ \\
\hline Wildboden & 3 & & & $1550-2200$ \\
\hline
\end{tabular}

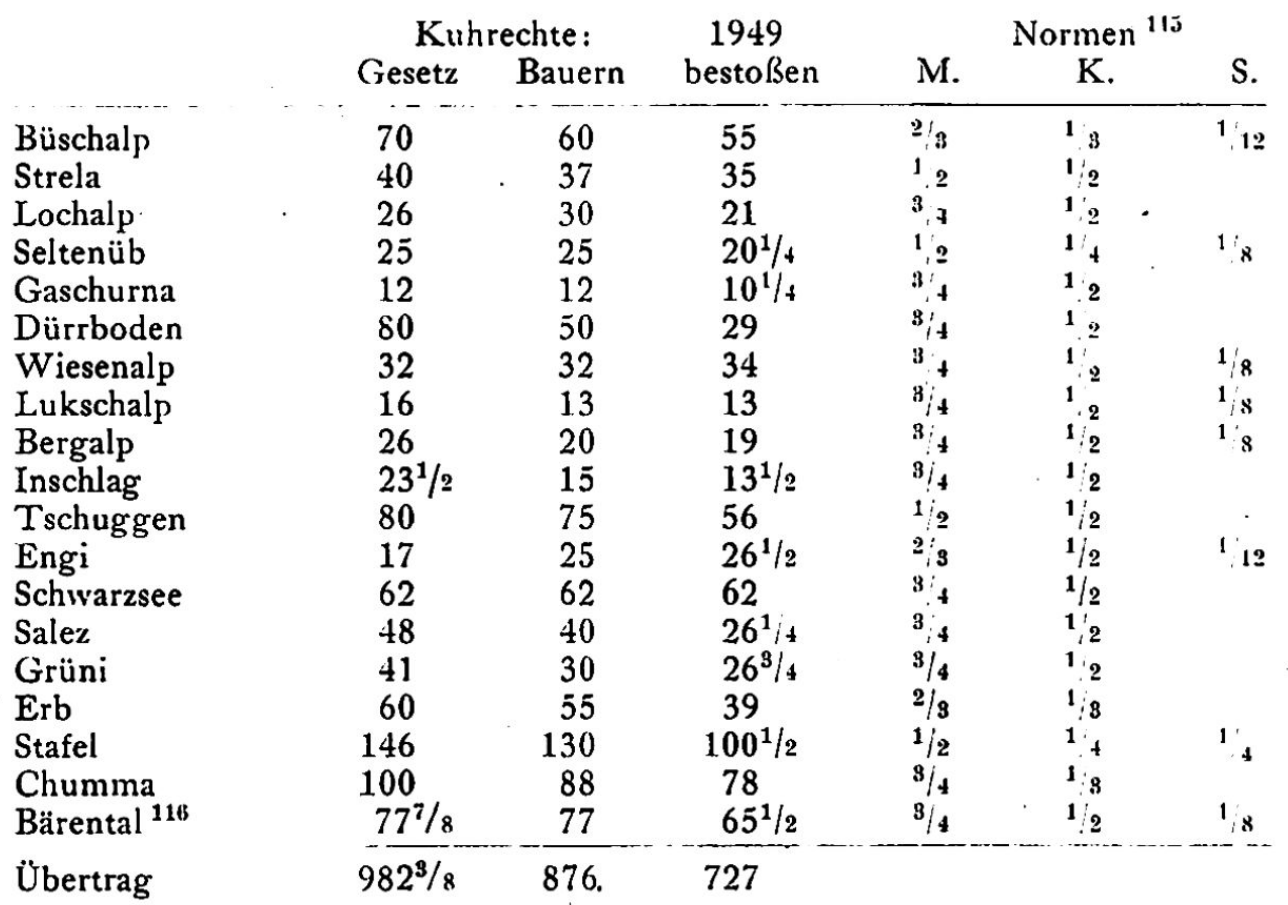

11 Gulrigenberg ist eine Schmalviehatzung ohne Alpgebäude und Frühlings- und Herbstweide von 4 Bauern.

${ }_{115}$ Normen in der Reihenfolge Mese, Kalb, Schmalvieh. Für Kühe und Rinder gilt immer 1. 116 Kühe $5 / 4$, Rinder ${ }^{4} / 4$. 


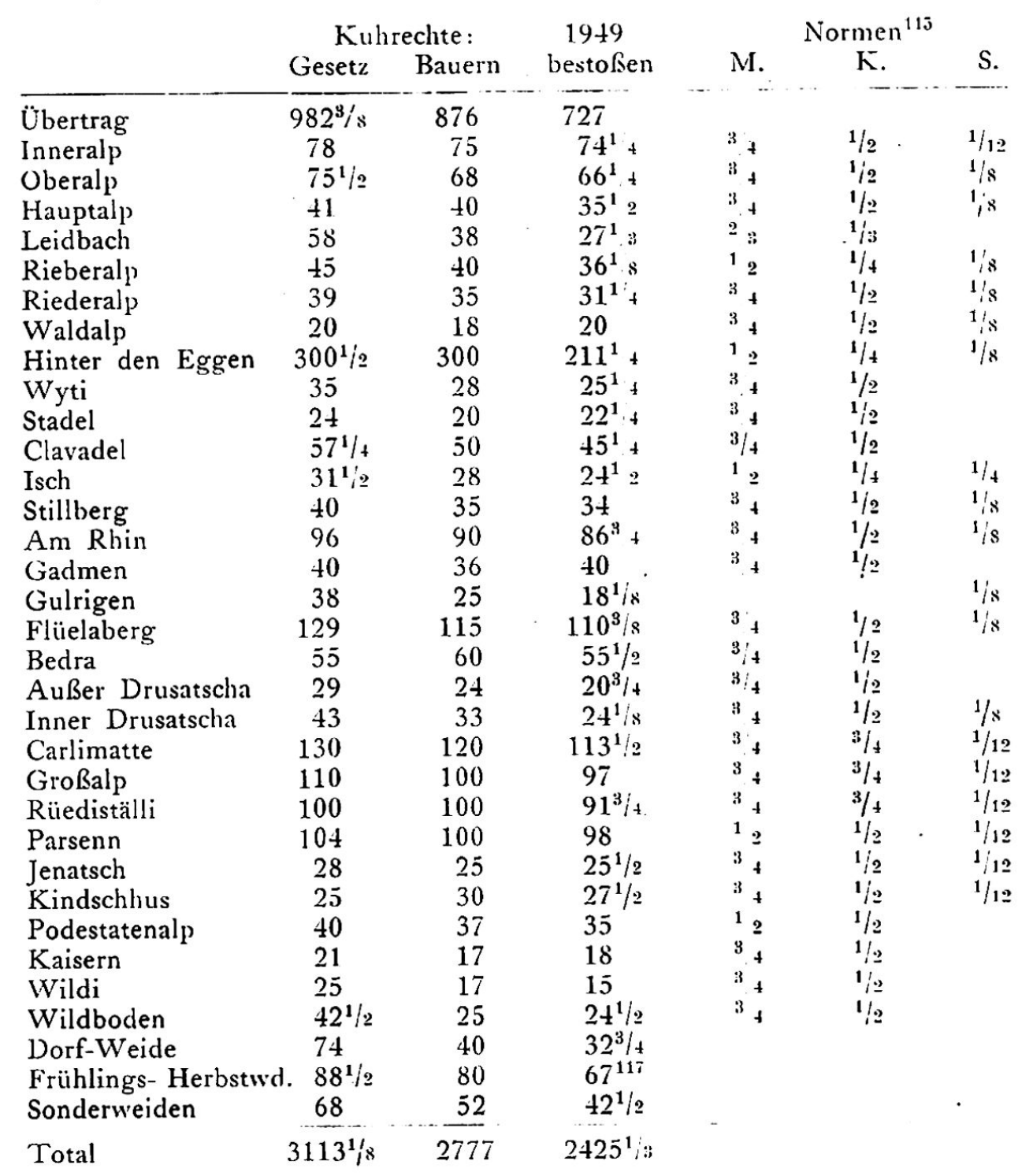

\begin{tabular}{lrrrrr} 
& Total & \multicolumn{2}{c}{ Kühe } & \multicolumn{2}{c}{ Jungvieh } \\
& 1949 & 1949 & 1909 & 1949 & 1909 \\
\hline Büschalp & 65 & 9 & 72 & 56 & 2 \\
Strela & 49 & 5 & 16 & 44 & 5 \\
Lochalp & 22 & 10 & $?$ & 12 & $\vdots$ \\
Seltenüb & 21 & 9 & 4 & 12 & 17 \\
Gaschurna & 12 & 5 & 6 & 7 & 7 \\
Dürrboden & 35 & 10 & 16 & 25 & 34 \\
Wiesenalp & 36 & 14 & 17 & 22 & 11 \\
Lukschalp & 13 & 6 & 10 & 7 & 6 \\
Bergalp & 17 & 12 & 12 & 5 & 7 \\
Infang & 13 & 10 & 15 & 3 & 4 \\
Tschuggen & 85 & 41 & 16 & 44 & 55 \\
Engi & 21 & 17 & - & 4 & 18 \\
Schwarzse & 81 & 25 & 30 & 56 & 33 \\
Salez & 27 & 20 & 20 & 7 & 21 \\
Grüni & 30 & 20 & 25 & 10 & 4 \\
Erb & 44 & 32 & 43 & 12 & 30 \\
Stafel & 109 & 88 & 104 & 21 & 35 \\
Chumma & 88 & 56 & 52 & 32 & 42 \\
Bärental & 56 & 43 & 36 & 13 & 33 \\
Inneralp & 75 & 57 & 50 & 18 & 27 \\
Übertrag & 899 & 489 & 444 & 410 & 391
\end{tabular}

117 Da nur etwa ein Monat geweidet wird, rechne ich ein Drittel der Weiderechte. 


\begin{tabular}{|c|c|c|c|c|c|}
\hline & 'Total & & & & igvieh \\
\hline & 1949 & 1949 & 1909 & 1949 & 1909 \\
\hline Übertrag & 899 & 489 & 444 & 410 & 391 \\
\hline Oberalp & 70 & 40 & 45 & 30 & 28 \\
\hline Hauptalp & 34 & 26 & 30 & 8 & 14 \\
\hline Leidbach & 28 & 23 & 27 & 5 & 27 \\
\hline Rieberalp & 38 & 33 & 34 & 5 & 17 \\
\hline Riederalp & 32 & 23 & 21 & 9 & 11 \\
\hline Waldalp & 21 & 14 & 10 & 7 & 23 \\
\hline Hinter den Eggen & 221 & 1.49 & 170 & 72 & 63 \\
\hline Wyti & 26 & 19 & 26 & 7 & 15 \\
\hline Stadel & 23 & 12 & 9 & 11 & 18 \\
\hline Clavadel & 53 & 31 & 40 & 22 & 28 \\
\hline Isch & 28 & 16 & 21 & 12 & 8 \\
\hline Stillberg & 36 & 22 & 23 & 14 & 28 \\
\hline Am Rhin & 88 & 50 & 60 & 38 & 52 \\
\hline Gadmen & 45 & 26 & 19 & 19 & 8 \\
\hline Flüelaberg & 116 & 87 & 100 & 29 & 25 \\
\hline Bedra & 61 & 47 & 45 & 14 & 7 \\
\hline Außer Drusatscha & 25 & 12 & 17 & 13 & 23 \\
\hline Inner Drusatscha & 21. & 16 & 32 & 5 & 2 \\
\hline Carlimatte & 95 & 5 & - & 90 & 90 \\
\hline Großalp & 122 & 2 & - & 120 & 125 \\
\hline Rüediställi & 121 & 4 & 22 & 117 & 60 \\
\hline Parsenn & 136 & 12 & 24 & 124 & 69 \\
\hline Janatsch 118 & 28 & 11 & - & 17 & - \\
\hline Kindschhus & 25 & 9 & 14 & 16 & 7 \\
\hline Podestatenalp & 50 & 21 & 14 & 29 & 7 \\
\hline Kaisern & 19 & 17 & 20 & 2 & - \\
\hline Wildi & 15 & 15 & 23 & 一 & 一 \\
\hline Wildboden & 26 & 18 & $?$ & 8 & ? \\
\hline Dorf-Weide & 34 & 31 & $?$ & 3 & ? \\
\hline Sonderweiden & 62 & 52 & $?$ & 10 & $?$ \\
\hline Total & 2578 & 1332 & 1390 & 1246 & 1146 \\
\hline
\end{tabular}

\begin{tabular}{|c|c|c|c|c|c|c|}
\hline & \multicolumn{2}{|c|}{ Ziegen } & \multicolumn{2}{|c|}{ Schafe } & \multirow{2}{*}{$\begin{array}{r}\text { Schweine } \\
1909 \\
\end{array}$} \\
\hline & & 1949 & 1909 & 1949 & 1909 & \\
\hline Büschalp & . & 10 & - & 61 & 一 & - \\
\hline Lochalp & & 3 & - & - & - & - \\
\hline Seltenüb & & - & 3 & - & - & - \\
\hline Gaschurna & & - & 2 & - & - & 1 \\
\hline Dürrboden & & - & 85 & - & - & - \\
\hline Wiesenalp & & $t$ & - & - & - & \\
\hline Lukschalp & & 2 & 30 & - & - & \\
\hline Bergalp ${ }^{119}$ & & 2 & - & - & - & \\
\hline Tschuggen & & - & 30 & - & - & \\
\hline Engi & & 一 & - & 48 & - & 2 \\
\hline Salez & & 4 & - & - & - & \\
\hline Stafel & & 35 & 70 & - & - & 5 \\
\hline Chumma & & - & 54 & - & - & 11 \\
\hline Bärental & & 16 & - & - & - & \\
\hline Inneralp & & 57 & 48 & - & - & \\
\hline Hauptalp & & 2 & - & -- & -- & \\
\hline Leidbachalp & & 2 & - & - & - & \\
\hline Rieber & & 2 & - & 一 & - & \\
\hline Rieder & & 3 & - & - & - & \\
\hline Waldalp & & 2 & $\overline{-}$ & $\overline{0}$ & - & \\
\hline Hinter den & Eggen & 80 & 80 & 95 & 220 & 63 \\
\hline Isch & & 5 & - & - & - & 二 \\
\hline Übertrag & & 229 & 402 & 204 & 220 & 10 \\
\hline
\end{tabular}

1181909 ist die Jenatschalp bei der Alp am Rhin mit eingerechnet.

119 Luksch- und Bergalp zusammen. 


\begin{tabular}{lcrrrr} 
& \multicolumn{2}{c}{ Ziegen } & \multicolumn{2}{c}{ Schafe } & Schweine \\
& 1949 & 1909 & 1949 & 1909 & 1909 \\
Übertrag & 000 & 000 & 000 & 000 & 000 \\
Am Rhin & 12 & - & 6 & - & - \\
Gadmen & 4 & - & - & - & 4 \\
Gulrigenberg & 20 & 80 & 29 & - & - \\
Flüelaberg & 9 & - & - & - & - \\
Carlimatte & 40 & - & 450 & 600 & - \\
Rüedistäli & - & - & - & 100 & - \\
Parsenn & - & 60 & 130 & - & - \\
Kindschhus & -58 & 60 & 31 & - & - \\
Total ${ }^{120}$ & 372 & 602 & 850 & 920 & 113
\end{tabular}

Bündnerisches. Sömmerungs:vieh bei Da.voser Bauern:

$\begin{array}{lrlrlr}\text { Alvaneu } & 2 & \text { Klosters } & 23 & \text { Schiers } & 34 \\ \text { Buchen } & 8 & \text { Küblis } & 25 & \text { Schmitten } & 5 \\ \text { Fideris } & 4 & \text { Luzein } & 28 & \text { Serneus } & 6 \\ \text { Filisur } & 3 & \text { Pany } & 8 & \text { Seewies } & 8 \\ \text { Grüsch } & 31 & \text { Pusserein } & 11 & \text { St. Antönien } & 4 \\ \text { Jenaz } & 3 & \text { Saas } & 28 & \text { Wiesen } & 5\end{array}$

Total 236

Bündnerisches Sömmerungsvieh von Bauern, die nichl in Davos wolhnen aber hier Alprechte besitzen:

Parsennalp (Conters) 123

Carlimatte. (Luzein) 95

Jenatschalp (Furna) 28

Schatzalp (Klosters) 25

Außerkantonales Vieh:

Rüediställi (Altstätten) 121

Strela-Alp $\quad 44$

Podestatenalp 13

Am Rhin 21

$\begin{array}{lr}\text { Großalp (Luzein) } & 122 \\ \text { Oberalp (Klosters) } & 10 \\ \text { Fliielaberg (Serneus) } & 5\end{array}$

Total 408

$\begin{array}{ll}\text { Wiesenalp } & 20 \\ \text { Büschalp } & 41 \\ \text { Tschuggen } & 60 \\ \text { Schwarzsee-Alp } & 27\end{array}$

Total 348

Sömmerungsvieh in der Landschatt Davos 1949 Total 992

Woher kommt das Sömmerungs:vieh aus andern Kantonen 19+7:

$\begin{array}{lrlrlrlr}\text { Altstätten (St. G.) } & 151 & \text { Frümsen } & 19 & \text { Lüchingen } & 8 & \text { Stein (App.) } & 5 \\ \text { Balgach } & 20 & \text { Gais } & 18 & \text { Marbach } & 11 & \text { St. Gallen } & 6 \\ \text { Birmensdorf } & 2 & \text { Gams } & 10 & \text { Oberriet } & 34 & \text { Teufen } & 4 \\ \text { Bühler } & 12 & \text { Grabs } & 6 & \text { Oberegg } & 3 & \text { Vilters } & 7 \\ \text { Dipoldsau } & 26 & \text { Haag } & 18 & \text { Rebstein } & 8 & \text { Widnau } & 14 \\ \text { Eichberg } & 8 & \text {. Jona } & 1 & \text { Reute } & 3 & & \end{array}$

Außerkantonales Sömmerungsvieh in Davos 1947: 394

\section{ZUSAMMENFASSUNG}

Die Landschaft Davos erfuhr die entscheidende Uingestaltung durch die Kolonisation der Walser im 13. Jahrhundert. In einem von Romanen dünn besiedelten Gebiet, wahrscheinlich nur im Sommer bewohnt, gründeten diese ihre Einzelhöfe. Alles gerodete Kulturland gehörte ihnen als freies Erblehen, der Wald und die Weide blieben als gemeine Mark. Die Bevölkerung wuchs sehr. schnell. Um die ersten 14 Höfe bildeten sich Nachbarschaften (Hofgenossenschaften), welche die engere Organisation des großen Siedlungsgebietes übernahmen. Schon zu Beginn des 15. Jahrhunderts war die offene Alpweide im Besitz von Privaten und Privatkorporationen. Die Aufteilung der Allmenden (Waldweide) fand im 16. Jahrhundert statt, und anschließend gingen auch die Wälder im 17. Jahrhundert in Privatbesitz über. Die heutigen Alp-und Weideverhältnisse sind ein Abbild dieser besaßen.

120 Es sind nur diejenigen Alpen aufgeführt, die 1949 oder 1909 Schmalvieh oder Schweine 
Entwicklung. Die Dorfweide blieb auf der Stufe der Allmend stehen, und nur der Wald machte die Aufteilung mit; weideberechtigt sind noch alle Wieslandbesitzer innerhalb der Grenzen der zwei alten Nachbarschaften. Die Sonderweiden und einige Atzungen im Raume der alten Allmend sind aufgeteilt als gemeine Weide und spiegeln so einen Zustand des 16. Jahrhunderts wieder. Die meisten Alpen. als die ältesten Glieder der aufgeteilten gemeinen Mark, übernahmen die aufgeteilte Allmend und reihten sie in die Alporganisation ein. Das 19. Jahrhundert brachte eine Umstellung von der Einzelsennerei zur Genossenschaftssennerei. Die Entwicklung des Kurortes führte in der Folge zur Gründung einer straffen und zentralen Milchgenossenschaft zur Deckung des großen Milchbedarfes. Diese vermochte die durch Jahrhunderte gewachsenen Zustände nicht umzugestalten, sondern führte nur zu einer Anpassung und Intensivierung der Landwirtschaft. Nach den Alpen wurden gute Verbindungswege (Alpstraßen, Luftseilbahnen) gebaut, die den schnellen Transport der Milch in die Zentralmolkerei nach Davos-Platz ermöglichten. Auf wenigen Alpen entstanden Schermen für eine bessere Ausnützung der Weide, im Tale wurden die Ställe umgebaut und den modernen hygienischen Verhältnissen angepaßt.

Die heutige Alpwirtschaft ist eng verbunden mit dem Kur- und Fremdenort Davos und ging von einer ursprünglichen Viehzucht mit Viehhandel über zu einer einseitigen Milchwirtschaft. Mit Ausnahme der wenigen fremden Jungviehalpen sömmern die Davoser Alpen nur wenig Jungvieh, das zu einer eigenen Aufzucht nicht genügt. Leistungsfähige und gesunde Kühe werden auf den bündnerischen Viehmärkten gekauft. - Die Davoser Alpwirtschaft gründet sich auf eine eigene, historische Entwicklung, deren Organisation und Wirtschaftsform gekennzeichnet ist durch den besondern Charakter der Walser. Sie erfährt infolgc der Entwicklung des Kurortes Davos eine Anpassung und teilweise Umgestaltung durch Forderungen, die eine moderne Milchwirtschaft an die Landwirtschaft stellt.

\section{ANHANG}

Viehzählungen:

\begin{tabular}{|c|c|c|c|c|c|c|c|c|c|}
\hline & Kühe & Rinder & Kälber & Zuchtstiere & Ochsen & Schafe & Ziegen & Schweine & Pferde \\
\hline $1805^{*}$ & 1000 & 580 & 700 & 14 & & 1800 & 2000 & 291 & 150 \\
\hline $1860 * *$ & 1428 & \multicolumn{2}{|c|}{1064} & & & 2042 & 1461 & 293 & 93 \\
\hline $1867 * *$ & 1376 & 571 & 524 & 20 & 5 & 1642 & 1790 & 282 & 118 \\
\hline 1870 & 1268 & 748 & 479 & 17 & 13 & 1591 & 1808 & 291 & 107 \\
\hline $1893 * *$ & 1144 & 565 & 333 & 30 & 27 & & & & \\
\hline 1896 & 1168 & 309 & 544 & 25 & 42 & 109 & 413 & 499 & 273 \\
\hline 1901 & 1229 & 331 & 364 & 25 & 20 & 94 & 282 & 501 & 350 \\
\hline 1906 & 1351 & 251 & 411 & 24 & 14 & 24 & 320 & 541 & 381 \\
\hline 1915 & 2283 & \multicolumn{2}{|c|}{$216 \pi$} & & & & & & \\
\hline 1919 & 887 & 462 & 330 & 15 & 13 & 437 & 607 & 410 & 258 \\
\hline 1926 & 1446 & 286 & 224 & 46 & 12 & 68 & 408 & 665 & 284 \\
\hline 1931 & 1627 & 215 & 290 & 24 & 18 & 222 & 316 & 935 & 302 \\
\hline 1936 & 1490 & 258 & 189 & 25 & 5 & 233 & 232 & 746 & 223 \\
\hline 1939 & 1539 & 280 & 177 & 23 & 6 & & & 670 & \\
\hline 1940 & 1516 & 256 & 149 & 30 & 4 & & & 753 & \\
\hline 1941 & 1419 & 299 & 200 & 20 & 7 & 382 & 310 & 617 & 186 \\
\hline 1942 & 1376 & 318 & 191 & 21 & 4 & 436 & 354 & 474 & 186 \\
\hline 1943 & 1392 & 325 & 203 & 16 & 5 & 450 & 537 & 535 & 180 \\
\hline 1944 & 1309 & 338 & 219 & 22 & 5 & 455 & 554 & 452 & 171 \\
\hline 1945 & 1227 & 335 & 194 & 18 & 3 & 405 & 477 & 521 & 166 \\
\hline 1946 & 1286 & 360 & 182 & 15 & 2 & 405 & 465 & 471 & 165 \\
\hline 1947 & 1346 & 291 & 206 & 21 & 1 & 401 & 425 & 618 & 150 \\
\hline 1948 & 1399 & 310 & 152 & 18 & 1 & 402 & & 716 & 149 \\
\hline 1949 & & 1625 & & & & 259 & & 863 & 135 \\
\hline 1950 & & 1894 & & & & 321 & & 728 & 126 \\
\hline
\end{tabular}

* nach VALÄr, J. ** Bündner Monatsblatt

Für 1860, 1915, = Gesamtzahl Jungvieh. 1949, $1950=$ Total Rindvieh. 


\begin{tabular}{lrrrrrrrrr}
- & 1 & 2 & 3 & 4 & 5 & 6 & 7 & 8 & 9 \\
\hline Januar & -6.9 & -11.5 & -1.4 & 60 & 30.8 & 50 & 14.0 & 15.8 & 16.9 \\
Februar & -5.4 & -10.7 & 0.7 & 60 & 28.0 & 54 & 13.1 & 15.8 & 16.9 \\
März & -2.1 & -7.1 & 3.9 & 57 & 29.8 & 51 & 11.3 & 15.0 & 15.8 \\
April & 2.3 & -2.6 & 7.7 & 58 & 23.1 & 47 & 11.4 & 14.2 & 14.6 \\
Mai & 7.1 & -1.7 & 12.9 & 72 & 8.6 & 46 & 9.8 & 12.7 & 13.0 \\
Juni & 10.4 & 4.6 & 16.0 & 113 & 1.5 & 49 & 7.6 & 10.3 & 11.3 \\
Juli & 12.2 & 6.4 & 17.8 & 136 & 0.3 & 54 & 7.0 & 9.7 & 10.6 \\
August & 11.6 & 6.2 & 17.2 & 131 & 0.5 & 56 & 6.6 & 9.4 & 10.8 \\
September & 8.4 & 3.6 & 14.5 & 93 & 3.9 & 54 & 7.9 & 10.6 & 11.6 \\
Oktober & 3.7 & -0.4 & 9.8 & 64 & 15.7 & 54 & 10.1 & 12.8 & 13.5 \\
November & -1.3 & -5.1 & 3.9 & 60 & 26.5 & 50 & 11.9 & 14.2 & 14.9 \\
Dezember & -5.5 & -9.5 & -0.7 & 66 & 30.8 & 46 & 13.7 & 15.6 & 16.5 \\
Jahr (Mittel, Summe) & -2.9 & & & 970 & 199.5 & 51 & 10.4 & 13.0 & 13.9
\end{tabular}

1. Luftemperatur in Celsiusgraden, Mittel $1876-1950$.

2. Mittleres Tagesminimum der Luftemperatur in Celsiusgraden (Mittel 1890-1950).

3. Mittleres Tagesmaximum der Luftemperatur in Celsiusgraden (Mittel 1890-1950).

4. Niederschlagsmenge in $\mathrm{mm}$ Wasser (Mittel 1876-1950).

5. Zahl der Frosttage mit Temperaturminimum unter 0 Grad Celsius (Mittel 1891-1950.

6. Relative Sonnenscheindauer in \% der möglichen (Mittel 1885-1950).

7.-9. Abkühlungsgröße in $\mathrm{mcal} / \mathrm{cm}^{2}$ sec (Mittel 1930-1945).
7. Vormittagsmittel
8. Nachmittagsmittel
9. Nachtmittel

Spruchbrief von Monstein $249 \mathrm{I}$ (in Textherstellung mit Interpunktionen).

Ich, Cuonradin Belin, der zit landamman uff tafaus, Tuon kund allermengklichem ${ }^{1}$ mit disem offenen brieffe, Wo der fürkumpt, das ich in dem jar vnd uf den tag, als datum ditz briefs wiset, offenlich zu gericht gesessen byn uff tafaus angewonlicher gerichtstat. Aldo kam für mich vnd offen gericht die wolbeschaidenen bernhart vnd töntz müstainer mit jrem mit recht erloupten fürsprechen, brachten für recht also, wie die uss der alppen venetz vermainten recht ze haben vnd ze farn herab jn die weid jm silberberg, das von alter her von gerechtigkait wegen nie beschehen wer ${ }^{2}$, besunder der jndren alpen zugehört hette mit jrem fech ze etzen ${ }^{3}$, als sy getruwetin, fürbass hin aber ze bruchen mit küeyen vnd andrem, vnd die uf venetz sölten billich $\mathrm{jr}$ müesig gan vnd mügen lezt lassen ${ }^{4}$. furor vermainten sy witer recht ze haben jro weid zu etzen die von mustainer wisen gat hintz an spiner weid. Wer von alter ouch nit beschehen, besunder der jndren zugehört. Darum sij getrüwetin, das venetzer billich dauon lassen sölten; $o b^{5}$ sy darwider reden welten, zügten sy sich an from lüt vnd fïegten das also hin zu recht mit mer worten, nit nott alles zu melden. Do stunden dar Hensly agten sunn vnd Stoffel michel uss mustain ouch mit jrem mit recht erloupten fürsprechen, gaben antwirt uf die clag, also sy nem jr fürnemen frömd, won sy nit anderst wüstin noch gehört hettin, den das die weid jm silberberg gemein sölt syn allen müstainern, ouch die weid von den güttern hintz an die hohen rüfinen vnder dem weg. witer vermaint der benant hensly rechte ze haben hintz an den rotschzug vnder dem weg vnd dar ob ouch, besunder twas tailen halb ${ }^{6}$, so den vor langer zit vor sym gedenken beschehen vnd zu sinen güetren gehört hette. als er getrruwet, sich noch marchstein finden sölten. zügten sich ouch an from lüt vnd aatzten das also hin zu recht mit mer worten/

Do fragt ich obgenanter richter des rechten $\mathrm{vmb}^{7}$ uf den aid, was recht wer nach allem, so für recht ${ }^{8}$ kommen wer. Do wart erkennt mit ainhelliger urtail, sitmal sij sich zu baiden tailen jro werlüt ${ }^{9}$ erbotten hetten, die sölten billich verhört werden, wie recht wer, vnd darnach sölt beschehen, was recht wer. das ouch also beschah nach ordnung des rechten, wie das mit vrtail erkent wart. Und lut die kuntschaft als sy den lut ${ }^{10}$. und fraget ich vorgenanter richter aber füror ${ }^{11}$ des rechten vmb uff den aid, was Nu recht wer nach der clag vnd antwirt vnd ouch der kuntschaft vnd allem, so für recht kommen wer.

1 jedermann.

2 was von Alters her nie geschehen wäre.

${ }^{8}$ besonders der „jnder alp “ zugekommen sei, mit ihrem Vieh abweiden zu lassen.

${ }^{4}$ Die von Venetz sollten sich billigerweise von der Weide im Silberberg fernhalten und endlich davon lassen.

${ }^{5}$ bevor, ehe... beriefen sie sich auf...

${ }^{6}$ besonders irgend welche Teile?

$7 \mathrm{Da}$ hielt ich... Umfrage nach dem Recht.

8 was vor Gericht gekommen sei.

0 Gewährsleute?

${ }^{10}$ und lautete das Zeugnis vor Gericht wie es lautete (ev. wie es schon vorher gelautet hatte?)

11 weiter. 
So wart erkent mit ainhelliger vrtail als vmb die weid jm silberberg, so vor die uss der jndren alpen mit jrem rinder fech obna herab gen möchten vnd hintz her gebrucht hetten von heimna oder der alpen, sölt jnen zu gehören, vnd die übrig weid sölt billich gemein sin, fürbas die weid vnder den wisen hintz an die hohen rufinen solt ouch beiden tailen gemein sin zu etzen.

Des rechten vnd vrtail die vorgenanten henslj agten vnd stoffel michel brieff vnd sigel begerten, das jnen nach min, des obgemelten richters vmbfrag mit ainhelliger vrtail erkent wart zu geben, doch jn jrer costung ${ }^{12}$, vnd mir zu besiglen, so der geschriben wurde, wider für gericht kam vnd stüend als er sölt vnd mit recht gegangen wer. Das alles beschehen ist nach ordnung des rechten, vnd hab ich obgenanter richter min aigen insigel offenlich gehenkt an disen brief von des rechten vnd der warheit wegen, doch fürbass mir vnd minen erben on schaden. Beschehen zu ussgendem brachot ${ }^{13}$ jn dem jar do man zalt von der geburt cristi vnnsers lieben herrn fiertzehen hundert nüntzig vnd darnach jn dem ersten jare.

\section{LITERATURVERZEICHN IS}

\section{Handschriften, Quellen:}

Ackerbaustelle Davos: Akten und Verordnungen über den Anbau 1939-45. Allgemeine ZentralMolkerei Davos: Akten und Abrechnungen, Geschäftsberichte 1905-1951. Archiv Davos: Ratsprotokolle, Urkunde Nr. 84. Archiv Monstein: Urkunden Nr. 3, 4, 7, 8, 10, 15. ERB, E.: Die Land schaft Davos, Sekundarlehramtsarbeit, Zürich 1905 (handgeschriebenes Manuskript). Grundbuchamt Davos: Grundbücher. Heimatmuseum Davos: Weidbrief Kircherbannatzung 1805, Urkunden. Jost, Chr.: Die Genossenschaften der Landschaft Davos, Seminararbeit jur. Fakultät Bern 1947 (Manuskript). SEnN, U.: Davos. Eine geographische Auswertung von Nutzungs- und Siedlungskarte mit Protokoll, unter besonderer Berücksichtigung der Alpwirtschaft. Diplomarbeit Geographisches Institut der Universität Zürich 1950 (Manuskript). Statuten und Akten der Davoser Alpen.

\section{Zeitschriften :}

(BM) Bündnerisches Monatsblatt, hrsg. von F. Pieth, Chur 1850 f. (DR) Davoser Revue, hrsg. J. Ferdmann, Davos 1925 f. (DZ) Davoser Zeitung, Davos 1880 f. (NS) Neuer Sammler. Ein gemeinnütziges Archiv für Bünden. 7 Bd. Chur 1804-1812. (ZM) Allgemeine Kontroll- und ZentralMolkerei Davos. Geschäftsberichte 1905 f.

\section{Statistik:}

Unveröffentlichtes Material: Ackerbaustelle Davos: Anbaustatistiken 1940-1945. Allg. Kontrollund Zentralmolkerei : Milch-, Vieh-, Handelsstatistiken, Statistik der Untersuchungen im Laboratorium. Einwohnerkontrolle Davos : Bevölkerungszählung. Gemeindebuchhaltung Davos: Viehzählungslisten, Zählungen der Silobetriebe. Grundhuch und Vermessungsamt Davos: Arealstatistik. Kant. Ackerbaustelle, Plantahof, Landquart: Eidgenössischer Produktionskataster für Davos 1945. Kant. Meliorationsamt, Chur: Liste der subventionierten Alpverbesserungen in Davos. Kreisforstamt Davos: Waldstatistik. Staatsarchiv Chur: Kantonale Zähllisten 1804-1914. SENN, U.: Statistische Aufnahmen 1949. Verkehrsverein Davos: Fremdenkontrolle, Beobachtungen der meteorologischen Station Davos.

Veröffentlichtes Material: Die Alpwirtschaft der Schweiz im Jahre 1864 (hrsg. vom Statistischen Bureau des Eidg. Departementes des Innern 1868). Eidg. Statistisches Amt: Anbaustatistik 1929. Eidg. Statistisches Amt: Betriebszählung 1903, 1929, 1939. Eidg. Statistisches Amt : Bodennutzung 1939 und Ackerbau 1940-1943. Eidg. Statistisches Amt: Nutztierbestände in der Schweiz 19411943. STrüBy, A.: Die Alpwirtschaft im Kanton Graubünden. (Schweiz. Alpstatistik, 18. Lieferung) Solothurn 1909.

\section{Karten :}

Schweizerische Grundbuchvermessung : Übersichtsplan der Landschaft Davos. 1:10 000 (6 Blätter, Parsenn, Seehorn, Frauenkirch, Flüelapaß, Monstein, Scalettapaß). Topographischer Atlas der Schweiz: Blätter 419, 422, 423. Zusammensetzung Albula. 1:50 000. Landeskarte der Schweiz: Prättigau Blatt 248, Bergün Blatt 258, 1:50 000. Geologische Karte von Mittelbünden: Blatt B, Davos. CaDisCH, LeUPold 1916/17. Blatt D, Landwasser. EUGST ER, LeuPold 1916-1929, 1:25 000. Landschaft Davos: Karte der Verbreitung des Ackerbaus, des Waldes und einiger Laubholzgebüsche. RICKLI, M.: Die Arve in der Schweiz (Schweiz. Naturforschende Gesellschaft Bd. XLIV, 1909), 1:50000. Davoser Wetterkarten $1887 \mathrm{f}$. Hrsg. von der Meteorologischen Station Davos.

\section{Literatur:}

Allgemeine Davoser Kontroll- und Zentralmolkerei : Schweizerische Milchzeitung Nr. 76, Schaffhausen 1933. ВАС̈, H.: Das Klima von Davos. Zürich 1907. BÆTsCHI, J.: Die Bsatzig. DR 1932, Heft 12. BIEngräber, H.: Die Davoser Milchwirtschaft. Davoser Blätter 1917, Nr. 18/19. Biert, L.:

12 doch auf ihre Kosten.

18 Brachmonat (Juni). 
Woher kommt der Name Davos! BM 1924, S. 111. BLAcHE, J.: Les types des migrations pastorales montagnards. (Essai de classification). Revue géographie alpine 1934. BöнME, G.: Der Herbst in Davos (meteorol.). DR 1936, Nr. 12. BœsCH, H.: Nomadismus, Transhumanz und Alpwirtschaft. Die Alpen, Jahrgang XXVII, 1951, Nr.6. BRANGER, E.: Rechtsgeschichte der freien Walser in der Ostschweiz. Diss. Bern 1905; - Davos in der Geschichte. Davos 1914; - Die Gemeinde Davos. DR 1932, Heft 12. BurRI, H.: Die Bedeutung des Terrainschutzwaldes im Hochgebirge. DZ 1899, 30. März. Búhler, V.: Davos in seinem Walserdialekt. 3 Bände. Heidelberg, Selbstrerlag 1870. СAdisch, J.: Zur Talgeschichte von Davos. Jahresbericht der Naturforichenden Gesellschaft Graubünden, Chur 1925/26. ConRaD, H.: Kann der Name Davos auf das Volk der Dacier zurückgeführt werden ? DR 1938, Heft 12. ConRad, N.: Vom Kirchlein in Sertig. DR 1942, Heft 11. Curschellas, M.: Jahresbericht der milchwirtschaftlichen Beratungsstelle. Chur 1937. Davos: Amtliche Gesetzessammlung der Landschaft Davos. 1936. Davos: Schneebruchordnung vom 29. Dezember 1920. Davos 1921. DoRNo, C.: Klimatologie des Hochgebirges. Verhandlungen der klimatologischen Tagung in Davos. Basel 1925. EвeL, J. G.: Anleitung auf die nützlichste und genußvollste Art die Schweiz zu bereisen. Zürich 1804, 2. Auflage 1809, 4. Auflage 1842. Eidgenössische Postverwaltung: Schweizerische Alpenposten. Flüelapaß. Ferdmann, J.: - Die Anfänge des Kurortes Davos, Davos 1938.; - Der Aufstieg von Davos. Aarau 1947; - Wann wurde das Höhenklima von Davos entdeckt? DR 1935; - Der Name Davos. DR 1936, Heft 10 ; - Aus der Geschichte der Davoser Bahnen. DR 1939, Heft 11; - Landwirtschaft und Bergbau in Davos vor 120 Jahren. DR 1941, Heft 3; - Die Davoser Landwirtschaft. DR 1944, Heft 6/7; - Tafaus, der alte Name der Landschaft Davos. DR 1945, Nr. 5 ; - Bergbauernprobleme von Davos aus gesehen. DR, 1945, Nr. 8;-Zur Milchversorgung der Landschaft Davos. DR 1948, Nr. 8 ; - Davoser Bahnbauten kulturhistorisch betrachtet. DR 1950, Heft 3. FRöDIN, J.: Zentraleuropas Alpwirtschaft. 2 Bände. Oslo 1940/41. Fứm, S.: Aus dem alten Davos. Davoser Blätter 1915, Nr 34-37; - Über Maße und Gewichte in Gräubünden. Jahresbericht der gewerblichen Fortbildungsschule Davos (J. g. F. D.) 1905/1906; - Bericht von der Jahrhundertfeier 1836. (J. g. F. D.) 1907/1908; - Industrie und Gewerbe in Graubünden im 18. Jahrhundert. (J. g. F. D.) 1910/1911 ; - Erwerbsleben in Davos in früherer Zeit. (J. g. F. D.) 1911/1912. Gabathul.ER, A.: Verbesserungen der Milchwirtschaft im Alpbetrieb. Alpwirtschaftliches Monatsblatt. Langnau 1922, März. Gessler, G.: Der Begriff der Vegetationszeit. Diss. Zürich 1946. Geologischer Führer der Schweiz : Exkursionen 82-91. Basel 1934. Gillardon, P.: Die Bevölkerung der VIII Gerichte im Frühling 1623. BM 1930, Heft 6. Good, O.: Schwebebahnen für unsere Alpwirtschaft. Bern 1914. Grass, N.: Beiträge zur Rechtsgeschichte der Alpwirtschaft. Schlern-Schriften Band 56, Innsbruck 1948. Grossmans, H.: Die Waldweide in der Schweiz. Diss. ETH, Zürich 1927. Gutzwili.ER, K.: Die Milchverarbeitung in der Schweiz und der Handel mit Milcherzeugnissen. Schaffhausen 1923. Haff, K.: Alpwirtschaft, Alpvolkskunde und Recht. Zeitschrift für Sozial- und Wirtschaftsgeschichte. Bd. 38, Heft 2, Stuttgart. Henne, A.: Die Lawinenverbauungen Schiahorn-Dorfberg. Bern 1925. Himmel, C.: Die Milchversorgung des Kurortes Davos, Davos 1911. Höstı, J.: Die Glarner Alp- und Landwirtschaft. Diss. Zürich 1948. IssLer, P.: Geschichte der Walserkolonie Rheinwald. Diss. Zürich 1935; - Beziehungen zwisçhen den Walserkolonien Rheinwald und Davos. DR 1936, Heff 12. Jecklin, F.: Das Davoser Spendbuch im Jahre 1562. Chur 1925. Jost, Chr.: Wirtschaft und Fremdenverkehr in der Landschaft Davos. DZ 1951, Nr. 17-20;- Der Einfluß des Fremdenverkehrs auf Wirtschaft und Bevölkerung in der Landschaft Davos. Diss. Bern 1951/52. KaRsTHOFER, K.: Bemerkungen auf einer Alpenreise über den Susten, Gotthard, Bernhardin, Oberalp, Furka, Grimsel. Aarau 1822. Keller, G. Steigerung der Futtererträge im Hochgebirge. Bündner Bauer 1924, Nr. 30-33. Koch, J.: Zweckmäßige Düngung unserer Bergweiden und Bergwiesen. Alpwirtschaftliches Monatsblatt, Langnau 1938, Heft 4. L.eLY, A.: Aus der Verwaltungs- und Verfassungsgeschichte der Landschaft Davos. DZ 1916, Nr. 252-254, 256; - Der Saum- und Paßverkehr in Alt-Davos. Davos 1943; - Kreuz und quer durch die Zügen. Davos 1943; - Der Wald in der Geschichte der Landschaft Davos. 1944; - Weiden und Alpen in der Landschaft Davos. Davos 1950; - Lawinenchronik der Landschaft Davos. Davos 1951. Landbuch der Landschaft und Hochgerichtsgemeinde Davos 1831: Herausgegeben von der Geschichtsforschenden Gesellschaft Graubünden. Davos 1912. Liver, P.: Vom Feudalismus zur Demokratie in den bündnerischen Hinterrheintälern. Diss. Zürich 1929;-Zur Rechts- und Wirtschaftsgeschichte des Heinzenbergs im 15., 16. und 17. Jahrhundert mit besonderer Berücksichtigung der Alpen, Allmenden und Maiensäße. BM 1932;-Zur Wirtschaftsgeschichte der freien Walser. DR 1936; - Mittelalterliches Kolonistenrecht und freie Walser in Graubünden Zürich 1943; - Ist Walser Recht Walliser Recht? BM 1944, Heft 1. LCEwY, A.: Der Höhenaufenthalt in seiner Wirkung auf Mensch und Tier. Neue Probleme der Tierzucht, Heft 11. Frauenfeld/Leipzig 1934. LüDI, W.: Mikroklimatische Untersuchungen an einem Vegetationsprofil in den Alpen von Davos. Geobotanisches Institut Rübel, Berichte 1936. Zürich 1937. MEYER, K.: Über die Anfänge der Walserkolonie in Rhätien. BM 1925, Heft 7-9; - Erste Niederlassung der Walser in Rhätien. DR 1932. MöRIKOFER, W.: Zur Klimatologie der Abkühlungsgröße. Acta davos. Nr. 3, 1933; - Die Klimaverhältnisse von Wiesen. Jahresbericht der Naturforschenden Gesellschaft Graubünden. 1950. PIETH, F.: Weid- und Murmendenbrief der Leidbachalp (Davos). BM 1924, Heft 12; - Eine Davoser Hauszeichensammlung. BM 1940, Heft 2. Pceschel, E.: Der Name Davos. BM 1924; - Die Kirchen der Landschaft Davos. DR Mai/Juni 1936. Planta, R. und SchorTa, A.: Rhätisches Namenbuch. Bd. I, Paris/Zürich 1939; - Der Name Davos. BM 1924, S. 163, 291. Rüttimañ, R.: Orts- und Fremdwörter der Walser Mundart. 
BM 1915. SAlis, C. U. von Marschlins: Bemerkungen auf einer Reise durch Graubünden. NS 1808; - Die Landschaft Davos. Abgedruckt DR 1938, Heft 2. SAr.Zmanis, C. : Eine Walser Alpurkunde 1717 aus Safien. BM 1949, Heft 6. SchatzManin, A.: Kurze Geschichte des Sennereiwesens. BM 1870, Heft 1. Schiebler, W.: Aus der Landschaft Davos. DR 1931. Heft 3;- Bauerntum in der Landschaft Davos. DR 1932, Heft 12. Schiess, T.: Kulturzustände in Davos und im Prättigau im 16. Jahrhundert. BM 1935, Heft 1. SснміDT, F.: Landwirtschaftliche Genossenschaftsbewegung in der Schweiz. Genossenschaftliche Volksbibliothek Nr. 52, Basel 1944. Schoop, A.: Davoser Orts- und Flurnamen. DR 1948, Hefte 12, 1, 2. SchorTa, A.: Zur Siedlungsgeschichte von Davos. DR Mai/Juni 1936. Sċhrörter, C.: Kleiner Führer durch die Pflanzenwelt der Alpen. Zürich 1932. SchüEPP, W.: Frostverteilung und Kartoffelanbau in den Alpen auf Grund von Untersuchungen in der Landschaft Davos. Schweizerische Landwirtschaftliche Monatshefte, Nr. 2, Bern 1948. SchŬLE, W.: Die Landschaft Davos im Lichte bündnerischer Ortsnamen. BM 1930, Heft 4. SснÜ РвACH, H.: Die technische Aufrüstung im Bergdorfe. Schriftenreihe zur Frage der Arbeitsbeschaffung. Bautechnische Reihe Nr. 13, Zürich 1947. Schweizerisches Bauernsekretariat: Der Schätzungsexperte. Brugg 1942. SERERHARD, N.: Einfalte Delineation aller Gemeinden gemeiner dreyen Bünden. 1742. Hrsg. von W. Kern, Chur 1944. Simmen, G.: Die Puschlaver Alpwirtschaft. Diss. Zürich/Chur 1949. Sprecher, J. A.: Geschichte der Republik der drei Bünde im 18. Jahrhundert. 2. Band (Kulturgeschichte), Chur 1875. STiffLER, J. P.: Davos vor 60 und mehr Jahren. DZ 1927, Nr. 62-67. STrüBr, A.: Die Alp- und Weidewirtschaft in der Schweiz. Schweiz. Alpstatistik, Schlußband, Solothurn 1914. STruB, J.: Das alte Silberbergwerk. DR 1950, Heft 12. SzADRowski, M.: Walserdeutsch. BM 1925, Heft 6;- Zum Davoser Spendbuch. Rhätier 1925, Nr. 152-156; - Ein paar Davoser Namen. DR 1940, Heft 3. TäNZER, E.: Die Milchwirtschaft in Davos. Zeitschrift für Züchtungskunde. Bd. III, Heft 10, Göttingen 1928. Theobald, G.: Naturbilder aus den rhätischen Alpen. Chur 1860. Thürer-Accola, P.: Der älteste Kornspeicher in Monstein. DR 1950, Nr. 1. VALïR, J.: Topographische Beschreibung der Landschaft Davos. NS 1806. VAI.ĖR, M. : Sechs Jahrhunderte Davoser Geschichte. Im Landbuch der Landschaft Davos, 1912. Verzeichnis der Mannschaft der Landschaft Davos von 16-60 Jahren von 1809, BM 1898, S. 225. Vital, N.: Kann der Bergbauer sich selber helfen? Schriften der Vereinigung für Innenkolonisation. Nr. 75, Zürich 1946. WeIss, R.: Das Alpwesen Graubündens. I. Teil, Zürich 1941; - Zur wirtschaftlichen Eigenart der Walser. BM 1941, Heft 1. WIEGNER, G.: Welche Weidetechnik gewährleistet die zweckmäßigste Ernährung der Milchtiere auf schweizerischen Talweiden. Institut für Haustierernährung ETH. Zürich 1934. Zimmert.l, E.: Bergbau im Zelıngerichtenbund. DR Mai $i$ Juni 1936.

\section{L'ÉCONOMIE ALPESTRE DE LA RÉGION DE DAVOS}

Le pays de Davos a subi sa transformation décisive au moment de la colonisation des "Walser», au 13ème siècle. Ceux-ci établirent leurs fermes isolées sur un territoire habité, l'été seulement, par un petit nombre de Romanches disséminés. Le terrain qu'ils défrichaient leur appartenait de droit en temps que patrimoine. La forêt et les pâturages demeurèrent biens communs. La population s'accrût très rapidement. Autour des quatorze premières fermes se formèrent des colonies voisines qui se chargèrent de l'organisation du vaste territoire colonisé. Au début du 15 ème siècle déjà, les pâturages supérieurs à la limite des forêts appartenaient à des particuliers ou à des associations de propriétaires privées. Le partage des biens communs eut lieu au 16 ème siècle; au 17 ème siècle, les forêts passèrent finalement à la propriété privée. Les conditions actuelles des alpages sont un reflet de cette évolution. $\mathrm{La}$ „Dorfweide“ demeura propriété commune tandis que la forêt fut divisée; tous les propriétaires de prairies dans les limites des deux anciennes colonies jouissent encore du droit de páture. Les biens communs divisés au 16 ème siècle furent transformés en pâturages privés d'une part et, d’autre part en pâturages réservés à un nombre déterminé de pièces de bétail appartenant à certains paysans; cette dernière catégorie de pâturages existe encore de nos jours. Les alpages créés en premier lieu entrainèrent plus tard le partage des anciens biens communs. Le 19ème siècle vit le passage du régime morcelé de la propriété privée à celui de la centralisation. Le développement de la station climatique de Davos entraina à sa suite la fondation d'une Fédération laitière étroitement organisée, destinée à couvrir les importants besoins en lait. Celle-ci, impuissante à transformer une situation résultant d'une évolution séculaire, tendit plutôt à l'adaptation et à l intensification de l'économie rurale. On construisit de bonnes voies de communication qui permirent un plus rapide transport du lait des alpages vers le centre de Davos-Platz. On construisit plus tard, sur un petit nombre d'alpages élevés : des étables communes en pierres, ce qui permit une meilleure exploitation des pâturnges. Les alpages proprement-dits ne comportent que des chalets privés. Dans la vallée, les étables furent reconstruites selon les données modernes de l'hygiène.

L'économie alpestre actuelle est étroitement liée au développement de la station de Davos; elle passa de l'élevage et par conséquent du commerce du bétail à une économie laitière unilatérale; à l'exception de quelques alpages étrangers pour jeune bétail, les alpages davosiens ne nourrissent que peu de jeune bétail; ce qui ne suffit pas à l'élevage. Les vaches saines et bonnes laitières sont vendues aux marchés grisons. L'économie alpestre de Davos a pour fondement son évolution historique et porte dans son organisation la marque caractéristique des "Walser"; par suite du développe- 
ment de la station de Davos elle a dû subir une adaptation et une transformation partielle, imposées par l'économie laitière à l'économie rurale toute entière.

\title{
L'ECONOMIA ALPESTRE DELLA REGIONE DI DAVOS
}

La regione di Davos conobbe la sua trasformazione decisiva nel sec. XII con la colonizzazione dei Walser. Essi fondarono le loro masserie in una contrada scarsamente popolata da stirpi romane, che probabilmente vi abitavano soltanto d'estate. Tutto il terreno dissodato appartenne ai Walser quale fondo ereditario libero; le foreste e i pascoli rimasero beni comunali. La popolazione si moltiplicò presto, di modo che attorno alle 14 masserie originarie, se ne formarono altre che costituirono poi 14 vicinie (Nachbarschaften). Ad esse venne affidata l'organizzazione particolare di tutta la grande regione. Però, già all'inizio del sec. XV, i pascoli situati sopra il limite della vegetazione arborea, i cosiddetti pascoli aperti (offene Alpweiden), erano nelle mani di persone o corporazioni private. La ripartizione dei pascoli comunali (Allmenden) - cioè dei pascoli situati nella foresta - avvenne nel sec. XVI. Nel sec. XVII anch'essi diventarono possesso di privati. Le condizioni attuali sono una conseguenza di questa evoluzione. Il pascolo del villagio (Dorfweide) rimase allo stato di pascolo comunale e soltanto la foresta venne ripartita. Diritto al pascolo comunale hanno i possessori di pasture che abitano entro il confine delle 14 vicinie originarie. Nel sec. XVI i pascoli comunali vennero ripartiti e diventarono pasture private (Sonderweiden) o pasture nelle quali certi contadini hanno determinati diritti (Gemeine Weide: $\mathrm{i}$ contadini che vi hanno diritto vi possono pascere un determinato numero di capi di bestiame). Più tardi molti alpi incorporarono parzialmente, prendendone possesso, antichi pascoli comunali.

$\mathrm{Nel}$ sec. XIX si procedette alla fusione dei singoli alpi in diverse cooperative alpestri. Lo sviluppo di Davos come luogo di cura condusse alla fondązione d'una latteria cooperativa centrale con una severa organizzazione per poter rispondere alle nuove esigenze. Questa evoluzione però non potè trasformare la struttura fissata ormai da secoli; essa condusse soltanto a un adattamento e a un'intensificazione dell'agricoltura. Per facilitare e accelerare il trasporto del latte alla latteria centrale di Davos-Platz si dovettero costruire buone strade 0 anche teleferiche. Poichè gli antichi villaggi alpestri dei Walser si trovano appena sopra il limite della vegetazione arborea, su alcuni alpi sorsero grandi stalle di pietra per il bestiame (Schermen) allo scopo di poter sfruttare meglio i pascoli superiori. Nella valle, le stalle furono trasformate in modo da poter rispondere alle esigenze igieniche moderne.

Oggidi l'economia alpestre è strettamente legata a Davos quale luogo di cura e di turismo. Cosi si spiega il passaggio da un'economia con allevamento e commercio di bestiame a un'economia alpestre limitata all'industria del latte. Poichè $\mathrm{i}$ contadini di Davos tengono in alpe un numero insufficiente di bestiame giovane da allevamento, essi sono costretti a comperare mucche sane e produttive alle diverse fiere di bestiame del cantone. L'economia alpestre della regione di Davos è fondata su un'evoluzione storica tutta particolare che porta nella sua organizzazione e nella sua forma l'impronta dei Walser, modificata per l'influsso della trasformazione di Davos in un luogo di cura e di turismo, che rese necessario un adattamento dell'agricultura alle esigenze di un'industria moderna del latte.

\section{DIE GOLDENE HORDE}

Ein Beitrag zur historischen Geographie

\section{Martin Schwind}

\author{
Mit einer Karte
}

Die ostwestliche Spannung, die das Geschehen in Europa heute beherrscht, erklärt sich nicht allein aus der Geschichte seit 1918. Bertold SPUler zeigte auf, wie die gegenwärtige Mächtegruppierung bereits durch die «Goldene Horde » (tatarisch 《Blaue Horde 》) seit dem beginnenden 13. Jahrhundert vorbereitet wurde ${ }^{1}$.

${ }^{1}$ Die Goldene Horde. Die Mongolen in Rußland, 1223-1502. Leipzig 1943. Mit 2 Karten skizzen, $556 \mathrm{~S}$. Zum Vergleich siehe die sowjetrussischen Darstellungen: A. JAKUBowskij und B. D. Grekow, Die Goldene Horde. Leningrad 1937; Enzyklopädie der Union der Russischen Sowjetrepubliken. Berlin 1950 (deutsch), Bd. I, 324-51; S. W. Bachruschin und B. D. Grexow, Die Goldene Horde. In: Geschichte der Völker der Sowjetunion, Basel 1945 ff. (deutsch), Bd. I, 277-90. In dieser Darstellung wird besonders der Gesichtspunkt der Unterdrückung der „Werktätigen “ durch das Tatarenjoch herausgearbeitet. 